\title{
A COMPARISON OF ACUTE TOXICITY OF BIODIESEL, BIODIESEL BLENDS AND DIESEL ON AQUATIC ORGANISMS
}

\author{
By \\ Nalissa Farrah Khan \\ Bachelor of Science (Honours), McMaster University, 2002
}

\author{
A thesis presented to \\ Ryerson University \\ in partial fulfillment of the \\ requirements for the degree of \\ Master of Applied Science \\ in the Program of
}

Environmental Applied Science and Management

Toronto, Ontario, Canada.

(C) Nalissa Farrah Khan 2005 
UMI Number: EC53030

\author{
All rights reserved \\ INFORMATION TO USERS
}

The quality of this reproduction is dependent upon the quality of the copy submitted. Broken or indistinct print, colored or poor quality illustrations and photographs, print bleed-through, substandard margins, and improper alignment can adversely affect reproduction.

In the unlikely event that the author did not send a complete manuscript and there are missing pages, these will be noted. Also, if unauthorized copyright material had to be removed, a note will indicate the deletion.

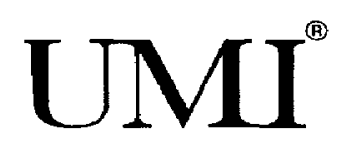

UMI Microform EC53030

Copyright 2008 by ProQuest LLC

All rights reserved. This microform edition is protected against unauthorized copying under Title 17, United States Code.

ProQuest LLC

789 East Eisenhower Parkway

P.O. Box 1346

Ann Arbor, MI 48106-1346 
I hereby declare that I am the sole author of this thesis.

I authorize Ryerson University to lend this thesis to other institutions or individuals for the purpose of scholarly, research

I further authorize Ryerson University to reproduce this thesis by photocopying or by other means, in total or in part, at the request of other institutions or individuals for the purpose of scholarly research 


\section{ACKNOWLEDGEMENTS}

I am truly grateful to Dr. Mostafa Warith for his assistance with every aspect of my research. His constant support and guidance throughout the course of my research is duly noted and much appreciated.

I would also like to extend my thanks to a number of individuals who assisted a great deal with experiments, including Robin Luong, Nidal Jaadlouk, Daniel Pennef and Reeyadh Khan.

Finally, I owe a tremendous amount of thanks to my parents, who have always supported and encouraged me in all that I do and to Ryan Mohammed for his ongoing understanding and encouragement. 


\title{
ABSTRACT \\ A COMPARISON OF ACUTE TOXICITY OF BIODIESEL, BIODIESEL BLENDS AND DIESEL ON AQUATIC ORGANISMS
}

\author{
By Nalissa Farrah Khan \\ Environmental Applied Science and Management, 2005 \\ Master of Applied Science, Ryerson University
}

The increasing demand of alternative energy sources has created interest in biodiesel and biodiesel blends; biodiesel is promoted as a diesel substitute. Like diesel spills, biodiesel spills can have deleterious effects on aquatic environments. The effect of neat biodiesel, biodiesel blends and diesel on $O$. mykiss and D. magna was evaluated using acute toxicity testing. Static non-renewal bioassays of freshwater organisms containing B100, B50, B20, B5 and conventional diesel fuel were used to compare the acute effects of biodiesel to diesel. Mortality was the significant endpoint measured in this study; percent mortality and lethal concentration (LC50) at different exposure times were determined from the acute toxicity tests performed. Trials were considered valid if the controls exhibited more than $90 \%$ survival. Based on percent mortality and LC50 values, a toxicity ranking of fuels was developed. The results of the definitive tests indicated that diesel is more toxic than neat biodiesel and biodiesel blends. This approach can provide insights into the lethality of biodiesel spills in the aquatic environment. 


\section{TABLE OF CONTENTS}

ABBREVIATIONS.

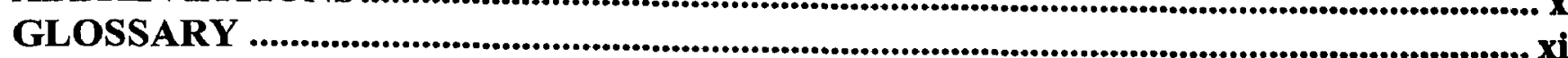

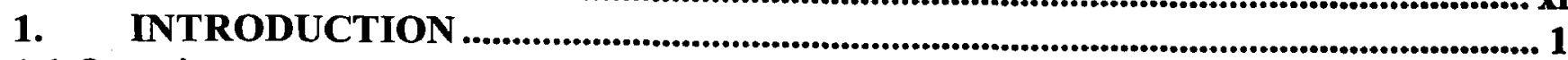

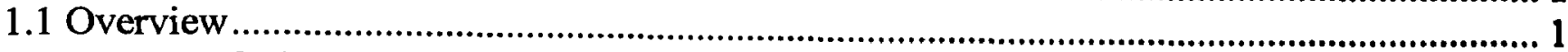

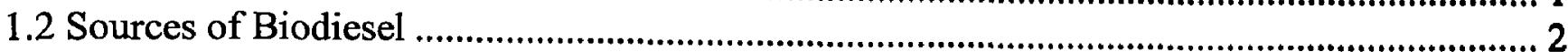

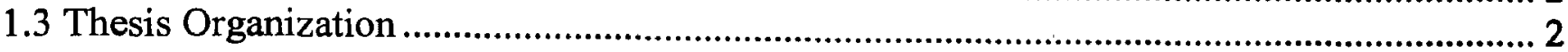

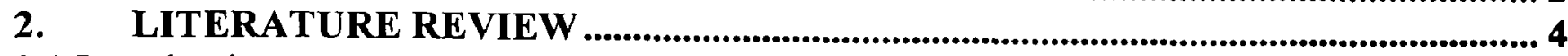

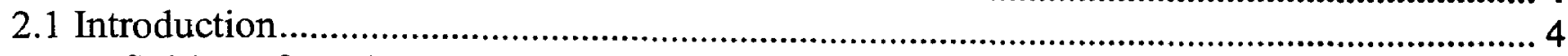

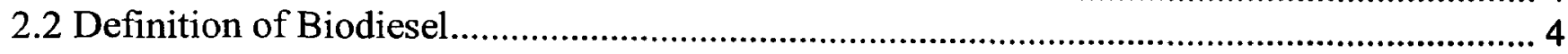

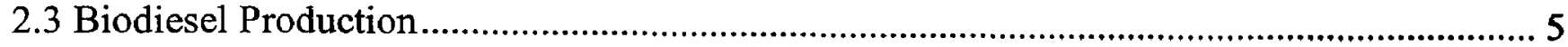

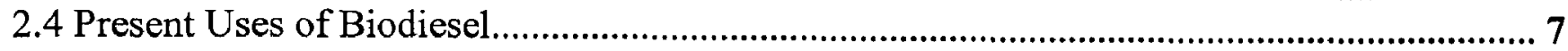

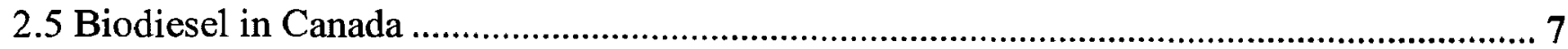

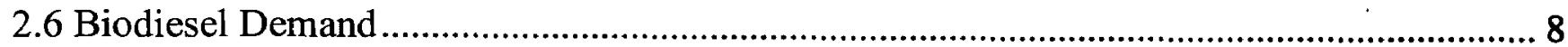

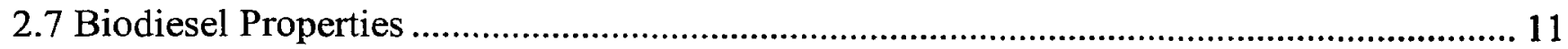

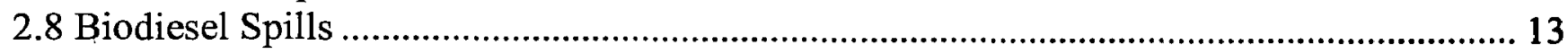

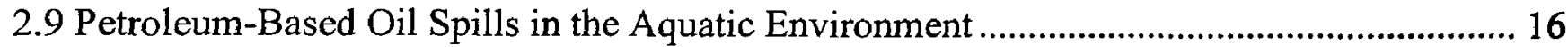

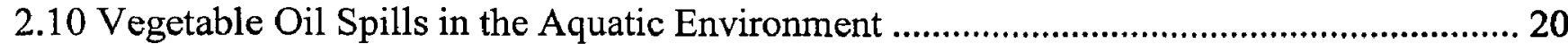

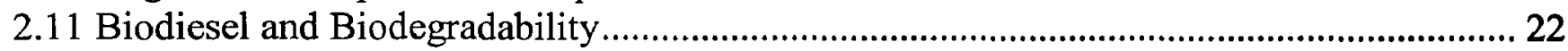

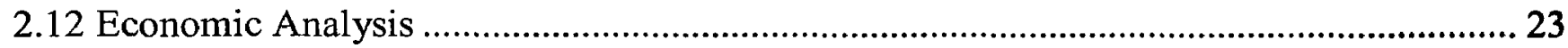

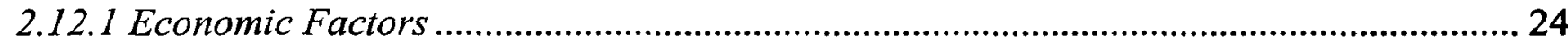

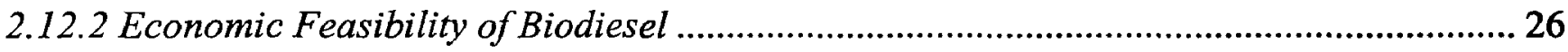

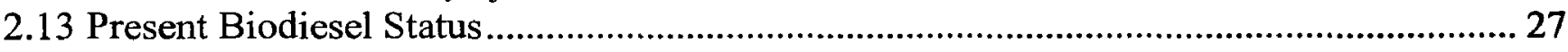

3. MATERIALS AND METHOD ..................................................................................... 29

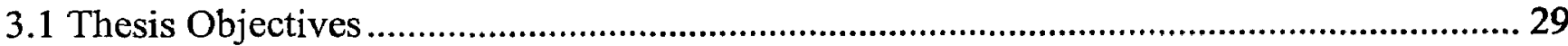

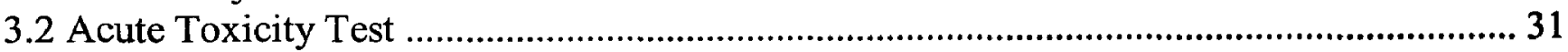

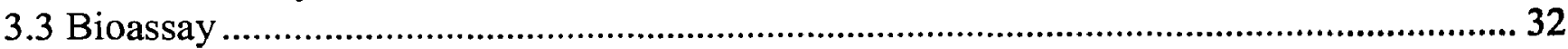

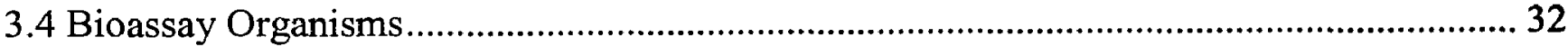

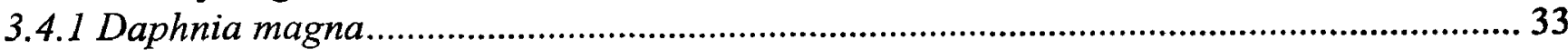

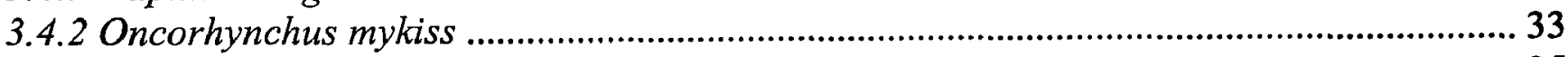

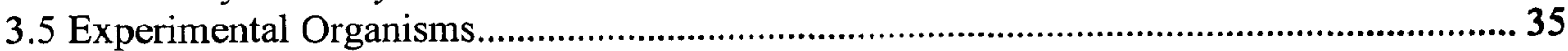

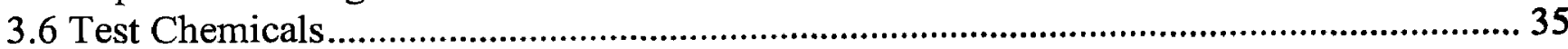

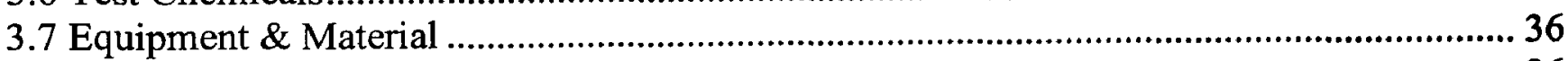

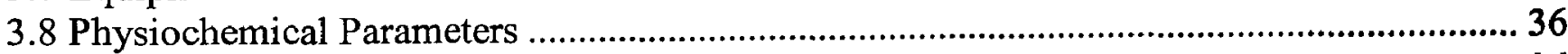

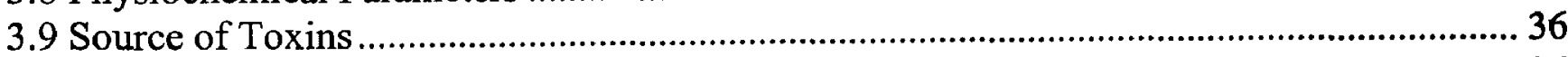

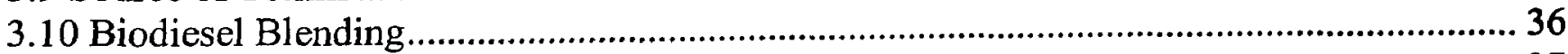

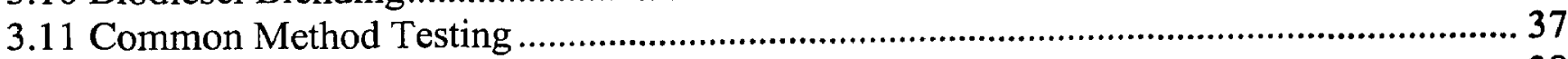

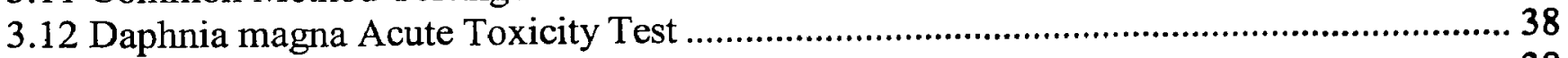

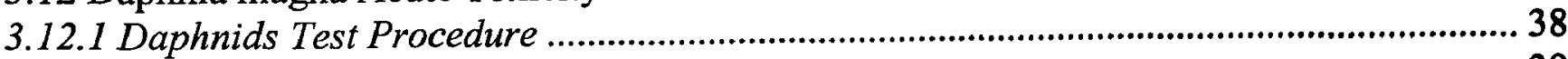

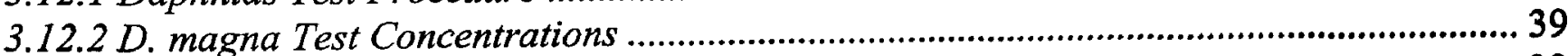

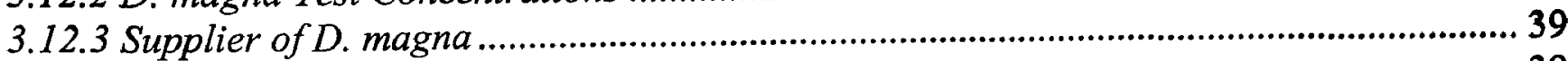

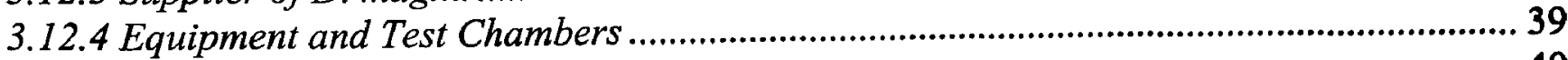

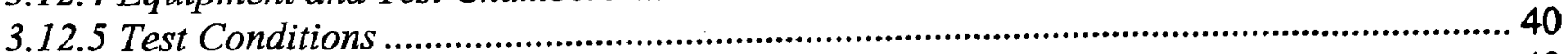

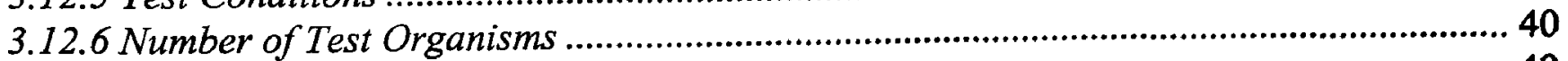

3.12.7 Replicate Test Chambers ........................................................................................... 40 
3.12.8 Quality of Test Organisms ................................................................................................ 40

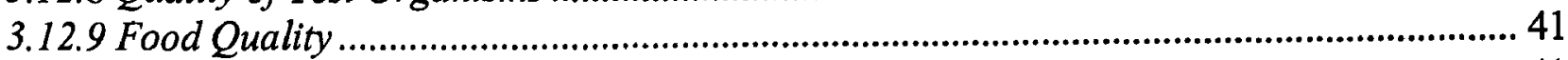

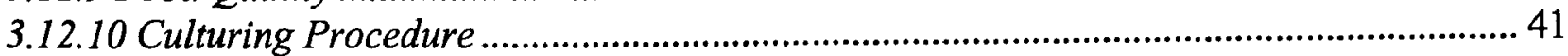

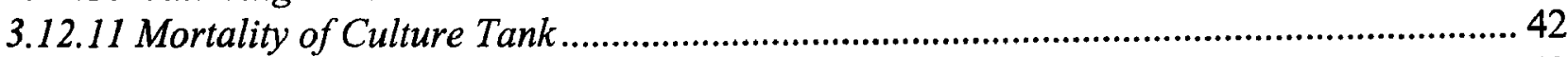

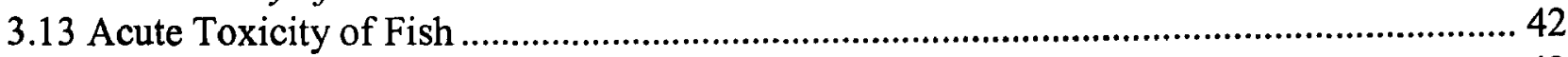

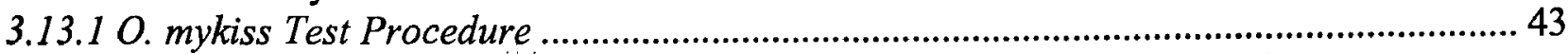

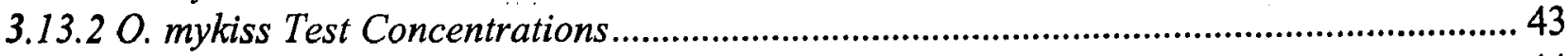

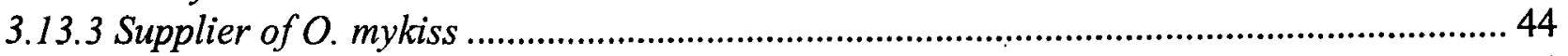

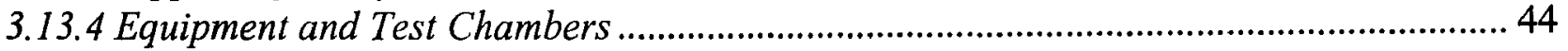

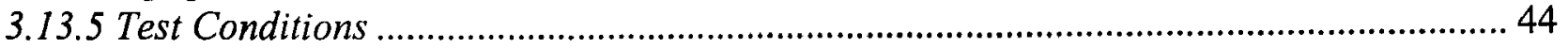

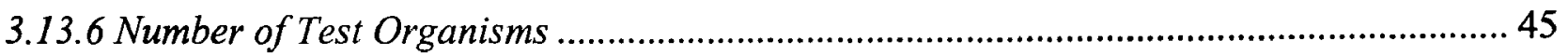

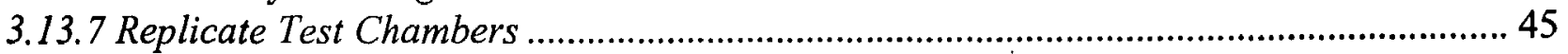

3.13.8 Quality of Test Organisms ………................................................................................... 46

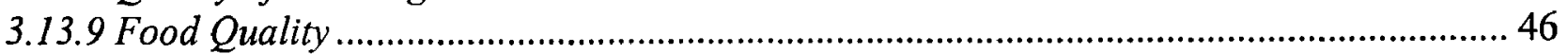

3.13.10 Holding and Handling Test Organisms ..................................................................... 46

3.13.11 Control Water \& Holding Water ................................................................................. 47

3.13.12 Mortality of Holding Tank ...................................................................................... 47

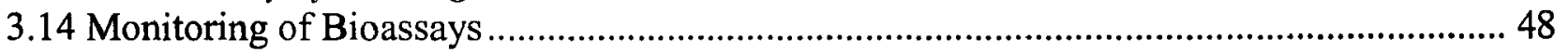

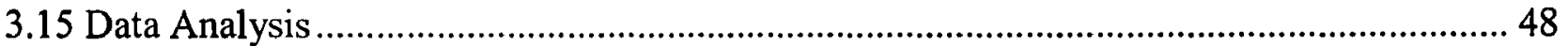

3.16 Acceptability of Acute Toxicity Test Results ........................................................................ 49

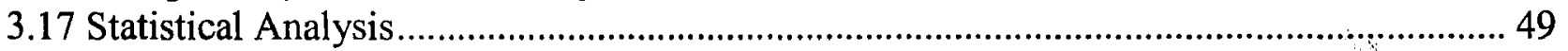

3.18 Concentration-Mortality-Time Relationship ..................................................................... 50

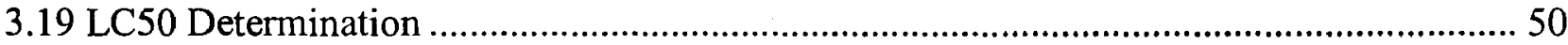

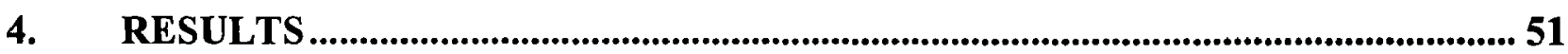

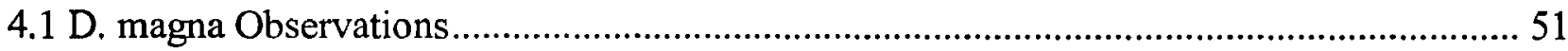

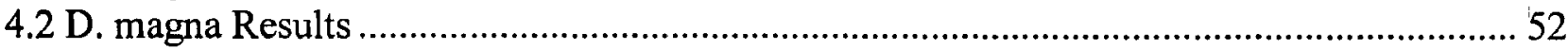

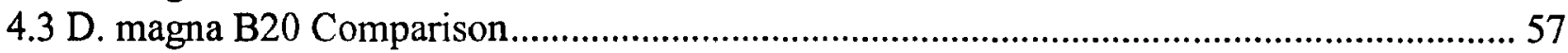

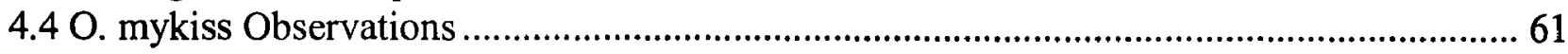

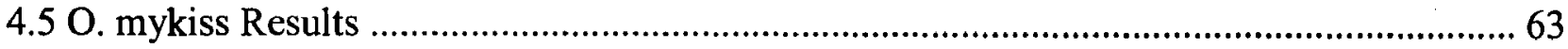

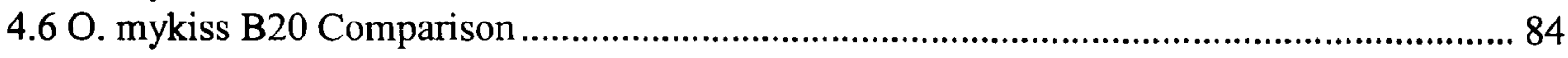

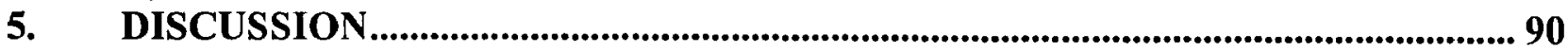

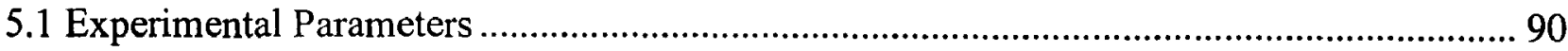

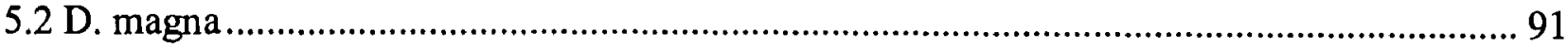

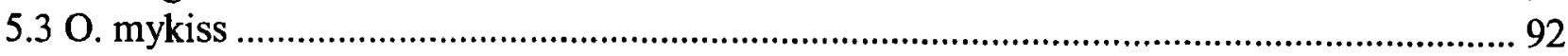

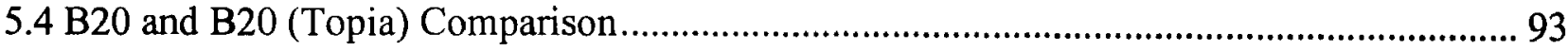

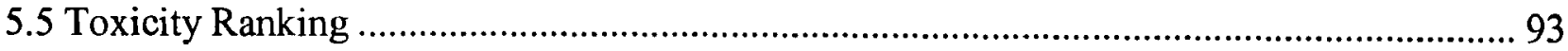

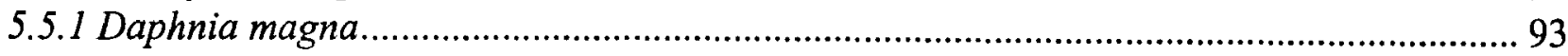

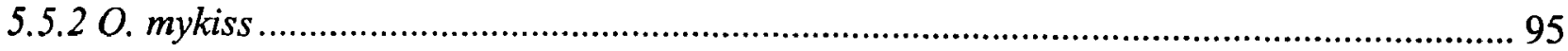

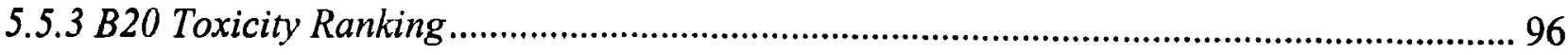

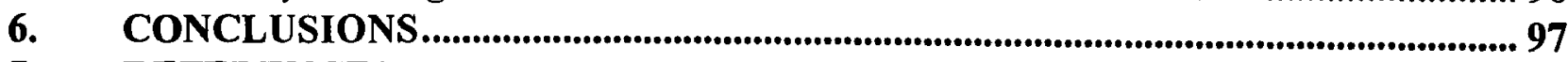

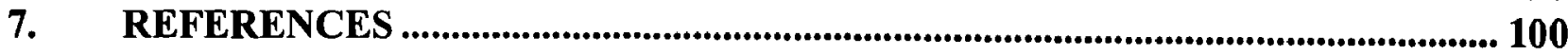

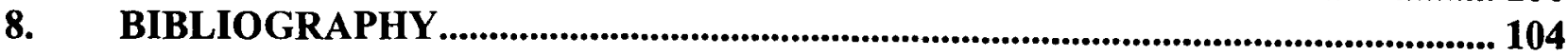

9. APPENDIX A: Experimental Parameters …............................................................... 114

10. APPENDIX B: D. Magna Bioassay Data ................................................................ 124

11. APPENDIX C: O. mykiss Bioassay Data....................................................................... 158 


\section{LIST OF TABLES}

Table 1: The average mortality rate for $D$. magna after $24 \mathrm{hrs}$. 53

Table 2: The overall mortality rate for $D$. magna 54

Table 3: The LC 50 of Acute Toxicity Test Using Daphnia magna 56

Table 4: The average mortality rate for $D$. magna affected with B20 and B20 (Topia) for $24 \mathrm{hrs} 57$ Table 5: The 24hr-LC50 value for D. magna treated with B20 and B20 (Topia) ........................ 59

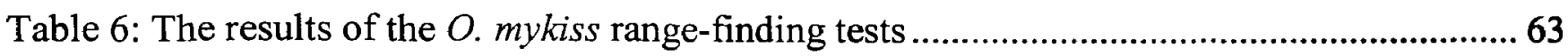

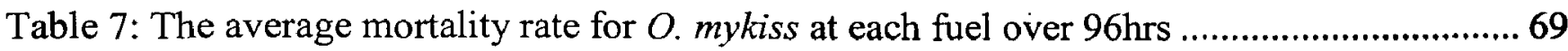

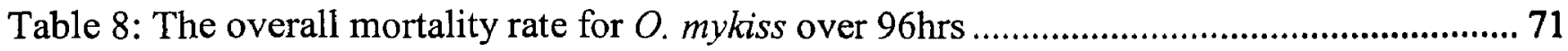

Table 9: The LC 50 of Diesel acute toxicity test using $O$. mykiss .................................................. 73

Table 10: The LC 50 of B100 acute toxicity test using $O$. mykiss.................................................. 75

Table 11: The LC 50 of B50 acute toxicity test using $O$. mykiss.................................................... 76

Table 12: The LC 50 of B20 acute toxicity test using $O$. mykiss.................................................... 78

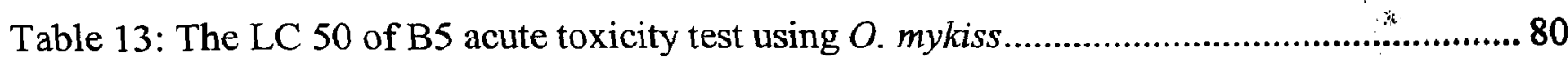

Table 14: The LC50 values for Diesel, B100, B50, B20 and B5 ............................................... 83

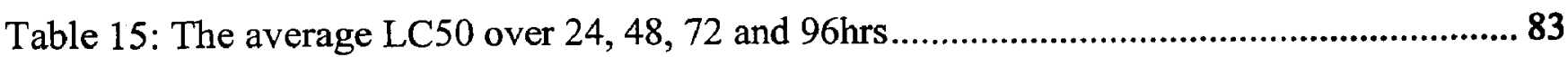

Table 16: The average mortality rate for B20 (Topia) over $96 \mathrm{hrs}$, using $O$. mykiss .................... 85

Table 17: The overall mortality rate for $O$. mykiss treated with B20 and B20 (Topia) ................. 85

Table 18: The LC50 values for $O$. mykiss treated with B20 (Topia) ......................................... 86 


\section{LIST OF FIGURES}

Figure 1: The average mortality rate of $D$. magna at different concentrations of different fuels over a period of $24 \mathrm{hrs}$

Figure 2: The mean mortality rate of D. magna for different concentrations over a period of 24 hrs. 55

Figure 3: The 24hr- LC50 values for Diesel, B100, B50, B20 and B5 56

Figure 4: Comparison of B20 and B20 (Topia) mortality rates. 58

Figure 5: The average $24 \mathrm{hr}$ mortality rate of B20 and B20 (Topia) 59

Figure 6: A comparison of B20 and B20 (Topia) 24hr-LC50 values 60

Figure 7: The results of the definitive tests with Diesel using 0. mykiss 65

Figure 8: The results of the definitive tests with $\mathrm{B} 100$ using $O$. mykiss. 66

Figure 9: The results of the definitive tests with B50 using $O$. mykiss. 67

Figure 10: The results of the definitive tests with $\mathrm{B} 20$ using $O$. mykiss. 68

Figure 11: The results of the definitive tests with B5 using O. mykiss. 69

Figure 12: Regression plots for different fuel over 96hrs

Figure 13: The mean mortality rate of $O$. mykiss for different concentrations over a period of 96hrs. 72

Figure 14: The LC50 values for Diesel. 73

Figure 15: The mean LC50 trend through time for $O$. mykiss exposed to Diesel. 74

Figure 16: The LC50 values for B100. 75

Figure 17: The mean LC50 trend through time for O. mykiss exposed to B100. 76

Figure 18: The LC50 values for B50... 77

Figure 19: The mean LC50 trend through time for O. mykiss exposed to B50 78

Figure 20: The LC50 values for B20 79

Figure 21: The mean LC50 trend through time for $O$. mykiss exposed to B20. 80

Figure 22: The LC50 values for B5 81

Figure 23: The mean LC50 trend through time for O. mykiss exposed to B5 82

Figure 24: The LC50 values for all fuels used in the acute toxicity tests 84

Figure 25: Comparison of mean mortality rate of B20 and B20 (Topia). 86

Figure 26: The LC50 values for B20 (Topia). 87

Figure 27: The mean LC50 trend through time for O. mykiss exposed to B20 (Topia) 88 
Figure 28: Comparison of the LC50 values of both B20 and B20 (Topia)

$$
\therefore:
$$




$\begin{array}{ll}\text { ASTM } & \text { American Society for Testing and Materials } \\ \text { BOD } & \text { Biological Oxygen Demand } \\ \text { B50 } & 50 \% \text { Diesel, } 50 \% \text { Biodiesel } \\ \text { B20 } & 80 \% \text { Diesel, } 20 \% \text { Biodiesel } \\ \text { B5 } & 95 \% \text { Diesel, } 5 \% \text { Biodiesel } \\ \text { COD } & \text { Chemical Oxygen Demand } \\ \text { DO } & \text { Dissolved Oxygen } \\ \text { FFA } & \text { Free Fatty Acid } \\ \text { LC50 } & \text { Lethal Concentration of } 50 \% \text { of a test population }\end{array}$




\section{GLOSSARY}

\section{Acclimation}

Physiological or behavioural adaptation of organisms to one or more environmental conditions associated with the test method.

\section{Acute test}

A comparative study in which organisms are subjected to different experimental conditions that are observed for a short period of time; it usually does not constitute a substantial portion of their life span. Acute tests often use mortality as the only measured effect or endpoint.

Acute toxicity

Any poisonous effect produced by a single short-term exposure, which results in severe biological harm or death.

\section{Additive}

Material added in small amounts to finished fuel products to improve certain properties or characteristics.

\section{Alevin}

A newly hatched trout is called an alevin. At this stage, the trout has a large yolk sac which provides all nutrition for the fish in the first weeks of its life. When the yolk sac is absorbed; the alevin work their way and become free-swimming, feeding fry.

\section{ANOVA}

Analysis of variance: A parametric method used for hypothesis testing that is, to determine if statistically significant differences in a response occur among two or more groups.

\section{Biodegradability}

The rate at which compounds may be chemically broken down by bacteria and or natural environmental factors.

\section{Biodegradation}

Decomposition of a material by the action of micro-organisms.

\section{Biochemical Oxygen Demand (BOD)}

Amount of oxygen in milligrams per litre used by micro organisms to consume biodegradable organics under aerobic conditions.

\section{Bioassay}

Using living organisms to measure the effect of a substance, factor or condition.

\section{Biodiesel}

A fuel comprised of alkyl esters of long chain fatty acids derived from vegetable oils or animal fats and meeting the requirements of ASTM D 6751. 


\section{Biodiesel Blends}

A blend of biodiesel fuel meeting ASTM D6751 requirements, with petroleum-based diesel fuel designated BXX, where XX is volume percent of biodiesel.

\section{Biofuel}

Any gas or liquid fuel derived either from organisms or metabolic by-products of living organisms.

\section{Cloud Point}

The temperature at which a sample of a fuel shows a cloud or haze of biodiesel or methyl ester crystals when it is cooled under standard test conditions, as defined in ASTM D2500.

\section{Contamination}

The polluting of members of the comparison or control group with any foreign material or chemical. Contamination threatens the validity of the study because the group is no longer untreated for the purposes of comparison.

\section{Cross-contamination}

Direct or indirect transfer of a pathogen from one medium to another.

Death

Is the 'effect' for determining toxicity in acute toxicity test.

\section{Deionised}

Freed from ions by a process of deionization.

Definitive Test

A test performed after the test conditions have been met and the test substance delivery system has been observed functioning properly.

\section{Emulsification}

The process that forms emulsions; mixtures of small droplets of oil and water. Two types of emulsions exist: water-in-oil and oil-in-water.

\section{Endpoint}

The variables that indicate the termination of a test; it also means the measurement(s) or value(s) derived that characterize the results of the test.

\section{Energy Carrier}

Any system or substance used to transfer energy from one place to another.

\section{Evaporation}

Occurs when the lighter or more volatile substances become vapours and leave the surface of the water. 
Experimental Control

A group of experimental subjects that is not exposed to a chemical or treatment being investigated.

Fatty Acid

Any of the saturated or unsaturated mono-carboxylic acids that occur naturally in the form of triglycerides or as free fatty acids in fats and fatty oils.

Free fatty acids

Any saturated or unsaturated mono-carboxylic acids that occur naturally in fats, oils or greases but are not attached to glycerol backbones.

Fossil fuels

Combustibles derived from the remains of ancient organisms.

Fork length

The length of the fish, measured from the tip of the nose to the fork of the tail.

Glycerin

A neutral, sweet-tasting, colourless, thick liquid. It freezes to a gummy paste, has a high boiling point of $290^{\circ} \mathrm{C}$ and can be dissolved into water or alcohol, but not oils.

\section{Immobilization}

Those organisms which are not able to swim within 15 seconds after gentle agitation of the test container are considered to be immobile.

LOEC

Lowest-Observed-Effect-Concentration, the lowest concentration of toxicant to which organisms are exposed that causes adverse effects.

Lethal concentration (LC50)

Median lethal concentration; the toxicant or effluent concentration that would cause death in $50 \%$ of the test organisms.

\section{Lethality}

The quality of being deadly.

\section{Monitoring}

The routine checking of quality and or collection and reporting of information, the periodic checking and measurement of certain biological or water quality variables.

\section{Mortality}

An organism is recorded as dead when it is completely immobile.

Mortality Rate

Number of deaths in a population during a defined time period. 
NOEC

No-Observed-Effect-Concentration, the highest concentration of toxicant to which organisms are exposed that causes no observable adverse effects.

\section{Opercular}

The principal opercular bone or operculum of fishes.

\section{Oxidation}

Occurs when oil comes into contact with water and oxygen combines with the oil hydrocarbons to produce water-soluble compounds.

$p H$

A measure related to the hydrogen ion content of a solution which represents the acidity or alkalinity of the solution.

ppm

Parts per million; a measure of concentration.

\section{Photoperiod}

The duration of illumination and darkness within a $24 \mathrm{hr}$ day.

Range-finding Test

Preliminary tests performed to determine the range of concentrations to be administered. Also involves tests to determine suitable experimental conditions.

\section{Replicate}

Experimental units that are tested simultaneously using the same experimental conditions.

\section{Swim-up Fry}

A young, post alevin fish which has commenced active feeding.

\section{Test chamber}

The individual containers in which test organisms are maintained during exposure to test solution.

\section{Toxicity}

The property of a chemical or combination of chemicals, to adversely affect organisms, tissues or cells.

\section{Toxicity Test}

A procedure to determine the toxicity of a certain chemical using living organisms.

\section{Trans-Esterification}

A chemical process; alcohol reacts with triglycerides contained in vegetable oils and animal fats to produce biodiesel and glycerin. The glycerin (by-product) is separated from the fat or vegetable oil. 
Weathering

A series of chemical and physical changes that cause spilled oil to break down and become heavier than water.

Yellow Grease

Used in the rendering industry; often refers to frying oils from restaurants. 


\section{INTRODUCTION}

\section{$\underline{1.1 \text { Overview }}$}

Biodiesel is viewed as a viable alternative fuel to petroleum-based diesel. Dwindling oil reserves, expanding capitalization, increasing fuel prices, socio-economic and environmental problems have heightened the interest in renewable, affordable energy sources. Biodiesel is referred to as an energy carrier; it is also classified as a type of modified or enhanced fuel. Biodiesel is characterized as methyl or ethyl esters derived from plant oil, animal fat or yellow grease; these esters must conform to certain standards and specifications for use in diesel engines (Van Gerpen et al., 2004). Biodiesel refers to the pure fuel before blending with diesel fuel occurs; it is also referred to as neat biodiesel.

Biodiesel is also categorized as a liquid biofuel; it is a clean burning alternative fuel, produced from renewable resources, such as biomass, for example, herbaceous and woody plants, agricultural crops, forestry by-products, municipal solid and industrial wastes. Raw materials for biodiesel are mostly vegetable oils and waste animal fats; recycled cooking oils and grease are also used in biodiesel production.

Biodiesel can be blended with diesel fuel or used straight in place of fossil diesel in conventional diesel engines. Neat biodiesel contains no diesel fuel however it can be blended with diesel to produce biodiesel blends. Biodiesel can be used as additive volumes to diesel fuel or as premium fuel on its own; biodiesel blends of B5 are additive volumes and blends higher than B5 are considered premium diesel. As green fuels, particularly bioethanol and biodiesel, are becoming more commercialized, their fate in the environment is an area of concern since fuel spills 
constitute a major source of aquatic ecosystem contamination (Zhang et al., 1995). Contamination of aquatic ecosystems by biodiesel may have serious consequences to organisms in these environments.

\subsection{Sources of Biodiesel}

Biodiesel is most commonly produced from edible oils; edible oils are oils fit for human consumption, such as vegetable oils. Biodiesel can be produced from many different types of plant oil; rapeseed oil is most common in Europe, soybean oil in North America and palm oil in Southeast Asia (Boyd et al, 2004). Biodiesel can be produced from a wide variety of feedstocks; some biodiesel feedstocks include soybeans, rapeseeds, maize, sunflower, coconut, canola oil, fish oils, waste animal fats, tallow and lard. Another feasible and realistic alternative source of biodiesel is waste cooking oils and fats from the restaurant and food processing industries (Rideout, 2004). These waste materials are becoming increasingly difficult to dispose of and create carbon dioxide emissions if they are dumped in landfills. Yellow grease can be chemically cleaned and processed; acceptable quality biodiesel can then be produced. Using waste oils and fats as a feedstock for biodiesel production may reduce further environmental pollution.

\subsection{Thesis Organization}

Section 2 is the literature review, which examines some pertinent issues involving biodiesel in the aquatic environment. This is followed by Section 3, the materials and method, which provides details on the methodology used for conducting all experiments. Section 4 presents the results obtained from the experiments performed on D. magna and O. mykiss. Section 5 consists 
of an analysis and discussion of the results obtained in the study and Section 6 is the conclusions and recommendations for further research in the area of biodiesel toxicity. 


\section{LITERATURE REVIEW:}

\subsection{Introduction}

The world relies heavily on fossil fuels, such as oil and natural gas, as its main source of energy. Reserves of non-renewable resources are considered depleted when supplies are too expensive to extract, process or mine (Puppán, 2000). It is estimated that crude oil reserves may be $80 \%$ depleted within the next 35 to 90 years, depending on its demand. At the current rate of consumption, global crude oil reserves will last at least 45 more years. With increasing industrialization, global oil consumption is projected to increase by about $25 \%$ by 2010 (Puppán, 2000). Projections of future economic and energy needs will increase the focus on more renewable sources of energy, such as biomass and waste products (Tashtoush et al., 2004).

Biomass is a likely alternative source of energy, particularly liquid biofuels. Two important liquid biofuels are bioethanol and biodiesel. Biodiesel has considerable potential as a new and feasible source of renewable energy, particularly as a transportation fuel in both more developed and less developed countries.

\subsection{Definition of Biodiesel}

Biodiesel are alkyl esters of vegetable oils, waste animal fats and other organic materials, however, biodiesel is not oils or fats. According to the ASTM standards:

The term "biodiesel" means the mono-alkyl esters of long chain fatty acids derived from plant or animal matter which meet $(A)$ the registration requirements for fuels and fuel additives established by the Environmental Protection Agency under section 211 of the Clean Air Act (42 U.S.C. 7545), and (B) the requirements of the American Society of Testing and Materials D6751

\footnotetext{
${ }^{1}$ Energy Policy Act of 2003, Conference Version, Section 1314
} 
Biodiesel can be either neat ethyl or methyl esters prepared from vegetable oils, animal fats and yellow grease. Biodiesel is an ester that can be made from several different types of oils; however, it is primarily recovered from vegetable and animal fats. The process of making biodiesel is called Trans-Esterification, organic oils and fats are combined with alcohol to form fatty esters, such as ethyl and methyl esters. These esters can be mixed with conventional diesel fuel; these fuel mixtures are referred to as biodiesel blends. Biodiesel can be used as a neat fuel, which is commercially referred to as $100 \%$ biodiesel (B100).

Numerous studies (Boyd et., 2004), (Sheehan et al.,1998) have suggested that biodiesel is a clean burning substitute for diesel fuel; biodiesel is processed from natural, renewable materials and in terms of engine performance, biodiesel has similar properties as conventional diesel. Biodiesel operates well in compression-ignition engines and low level blends, i.e. blends of up to $20 \%$ biodiesel, can be used in almost all diesel equipment, engines and vehicles. Due to the applicability of biodiesel as a substitute for diesel fuel, there has been recent interest in the production of biodiesel as an alternative energy source for commercial and industrial processes.

\subsection{Biodiesel Production}

Biodiesel is commonly produced from new and even used vegetable oils and animal fats. Biodiesel is recovered from vegetable fats from such crops as soybean, rapeseed, canola, maize, sunflower, palm and coconut oil; they can also be recovered from animal fats, such as tallow and lard, as well as fish oils. In addition, waste cooking oils and fats have become a very popular feedstock in biodiesel production. 
Biodiesel is made by reacting any natural oils or fats with alcohol, in most cases, methanol is used to produce fatty acid alkyl esters. These raw materials are transformed into biodiesel using a variety of Trans-Esterification technologies. There are three primary methods for producing biodiesel from fats and oils:

1) Base catalyzed Trans-Esterification of the oil with alcohol (usually methanol).

2) Direct acid catalyzed Trans-Esterification of the oil with methanol.

3) Conversion of the oil to its fatty acids by acid catalysis and then to biodiesel.

Oils and fats are mainly composed of triglycerides, which are chemical compounds of fatty acids, glycerin and free fatty acids (FFAs). The FFAs are bonded with methanol to produce biodiesel under acidic conditions. The triglycerides are also transformed into biodiesel and glycerin under base conditions, as indicated in Appendix A (Puppán, 2002). Base catalyzed reaction is the most common form of producing biodiesel because this type of reaction requires low temperatures and pressures, it also yields a high conversion with very few side reactions, minimal reaction time and there is direct conversion with no intermediate compounds (Van Gerpen et al., 2004).

Although there are different ways to produce alkyl esters, some important factors in the fuel production process include (i) a complete Trans-Esterification process, (ii) mixing intensity, (iii) reaction variables (reaction temperature, catalyst used, ratio of alcohol to oil, purity of reactants), (iv) glycerin, alcohol and any catalyst used must be removed from the end products and (v) no FFAs should be present in the alkyl esters produced (Barnwal and Sharma, 2005).

Biodiesel refers to the pure fuel; biodiesel blends (BXX) refers to a fuel that is composed of $\mathrm{XX} \%$ biodiesel and 1- XX\% diesel fuel (Tyson, 2001), for example, $\mathrm{B} 100$ is pure biodiesel and 
B20 is a blend of $20 \%$ biodiesel and $80 \%$ diesel fuel. The diesel fuel can be no. 1, no. 2, or JP8 (Dmytryshyn, et al., 2004). At present, Europe is the largest producer and consumer of biodiesel and biodiesel blends, however, there are many potential markets in North America.

\subsection{Present Uses of Biodiesel}

Fuel markets that can benefit from biodiesel include bus and truck fleets, heavy construction equipment, diesel cars and boats, railways and electric generators. In 1991, biodiesel was commercially introduced in Germany, since then European biodiesel production has increased tremendously; biodiesel is the fastest developing alternative fuel source in Europe (Boyd et al., 2004). In 2000, Germany, France, Austria and Italy produced approximately one billion litres of biodiesel. Different legislations, tax incentives and oil production subsidies and grants have resulted in biodiesel being priced competitively with diesel fuel in these European countries. Also, in some European countries, marketing cooperatives have produced biodiesel on a smallscale for their own consumption and many European car manufacturers, including Mercedes Benz and Volkswagen have approved biodiesel use for their engines (Boyd et al., 2004).

\section{$\underline{2.5}$ Biodiesel in Canada}

In Canada, biodiesel is still in the early stages of commercial and research development; in 1994, Agriculture and Agri-food Canada investigated the feasibility of biodiesel and analyzed a number of Canadian industries that may be potential biodiesel consumers (Prakash, 1998). The markets which were researched included (i) mining and petroleum exploration activities, (ii) government fleets and urban transit systems, (iii) national parks and ski resorts, (iv) forestry and (v) marine areas (Prakash, 1998). Before successful biodiesel consumption can succeed, some 
concerns must be addressed. These concerns include: (i) high price of biodiesel compared to conventional diesel, (ii) lack of engine and vehicle manufacturers' approval of biodiesel usage, (iii) the performance and quality of biodiesel produced and (iv) the availability of reliable biodiesel feedstock (Prakash, 1998). Some Canadian initiatives include the Alternative Fuels Act; this act introduces legislation asserting the use of alternative fuel vehicles by all federal government departments, agencies and Crown Corporations. Unfortunately, at present, there is no major commercial use of biodiesel in Canada; however, some urban bus fleets are using biodiesel blends on an experimental basis. The practicality and environmental benefits of biodiesel have garnered attention from the Canadian government; the federal government has set a target production rate of 500 million litres per annum by 2010, under Canada's Climate Change Action Plan (Boyd et al., 2004).

\subsection{Biodiesel Demand}

Diesel is essential in the transportation sector of many industrial and commercial regions; diesel is used quite extensively in transporting goods and services; this demand is increasing both in more developed and less developed countries. With fluctuating oil prices, demand uncertainty and growing environmental concerns, an alternative fuel which is technically feasible, economically competitive, environmentally acceptable (Dmytryshyn et al., 2004) and readily available is needed to alleviate concerns about current and future use of non-renewable resources.

Biodiesel is not a new fuel technologically; Rudolf Diesel invented the diesel engine over 100 years ago, he suggested that the compression-ignition engine could have been operated with 
peanut oil. However, as industrialization increased; petroleum became the prevailing energy source and diesel replaced vegetable oil as the fuel source for compression-ignition engines. However, interest in vegetable oils as a potential fuel source has waxed and waned over the years, with interest escalating during emergency conditions, such as World Wars I and II and the Persian Gulf War, as well as during the energy crisis of the 1970s, when petroleum supplies were interrupted (Raneses et al., 1999). In the past decade, environmental and energy security issues have led to renewed concern in alternative fuels, such as biofuels, particularly bioethanol and biodiesel.

Biodiesel can easily be substituted for petroleum diesel fuel in most diesel engines with no or only minor modifications and a slight decrease in power and fuel efficiency (Raneses et al., 1999). Biodiesel can be used as a diesel additive or a premium diesel to reduce vehicle exhaust emissions. The most common blend is $20 \%$ biodiesel and $80 \%$ petroleum diesel, popularly referred to as B20. B20 is referred to as premium blend and it also significantly reduces particulate matter emissions from diesel engines (Sheehan et al., 1998). Biodiesel demand along with expectations of increasing commercial demand has prompted great interest in biodiesel production.

In North America, more specifically, the biodiesel industry in the United States has identified three specific markets, which include: (i) public transportation (especially bus fleets), (ii) mining and (iii) marine and environmentally sensitive areas. These niche markets are considered possible candidates for potential biodiesel commercialization. 


\section{Transportation Fleets}

Biodiesel production has increased rapidly over the past decade. In Europe, biodiesel blends are readily available at filling stations, however, the commercial transportation sector is the largest consumer of biodiesel fuel. In 2003, Germany, France, Austria and Italy produced over two billion litres of biodiesel and European car manufacturers, such as Mercedes Benz and Volkswagen, have approved biodiesel use for their European designed vehicles. In Europe, there is a healthy demand for biodiesel, predominantly due to the support of the European Union (EU) and its farm production and environmental health programs and also energy security concerns (Raneses et al., 1999). The EU has polices that allow farmers and farming cooperatives to grow crop feedstock for industrial and commercial uses, such as feedstock cultivation on 'set aside' land. In France, there is a 5\% biodiesel blend in all commercial diesel fuel (Boyd et al., 2004); Austria and Germany have many tax benefits that promote the use of neat biodiesel in ecologically sensitive regions, such as mountainous areas and lakes (Raneses et al., 1999). In the United States, the urban transit market has been regulated as a result of the Clean Air Act Amendments of 1990; many urban fleets throughout the United States run on B20 (Prakash, 1998). One advantage of biodiesel in public transportation is practicality; the fuel demand could be met with a relatively few number of filling stations as bus fleets are fuelled at centrally located areas. However, privately owned vehicles must rely on filling stations; biodiesel pumps may not be conveniently located.

\section{Mining}

In the United States, most underground coal, metal and non-metal mines use diesel engines; diesel powered equipment is used to load, drill and transport material and personnel (Raneses et al, 1996). Diesel-powered machines are potentially less expensive to operate than other transport 
systems. Biodiesel could be a very feasible form of fuel for the diesel powered equipment used in the mining industry. With greater use of diesel equipment, the potential advantages of using biodiesel as a fuel source, also has related possible health and environmental benefits. In underground and surface mining, biodiesel could be used as a fuel and a dust suppressant (Raneses et al., 1996). Biodiesel releases less particulate matter into the air (Sheehan et al., 1998) for potential inhalation by miners. In addition, biodiesel has a higher flash point, which provides a safer working environment in the mining industry than diesel (Prakash, 1998). However, before biodiesel or biodiesel blends could be used in mining, their impacts on human, environmental and ecosystem health, relative to petroleum diesel, would need to be thoroughly examined.

\section{Marine Environments}

Land transportation is not the only potential market for biodiesel use; biodiesel may have a considerable impact on marine transportation (Gustafson, 2003); many sea-going vessels rely on diesel as their primary source of fuel. Biodiesel could be used to reduce soot, odour, particulate matter and exhaust emissions (Raneses et al., 1996). Also, biodiesel and biodiesel blends maybe better able to mitigate the dangers of diesel fuel leaks and spills on lakes, rivers and estuaries. Biodiesel and biodiesel blends can also find a sustainable market as a fuel for large recreational boats and vessels.

\subsection{Biodiesel Properties}

Biodiesel is a reasonable alternative to diesel fuel; it is a fuel produced from renewable resources and has lower exhaust emissions than conventional petroleum diesel. One gallon of biodiesel displaces 0.95 gallons of diesel over its life cycle (Sheehan et al., 1998). It is also very energy 
efficient, for every unit of fossil energy used to produce biodiesel, 3.37 units of biodiesel energy is created; it has a high energy yield when compared to fossil fuels; biodiesel also significantly reduces the amount of carbon dioxide being released into the atmosphere by diesel-engine vehicles.

Biodiesel is also an oxygenated fuel; fuel burns more efficiently and this greatly improves the emissions profile of a diesel engine. The more biodiesel used in a blend, the higher the emission reductions, in addition, biodiesel also releases less carbon dioxide than conventional diesel. Additionally, the crop feedstock used to produce biodiesel absorb large amounts of carbon dioxide as they grow (Sheehan et al, 1998). One of the unique benefits of biodiesel is that it drastically reduces air toxins, such as sulphur oxides and carbon dioxide, which are associated with petroleum diesel exhaust and are suspected of causing cancer and other human health problems.

Nitrogen oxide emissions are an exception to the rule, since biodiesel tends to increase nitrogen oxide emissions. Recent research has shown a number of ways to mitigate this problem. Through the Trans-Esterification process, the conversion of triglycerides into methyl or ethyl esters reduces the molecular weight of biodiesel to one-third, which reduces the viscosity by about one-eighth and slightly increases the volatility (Barnwal and Sharma, 2005). However, studies (Tyson, 2001) have suggested that some cold-flow starting problems persist in temperate conditions because biodiesel has low volumetric heating values, a high cetane number and a high flash point (Barnwal and Sharma, 2005). Nevertheless, biodiesel is rated as a strong candidate as an alternative to diesel. 
Biodiesel is also safer to use than petroleum diesel; biodiesel has a higher flash point, neat biodiesel has a minimum flashpoint of $127^{\circ} \mathrm{C}$, compared to $53^{\circ} \mathrm{C}$ for regular no. 2 diesel (Dmytryshyn, et al, 2004). It also handles like diesel and is safe to transport and store, it does not require special storage, either in its pure form or in blends. Biodiesel and biodiesel blends can be stored in the same containment areas as diesel, with the exception of concrete-lined tanks. Like petroleum diesel, biodiesel operates in diesel engines; essentially no engine modifications are required and biodiesel offers comparable lubricity, horsepower and torque to petroleum diesel (Dmytryshyn et al., 2004).

\subsection{Biodiesel Spills}

Biodiesel is becoming more prominent in North America; with the expected increase in use; the fate of this green fuel is an area of concern since fuel spills constitute a major source of contamination and pollution. According to the Environmental Protection Act; a spill is defined as "a discharge into a natural environment, from or out of a structure, vehicle or other container, and that is abnormal in quantity or quality in light of all the circumstances of the discharge" $(\mathrm{Li}$, 2005). There are many causes of spills, including (i) vehicular and watercraft collisions, (ii) underground tank leaks (iii) discharges directly into watercourse, (iv) human error and negligence and (v) natural processes (flooding, land subsidence, earthquakes, slides). Among these concerns, water quality is one of the most important issues for living systems. Biodiesel consists of mainly fatty acids; however, it is not desirable if ethyl or methyl esters accumulate in the waterways (Tyson et al., 1998). Consequently, biodegradability and toxicity of biodiesel fuels is of interest, particularly if they accidentally enter into the aquatic environment in the course of their transportation, use, storage or disposal. 
Biodiesel is an alternative fuel derived from renewable organic material such as vegetable oils or animal fats. Vegetable oil and animal fats spills do have deleterious effects on waterways; similarly, spills of biodiesel could have some negative impacts on aquatic environments. Large discharges of non-petroleum oils, as well as biodiesel, in an aquatic environment may cause significant oxygen depletion in waters due to rapid biodegradation rates. Like other petroleumbased products, discharges of these substances could pollute water and endanger organisms living in freshwater ecosystems.

A twenty-year (1982-2002) trend analysis of oil spills in EPA jurisdiction of spills of 50 gallons and more has indicated that $80 \%$ of volume spills originated from pipelines (43\%) and other facilities (37\%), the other $20 \%$ of spills came from other sources, for example, tank leakage and transportation accidents. Although, crude oils spills accounted for the greatest volume of oil spilled (43\%), light fuels, such as no. 2 diesel, accounted for the greatest number of recorded oil spills (36\%) in areas under EPA jurisdictions (Etkin, 2004). Diesel has a high frequency of recorded accidents and spills, however, a trend analysis has not been conducted on spills of biodiesel or biodiesel blends. If biodiesel becomes a commercially viable substitute for diesel, there may also be an increase of biodiesel spills into the environment.

There is not much data on recorded biodiesel spills; however, biodiesel spills can still be compared to petroleum oil spills. Biodiesel spills may generally be very small in volume due to the differences in the processing operations of crude oil and biodiesel. Petroleum tankers can exceed 250000 tonne capacity however; vegetable oils are usually carried in smaller tankers with a capacity of approximately 3500 tonnes. Consequently, a vegetable oil or waste animal fat spill 
may not be comparable in magnitude to a petroleum spill; the probability is very small. Transportation processes of vegetable oils, waste animal fats and even yellow grease are also conducted at substantially different volumes and magnitudes than crude oils (Sagrans, 1998). Nevertheless, the frequency of an feedstock or biodiesel accident occurring is still high because of (i) the increasing number of biodiesel processing plants, (ii) the location of plants near freshwater environments and (iii) biodiesel and feedstock transportation routes are mainly situated inland. Consequently, the impact of a biodiesel spill in waterways may have similar consequences to a petroleum- based oil spill in marine environments.

With the expected increase in biodiesel demand as an alternative fuel source in North America, biodiesel production and biodiesel blending is also expected to increase. Increased use in the transportation sector may also lead to a rise in the number of accidental spills. Oil spills endanger public health, jeopardize drinking water supply, spoil natural resources, disturb ecosystems and disrupt the economy of a country. Nations have become more dependent upon oil-based products to help maintain a certain standard of living. Petroleum based products and non-petroleum oils, such as vegetable oils and animal fats, are increasingly being consumed. With this increased consumption, there is more biodiesel being transported from process plants to filling stations. Consequently, there is a greater chance of these fuels being spilled into the aquatic environment. Spilled biodiesel can contain toxic components that can produce chemical and physiological effects that are similar to petroleum oils; biodiesel spills may pose many threats to public health and safety. Like any other transportation fuel, biodiesel and biodiesel blends are usually stored and transported in large volumes; during storage or transport or even production, oils and other 
oil-based products are sometimes spilled onto land or into waterways. When this occurs, human health and environmental quality are put at risk.

\subsection{Petroleum-Based Oil Spills in the Aquatic Environment}

There is limited research on biodiesel or biodiesel blend spills; however, there are studies on diesel spills and vegetable oil spills. Although spills occur on land, particularly along transportation routes, crude and petroleum-based oil spills are very prevalent in marine and freshwater ecosystems (Cripps and Shears., 1996). The short and long term risk posed from accidental spillage during transportation and storage to the environment can be particularly high, especially in aquatic ecosystems (Cripps and Shears., 1996). The product loss from leaking tanks is a significant environmental problem and may be a point source of groundwater and coastal zone contamination. These fuels may have deleterious effects on ecosystems, resulting in physical impairment of organisms and eventual mortality. According to the Alaska Administrative Code 2002, the toxicity of petroleum, petroleum products and petroleum byproducts are classified as: (i) highly toxic (nos. 1 and 2 and artic diesel fuel, jet fuels A and B, motor gasoline, kerosene and stationary turbine fuels); (ii) moderately toxic (waste oil and lubricating oil); (iii) less toxic (bunker oil and hydraulic oil) and relatively non-toxic (asphalt and tars) (Mohammed, 2005). All of these oil types are transported by either trucks or tankers; both terrestrial and aquatic environments are at risk.

Most research on the fate and effects of oil entering the aquatic environment has focused on marine ecosystems, as most of the large oil spills that have received much attention have occurred in marine environments. Similar concern for freshwater aquatic ecosystems has been lacking. Nevertheless, oil spills do occur in freshwater areas as a consequence of the many oil- 
related activities in this type of environment. It is important that fuel spills in freshwater habitats be addressed; one of the major sources of diesel oil spills is due to storage and transportation accidents.

Crude oil in freshwater environments is of particular concern because of its large retention time in aquatic environments. Oil retention times in marshes, swamps and other low energy environments are longer than oil spilled on high-energy coastlines (Bhattacharyya et al., 2003). Spilled crude oil may be present in sediments at low energy sites long after the occurrence of the spills; in addition, oil could be released into the water column many years after the initial spill. Water-column species and sediment-inhabiting species may both be affected by crude oil spilled in aquatic environments. Fuel may have both acute and chronic effects on freshwater ecosystems; chronic effects on water-column species include neurosensory disruption, behavioural and developmental abnormalities and reduced fertility (Bhattacharyya et al., 2003). Oil-based products spilled in waterways may limit oxygen exchange; acute effects include coating of the gills and skin, creating respiratory problems and death for many organisms.

Many studies have addressed the toxicity of crude oils and fuel oils on a variety of marine organisms. In comparison to the number of marine studies conducted on the effects of petroleum fuels, relatively few investigations have been done on freshwater habitats and organisms. Under marine conditions, wave action and surface turbulence are usually high, the volume and depth of water affected is usually large and the land-water interface comparatively small. Bhattacharyya et al (2003) have suggested that there is little surface turbulence, smaller volume and depth of water and the land-water interface is larger in freshwater environments when compared to 
marine areas. Consequently, processes such as water mixing and dilution are usually limited in freshwater systems and infiltration of spills into surrounding areas may be increased. Conditions such as reduced turbulence and mixing increase the retention time of spilled hydrocarbons in the environment; the longer spilled oil is present, the greater the environmental damage. Another factor that has an effect on toxicity is the type of organisms exposed to toxins; marine and freshwater organisms are physiologically different; marine and freshwater organisms may be resistant to different types of pollutants. This can lead to a possible shift in species diversity; particularly towards a pollutant-tolerant species dominating the affected area. Unfortunately, very little research has been done on the effectiveness and toxicity implications for freshwater biodiesel oil spills on freshwater organisms.

When petroleum-based hydrocarbons are spilled into an aquatic environment, toxins can affect organisms that live in or around the water surface as well as those that live underwater. Oil spills can also harm parts of the food chain, including human food resources. Aquatic environments are seriously threatened by a variety of human activities. Many studies have shown that the extent of damage to stream flora and fauna following accidental oil spills is diverse and complex. The effect of a pollutant in aquatic environments depend on: (i) the chemical characteristics of the petrochemical involved (ii) the volume and severity of the spill (iii) the nature of the receiving water and its biota and the (iv) physical and natural conditions of the ecosystem affected, such as temperature and weather (Lytle and Peckarsky, 2001).

Oil consists of heavy insoluble compounds and lighter soluble compounds; crude oil containing heavy insoluble compounds is generally more persistent than lighter water soluble oils that 
evaporate faster, however, lighter compounds are also highly toxic. The insoluble fraction can combine with the particulate organic matter or inorganic matter on the stream bed resulting in persistently toxic effects or an increased consumption of oxygen by bacteria during decomposition (Mudge, 1995). However, some studies suggest that exposure to water soluble fractions of oil causes more mortality than exposure to the products of oil degradation in sediment residues (Lytle and Peckarsky, 2001). As a result, it is very important to study the acute effects of oil and oil-based byproducts on aquatic ecosystems. Stream discharge also plays an important role in determining the extent of damage caused by oil spills; smaller streams are more susceptible than larger streams. Oil spills in streams and rivers with low discharge can create very deleterious effects to aquatic habitats; particularly areas in close vicinity to the source of the spill. Also, high volume spills cause more damage than smaller ones. However, turbulent flow at the time of a spill can enhance dispersion of chemicals, thereby affecting the spatial extent and immediate impact of the toxins on organisms. In contrast, scouring flows have been shown to accelerate recovery from oil spills not only by removing oil from the sediment but also by enhancing the recolonization of stream biota from upstream (Lytle and Peckarsky, 2001). Unfortunately, many small streams and other low energy areas have minimal scouring and erosional processes present.

Natural processes and physical conditions are present in all aquatic environments; these can reduce the severity of an oil spill and accelerate the recovery of an affected area. Some natural processes include weathering, evaporation, oxidation, photo-oxidation, biodegradation and emulsification. The intensity and extent of some of these natural processes may differ in freshwater ecosystems when compared with marine environments. Freshwater environmental 
impacts can be more severe because water movement is decreased in these habitats. In standing water bodies, oil tends to pool and can remain in the environment for long periods of time. In flowing streams and rivers, oil tends to collect on sediments, as well as, plants and grasses growing on the banks and on the stream and river beds. These hydrocarbons can also interact with the sediment at the bottom of the freshwater bodies, affecting organisms that live in or feed off sediments.

Plant, animal and human exposure to toxic substances is generally reduced with time and is usually limited to the initial spill area since oil spill toxins may evaporate or biodegrade quickly. Both petroleum and non-petroleum oil can affect the environment surrounding an oil spill; all petroleum hydrocarbons possess similar chemical and physical properties that produce comparable effects on the environment. Some studies have shown that non-petroleum oil spills, such as plant and vegetable oils, can produce comparable effects as petroleum oil spills.

\subsection{Vegetable Oil Spills in the Aquatic Environment}

Vegetable oils are classified as non-petroleum oils; vegetable oils are commonly used as feedstock in biodiesel production (Van Gerpen, 2004). Research concerning the effects of vegetable oils in the marine and freshwater environment is limited when compared with the number of studies conducted on crude oil spills. Vegetable oils are transported and stored in similar ways to petroleum oils and the likelihood of spills of vegetable oils is no different from that of petroleum oils (Pereira et al., 2002). The lack of research on the effects of vegetable oils spills is possibly due to the assumption that vegetable oils are easily metabolized by organisms 
and therefore are considered less harmful than crude oil spills or even that some renewable oils are more easily biodegraded than the more persistent petroleum-based oils (Pereira et al., 2002).

Large quantities of vegetable oils are transported from production sites to consumption areas, creating the possibility of spills to aquatic environments. Contamination can be caused by small spills during loading and unloading; acute pollution can be caused by shipping accidents. Large spills of vegetable oils have been reported all over the world. Pereira et al. (2003) have done extensive research on vegetable oil spills, some examples of spills include 2.5 million gallons of soybean oil spilled into the Minnesota River and Upper Mississippi River in 1963, a spill of 10 000 tonnes of palm and coconut oil and edible raw material occurred in 1975 on Fanning Island in the Pacific Ocean. Other examples include a palm oil spill in The Netherlands and a 400 gallon spill of rapeseed oil during the winter of 1989 in Vancouver Harbour, Canada. Although these spills caused many adverse effects to birds, fish and other aquatic organisms, vegetable oils have not been as extensively studied as those of crude oils.

Although not much research has been conducted in terms of biodiesel spills, there have been many studies involving petroleum-based oil and some on vegetable oil spills. Mudge (1995) has researched vegetable oil spills in marine environments, which has led to three main areas of concern about any such spillage. Sublethal effects on the environment may be caused by (i) Smothering (ii) Direct Toxicity and (iii) Polymerization of the oils with the sediments. Most vegetable oils float on water because of their lower density. When vegetable oils spill into waterways they reduce the oxygen exchange across the air-water interface, reducing oxygen supply by the process of smothering. Besides oxygen depletion, oils may adhere to organisms, 
resulting in injury and even death. Direct toxicity may cause sublethal effects in organisms; these sublethal effects include reduced growth, suffocation, genetic variations and changes in reproductive cycles may also occur (Mudge, 1995). Polymerised oil decreases bacterial degradation; over time some polymerised oils form an impermeable cap over sediments, anoxic conditions may develop below the surface; this change in available oxygen may lead to a change in species diversity (Mudge, 1995). It can be postulated that similar effects may occur to freshwater organisms. Biodiesel is also produced from animal fats and waste cooking oils. However, research is limited on the influence of these feedstocks in aquatic environments.

\subsection{Biodiesel and Biodegradability}

Million of tonnes of oil are spilled each year into the environment during transport, storage and processing. For example, the Exxon Valdez incident in 1989 released 11.2 million gallons of crude oil into the Alaskan region (Biswas et al., 2005). As interest in biodiesel increases, their fate in aquatic environments is an area of relevance since fuel spills constitute a major source of contamination of many ecosystems (Zhang et al., 1995). It is important to examine biodegradability concepts in terms of biodiesel fuels and their biodegradation rates. Research on biodiesel biodegradability is limited, however, one study was found, which dealt with comparing two types of biodiesel with diesel.

It was determined that biodiesel has desirable degradation attributes; studies at the University of Idaho have been conducted to determine the biodegradation of biodiesel in an aqueous solution. Biodiesel, in particular, rapeseed methyl and rapeseed ethyl esters, was compared to diesel fuel and dextrose (Zhang et al., 1995). The biodegradability project examined chemical oxygen 
demand (COD) and biological oxygen demand (BOD), biodegradation in aqueous solutions and biodegradation in soils. It is generally better if COD and BOD data have very low values because it indicates how much of this material is in water, sewage or in an effluent (Biswas et al, 2005). However, when biodegradation is of interest and it is desirable to have the toxin break down very quickly, high BOD and COD would be desired.

According to the studies performed, rapeseed methyl and ethyl esters have high COD and BOD values; biodegradation was determined in an aqueous solution using a 28 day shake flask test.

Both esters degraded more rapidly than the dextrose control, the esters degraded at almost identical rates to about $95 \%$ at the end of 28 days. The diesel fuel in this test was approximately $40 \%$ biodegraded after 28 days. Although neat biodiesel has a high biodegradability rate in comparison to conventional diesel fuel, there may be acute short term risk associated with large volumes of biodiesel and biodiesel blend spillage (Zhang et al., 1995). The two types of biodiesel used in the study were produced from a vegetable oil feedstock. Research on biodegradability of biodiesel produced from waste animal fats and spent cooking oil is very limited.

\subsection{Economic Analysis}

For the past decade, many countries have been confronted with fossil fuel Idepletion and environmental degradation; these two predicaments have sparked interest in alternative fuels. Alternative fuels, energy conservation, energy efficiency and environmental protection have become pertinent issues regarding natural resource management (Barnwal and Sharma, 2005). There is an interest in biodiesel production because of the (i) increasing demand for liquid (biofuel) energy, (ii) continuing surpluses of agricultural commodities and (iii) rural 
communities seeking diversification opportunities from mainstream farming (Radich, 2004). Studies have suggested that world oil consumption will increase primarily due to the growth in consumption of transportation fuels. Increased production of biodiesel could partially alleviate this increasing crude oil deficit.

\subsubsection{Economic Factors}

Information on the economic feasibility of biodiesel is limited. It is difficult to determine feasibility because of the complexity of all the factors involved in biodiesel production and marketing. Several feasibility studies have evaluated the market potential and economic costs of producing biodiesel, most using vegetable oil as the primary feedstock. Others excluded cost elements such as land and property taxes, administration, transportation and market development. Nevertheless, some fundamental analysis is possible based solely on economic factors.

To determine the feasibility of biodiesel as an alternative source of energy, economic input and economic output factors should be considered. Biodiesel costs are segmented according to fixed and variable costs. Fixed costs are estimated for extracting the vegetable oil from seed and for processing the oilseed into biodiesel (Enguídanos, 2002). Variable costs depend on the (i) type of raw materials used, (ii) type of oil extraction process and (iii) size of overall biodiesel operation.

The major economic input factor in biodiesel production is the feedstock costs (Enguídanos, 2002). Feasibility of biodiesel production is predominantly determined by which type of organic feedstock is used in the Trans-Esterification process. Technologies and processes involved in biodiesel manufacture may vary. Nevertheless, the greatest share of the production expense is the 
feedstock cost; feedstock cost is the major barrier to the feasibility of biodiesel in urban and rural markets (Bender, 1999). Raw material costs account for a major portion of the total manufacturing cost, which is approximately 80 percent of the total operating cost (Enguídanos, 2002). Reduction of the raw material cost would optimize the total manufacturing cost. The type of feedstock used also foreshadows biodiesel prices. Some studies have shown that biodiesel made from non-edible oils such as waste animal fats are less expensive than edible oils such as canola, sunflower and rapeseed oils (Bender, 1999). Virgin oil costs approximately 2-3 times more than waste oils, such as restaurant cooking oils and by-products from livestock processing plants; the use of virgin oil leads to a significant increase in total manufacturing cost (Zhang et al., 2003).

The important economic output factors for biodiesel production are the end products, break-even price and regulations and initiatives. Besides biodiesel, glycerin is the other major end product; glycerin is widely used as an ingredient or processing aid in the cosmetic, drug and food industries. The profits from reusing glycerin can be used to offset cost incurred by the feedstock as well as other raw materials used in biodiesel production (Prakash, 1998). Break-even prices may vary from one biodiesel processing facility to another depending on the scale of the operation. Plants are classified into three groups (i) community, (ii) industrial and (iii) large industrial; the size of the operation has an influence on cost (Bender, 1999), differences in fixed and variable costs create elastic break-even prices. Other important economic factors include regulations and initiatives, these procedures will vary from one country to another (Prakash, 1998). 


\subsubsection{Economic Feasibility of Biodiesel}

Biodiesel produced from vegetable oils is currently not economically feasible; the economics of biodiesel are unstable due to the large feedstock cost. Also, factors such as capital costs, electricity and water costs and glycerin credit can significantly affect biodiesel production costs (Bender, 1999). Economic feasibility studies show that the biodiesel obtained from non-edible oils is cheaper than that from edible oils (Barnwal and Sharma, 2005). Biodiesel manufactured from non-edible oils, such as waste animal fats, is closer to being cost competitive with petroleum diesel than biodiesel produced from vegetable oils, such as soybean oil. However, the currently available supply of such yellow greases will probably limit its use for successful longterm biodiesel production (Radich, 2004). Prices of edible oils, such as vegetable oils, need to decrease considerably in order for large quantities of biodiesel to become competitive with petroleum diesel prices.

The economic feasibility of biodiesel also depends on the price of crude oil and the cost of transporting diesel over long distances to remote areas. The cost of diesel will increase in the future due to the increase in its demand and limited supply (Barnwal and Sharma, 2005). Low production costs of crude oil derivatives are another significant limitation for biodiesel success. Increasing crude oil prices may open the biodiesel market; biodiesel demand may increase biodiesel production. Production costs may be lowered to levels where biodiesel prices at the gas pumps are comparable to those of fossil diesel. Fluctuating crude oil prices may become a potential opportunity for enhancing biodiesel demand in selective niche markets (Enguídanos, 2002). 
Important factors for feasible biodiesel production are in place for the industry to succeed: such as environmental concerns with diesel fuel, diminishing petroleum reserves and awareness of the increased environmental consequences of emissions from diesel and gas-fuelled engines. A viable biodiesel industry in North America has potential benefits including: (i) increased feedstock value for oilseeds, animal fats and yellow grease, (ii) increased employment rates, (particularly in rural areas) and (iii) increased tax base from plant processing operations as well as income tax benefits and investments from feedstock processing ventures.

\subsection{Present Biodiesel Status}

Biodiesel has been established in Europe as the leading alternative fuel source, in North America, enthusiasm for biodiesel has been slow but growing. At present, biodiesel price is the main hindrance to its success in North America. The cost of biodiesel without tax in North America is about 2 to 3 times more than the selling price of diesel (Prakash, 1998). This gap can be reduced by offering subsidies to biodiesel or by imposing additional taxes on conventional diesel fuel. Additionally, the cost of biodiesel could be reduced by employing lower cost feedstocks, such as animal fats and waste grease or through innovative technologies, such as biodiesel treated with supercritical methanol. The engine and vehicle manufacturers in North America have not yet approved the use of biodiesel blends greater than B5 in their products (Holbein et al., 2004). However, the biodiesel industry in the United States is pursuing a number of initiatives to promote and expand the use of biodiesel, such as the Biodiesel Tax Incentive and the Energy Bill. The tax incentive, established originally as part of the American JOBS Creation Act of 2004, has been extended until 2008. The excise tax credit provides an incentive to fuel 
distributors to blend biodiesel into diesel fuel, such as that made from soybean oil and recycled cooking oil (ENN, 2005).

The U.S. Energy Bill provides incentives and credits for alternative fuel installations; the bill also supports demonstration and testing projects for biodiesel use. The Energy Bill also promotes the U.S. departments of the Interior, Commerce and Agriculture to use energy efficient vehicle technologies, including biodiesel. The Energy Bill states that biodiesel is eligible for the Clean Bus EPA program; for example, those implemented for school buses (ENN, 2005). These activities should have some positive impact on biodiesel use in Canada. There is great prospects for biodiesel use in Canada, particularly in the mining industry, marine and transportation sectors (Prakash, 1998). 


\section{MATERIALS AND METHOD}

\subsection{Thesis Objectives}

Various types of habitats have differing sensitivities to spills, either from petroleum-based oils or oils produced from vegetable oils, animal fats or yellow grease. There has been an increased interest in the use of biodiesel as a potential fuel and a feasible alternative to diesel fuel. However, like diesel fuel, any fuel could accidentally be spilled into rivers, lakes and oceans. Aquatic environments are made up of complex interactions between plant and animal species and their physical environment. Harm to the physical environment will often lead to harm to one or more species in a food chain, which may lead to damage for other species further up the chain, particularly humans.

This thesis addresses the effect of different biodiesel blends on aquatic organisms; diesel fuel is refined, stored and transported throughout estuarine, coastal ecosystems as well as freshwater environments which include watersheds and wetlands. These ecosystems provide essential habitat for aquatic species; which are vulnerable to accidental fuel and oil spills. Even though natural oozes of crude oil occur in the ocean floor and stable marine biotic communities are associated with them, the sudden introduction of high concentrations of oil or oil-based products can potentially kill or cause sublethal effects in some aquatic organisms.

Biodiesel has been proposed as a possible alternative source of fuel; an alternative to conventional diesel fuel. Diesel spills account for many spills, particularly along transportation routes, if biodiesel is being considered as a diesel substitute; biodiesel may also prone to such spills. Consequently, it is important to study the impacts of such energy alternatives on the 
environment, toxicological studies are necessary to evaluate the potential impact of biodiesel and biodiesel blends on aquatic organisms and the freshwater environment. Unfortunately, there is a discerning lack of information concerning the acute toxicity of biodiesel and biodiesel blends on freshwater organisms.

The aim of this study was to determine the effects of biodiesel and biodiesel blends on the freshwater aquatic environment. Toxic effects of neat biodiesel and biodiesel blends were compared to conventional diesel fuel. Aquatic toxicity testing used in this study involved static non-renewal bioassays. In static non-renewal tests, the toxin is introduced into the test water at the beginning of the test and then the water is not changed during the duration of the test. The duration of the test may vary with the organism being tested. The organisms used in this experiment were the water flea, Daphnia magna (D. magna) and Oncorhynchus mykiss (O. mykiss), commonly referred to as rainbow trout. Acute toxicity was generally measured using a multi-concentration test, consisting of a control and a minimum of six and five toxin concentrations for D. magna juveniles and $O$. mykiss frys respectively.

The thesis undertaken examines the influence of different concentrations of neat biodiesel and biodiesel blends (B20, B50 and B5) on two freshwater organisms; D. magna juveniles and $O$. mykiss (rainbow trout) fry. Acute toxicity testing was done with different concentrations of biodiesel, biodiesel blends and diesel fuel. The purpose of this study was to determine (i) the mortality rate of biodiesel and biodiesel blends (B50, B20, and B5), (ii) the LC50 values of neat biodiesel and biodiesel blends after different exposure times and (iii) the relationship and 
significance of biodiesel results obtained to conventional diesel fuel. The two endpoints of the testing were (i) mortality rate and (ii) lethal concentration (LC50) values at 24, 48, 72 and $96 \mathrm{hrs}$.

To determine the relative toxicity of certain chemicals on an aquatic organism, an acute toxicity test was conducted to estimate the lethal concentration of the toxin. The tests were designed to provide concentration-response information, expressed as the toxin concentration that is lethal to $50 \%$ of the test organisms (LC50) within the prescribed period of time (24-96 hrs). The measured endpoints of the static non-renewal test were mortality rate and LC50. A 24hr-LC50 toxicity test was conducted on D. magna juveniles and a $96 \mathrm{hr}-\mathrm{LC} 50$ was conducted on $O$. mykiss frys, according to the EPA guidelines outlined in the Methods for Measuring the Acute Toxicity of Effluents and Receiving Waters to Freshwater and Marine Organisms. Most oil toxicity studies have focused on early life stages of test species because these stages are generally more sensitive to toxic effects than adults.

\subsection{Acute Toxicity Test}

Acute toxicity is the apparent adverse effect induced in an organism within a short time of exposure to a substance or chemical. In the tests performed, acute toxicity was expressed as the median lethal concentration (LC50); the concentration in a water medium which kills $50 \%$ of the test organisms within a continuous period of exposure. For this study, acute toxicity was measured using a multi-concentration definitive test; consisting of a control and a minimum of five sample concentrations. The tests were designed to provide concentration-response information, expressed as concentration that is lethal to $50 \%$ of the test organisms, also referred to as the LC50 within the prescribed period of time, usually between 24 and $96 \mathrm{hrs}$. Static non- 
renewal tests were used in this study, this type of test involved the test organisms being exposed to the same test solution for the entire duration of the test. Static non-renewal tests were utilized because this type of test is simple and inexpensive, little space and equipment is needed and small volumes of fuel concentrations are required (EPA, 2002). This type of testing was also chosen because only toxic effects in a freshwater (small stream) situation over a short time period was considered in the study.

\subsection{Bioassay}

The test organisms were exposed to static non-renewal testing which involved a multiconcentration test used to determine the effects of acute toxin exposure. Bioassays were performed to determine the LC50 of both D. magna and $O$. mykiss under the influence of different biodiesel blends and diesel fuel. This bioassay used static non-renewal tests; this type of test involved the test organisms being exposed to the same test solution for the duration of the test. The test solutions involved are conventional diesel, neat biodiesel and biodiesel blends of $\mathrm{B} 20, \mathrm{~B} 50$ and $\mathrm{B} 5$ in a water medium.

\section{$\underline{3.4 \text { Bioassay Organisms }}$}

The two bioassay organisms used were the water flea $D$. magna and $O$. mykiss, commonly referred to as rainbow trout; young organisms are often more sensitive to toxicants than are adults. For this reason, the use of early life stages, such as daphnid juveniles and fish swim-up fry, was required for all tests. In a given test, all organisms had similar physiological characteristics and were approximately the same age and were taken from the same source. Since 
age may affect the results of the tests, it enhanced the value and comparability of the data when the same species in the same life stages were used throughout the experiment (EPA, 2002).

\subsubsection{Daphnia magna}

Daphnia magna (D. magna) is a small crustacean, often referred to as a water flea, which is barely visible with the naked eye. It lives in water and has large antennae in comparison with the rest of its body. D. magna is used as a bio-indicator and it is often used to measure the toxicity of a chemical compound in water. This species is often used in LC50 measurements. D. magna has a worldwide distribution in the northern hemisphere; $D$. magna found throughout many parts of Canada and the United States (EPA, 2002).

\subsubsection{Oncorhynchus mykiss}

Fish may be exposed to pollutants in different ways; they may come into (i) direct or (ii) indirect contact. Toxins may contaminate their gills and other external appendages, in addition, the water column may contain toxic and volatile components of fuel that may be absorbed by their eggs and juvenile stages; fish may also be affected by eating contaminated food, which may include algae, plankton or even other fish. Fish that are exposed to petroleum-based hydrocarbons may suffer from heart and respiratory problems, fin erosion, reduced growth and reproductive and behavioural responses (EPA, 2002). Some studies have shown that chronic exposure to some chemicals present in oil may cause genetic abnormalities or cancer in some sensitive fish species. For this project, $O$. mykiss young were used; acute exposure was measured by mortality. $O$. mykiss are a variable species that differ considerably over their range. The native range of the 
rainbow trout group in North America is west of the Rocky Mountains and along the eastern Pacific Ocean but $O$. mykiss has been introduced into many parts of North America. Rainbow trout has also been widely introduced and established in other cold water habitats all over the world (EPA, 2002).

The fish should be in good health and free from any apparent physical deformity or disease. The species used were selected on reason, such as availability, maintenance, testing convenience and sensitivity to chemicals (EPA, 2002). The testing used O. mykiss as the preferred fish species because of its worldwide availability, moderate fat content and adaptability to fresh or sea water (Environment Canada, 2000).

The procedures of the experimental work were divided into two sections; (i) toxicity effects of fuel concentrations on D. magna juveniles and (ii) toxicity effects of fuel concentrations on $O$. mykiss frys. Lethality and other toxic effects of a chemical are dependent on both concentration and exposure time (Lee et al., 1995). The toxicity of biodiesel and biodiesel blends was investigated using acute toxicity tests; a comparison was made to diesel fuel toxicity. For both daphnids and fish, this was done by observing lethality resulting from exposure to a series of chemical concentrations, at $24,48,72$ or 96 hours. 


\subsection{Experimental Organisms}

\section{Daphnids}

Two different types of daphnids were used, D. magna and D. pulex. Daphnids were obtained from Carolina Biological Supply Ltd and Ward's Natural Science. Daphnids were maintained and cultured at $20 \pm 1{ }^{\circ} \mathrm{C}$. The photoperiod consisted of 16 hours of light and 8 hours of darkness.

O. mykiss (Rainbow Trout)

Rainbow trout (O. mykiss) (weighing between $0.5-1.0 \mathrm{~g}$ ) were obtained from two local suppliers (Linwood Acres Trout Farm Ltd, Campbellcroft, ON, and Blue Springs Trout Farms Ltd, Hanover, ON). Although, there was two different fish stock, there was no mixing of the stocks throughout the experiments. All fish were maintained at $12 \pm 2^{\circ} \mathrm{C}$. Fish acclimation, in terms of temperature, was tested for exposures between 8 and $23^{\circ} \mathrm{C}$. Fish were acclimated at $12 \pm 2^{\circ} \mathrm{C}$ for fourteen days prior to use. Water temperature was regulated to within $2{ }^{\circ} \mathrm{C}$ of the desired test temperature by a refrigerator. Photoperiod was 16 hours of light and 8 hours of darkness. The fish stocks were fed daily with commercially prepared trout pellets obtained from Linwood Acres Trout Farm Ltd.

\subsection{Test Chemicals}

The fuels used in the bioassays were conventional diesel, B100 and biodiesel blends, the biodiesel blends included B50, B20 and B5. Biodiesel blends were made from the same B100 feedstock. 


\subsection{Equipment \& Material}

Sample containers, culture units, analytical balance, test chambers, volumetric flasks \& graduated cylinders $(10-1000 \mathrm{ml})$, volumetric pipettes $(1-100 \mathrm{ml})$, graduated serological pipettes (1-10ml), graduate micropipettes $(1-5 \mu 1)$, pipette bulb \& fillers, droppers, wash bottles, thermometers (for measuring water temperature and environmental temperature), DO meter, $\mathrm{pH}$ meter, $\mathrm{pH}$ buffers $(4,7,10)$, Sources of food for cultures and stock organisms, dip nets, test organisms: D. magna juveniles and $O$. mykiss frys, holding tanks, deionised distilled water (DDI), Refrigerator.

\subsection{Physiochemical Parameters}

The $\mathrm{pH}$, temperature and dissolved oxygen content of the various concentrations and the control water were the physicochemical parameters measured in this study.

\subsection{Source of Toxins}

B100 was obtained from Rothsay; a rendering company, B100 was made from recycled cooking oils and fats. B20 (Topia) was a B20 blend commercially blended by Topia Energy Ltd. and obtained at a local filling station. Diesel was obtained from the same local gas station.

\subsection{Biodiesel Blending}

The chemical nature of biodiesel allows it to be blended with distillate and diesel fuel; this includes light fuels such as jet fuel, kerosene, no.1 diesel, or military fuels (JP8, JP5), as well as normal diesel fuel like no. 2 diesel for diesel engines. Biodiesel is blended thoroughly with diesel 
fuel; if maintained at temperatures above its cloud point, biodiesel blends stay mixed (Tyson, 2001). Biodiesel mixes well with diesel fuel in any proportion and stays blended even in cold temperatures. Biodiesel tends to store as well as diesel fuel. Consequently, mixed fuels were stored at room temperature in fuel storage containers. Biodiesel blends of B20, B50 and B5 were made with B100 feedstock. Blends were made by a procedure called splash blending; specific amounts of B100 were 'splashed' (poured on top) on specific amounts of diesel fuel and then agitated.

B20 Blending

A fuel storage container was filled with 8 litres of diesel, and then 2 litres of B100 was poured into the fuel container.

B50 Blending

A fuel storage container was filled with 5 litres of diesel, and then 5 litres of B100 B was poured into the fuel container.

B5 Blending

A fuel storage container was filled with 9.5 litres of diesel, and then 0.5 litres of B100 was poured into the fuel container.

\subsection{Common Method Testing}

Procedures and analytical tools used in the acute toxicity tests performed with both $D$. magna and O. mykiss followed guidelines from the Environmental Protection Agency's (EPA) Methods for Measuring the Acute Toxicity of Effluents and Receiving Waters to Freshwater and Marine Organisms. Testing used in this study, solely involved B100, B50, B20, B5 and diesel; the effects of components of diesel was not tested but the effects of diesel was compared to biodiesel and biodiesel blends. Although oil spills are dynamic in nature and may change chemically and physically over a period of time; this study examined the acute toxic effects of biodiesel and diesel concentrations over a short period of time. 


\subsection{Daphnia magna Acute Toxicity Test}

Each 24 hour D. magna test involved placing groups of $D$. magna juveniles into a range of test substance concentrations and environmental control to which the daphnids were acclimated. Toxicity tests with D. magna were conducted in $200 \mathrm{ml}$ samplers. For each concentration including controls, 4 replicate test chambers were used. All tests were conducted at $20 \pm 1^{\circ} \mathrm{C}$. Tests were conducted under static conditions with no renewal of the test solution. For all tests, temperature and photoperiod were similar to those of culture and holding conditions and kept constant between all tests. Observations for immobility and mortality were recorded after 24 hours. A daphnid was considered to be dead if there was no movement. The fuel was stirred into the water before the $D$. magna were introduced into the test chamber. There was a slight sheen of fuel on the top of some test chambers.

\subsubsection{Daphnids Test Procedure}

A range-finding test was followed by a definitive test; this type of test was performed in order to obtain information about the range of concentrations to be used in the main test. A static nonrenewal test was done; trials of control without any test substances were conducted as well as trials of different concentrations of diesel, B100 and B20. Daphnids were exposed to the substance for a 24 hour duration. Temperature ranged within $20 \pm 1^{\circ} \mathrm{C}$ among test trials, the daphnids were not fed during the $24 \mathrm{hr}$ test period. The daphnids were inspected after the first 2 to 4 hours and at the 24-hour interval. Daphnids were considered dead if touching did not produce any reaction and no breathing movements were visible. Dead daphnids were removed when observed and mortalities were recorded. 


\subsubsection{D. magna Test Concentrations}

A $24 \mathrm{hr}$ bioassay using the water flea, D. magna was conducted for this study. The fuels used were diesel, biodiesel (B100) and biodiesel blends of B20, B50 and B5. Range-finding tests on different concentrations were first performed; from the results obtained; definitive concentrations were then tested. Four trials were performed for each concentration; the concentrations tested for trials $1,2,3$ and 4 were $1.57,3.13,6.25,12.5$ and 50ppm with DDI water as the control. All concentrations of the fuels tested were measured in parts per million (ppm).

\subsubsection{Supplier of D. magna}

The D. magna were obtained from Carolina Biological Supply and Ward's Science Ltd. All organisms tested were fed and maintained during culturing and acclimation. The test organisms appeared vigorous and in good condition prior to testing. The $D$. magna were placed below the test surface at test initiation due to the slight sheen of some test samples observed in the rangefinding tests.

\subsubsection{Equipment and Test Chambers}

Separate holding and toxicity testing were conducted to prevent any loss of cultures due to crosscontamination (EPA, 2002). Water used for holding and test samples were DDI water left to stand for 5 days. During culturing and testing, daphnids were shielded from external disturbances such as pedestrian traffic. All material was thoroughly rinsed before use in the test trials. 


\subsubsection{Test Conditions}

The temperature of the test solutions was measured by placing a thermometer into the samples. Temperature was recorded at test initiation and test termination. Test solution temperatures were maintained within the limits specified for trials.

\subsubsection{Number of Test Organisms}

Five daphnids were exposed to each concentration; in the toxicity test performed six concentrations and one environmental control (seven concentrations $x 20$ organisms per concentration) were included in a test trial; four trials were performed. Daphnids were captured from a common pool and distributed sequentially to the test chambers. Excessive handling and carryover of culture water was avoided by placing the tip of the transfer pipettes below the surface of the water in the test chambers and allowing the organisms to swim out of the pipettes without discharging the contents.

\subsubsection{Replicate Test Chambers}

Four test chambers were provided for each substance concentration as well as the control to increase data quality. The data from these replicate chambers were combined to determine the (i) mortality rate and (ii) lethal concentration (LC50).

\subsubsection{Quality of Test Organisms}

The health of daphnids was assessed by the performance (survival, growth and reproduction) of D. magna in culture tanks and control tests; notes on such performances were maintained. 


\subsubsection{Food Quality}

The quality of the food used in culturing and testing invertebrates is an important factor in the study, daphnid food pellets were obtained from Carolina Biological Supply Ltd.

\subsubsection{Culturing Procedure}

Immediately upon receiving the daphnid culture, the daphnia culture was examined to determine if the culture arrived in satisfactory condition; health was determined by actively swimming daphnids. If the $D$. magna culture arrived in satisfactory condition, the lid was opened to permit air exchange. The daphnia culture was placed in an undisturbed location that was shielded from direct sunlight. A 1-gallon plastic aquarium was filled with DDI water, the aquarium water was allowed to stabilize for $24 \mathrm{hrs}$; temperature was maintained at $20 \pm 1^{\circ} \mathrm{C}$. The lids from the jars of D. magna were removed and the jars were slowly submerged in the aquarium.

Daphnid culturing guidelines were taken from Methods for Measuring the Acute Toxicity of Effluents and Receiving Waters to Freshwater and Marine Organisms (EPA, 2002). Once the jar was completely filled and underwater, the culture of daphnia was gently turned into the aquarium. This prevented air bubbles from becoming trapped under the carapaces of the daphnids (EPA, 2002). Dried daphnia food pellets were sprinkled into the aquarium; the daphnids were fed every other day. Aerated DDI water was used as the culture medium, DO content in the culture were maintained above $6 \mathrm{mg} / \mathrm{l}$; aeration of the culture medium was not necessary. A minimum of $16 \mathrm{hr}$ of illumination was provided each day. Two culture chambers were maintained to ensure back-up cultures were present so that in the event of a population 'crash' in one of the culture chamber (EPA, 2002), the entire D. magna population will not be 
lost. All culture containers were washed thoroughly, after the culture was established, each chamber was cleaned weekly of accumulated food, debris and dead daphnids. The medium in each stock culture vessel was replaced two times each week with fresh medium (EPA, 2002).

\subsubsection{Mortality of Culture Tank}

Following a $24 \mathrm{hr}$ acclimation period, mortalities of the stock daphnid population were recorded. Mortalities are recorded at a 24 -hour interval and the concentrations killing $50 \%$ of the daphnids (LC50) at $24 \mathrm{hrs}$ was calculated. For acceptable results, the mortality in the culture tanks and controls did not exceed $10 \%$ by the end of the test period.

\section{$\underline{3.13 \text { Acute Toxicity of Fish }}$}

Test procedures were similar to those for the LC50 D. magna toxicity test; The LC50 toxicity test involved placing groups of fish (10 per concentration) in a range of concentrations of different fuels. The tests were conducted at controlled temperatures of $12 \pm 2{ }^{\circ} \mathrm{C}$. Solutions were gently aerated throughout the 96 hour exposure period. Tests were conducted under static conditions with no renewal of the test solution. For all tests, temperature and photoperiod were similar to those of holding conditions and kept constant throughout all tests. Observations for immobility and mortality were recorded after 24, 48, 72 and 96 hours. A fish was considered dead if there was no evidence of opercular activity and it showed no response to gentle prodding. 


\subsubsection{O. mykiss Test Procedure}

A range-finding test was followed by a definitive test, in order to obtain information about the range of concentrations to be used in the main test. A static non-renewal bioassay was performed; trials with control (DDI water), i.e., without the test substance, diesel, B100 and B20 were performed. Fish were exposed to the toxins and the control for a period of 96 hours. There was a temperature range of $12 \pm 2^{\circ} \mathrm{C}$ for any particular test trial; the O. mykiss were not fed during the $96 \mathrm{hr}$ test period. The fish were inspected after the first 2 to 3 hours and at consecutive 24-hour intervals thereafter. Dead fish were removed when observed and mortalities were recorded. Visible abnormalities, such as changes in swimming behaviour and pigmentation change were noted. Measurements of $\mathrm{pH}$ and temperature were carried out daily.

\subsubsection{O. mykiss Test Concentrations}

Range-finding tests on different concentrations were first performed; from the results obtained; definitive concentrations were then tested. Two trials were done for each concentration; the concentrations tested for trials 1 and 2 were $100,300,600,900$ and 1200 ppm with DDI water as the control. All concentrations of the test substance were given in parts per million (ppm). The rainbow trout bioassays were conducted in 5 litre containers, with $4 \mathrm{~L}$ test solution. The samples were performed in duplicate with 10 organisms per trial. The photoperiod was 16 hours of light and 8 hours of darkness. The temperature range was $12 \pm 2^{\circ} \mathrm{C}$. The fuel was stirred into the water before the rainbow trout were introduced into the chamber, chambers were then aerated. Mortality was recorded after $24,48,72$ and $96 \mathrm{hrs}$. 


\subsubsection{Supplier of O. mykiss}

The $O$. mykiss used in the first round of tests were obtained from Linwood Acres Trout Farms Ltd. Campbellcroft, Ontario and were 6 weeks old and $151 \pm 2 \mathrm{~mm}$ in fork length. The rainbow trout were acclimated to test conditions (control water and temperature) for 14 days prior to test initiation. All trout fry were vigorous and in good condition prior to testing. A second batch of 30 day old rainbow trout hatchlings, at the alevin stage, was obtained from Blue Springs Trout Farm Ltd, Hanover, ON. All fish appeared healthy and in good physical condition.

\subsubsection{Equipment and Test Chambers}

Separate holding and toxicity testing chambers were provided to prevent possible loss of fish due to cross-contamination as well as to reduce the risk of compromised test results. All material was thoroughly cleaned before use in the trials. Water temperatures for the holding tanks and test chambers were maintained by a refrigerator. During holding and testing, rainbow trout frys were shielded from external disturbances such as rapidly changing light conditions and pedestrian traffic (EPA, 2002).

\subsubsection{Test Conditions}

The temperature of test solutions was measured by placing a thermometer directly into the test solutions. Temperature was recorded continuously in at least one holding tank during the duration of each test; temperature of the water supply was also measured daily. Test solution temperatures were maintained within the limits specified for each test. Experimental temperature 
was also measured by placing a thermometer outside the environmental chambers; environmental temperatures were also measured daily.

\subsubsection{Number of Test Organisms}

A minimum of 20 fish were exposed to each concentration. Toxicity test involved five concentrations and a control; fish were used from common pool and distributed to the test chambers. A minimum of two trials were performed for all concentrations; trials done in triplicate were noted.

\subsubsection{Replicate Test Chambers}

Two test chambers were provided for each biodiesel concentration and the control. Although the data from duplicate chambers are usually combined to determine the LC50 and confidence interval values; replicate trials were performed for each fuel concentration. This was done because it: (i) permitted easier viewing and counting trout frys, (ii) avoided possible excess loading of fish, which might occur if all of the test organisms are placed in a single test chamber and (iii) ensured against the invalidation or compromise of the test which might result from accidental loss of a test vessel, when all of the test organisms for a given treatment are in a single chamber (EPA, 2002). 


\subsubsection{Quality of Test Organisms}

The health of the frys was assessed by the performance of rainbow trout (O. mykiss) in holding tanks and control tests. Rainbow trout performance was measured by survival and growth data. Mortality data was also recorded for fish in the holding tanks.

\subsubsection{Food Quality}

Food used in holding and testing fish was an important factor in toxicity testing; rainbow trout fish food was obtained from Linwood Acres Trout Farm Ltd.

\subsubsection{Holding and Handling Test Organisms}

All fish were previously exposed to water of the quality and the temperature used in the trials for at least fourteen days before they were used. Test organisms were not subjected to changes of more than $3{ }^{\circ} \mathrm{C}$ in water and environmental temperatures in any $12 \mathrm{hr}$ period, particularly when organisms were being transferred from holding chambers to test chambers. Fish were handled as little as possible; when handling was necessary, it was done as gently, carefully and quickly as possible to minimize stress to the trout (EPA, 2002); dipnets were used to handle the swim-up frys. Holding tanks for fish were supplied with DDI water; with the aid of a recirculation system, the control water flowed through an activated carbon filter to remove dissolved metabolites; crowding was also avoided. The dissolved oxygen (DO) content was maintained at a minimum of $6.0 \mathrm{mg} / 1$; the standard required for cold-water freshwater species (EPA, 2002). Fish were fed once a day with commercially prepared fish food (EPA, 2002). Excess food and fecal material was removed from the bottom of the tanks at least once every two days by siphoning. Holding 
tank water was changed every two days. Each day rainbow trout frys were observed for signs of disease, stress, physical damage and mortality (EPA, 2002). Dead and abnormal specimens were removed as soon as observed. A daily record of feeding, behavioural observation and mortality was maintained.

\subsubsection{Control Water \& Holding Water}

DDI water was used both as the control and holding water. A given batch of holding water was not used for more than five days following preparation because of the possible build-up of bacterial, fungal or algal slime growth and the problems associated with it. The control water was aerated at least $24 \mathrm{hrs}$ prior to use in the toxicity tests and holding water was continuously aerated and filtered. DDI water was kept at temperature of $12 \pm 2^{\circ} \mathrm{C}$.

\subsubsection{Mortality of Holding Tank}

Following a 48-hour acclimation period, mortalities were recorded and the following criteria applied:

(i) If after seven days, mortality is greater than $10 \%$ of the total population, the entire batch was rejected.

(ii) If after seven days, mortality is between 5 and $10 \%$ of the total population, the holding period is to be continued for seven additional days. Then, if no further mortalities occurred; the batch is acceptable; otherwise it must be rejected.

(iii) If after seven days, mortality is less than $5 \%$ of the total population, the batch was accepted (EPA, 2002). 
The fish were exposed to water with the added test substances at a range of concentrations for a period of 96 hours. Mortalities were recorded at 24-hour intervals and the concentrations killing $50 \%$ of the fish (LC50) at each observation time are calculated where possible. The mortality in the controls did not exceed $10 \%$ of the entire population by the end of the test (EPA, 2002).

\section{$\underline{3.14 \text { Monitoring of Bioassays }}$}

The static non-renewal tests were monitored at test initiation and termination for $\mathrm{pH}$ and hardness and every 24 hours thereafter for mortality. Temperature was monitored continuously throughout the test periods. A static non-renewal test was used; there was no renewal of test solution.

\section{$\underline{3.15 \text { Data Analysis }}$}

The objective of acute toxicity testing is to identify discharges of toxins and chemicals in acutely toxic amounts. Results are derived from tests designed to determine the adverse effects of toxins in aquatic waterways on the survival of the test organisms. The toxicity test consists of a control and five or more concentrations of fuel; the endpoint of these tests was mortality. The results of the endpoint of the multi-concentration test gives an estimate of the fuel concentration which is lethal to $50 \%$ of the test organisms in the time period prescribed; the value is expressed as the LC50 (EPA, 2002). Mortality rate can also be estimated by the mortality data obtained for each fuel tested. Control survival must be $90 \%$ or greater for an acceptable test; the test is acceptable if survival in the control equals or exceeds $90 \%$ (EPA, 2002). 


\subsection{Acceptability of Acute Toxicity Test Results}

For the test results to be acceptable for both the daphnid (D. magna) and rainbow trout $(O$. mykiss) experiments, the control survival must equal or exceed $90 \%$. Tests are acceptable if temperature, DO content and other specified conditions fall within certain specifications. Any deviation from test specifications outlined in the procedure guidelines was noted when reporting data from test trials.

\section{$\underline{3.17 \text { Statistical Analysis }}$}

(1) Survival raw data in replicate exposure chambers was analyzed using a one-way analysis of variance (ANOVA) statistical tool. This analysis determined whether replicates were significantly different from each other and the control. If a significant difference between replicates exists, the cause for the difference was determined (EPA, 2002), however if there was no significant difference, the trials were continued. If no significant difference was observed, replicates were pooled for further analyses. Mortality results obtained for each set of organisms were then tabulated and analysed.

(2) Concentration-mortality-time responses for all test substances were analysed for any significant trends in mortality rate as a function of time and concentration.

(3) The LC50 values for both D. magna and O. mykiss were determined by the Trimmed Spearman-Karber Method developed by Hamilton et al., 1977.

(4) Mortality rates for diesel, B100, B50, B20 and B5 were compared to each other in order to develop a rank order of toxicity among the five substances tested.

(5) Results of B20 blended in the lab were tested with B20 commercially blended and obtained from a filling station. 
(6) Lethal Concentrations (LC50) for Diesel, B100, B50, B20 and B5 were compared to each other in order to develop a rank order of toxicity among the five substances tested.

\subsection{Concentration-Mortality-Time Relationship}

A concentration-mortality-time analysis was conducted to determine if there was any relationship between concentration and mortality and mortality and time among the five different fuels used in the toxicity tests.

\subsection{LC50 Determination}

The number of dead organisms per group was recorded against the time of their death. The data obtained was used to calculate the median lethal concentration (LC50) of the fuel on D. magna juveniles and O. mykiss (rainbow trout) frys (Dede and Kaglo, 2001). Mortality rates for diesel, B100, B50, B20 and B5 were compared to each other in order to develop a rank order of toxicity among the five substances tested. 


\section{RESULTS}

\section{DAPHNIA MAGNA}

\subsection{D. magna Observations}

Initially, it was the intention that Daphnia pulex be used in the range-finding and definitive tests, however, after the initial culturing phase, it was determined that these daphnids were too small to be observed for any signs of mobility or mortality. It was very difficult to detect mobility or any other signs of death from physical observations. Daphnia magna were then used in the acute toxicity experiments; they responded better than the $D$. pulex. However, it was just as difficult to get viable results; $100 \%$ mortality of $D$. magna was observed at 60,80 and $100 \mathrm{ppm}$ for diesel

fuel as well as for B100 and B20, as indicated in Appendix B. Mortality was noted by the lack of daphnid movement, i.e., immobilization; similar observations were recorded for daphnids affected by diesel as well as those affected by neat biodiesel as well as the biodiesel blends.

\section{Diesel}

There was a slight sheen of fuel on the surface of the water and many daphnids were trapped as soon as they were placed in the test chamber (on average 6hrs), because of this a pipette was used to insert daphnids beneath the water surface.

\section{$B 100, B 50, B 20$ and $B 5$}

Neat biodiesel and biodiesel blends also had similar observations to those conducted with diesel. A sheen was present on the water surface of some samples and the daphnids experienced similar effects to those exposed to diesel. Mortality was noted by the lack of swimming and the lack of 
physical movement by the daphnids. Some of the mortality seen in the tests may have been caused by the physical nature of the test substances.

\subsection{D. magna Results}

Results of Range-Finding Tests

A range-finding test was done to determine a range of concentrations to be administered for the definitive tests. A range of $35 \mathrm{ppm}$ to $100 \mathrm{ppm}$ was performed in the initial testing stage. There was less than $100 \%$ mortality for organisms at $35 \mathrm{ppm}$ and more than $100 \%$ mortality at $100 \mathrm{ppm}$, as noted in Appendix B.

\section{Control Survival}

The controls met the overall survival acceptability standards; more than $90 \%$ of the control population were alive after the $24 \mathrm{hr}$ test period.

\section{Significant Difference}

There was a difference in the survival means of the experimental control groups when compared to the survival means from the daphnids treated with diesel, B100, B50, B20 and B5. There was no significant difference between trials.

\section{Mortality}

Mortality results are listed in Appendix B. Table 1 illustrates the average percent mortality of four trials of each concentration of the five test substances (Diesel, B100, B50, B20 and B5). There is a general increase in mortality as concentration increases. The highest mortality was 
recorded at the highest concentration tested, i.e. $50 \mathrm{ppm}$, for all test substance. Similarly, the lowest mortality was recorded at the lowest concentration of $1.57 \mathrm{ppm}$.

Table 1: The average mortality rate for $D$. magna after $24 \mathrm{hrs}$.

\begin{tabular}{lccccc}
\hline $\begin{array}{c}\text { Concentration } \\
{[\text { ppm }]}\end{array}$ & Mean Mortality Rate (\%) \\
\hline & Diesel & B100 & B50 & B20 & B5 \\
1.57 & 40.00 & 34.17 & 42.50 & 40.00 & 45.00 \\
3.13 & 75.00 & 45.00 & 55.00 & 40.56 & 60.00 \\
6.25 & 85.00 & 55.00 & 75.00 & 60.00 & 80.00 \\
12.5 & 90.00 & 60.00 & 80.00 & 65.00 & 90.00 \\
25 & 90.00 & 70.00 & 80.00 & 71.67 & 90.00 \\
50 & 90.00 & 71.67 & 85.00 & 69.43 & 100.00 \\
\hline
\end{tabular}

Figure 1 illustrates the average mortality rate over of all fuels tested within $24 \mathrm{hrs}$. There is a recorded increase in mortality rate with increasing concentrations. Only B20 showed a slight decrease in percent mortality from $71.67 \%$ to $69.43 \%$ for D. magna treated with 25 and 50ppm respectively. 


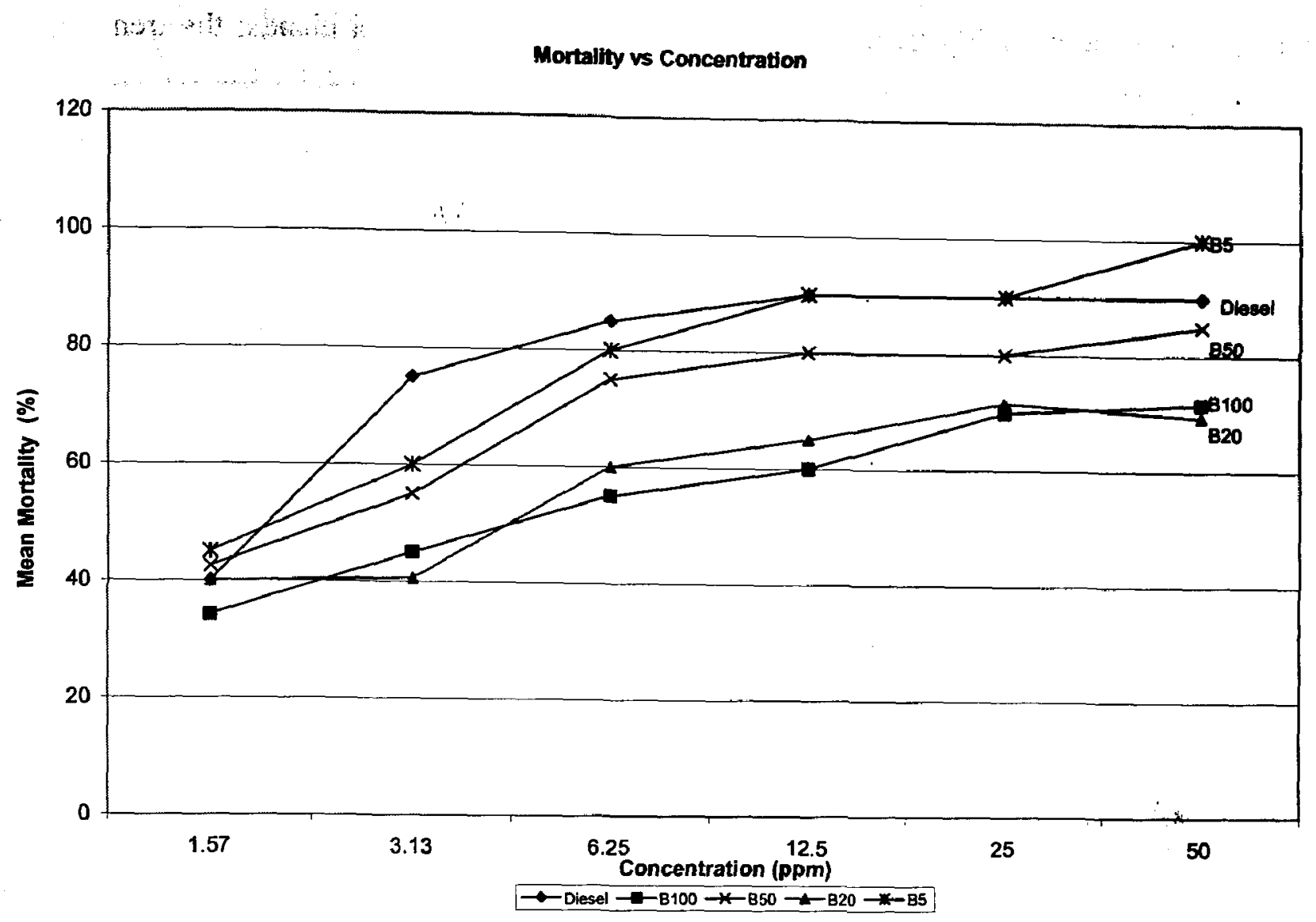

Figure 1: The average mortality rate of $D$. magna at different concentrations of different fuels over a period of $24 \mathrm{hrs}$

Table 2 shows the overall mortality rate of all concentration over $24 \mathrm{hrs}$; the mortality rate represents the percentage of dead daphnids over all six concentrations over the $24 \mathrm{hr}$ time period.

Table 2: The overall mortality rate for D. magna

\begin{tabular}{ccccc}
\hline \multicolumn{5}{c}{ Mean Mortality Rate (\%) } \\
\hline Diesel & B100 & B50 & B20 & B5 \\
78.34 & 55.98 & 69.58 & 57.78 & 77.50 \\
\hline
\end{tabular}

Diesel fuel has the highest mortality rate of $78.34 \% ; 78.34 \%$ of all daphnids treated with diesel fuel died. B100 has the lowest average mortality rate of $55.98 \%$, which was slightly lower than B20 (57.78\%). 
Figure 2 shows the mortality trends for diesel, biodiesel and biodiesel blends; the trend shows that diesel has the highest mortality, closely followed by B5 (77.50\%), B50, B20, while B100 has the lowest mortality.

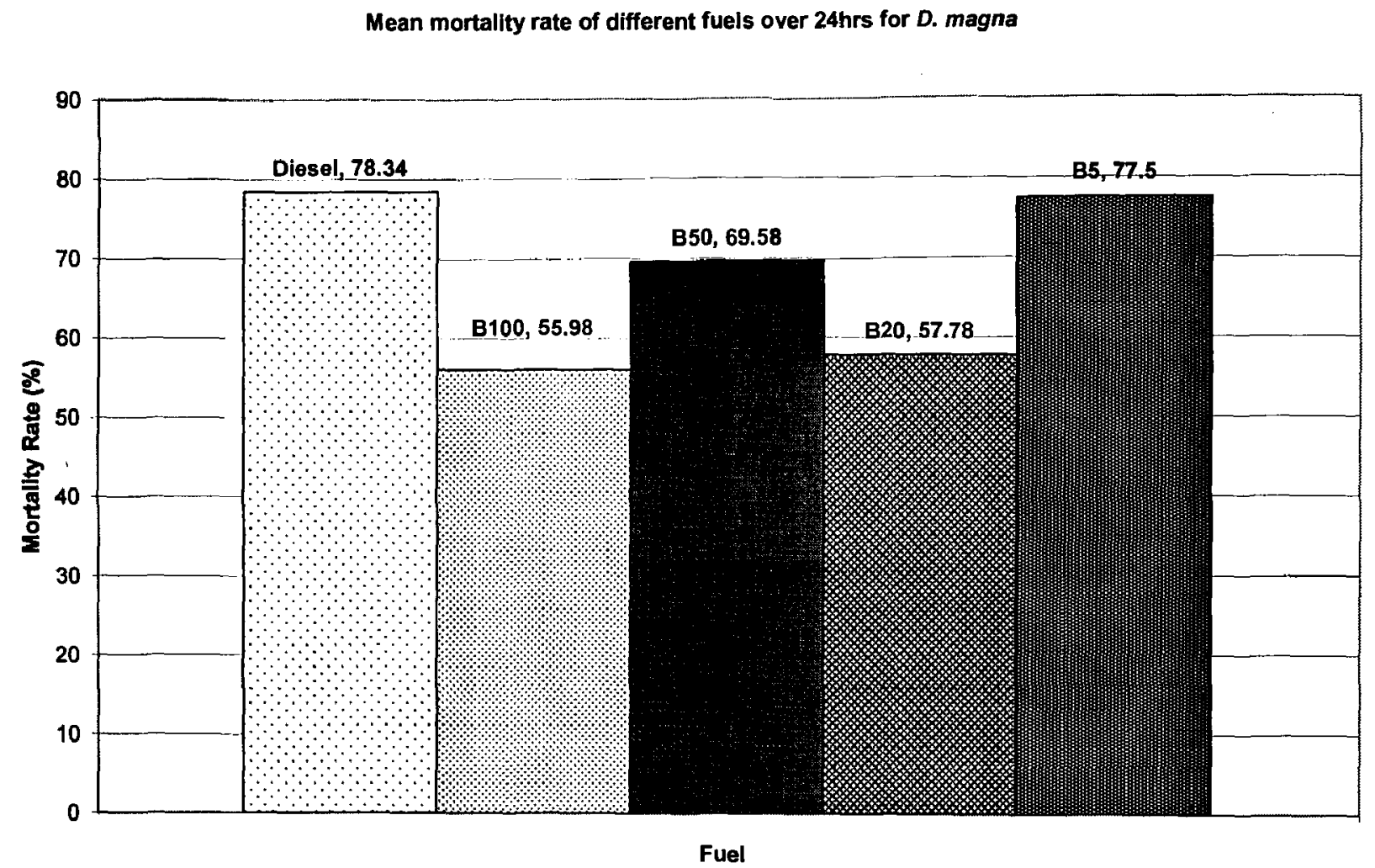

Figure 2: The mean mortality rate of $D$. magna for different concentrations over a period of $24 \mathrm{hrs}$

\section{Lethal Concentration (LC50)}

The lethal concentration that kills $50 \%$ of the test population was also calculated using the Trimmed Spearman-Karber Method. Table 3 shows the LC50 of diesel, B100, B50, B20 and B5. B100 had the highest LC50 of 4.65ppm, while diesel had the lowest of $1.78 \mathrm{ppm}$. 
Table 3: The LC 50 of Acute Toxicity Test Using D. magna

\begin{tabular}{lcccc}
\hline \multicolumn{1}{r}{ Fuel } & LC 50 & Lower 95\% & Upper 95\% & \% Trim \\
\hline Diesel & 1.78 & 1.15 & 2.76 & $\mathbf{4 4 . 4 4}$ \\
B100 & 4.65 & 2.22 & 9.72 & 31.82 \\
B50 & 3.29 & 1.36 & 7.95 & 41.18 \\
B20 & 4.54 & 2.55 & 8.09 & 38.64 \\
B5 & 1.98 & 0.92 & 4.23 & 45.00 \\
\hline
\end{tabular}

Figure 3 shows the LC50 trend, there are small differences in the lethal concentrations calculated for the different fuels tested. Diesel has the lowest $24 \mathrm{hr}-\mathrm{LC} 50$, followed by B5, B50, B20 and B100 has the highest $24 \mathrm{hr}-\mathrm{LC} 50$. The lowest static D. magna $24 \mathrm{hr}-\mathrm{LC} 50$ is indicative of the highest toxicity level, which was $1.78 \mathrm{ppm}$ for Diesel, the highest static $24 \mathrm{hr}$-LC50 value was determined for $\mathrm{B} 100$ at $4.65 \mathrm{ppm}$, which was the least toxic of all the toxins tested over the $24 \mathrm{hr}$ period.

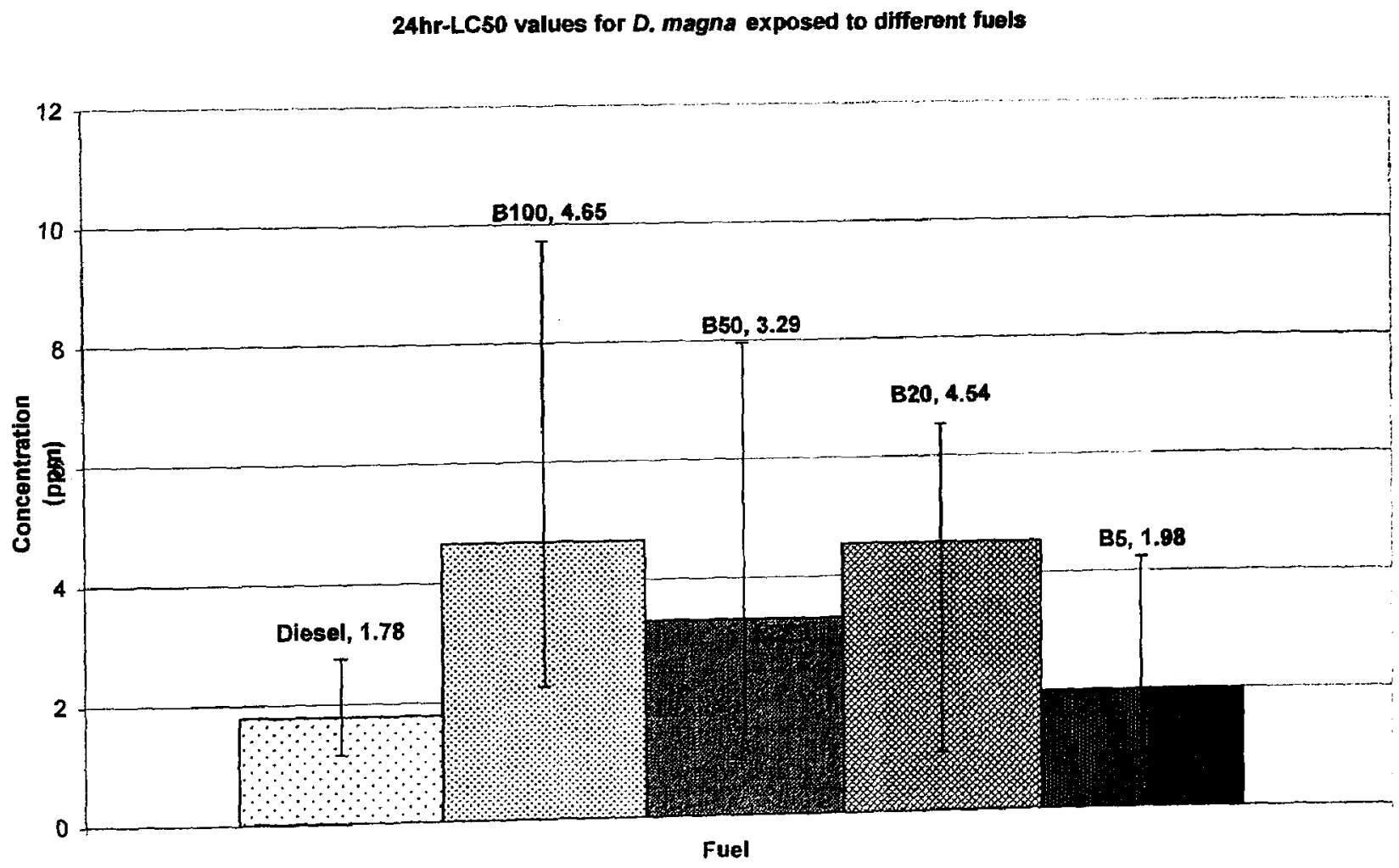

Figure 3: The 24hr- LC50 values for Diesel, B100, B50, B20 and B5 


\subsection{D. magna B20 Comparison}

\section{Mortality Rate}

A comparison of $\mathrm{B} 20$ and B20 (Topia) was performed; daphnids treated with B20 (Topia) were subjected to the same concentrations as daphnids exposed to B20. There was no significant difference in mortality among the four sets of trials. Table 4 shows the average mortality rate of these 4 trials over a $24 \mathrm{hr}$ period. For both $\mathrm{B} 20$ and B20 (Topia), mortality rate increases as concentration increases.

Table 4: The average mortality rate for D. magna affected with B20 and B20 (Topia) for 24 hrs

\begin{tabular}{lcc}
\hline Concentration $(\boldsymbol{p p m})$ & B20 & B20(Topia) \\
\hline 1.57 & 40.00 & 35.00 \\
3.13 & 40.56 & 39.55 \\
6.25 & 60.00 & 55.00 \\
12.5 & 65.00 & 55.00 \\
25 & 71.67 & 75.00 \\
50 & 69.43 & 69.29 \\
\hline
\end{tabular}

Figure 4 illustrates the trend obtained from B20 (Topia) compared to those obtained from B20. Mortality rate increases with increasing concentration, however, B20 has slightly higher mortality rates for each concentration when compared to B20 (Topia). 
Mean mortality rate vs Concentration for B20 and B20 (Topla)

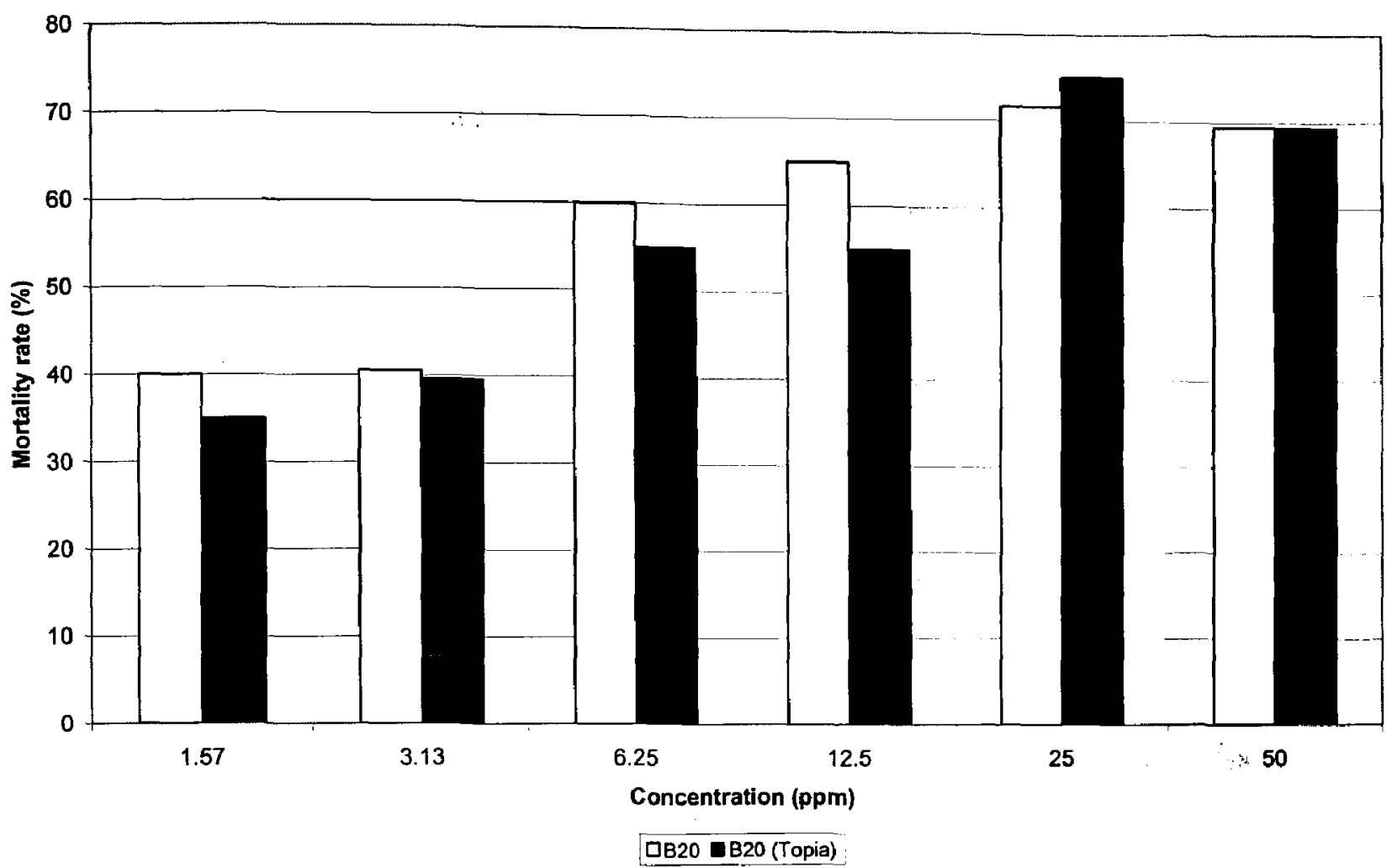

Figure 4: Comparison of B20 and B20 (Topia) mortality rates

Figure 5 shows the overall mortality rate of all concentrations, over the $24 \mathrm{hr}$ period, B20 has the higher mortality rate of $57.78 \%$, while B20 (Topia) has a mortality rate of $54.81 \%$, a difference of $2.97 \%$ 


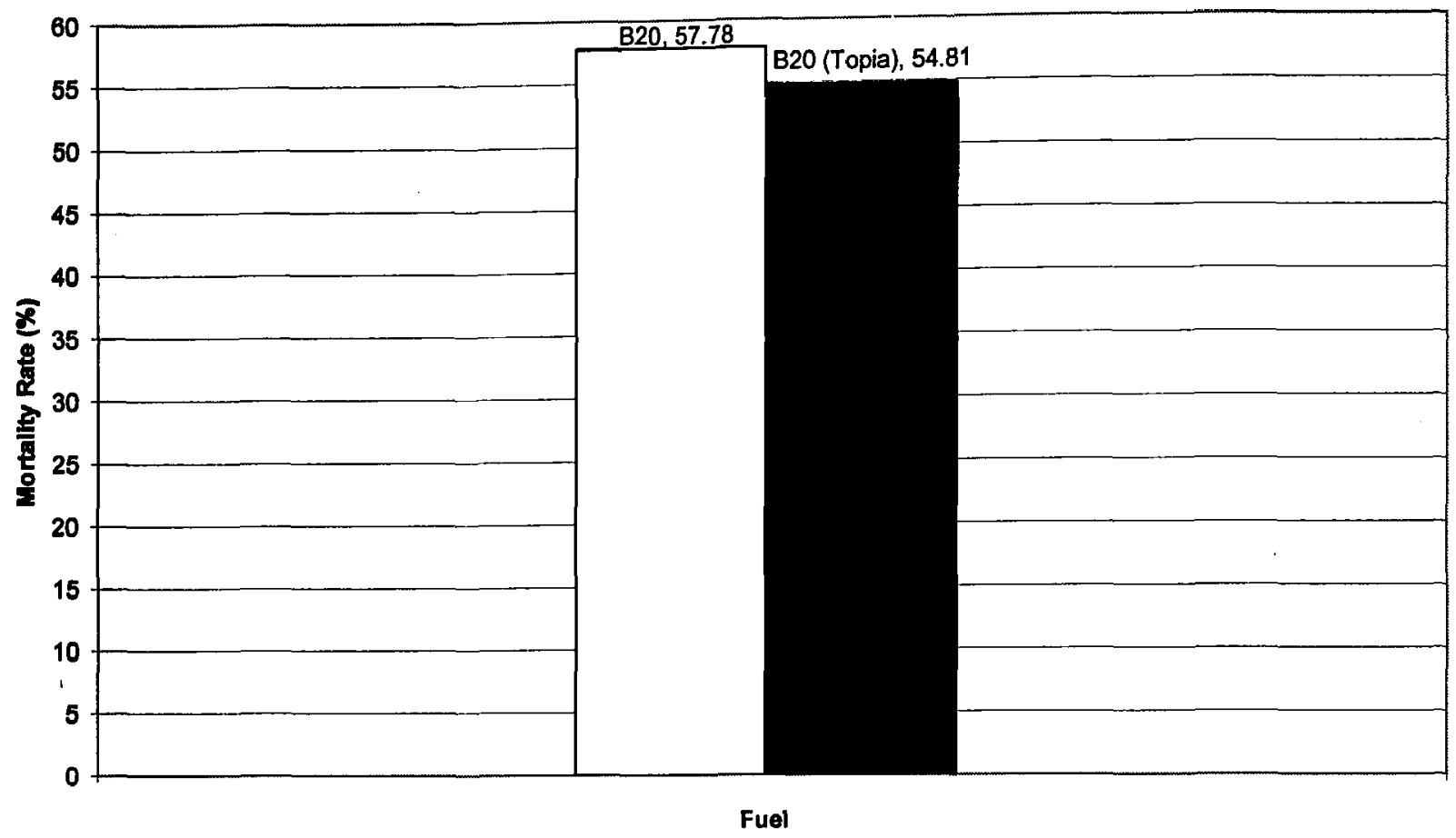

Figure 5: The average 24hr mortality rate of B20 and B20 (Topia)

\section{Lethal Concentration}

Lethal concentration (LC50) which killed $50 \%$ of organisms was calculated using the Trimmed Spearman-Karber Method. Table 5 illustrated the LC50 and confidence intervals obtained for both B20 and B20 (Topia).

Table 5: The 24hr-LC50 value for D. magna treated with B20 and B20 (Topia)

\begin{tabular}{lcccc}
\hline \multicolumn{1}{c}{ Fuel } & LC50 & Lower 95\% & Upper 95\% & Trim \\
\hline B20 & 4.54 & 2.55 & 8.09 & 38.94 \\
B20 (Topia) & 6.74 & 3.25 & 13.96 & 34.78 \\
\hline
\end{tabular}


Figure 6 illustrates the 24hr-LC50 values obtained for both B20 and B20 (Topia); the 24hr-LC50 value for $\mathrm{B} 20$ is $4.54 \mathrm{ppm}$, while the $24 \mathrm{hr}-\mathrm{LC} 50$ value for B20 (Topia) is $6.74 \mathrm{ppm}$, there is a difference of $2.2 \mathrm{ppm}$.

24hr-LC50 values for D. magna treated with B20 and B20 (Topla)

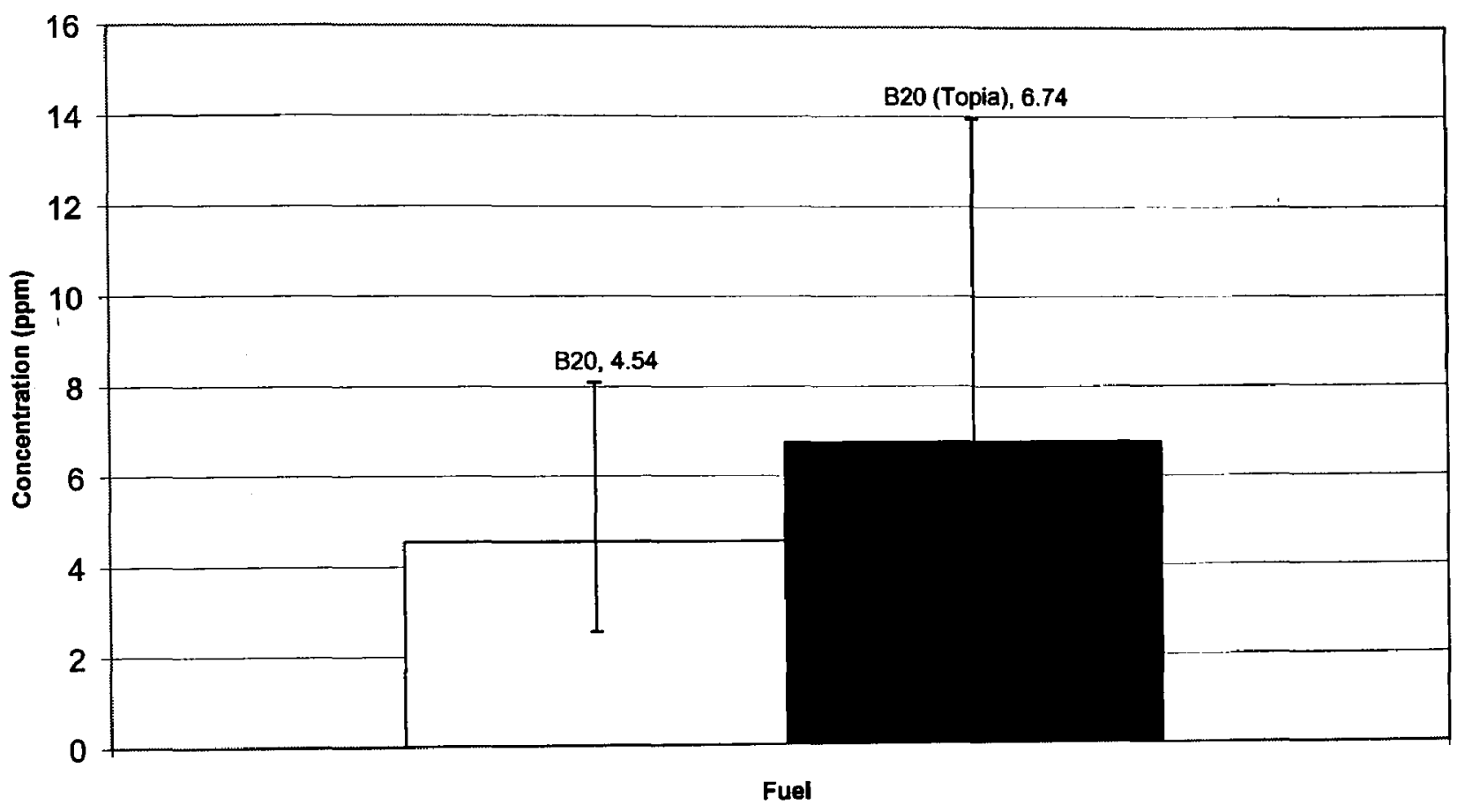

Figure 6: A comparison of B20 and B20 (Topia) 24hr-LC50 values 


\section{O. MYKISS}

\subsection{O. mykiss Observations}

There are different stages in the life of the $O$. mykiss species; it was suggested in the Methods for Measuring the Acute Toxicity of Effluents and Receiving Waters to Freshwater and Marine

Organisms (EPA, 2002) that fish between 28 and 30 days be used in toxicity experiments. However, it was determined at this stage the trout are still feeding off their embryonic (yolk) sac; they are unable to eat and do not swim but remain at the bottom of the holding tank. These fish are at alevin life stage; they are very sensitive to light, water, movement and temperature. Consequently, it was difficult to determine if fish mortality was due to ambient experimental conditions or to actual acute effects of the fuels tested. In toxicity experiments, it was too difficult to use the 15-30 day old trout results since there is uncertainty in the cause of mortality. Instead, 6-week old trout frys were used, at this stage the trout fry are able to feed off commercial fish food and are able to swim from the bottom of the holding tank to the surface. In the toxicity tests conducted with the different fuels, death or mortality was noted by lack of movement and breathing.

\section{Diesel}

Before eventual death, fish swam erratically up and down the test chamber, there appeared to be irregular breathing; there was also irregularity in the movement of their gills. The trout fry also developed slimy mucus on their body with an almost a 'half-eaten' appearance; their fins and tails were torn and tattered. Another sign of death was the bulging eyes and discolouration of the fish from a brown to greyish black. Many rainbow trout were swimming on their sides, dead fish 
were found at the bottom of environmental chambers. Some fish experienced curling after being exposed to diesel concentration of 600ppm and above.

\section{$B 100, B 50, B 20$ and $B 5$}

The trout fry showed very similar signs to the affects of diesel and biodiesel blends. There was the irregularity in gill movement and haphazard swimming from the bottom of the environmental test chamber to the surface. There was a consistent bulging of the eyes which was followed by detachment from the eye socket, at death, eyes appeared white. There was also fin erosion on frys affected with the neat biodiesel and the biodiesel blends. However, fin erosion was more pronounced in fish exposed to B50 and B5, when compared to B100 and B20. Some curling was also present for B100, B50, B20 and B5 for concentrations of 600ppm and above, dead fish were also found at the bottom of environmental test chambers.

\section{General Observations}

Surviving fish were in poor condition; barely breathing with slow and erratic swimming. There was an increase in fry movements; some fry exhibited spiral swimming. Forced efforts to swallow air from the surface were also observed; the mouth and the gills of dead fish were gaping, particularly after 72 and 96 hrs. Many fry had increased amounts of mucus secretion around the gills and on the body surface, as well as darkening of the fish body. For a short period of time, many fish were in a coma-like state prior to death; where there were no body motions except weak movements of the gills. At death, the mouth was usually gaping and the gills were widely extended. 


\subsection{O. mykiss Results}

Results of Range-Finding Tests

Range-finding tests were conducted on 4 and 6-week old $O$. mykiss frys, range-finding tests are documented in Table 6 were conducted on 6-week old O. mykiss. A range-finding test was performed to determine a range of concentrations to use for the definitive tests. Three fuels were used; diesel, B100 and B20. A test range of $2 \mathrm{ppm}$ to $90 \mathrm{ppm}$ was first performed on these substances. There was less than $50 \%$ mortality recorded from $2.5 \mathrm{ppm}$ to $50 \mathrm{ppm}$ for diesel, B100 and B20. A second range finding test was done, the concentrations tested were 100, 1000 and 2000ppm, as listed in Table 6. NOEC for diesel, B100 and B20 were observed between 2.550ppm and between 2.5-50ppm for diesel. LOEC for B100 and B20 was recorded at 100ppm and 90ppm was recorded for diesel.

Table 6: The results of the $O$. mykiss range-finding tests

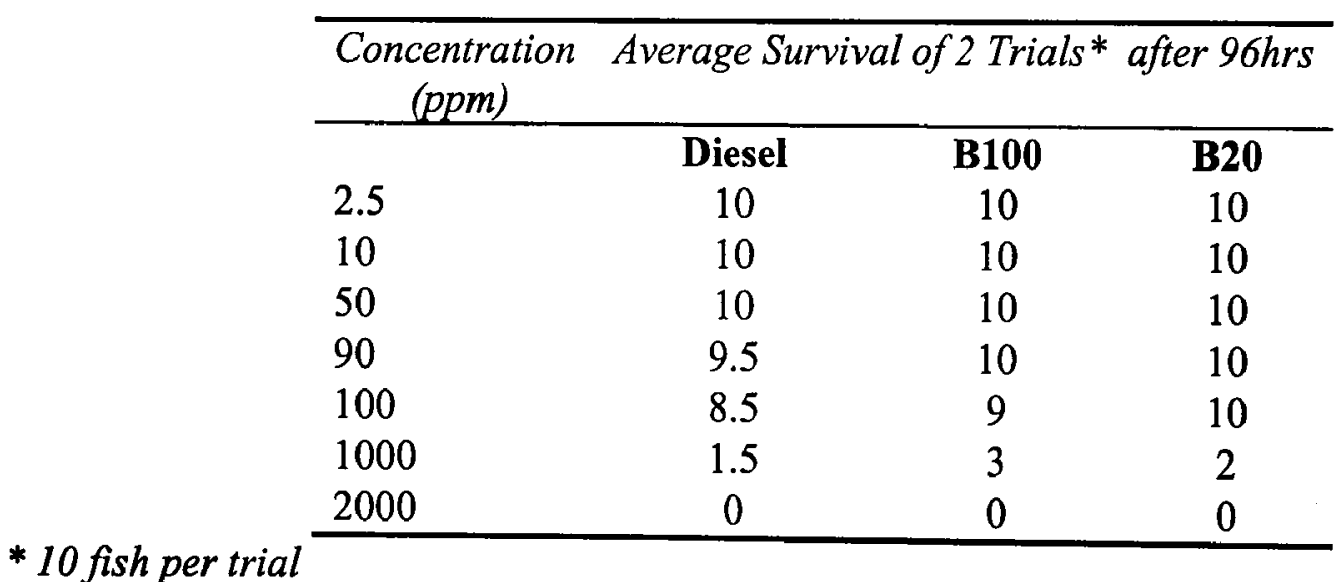

\section{Control Survival}

All control groups met the overall survival acceptability standards; there was less than $10 \%$ mortality in all experimental control groups. 
Significant difference

There was a difference in the survival means of the experimental control groups when compared to the survival means from the daphnids treated with diesel, B100, B50, B20 and B5. However, there was no significant difference between trials.

\section{Mortality Data}

Mortality results are listed in Appendix C. A concentration-mortality-time comparison was made for each test substance. Two trials were conducted for each concentration and the average of these trials was used in the comparisons.

Figure 7 shows the average mortality (in percent) for $O$. mykiss exposed to different concentrations of diesel across time. The data exhibit the typical concentration-response, with mortality increasing with increasing concentration of toxin over the exposure period. The average mortality of concentrations increased from $50.33 \%$ after $24 \mathrm{hr}$ to $64.50 \%$ after $48 \mathrm{hr}$, to $80 \%$ at $72 \mathrm{hr}$ and $85.33 \%$ at the end of the 96 -hour exposure. 


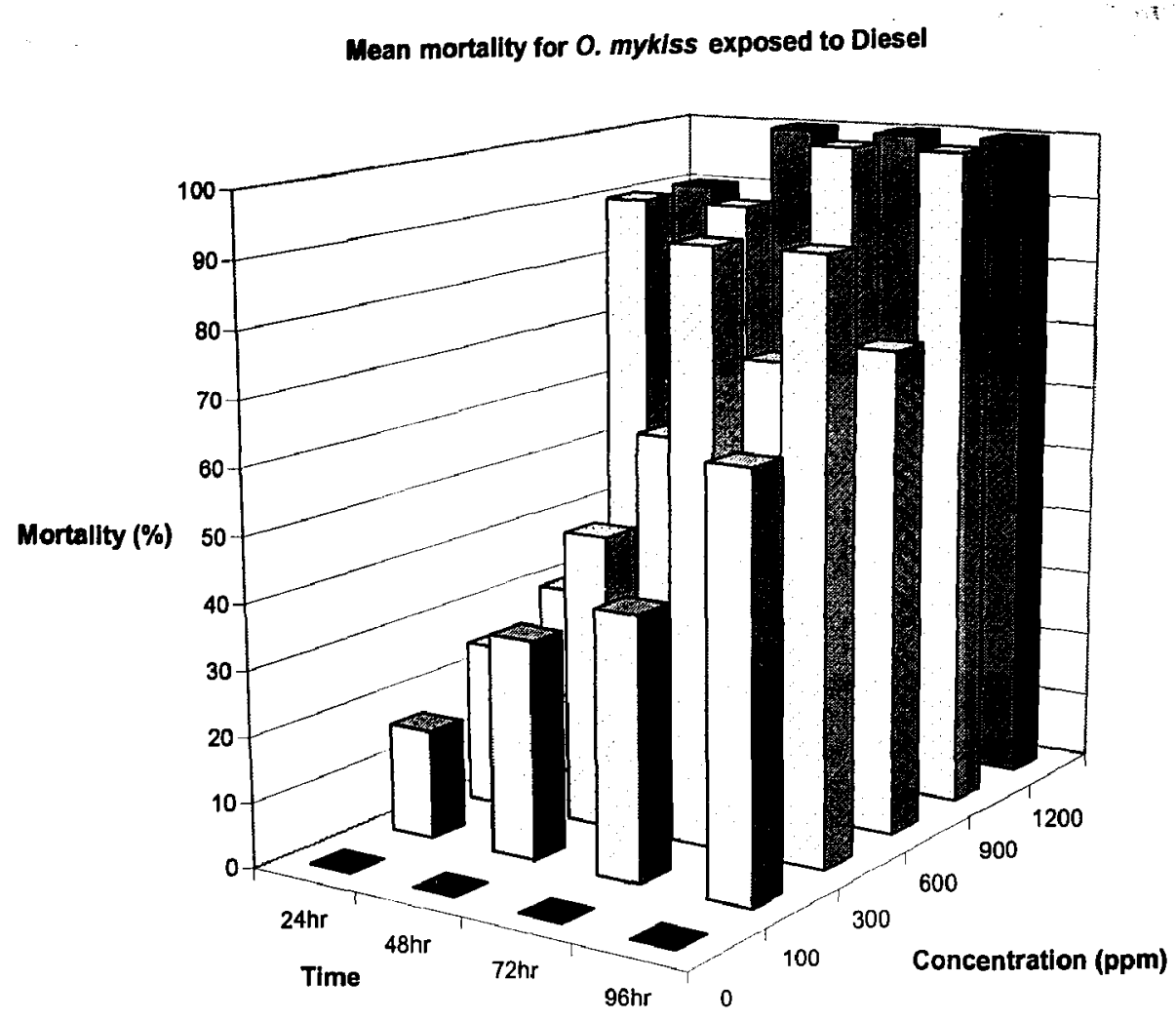

Figure 7: The results of the definitive tests with Diesel using $O$. mykiss

Figure 8 shows the average percent mortality for rainbow trout fry exposed to different concentrations of B100 across time. The data exhibit the typical concentration-response, with mortality increasing with increasing concentration of toxin over the exposure period. The average mortality increased from $25.33 \%$ after $24 \mathrm{hrs}$ to $37.33 \%$ after $48 \mathrm{hrs}$, to $49.33 \%$ at $72 \mathrm{hrs}$ and $57.98 \%$ at the end of the 96 -hour exposure. 


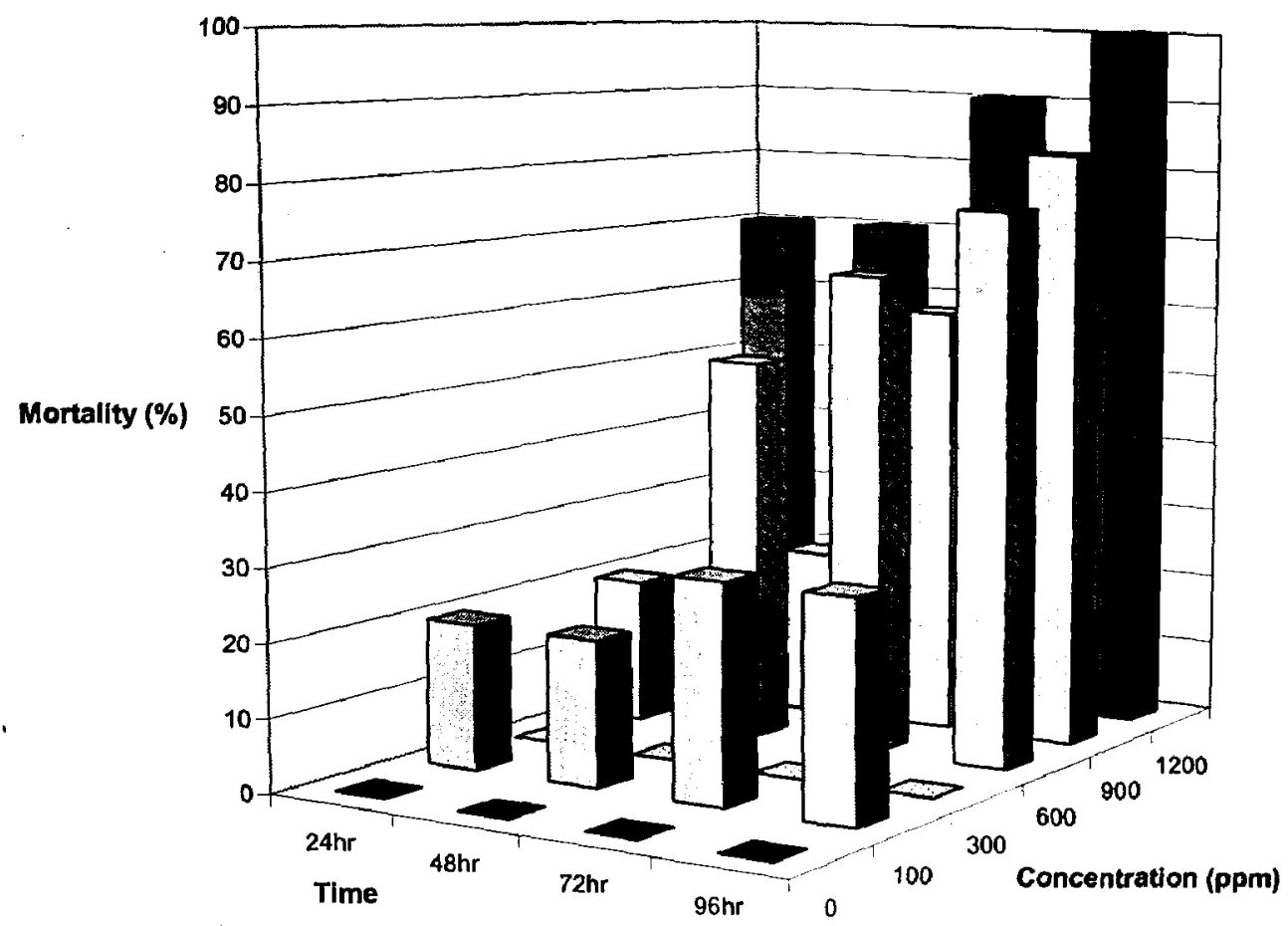

Figure 8: The results of the definitive tests with B100 using $O$. mykiss

Figure 9 shows the average percent mortality for $O$. mykiss exposed to different concentrations of B50 across time. The data exhibit the typical dose-response, with mortality increasing with increasing concentration of toxin over prolonged exposure period. The average mortality increased from $22 \%$ after $24 \mathrm{hrs}$ to $50 \%$ after $48 \mathrm{hrs}$, to $64 \%$ at $72 \mathrm{hrs}$ and $71 \%$ at the end of the 96-hour exposure. 


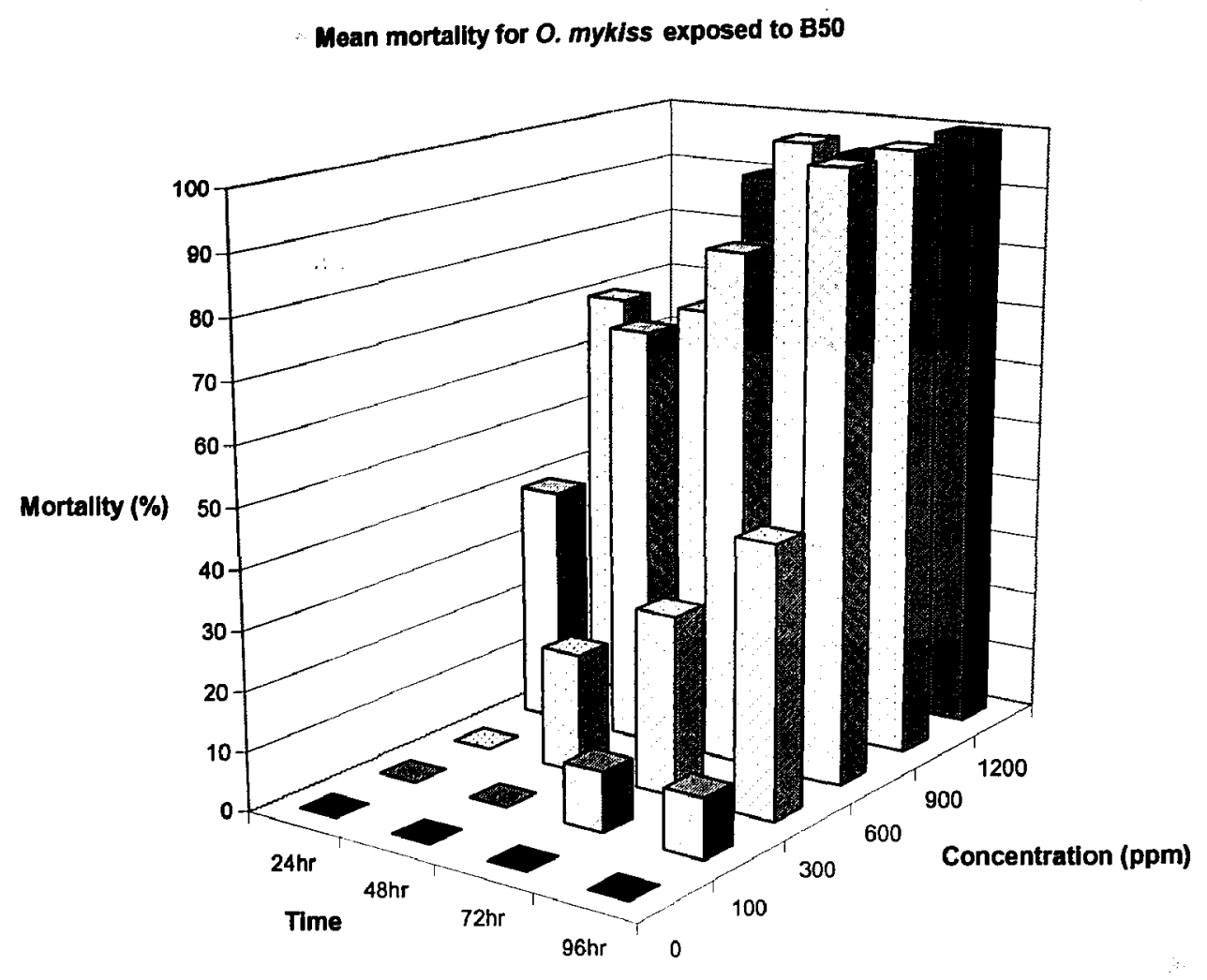

Figure 9: The results of the definitive tests with B50 using $O$. mykiss

Figure 10 shows the average percent mortality for rainbow trout fry exposed to different concentrations of B20 across time. The data exhibit the typical concentration-response, with mortality increasing with increasing concentration of toxin over prolonged exposure period. The average mortality increased from $24.67 \%$ after $24 \mathrm{hrs}$ to $41.67 \%$ after $48 \mathrm{hrs}$, to $53.67 \%$ at $72 \mathrm{hrs}$ and $59 \%$ at the end of the 96-hour exposure. 


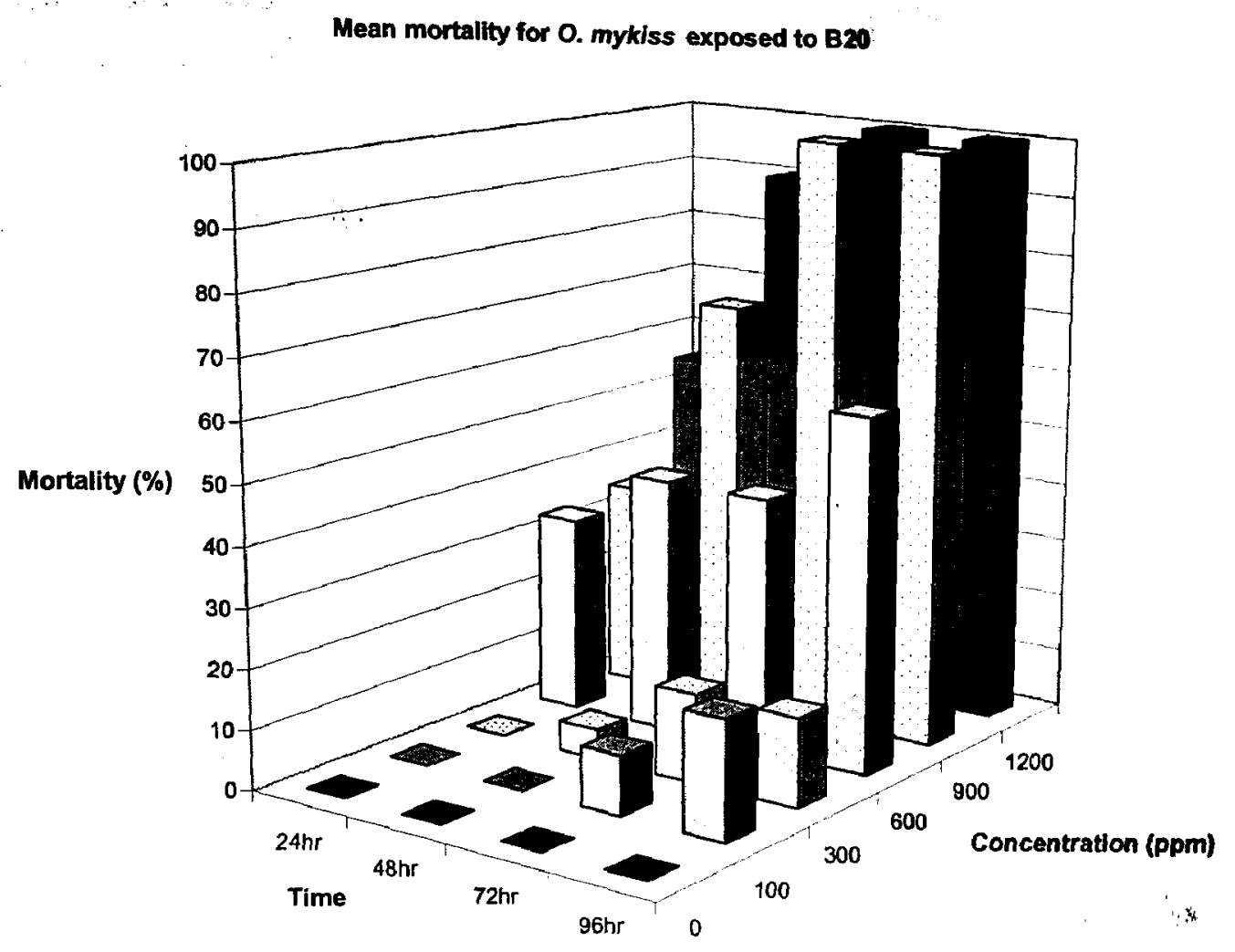

Figure 10: The results of the definitive tests with B20 using $O$. mykiss

Figure 11 shows the average mortality (in percent) for $O$. mykiss exposed to different concentrations of B5 across time. The data exhibit the typical concentration-response, with mortality increasing with increasing concentration of toxin over prolonged exposure period. The average mortality increased from $35 \%$ after $24 \mathrm{hrs}$ to $53 \%$ after $48 \mathrm{hrs}$, to $70 \%$ at $72 \mathrm{hrs}$ and $83 \%$ at the end of the 96-hour exposure. 


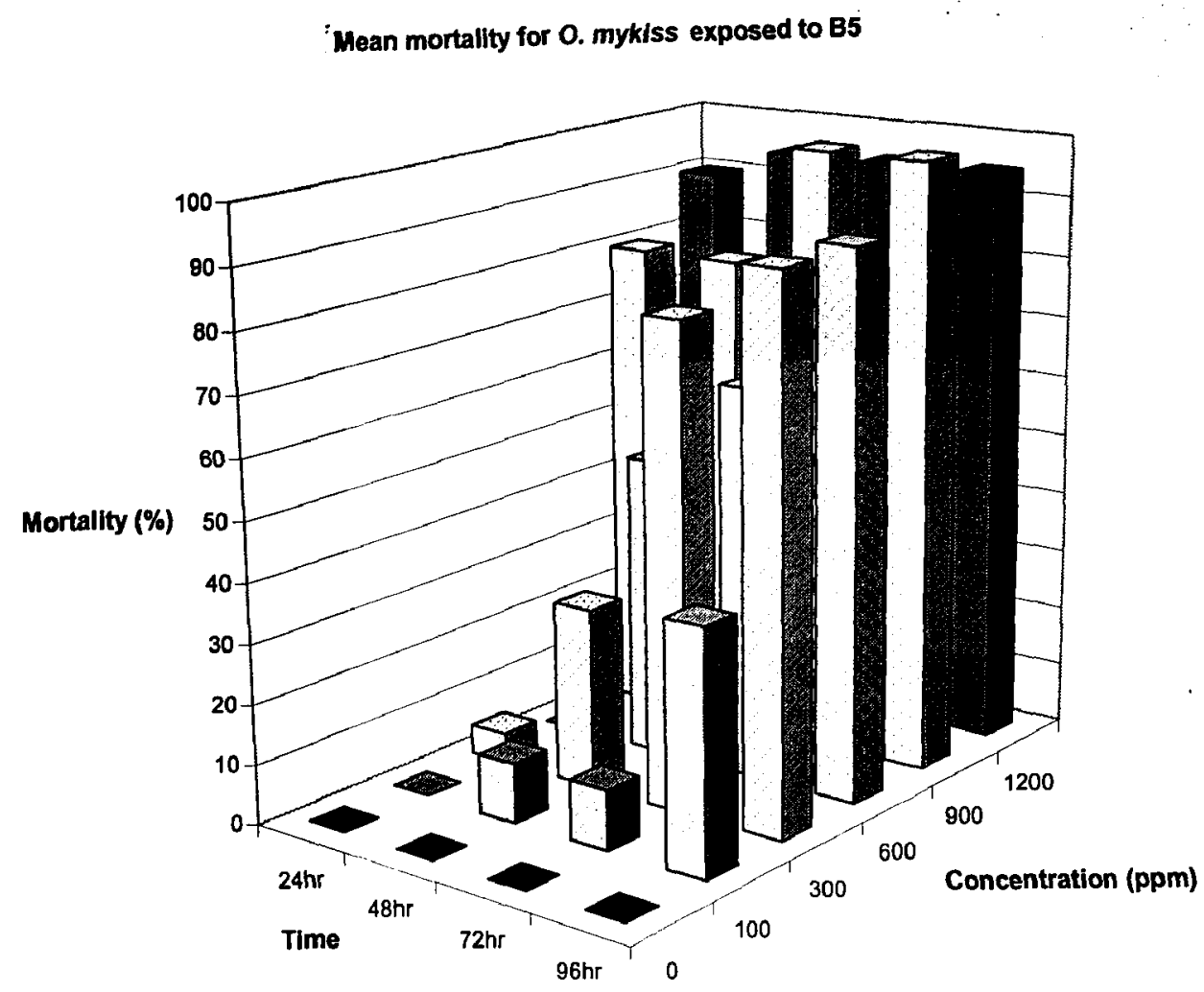

Figure 11: The results of the definitive tests with B5 using $O$. mykiss

The mean mortality of each concentration was calculated and the average over the four time periods (24hr, $48 \mathrm{hr}, 72 \mathrm{hr}$, and $96 \mathrm{hr}$ ) was tabulated, as illustrated in Table 7.

Table 7: The average mortality rate for 0 . mykiss at each fuel over $96 \mathrm{hrs}$

\begin{tabular}{lccccc}
\hline $\begin{array}{c}\text { Concentration } \\
{[p p m]}\end{array}$ & \multicolumn{5}{l}{ Average Mortality Rate (\%) of 2 replicates over $96 \mathrm{hrs}$} \\
\hline & Diesel & B100 & B50 & B20 & B5 \\
100 & 38.33 & 25.00 & 5.00 & 7.50 & 15.00 \\
300 & 62.50 & 0.00 & 23.75 & 8.75 & 51.25 \\
600 & 57.50 & 54.16 & 73.75 & 45.00 & 51.25 \\
900 & 95.00 & 45.83 & 85.00 & 76.25 & 90.00 \\
1200 & 97.50 & 87.50 & 71.25 & 86.25 & 93.75 \\
\hline
\end{tabular}


There was a general increase in average mortality rate for each fuel had over the $96 \mathrm{hrs} ; \mathrm{B} 100$ had a slight decrease from $25 \%$ to $0 \%$ from $100 \mathrm{ppm}$ to $300 \mathrm{ppm}$ and a decrease from $54.16 \%$ at $600 \mathrm{ppm}$ to $45.83 \%$ at $900 \mathrm{ppm}$ as illustrated in Figure 12. B50 at 1200ppm had a slight decrease from $85 \%$ (at $900 \mathrm{ppm}$ ) to $71.25 \%$. B100 had a higher mortality rate for 100,600 and $1200 \mathrm{ppm}$ when compared to $\mathrm{B} 20$.

Figure 12 shows the regression plots for the five test substances based on mean percent mortality values over $96 \mathrm{hrs}$ in function of concentration. Trend analysis indicates that there is a small difference among the slopes of the five fuels; there is a relatively proportional change in percent mortality for every measured change in concentration for the different toxins.

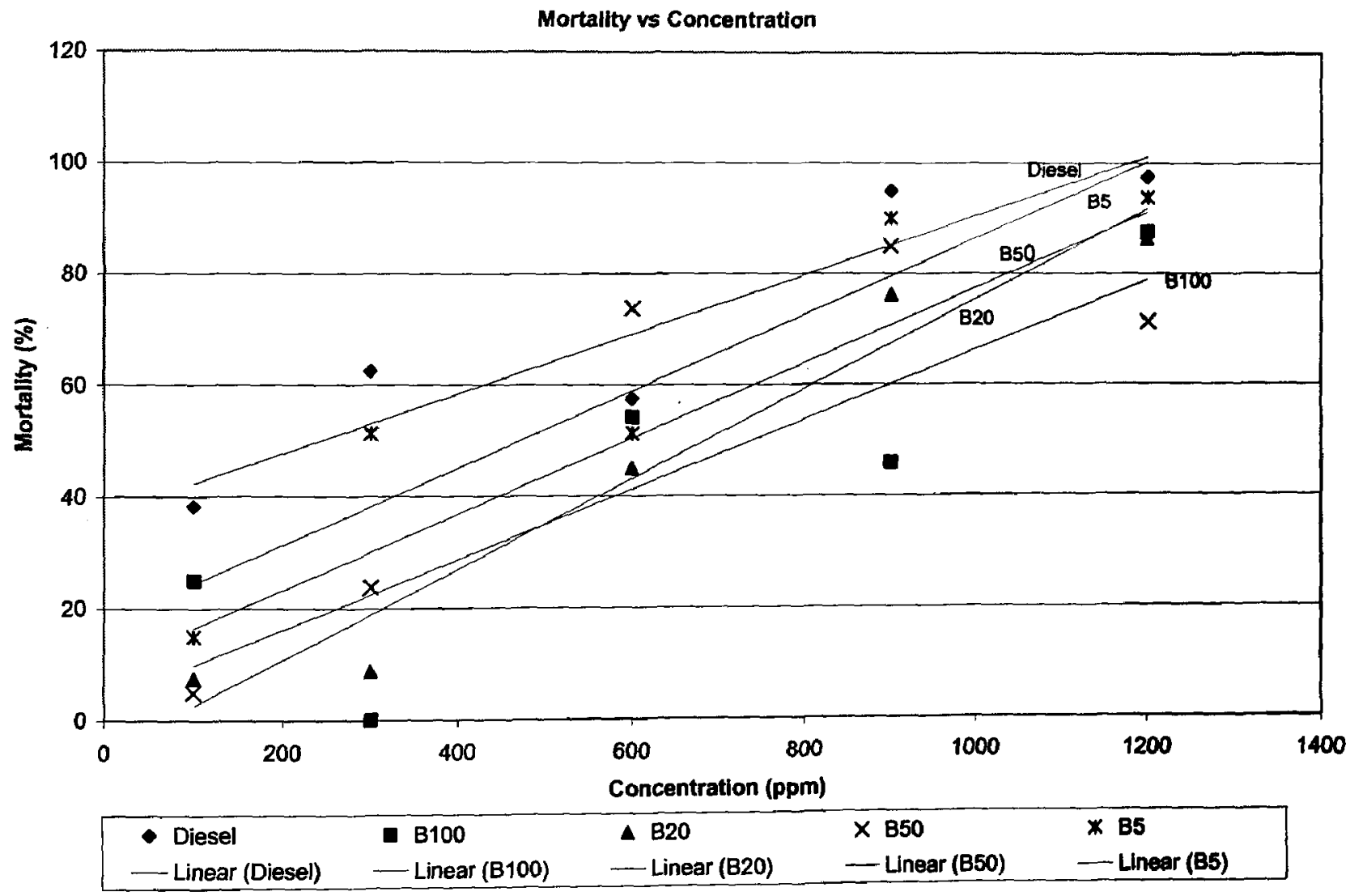

Figure 12: Regression plots for different fuel over $96 \mathrm{hrs}$ 
Diesel has the largest mortality rate for all concentrations measured; B100 has the lowest recorded mortality for all measured concentrations. B50 has a slightly higher mortality rate for 600 and $900 \mathrm{ppm}$, when compared to B20.

\section{Mortality Rates}

The mean mortality rates were calculated for the two replicates conducted for each concentration of the different fuels over a period of $96 \mathrm{hrs}$; these results are summarised in the Table 8 . Diesel has the highest mortality rate of $70.17 \%$, while neat biodiesel has the lowest mortality rate of $42.5 \%$ over $96 \mathrm{hrs}$.

Table 8: The overall mortality rate for $O$. mykiss over $96 \mathrm{hrs}$

\begin{tabular}{ccccc}
\hline \multicolumn{5}{c}{ Mean Mortality Rate (\%) of all five concentrations of the 2} \\
replicates over 96hrs \\
\hline Diesel & B100 & B50 & B20 & B5 \\
70.17 & 42.50 & 51.75 & 44.75 & 60.25 \\
\hline
\end{tabular}

Figure 13 illustrates the cumulative mortality rate of all five substances tested; neat biodiesel, $\mathrm{B} 100, \mathrm{~B} 20, \mathrm{~B} 50$ and B5. From the results obtained, diesel (70.17\%) appears to be the most toxic, while B100 seems to be less toxic as B100 has the lowest recorded mortality rate (42.50\%). B20 (44.75\%) has a slightly lower mortality rate than B50 (51.75\%); B5 has a mortality rate of $60.25 \%$. 


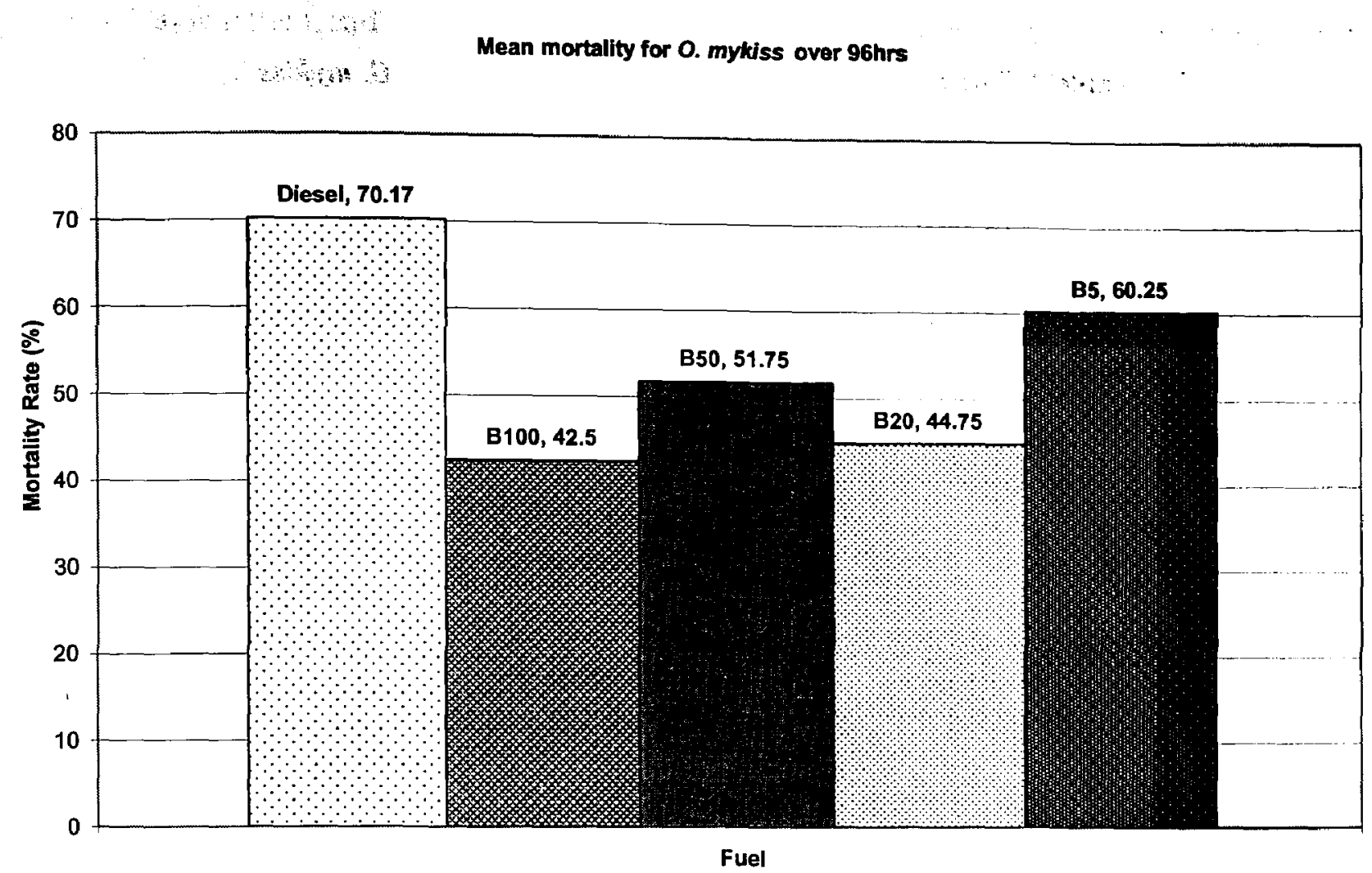

Figure 13: The mean mortality rate of $O$. mykiss for different concentrations over a period of $96 \mathrm{hrs}$

\section{Lethal Concentration}

Lethal concentration that kills $50 \%$ (LC50) of the population was also calculated using the Trimmed Spearman-Karber Method. Upper and lower confidence intervals for all test substances were also calculated using the same procedure.

\section{1) Diesel}

Table 9 illustrates the LC50 calculated for $O$. mykiss treated with different concentrations of diesel fuel at $24,48,72$ and $96 \mathrm{hr}$. 
Table 9: The LC 50 of Diesel acute toxicity test using 0 . mykiss

\begin{tabular}{ccccc}
\hline Time & LC 50 & Lower 95\% & Upper 95\% & \% Trim \\
\hline $24 \mathrm{hrs}$ & 578.13 & 421.28 & 793.37 & 16.67 \\
$48 \mathrm{hrs}$ & 350.38 & 173.04 & 709.47 & 33.33 \\
$72 \mathrm{hrs}$ & 133.52 & 88.94 & 200.45 & 40.00 \\
$96 \mathrm{hrs}$ & $\mathrm{NC}$ & $\mathrm{NC}$ & $\mathrm{NC}$ & $\mathrm{NC}$ \\
\hline
\end{tabular}

${ }^{*} \mathrm{NC}=$ Not Calculable

LC50 decreases over the $96 \mathrm{hr}$ period. The LC50 at the endpoint of $96 \mathrm{hr}$ was not calculable since no trials reported results with $50 \%$ or more survival rate. LC 50 decreases over time; with the highest resistance to the diesel fuel at $24 \mathrm{hrs}$ with a LC50 of $578.13 \mathrm{ppm}$. However, there is a steady decrease in LC50 over time, as illustrated in Figure 14.

LC50 vs Time for O.mykiss exposed to Diesel

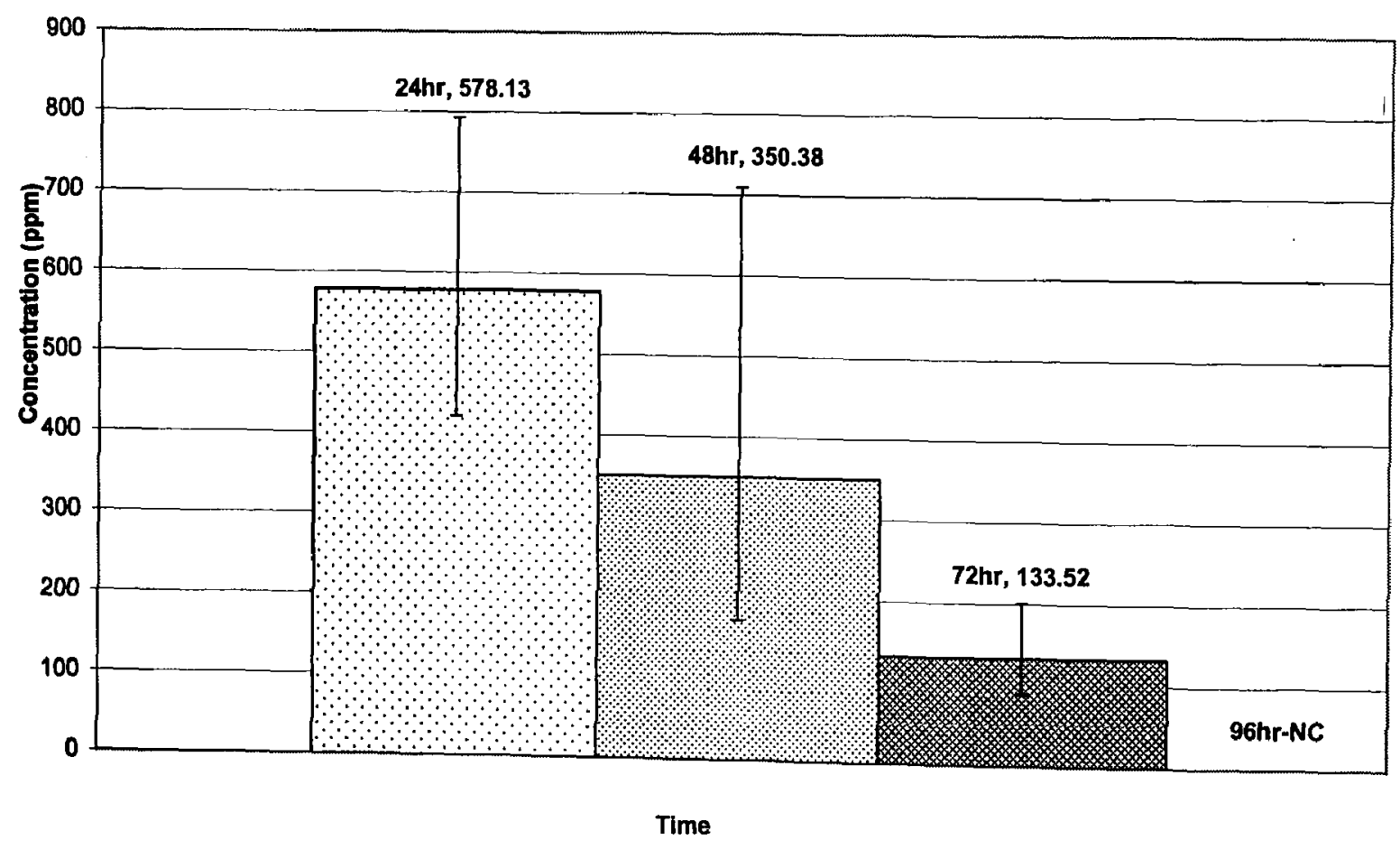

Figure 14: The LC50 values for Diesel 
Figure 15 shows the trend of the mean LC50 values for diesel through time. The equation of the line offers an idea of how diesel behaves through time. A slope of -150.71 indicates that the LC50 of diesel decreases every $24 \mathrm{hr}$ at a rate of $150.71 \mathrm{ppm}$.

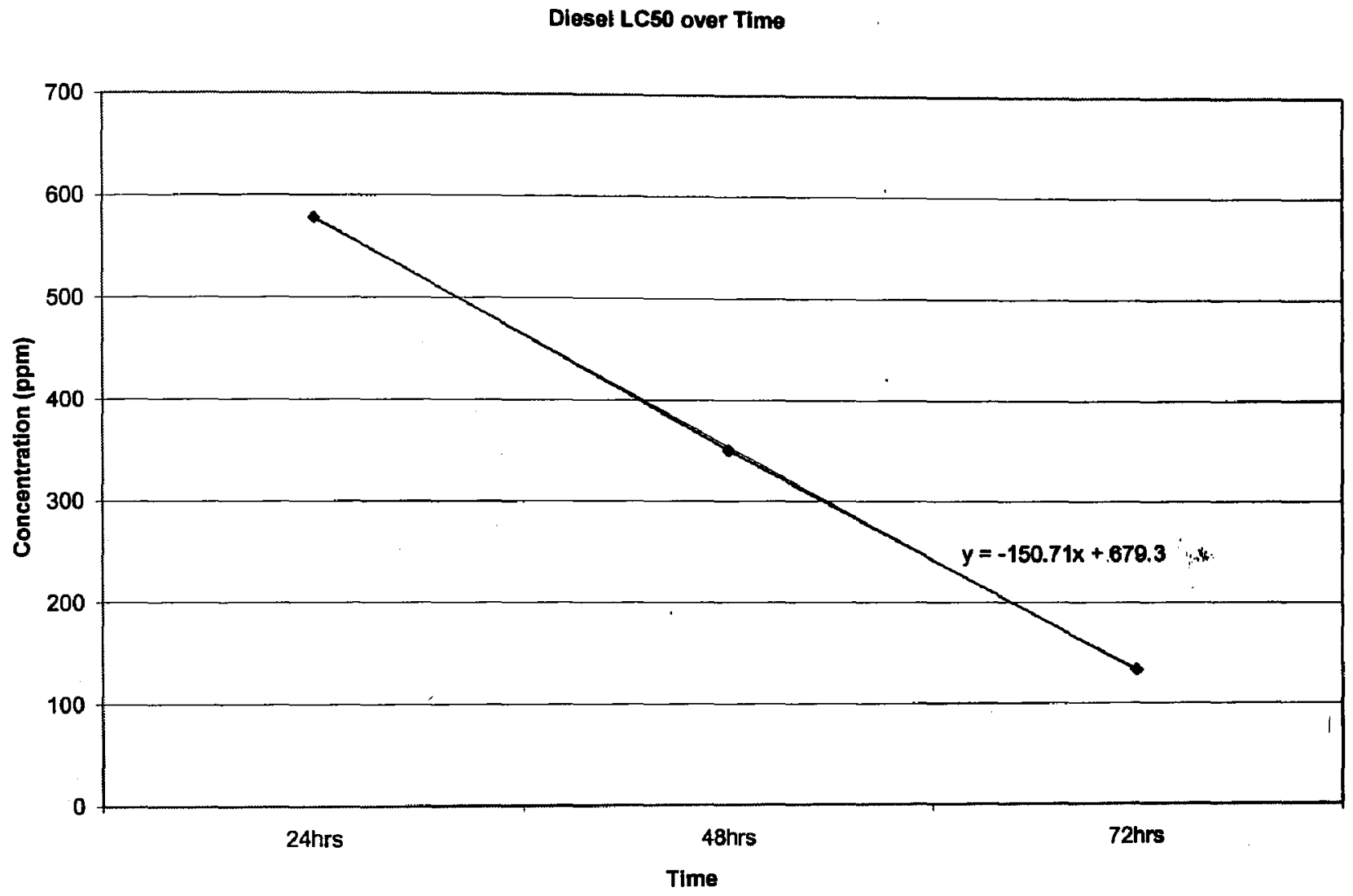

Figure 15: The mean LC50 trend through time for $O$. mykiss exposed to Diesel

2) Biodiesel

(i) $\mathrm{B} 100$

Table 10 shows the $50 \%$ lethal concentration calculated for $O$. mykiss treated with different concentrations of B100 fuel at $24 \mathrm{hr}, 48 \mathrm{hr}, 72 \mathrm{hr}$ and $96 \mathrm{hr}$. 
Table 10: The LC 50 of B100 acute toxicity test using $O$. mykiss

\begin{tabular}{lcccc}
\hline Time & LC 50 & Lower 95\% & Upper 95\% & \% Trim \\
\hline 24hrs & 1073.54 & 994.69 & 1158.63 & 30 \\
48hrs & 756.68 & 646.56 & 885.56 & 10 \\
$72 \mathrm{hrs}$ & 555.19 & 462.94 & 665.82 & 15 \\
$96 \mathrm{hrs}$ & 455.28 & 391.30 & 529.73 & 15 \\
\hline
\end{tabular}

LC50 decreases over the $96 \mathrm{hr}$ period, as illustrated in Figure 16. The LC 50 at the endpoint of 96hr is approximately $455 \mathrm{ppm}$. There is a consistent decrease in LC50 over the 96hours; the highest LC50 of $1073.54 \mathrm{ppm}$ occurs after $24 \mathrm{hrs}$.

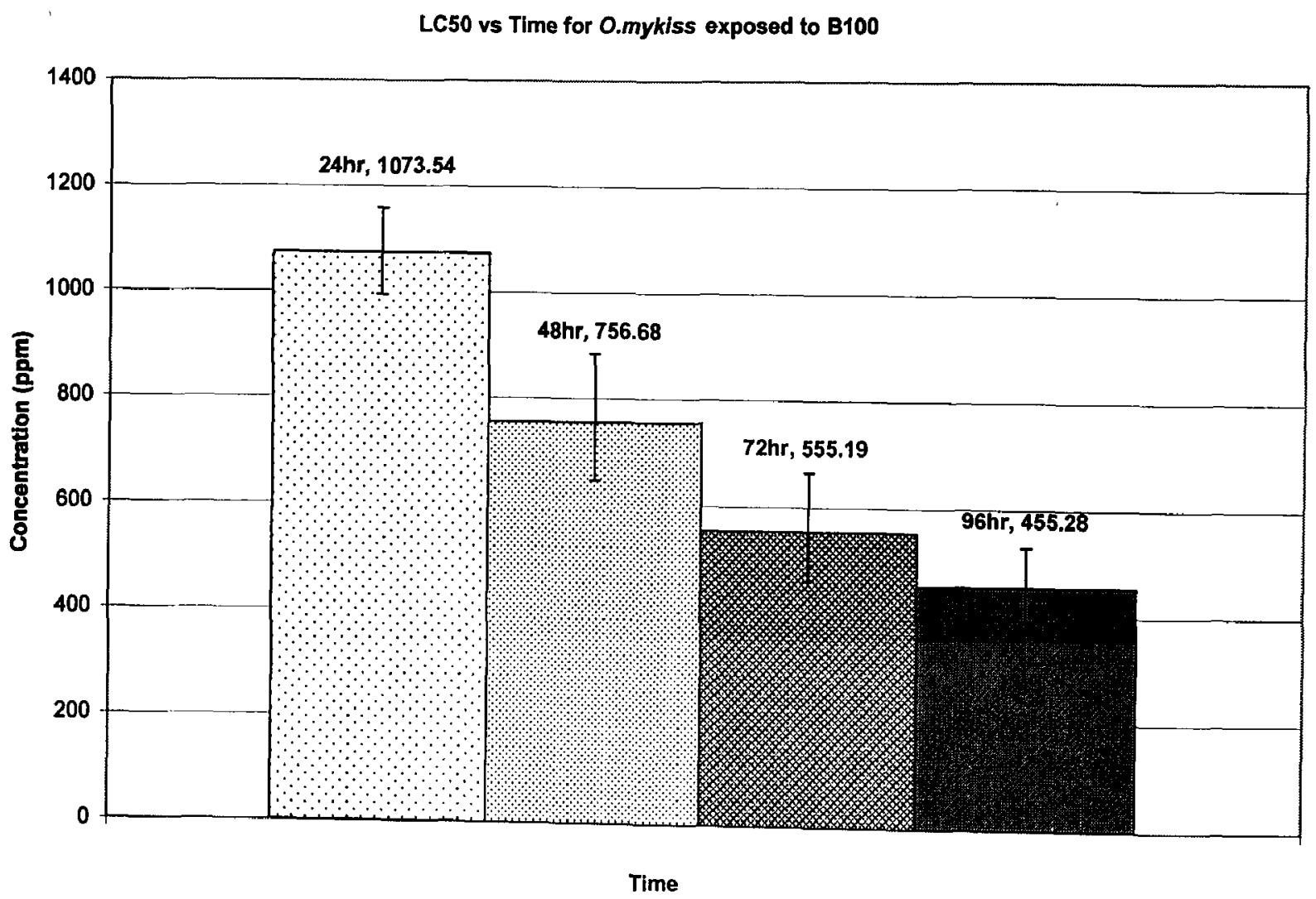

Figure 16: The $L C 50$ values for $B 100$

Figure 17 shows the trend of the mean LC50 values for B100 through time. The equation of the line offers an idea of how B100 behaves through time. A slope of -205.63 indicates that the LC50 of B100 decreases every $24 \mathrm{hr}$ at a rate of $205.63 \mathrm{ppm}$. 


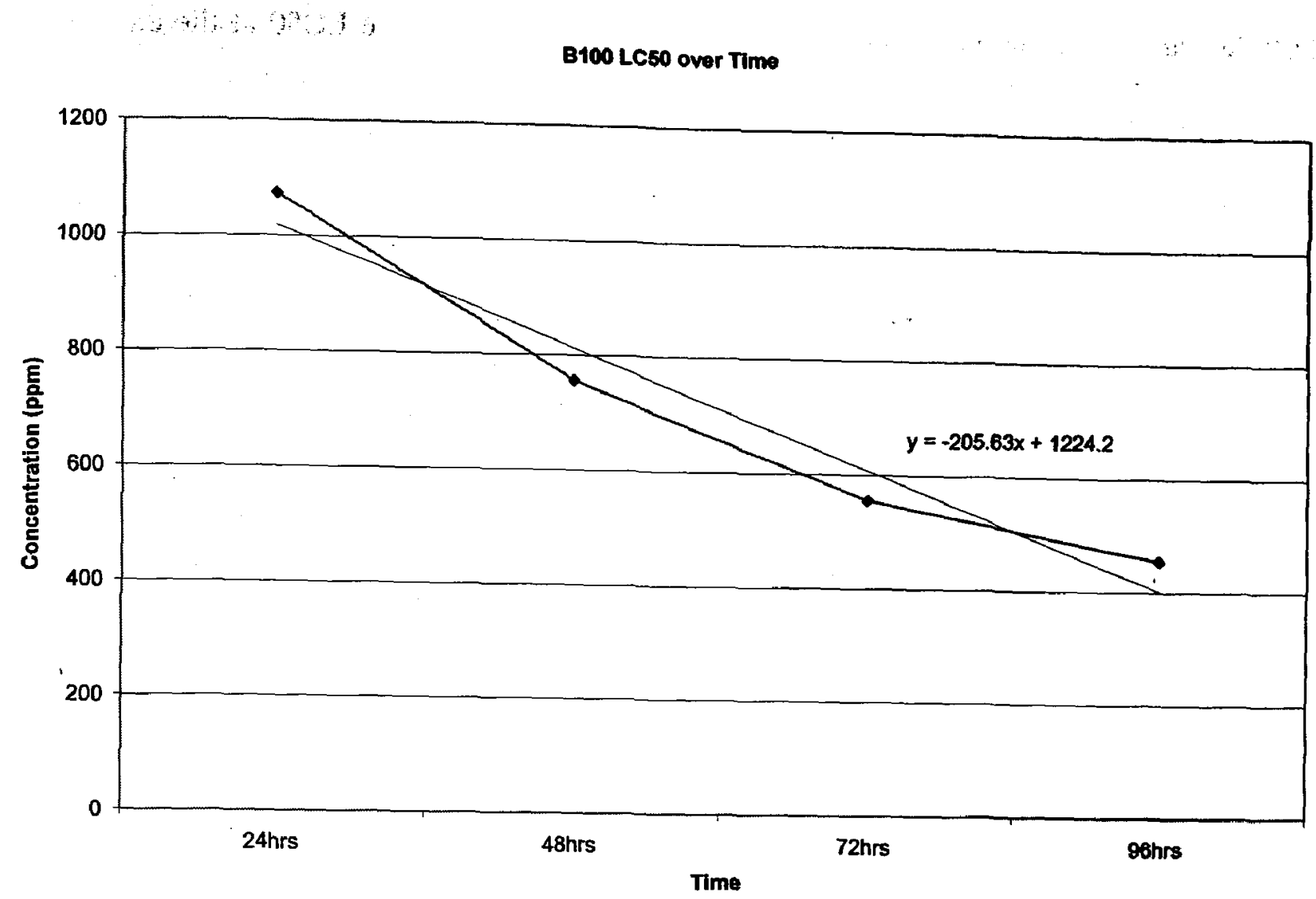

Figure 17: The mean LC50 trend through time for $O$. mykiss exposed to B100

(ii) $\mathrm{B} 50$

Table 11 illustrates the LC50 calculated for $O$. mykiss treated with different concentrations of B50 fuel at 24, 48, 72 and 96 hrs.

Table 11: The LC 50 of B50 acute toxicity test using $O$. mykiss

\begin{tabular}{ccccc}
\hline Time & LC 50 & Lower 95\% & Upper 95\% & \% Trim \\
\hline 24hrs & NC & NC & NC & NC \\
48hrs & 491.11 & 386.78 & 623.59 & 10 \\
$72 \mathrm{hrs}$ & 348.32 & 267.24 & 453.99 & 10 \\
$96 \mathrm{hrs}$ & 276.71 & 212.79 & 359.82 & 10 \\
\hline
\end{tabular}

* $\mathrm{NC}=$ Not Calculable 
LC50 decreases over the $96 \mathrm{hr}$ test period as shown in Figure 18. The LC50 at the endpoint of $96 \mathrm{hr}$ is approximately $277 \mathrm{ppm}$. The LC50 for $24 \mathrm{hrs}$ could not be accounted for by the Trimmed Spearman-Karber Method since there were no mortalities within the 0.5 (50\% mortality) bracket.

LC50 vs Time for O.mykiss exposed to B50

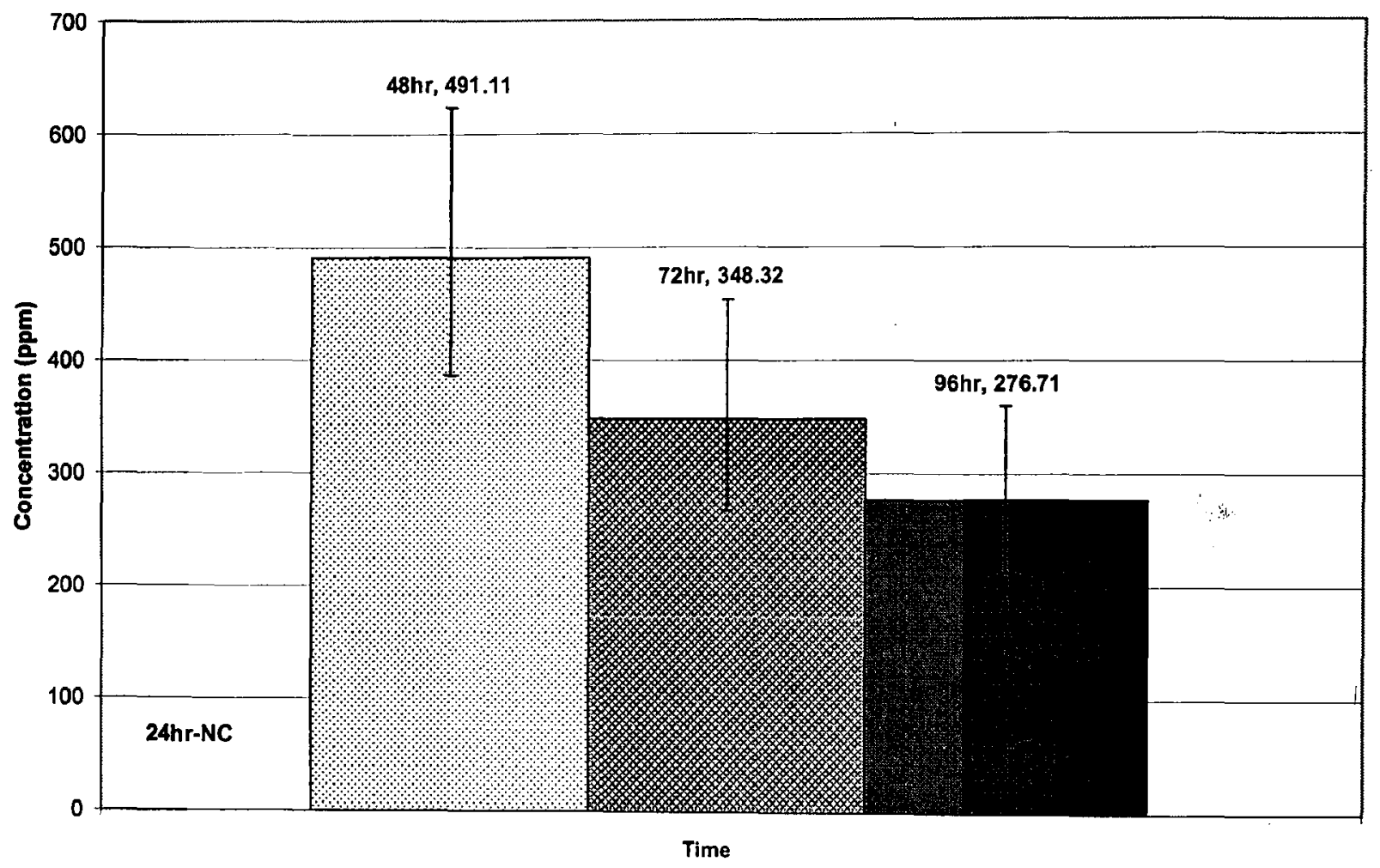

Figure 18: The LC50 values for $\mathrm{B50}$

Figure 19 shows the trend of the mean LC50 values for B50 through time. The equation of the line offers an idea of how B50 behaves through time. A slope of -107.2 indicates that the LC50 of B50 decreases every $24 \mathrm{hr}$ at a rate of $107.2 \mathrm{ppm}$. 


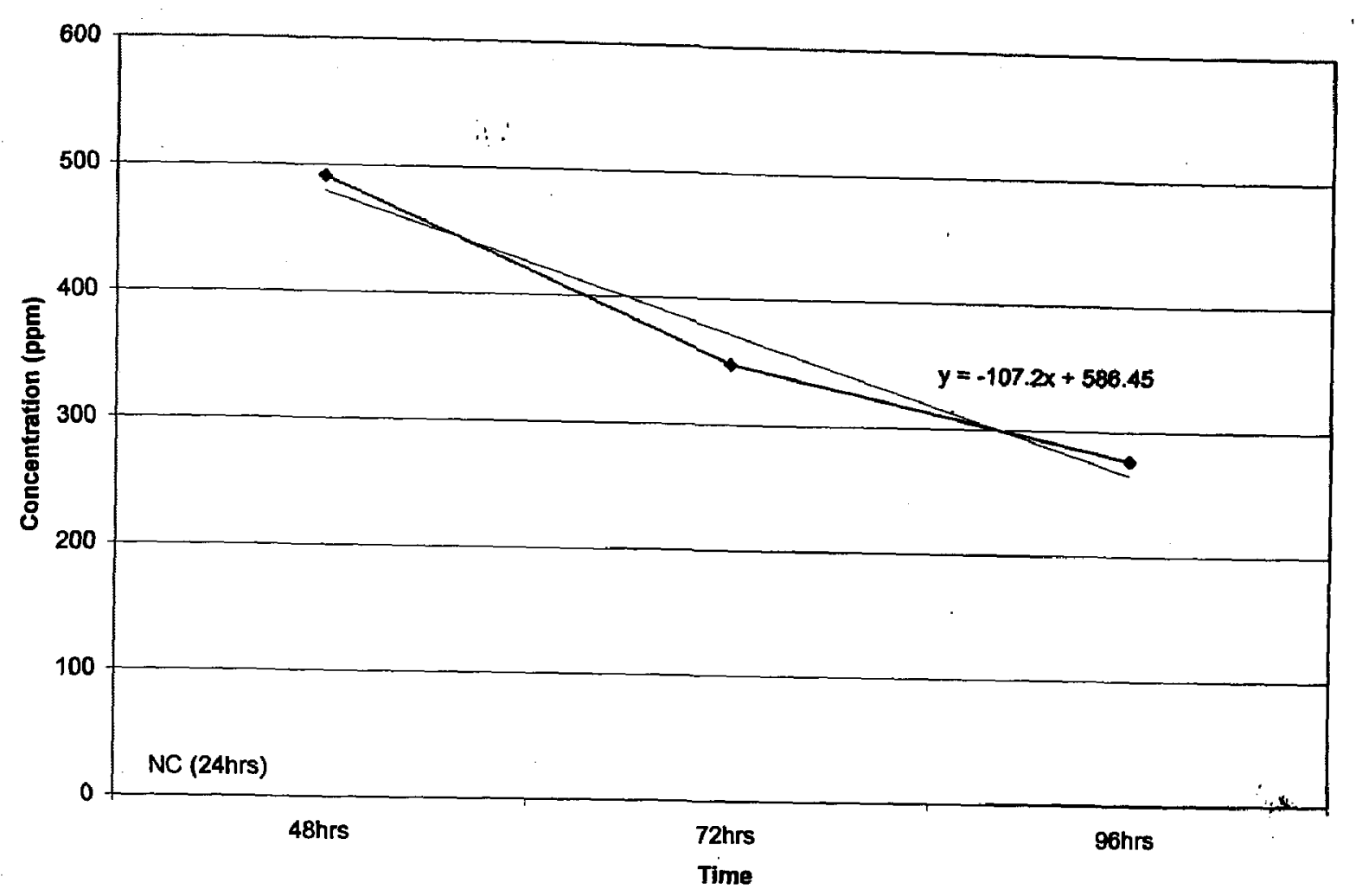

Figure 19: The mean LC50 trend through time for O. mykiss exposed to B50

(iii) $\mathrm{B} 20$

Table 12 illustrates the LC50 calculated for $O$. mykiss treated with different concentrations of B20 fuel at $24 \mathrm{hr}, 48 \mathrm{hr}, 72 \mathrm{hr}$ and $96 \mathrm{hr}$.

Table 12: The LC 50 of $\mathrm{B20}$ acute toxicity test using $O$. mykiss

\begin{tabular}{ccccc}
\hline Time & LC 50 & Lower 95\% & Upper 95\% & \% Trim \\
\hline 24hrs & 1074.31 & 752.15 & 1534.46 & 45 \\
$48 \mathrm{hrs}$ & 659.02 & 566.51 & 766.64 & 10 \\
$72 \mathrm{hrs}$ & 541.27 & 427.62 & 685.13 & 10 \\
$96 \mathrm{hrs}$ & 497.60 & 421.00 & 588.15 & 17.50 \\
\hline
\end{tabular}


LC50 decreases over the $96 \mathrm{hr}$ period. The LC 50 at the endpoint of $96 \mathrm{hr}$ is approximately 498ppm; as shown in Figure 20. There is a consistent decrease in the LC50 over the 96 hours.

LC50 vs Time for O.mykiss exposed to B20

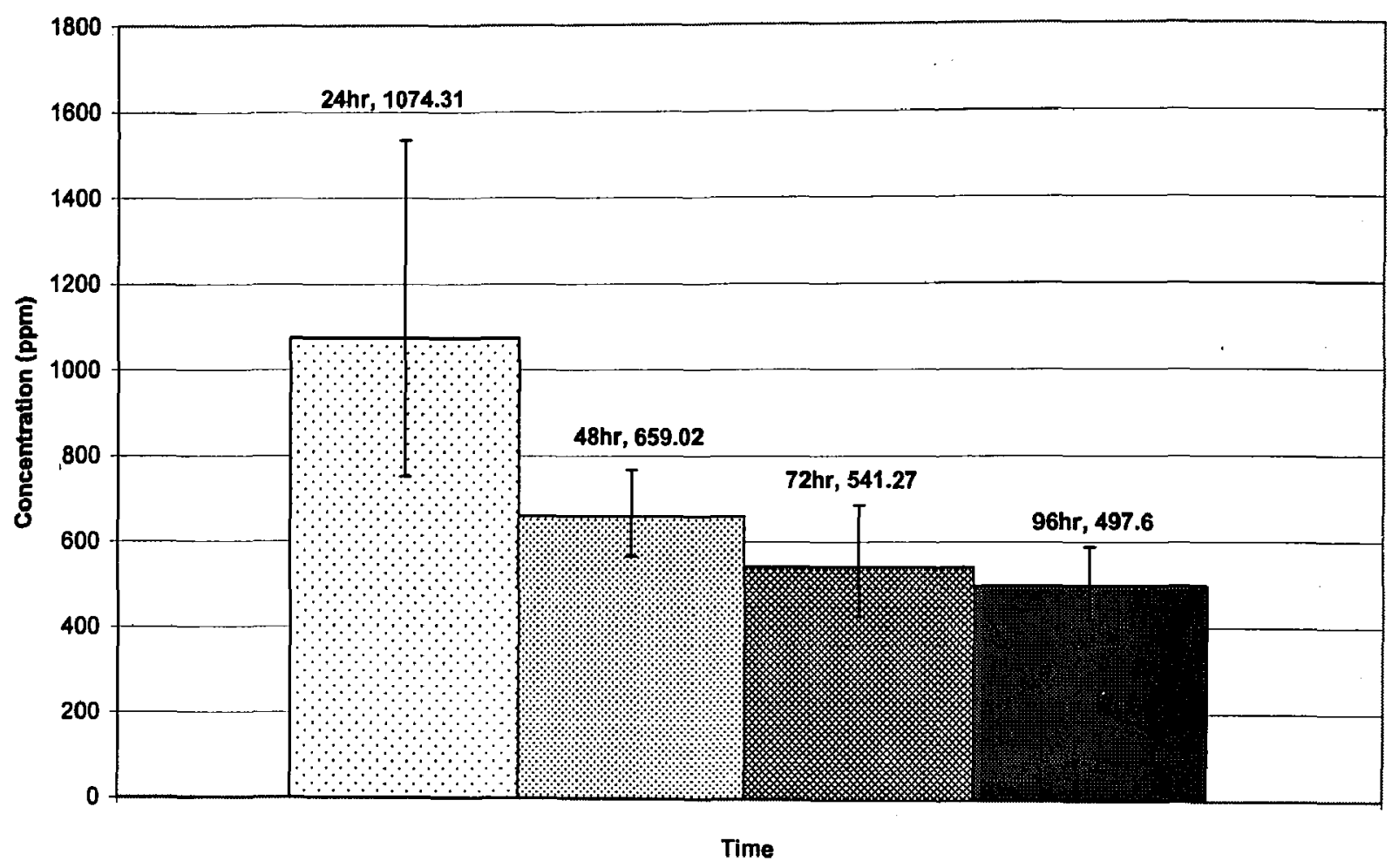

Figure 20: The LC50 values for B20

Figure 21 shows the trend of the mean LC50 values for B20 through time. The equation of the line offers an idea of how B20 behaves through time. A slope of -184.79 indicates that the LC50 of B20 decreases every $24 \mathrm{hr}$ at a rate of $184.79 \mathrm{ppm}$. 


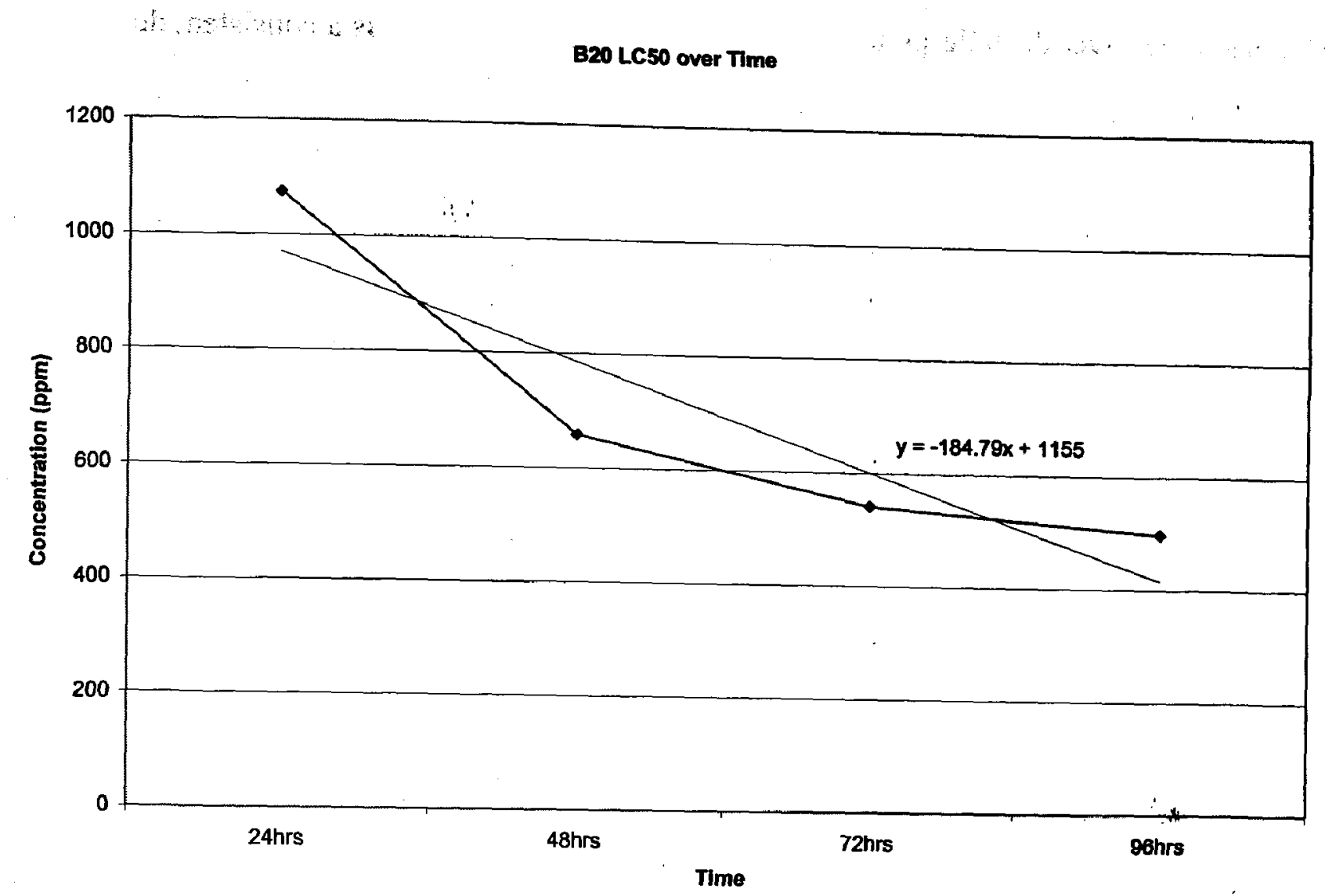

Figure 21: The mean LC50 trend through time for $O$. mykiss exposed to B20

(vi) B5

Table 13 illustrates the LC50 calculated for $O$. mykiss treated with different concentrations of B5 fuel at $24,48,72$ and $96 \mathrm{hrs}$.

Table 13: The LC 50 of $\mathrm{B} 5$ acute toxicity test using $\boldsymbol{O}$. mykiss

\begin{tabular}{lcccc}
\hline Time & LC 50 & Lower 95\% & Upper 95\% & \% Trim \\
\hline 24hrs & 780.67 & 718.61 & 848.09 & 10 \\
$48 \mathrm{hrs}$ & 463.30 & 343.07 & 625.65 & 10 \\
$72 \mathrm{hrs}$ & 234.47 & 177.93 & 308.97 & 10 \\
$96 \mathrm{hrs}$ & 129.57 & 84.38 & 183.92 & 40 \\
\hline
\end{tabular}


LC50 decreases over the $96 \mathrm{hr}$ period; as indicated in Figure 22. There is a consistent decrease in the LC50 over the 96 hours. The LC 50 at the endpoint of $96 \mathrm{hr}$ is approximately $125 \mathrm{ppm}$.

LC50 vs Time for O.mykiss exposed to B5

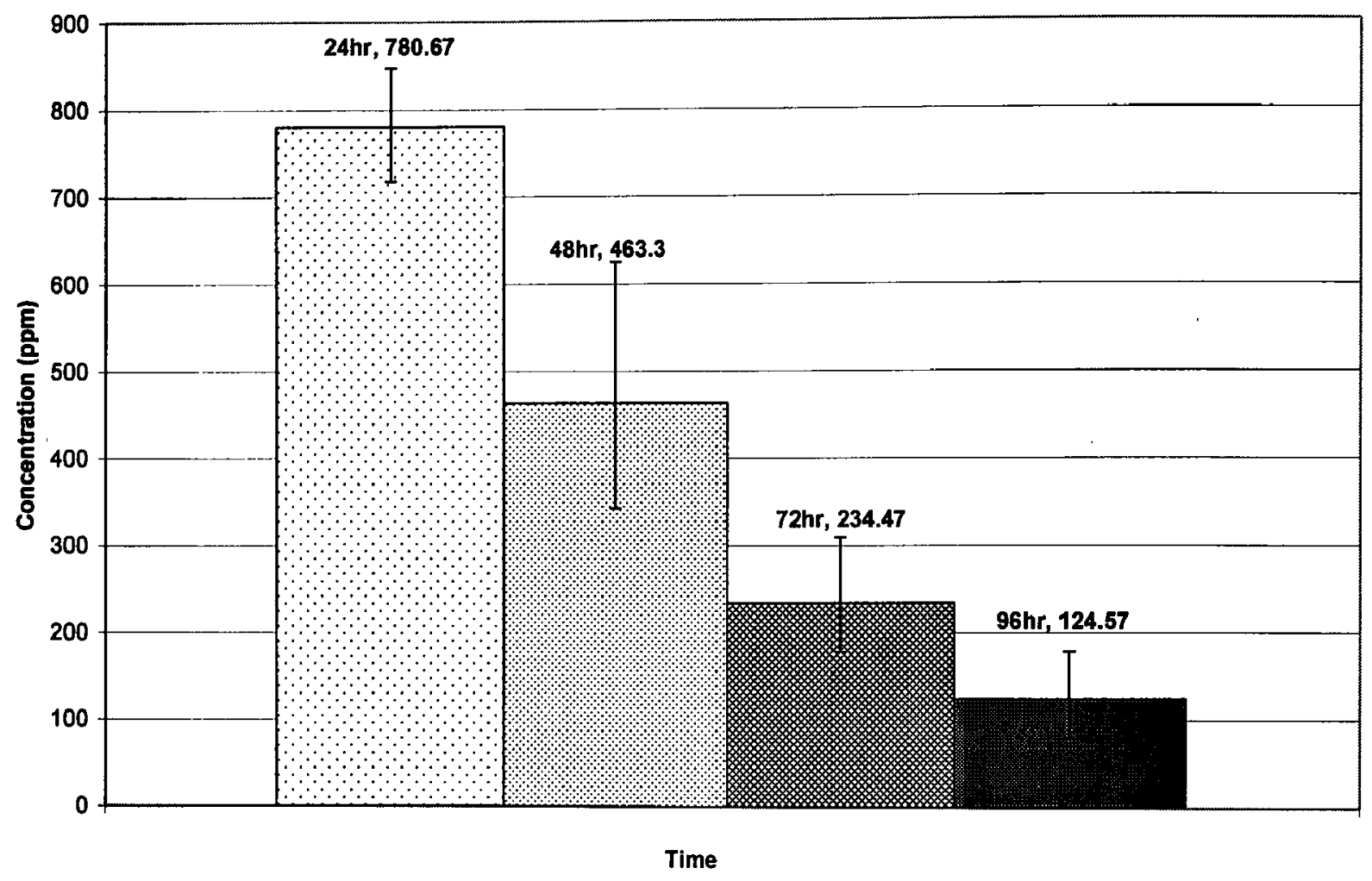

Figure 22: The LC50 values for B5

Figure 23 shows the trend of the mean LC50 values for B5 through time. The equation of the line offers an idea of how B5 behaves through time. A slope of -218.21 indicates that the LC50 of B5 decreases every $24 \mathrm{hr}$ at a rate of $218.21 \mathrm{ppm}$. 


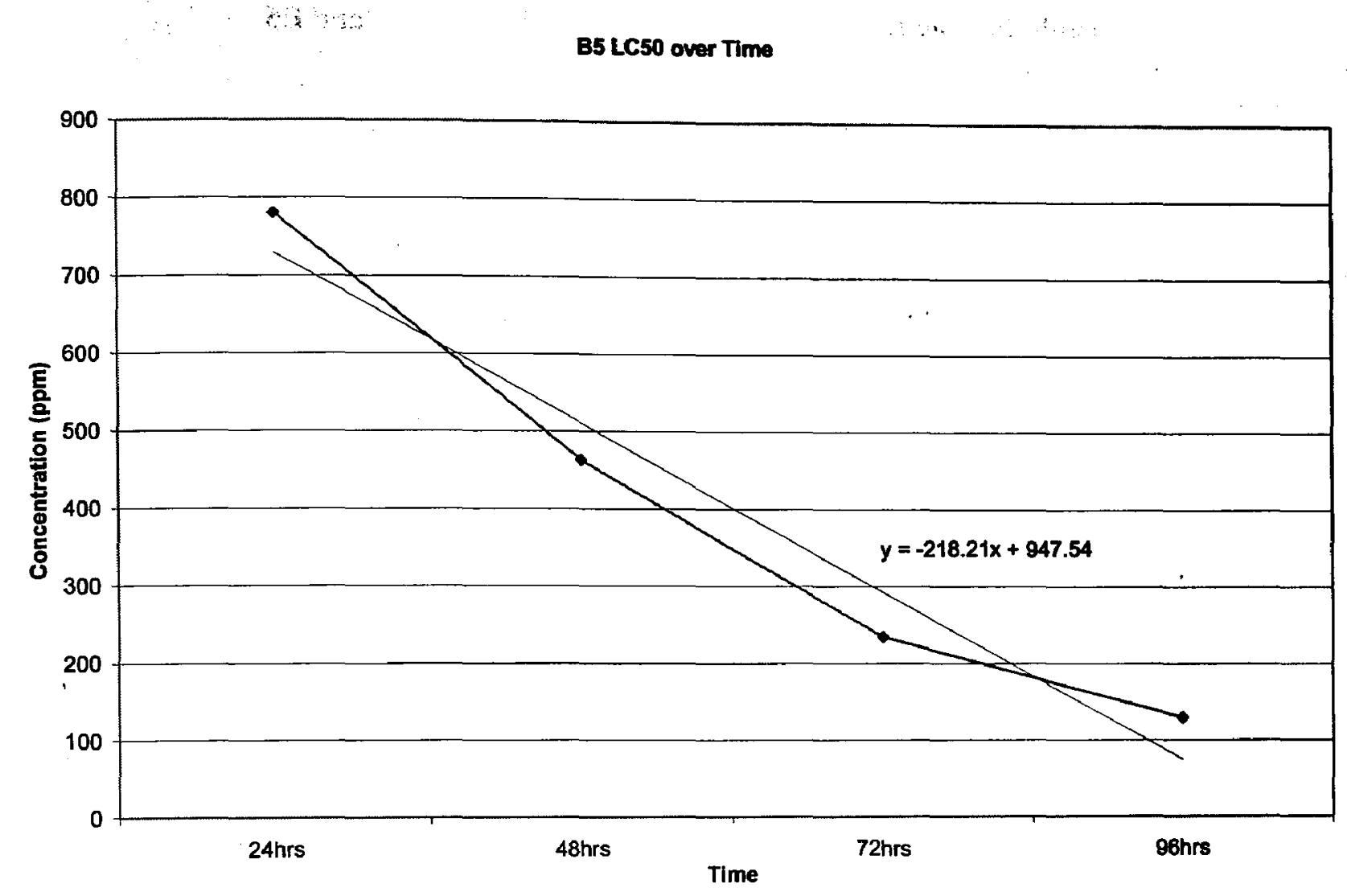

Figure 23: The mean LC50 trend through time for $O$. mykiss exposed to B5

The results of the definitive toxicity tests for the five fuels are tabulated in Table 14. The data are expressed as average LC50s of two trial runs in function of time. The mean LC50 values for diesel ranged from a minimum of $133.52 \mathrm{ppm}$ to a maximum of $578.13 \mathrm{ppm}$, a difference of a factor of 4.33 . B100 LC50 values ranged from $455.28 \mathrm{ppm}$ to a maximum of $1073.54 \mathrm{ppm}$, a factor difference of 2.36; B50 ranged from $276.71 \mathrm{ppm}$ to $491.11 \mathrm{ppm}$, a factor difference of 1.77 . B20 ranged from $497.60 \mathrm{ppm}$ to $1074.31 \mathrm{ppm}$, a factor difference of 2.16 , B5 ranged from $129.57 \mathrm{ppm}$ to $780.67 \mathrm{ppm}$, a factor difference of 6.03 . 
Table 14: The LC50 values for Diesel, B100, B50, B20 and B5

\begin{tabular}{lccccc}
\hline \multicolumn{1}{c}{ Time } & Diesel & B100 & B20 & B50 & B5 \\
24hrs & 578.13 & 1073.54 & 1074.31 & NC & 780.67 \\
48hrs & 350.38 & 756.68 & 659.02 & 491.11 & 463.30 \\
72hrs & 133.52 & 555.19 & 541.27 & 348.32 & 234.47 \\
96hrs & NC & 455.28 & 497.60 & 276.71 & 129.57 \\
\hline
\end{tabular}

There is a consistent decrease in the LC50 for all the fuel types over the 96hr period. Table 15 shows the average LC50 over the four exposure periods. The average LC50 value for diesel and B50 are not true indications for a toxicity ranking as LC50 at $24 \mathrm{hrs}$ for B50 was not available since not deaths were greater than $50 \%$ of the population. Also, deaths at $96 \mathrm{hrs}$ for diesel exceeded 50\%; the program used was not able to calculate a value for lethal concentration.

Table 15: The average LC50 over 24, 48, 72 and $96 \mathrm{hrs}$

\begin{tabular}{ccccc}
\hline $\begin{array}{c}\text { Diesel } \\
(\mathrm{ppm})\end{array}$ & $\begin{array}{c}\text { B100 } \\
(\mathrm{ppm})\end{array}$ & $\begin{array}{c}\text { B50 } \\
(\text { ppm })\end{array}$ & $\begin{array}{c}\text { B20 } \\
(\mathrm{ppm})\end{array}$ & $\begin{array}{c}\text { B5 } \\
(\mathrm{ppm})\end{array}$ \\
\hline $354.01 \pm 128.36$ & $710.17 \pm 136.38$ & $372.71 \pm 63.02$ & $693.05 \pm 131.58$ & $402.00 \pm 144.17$
\end{tabular}

Fig 24 shows all the LC50 values obtained for diesel, biodiesel and biodiesel blends. $24 \mathrm{hr}$-LC50 values are the highest recorded values for all test substances while the lowest recorded lethal concentration values were observed at the $96 \mathrm{hr}$ period. 


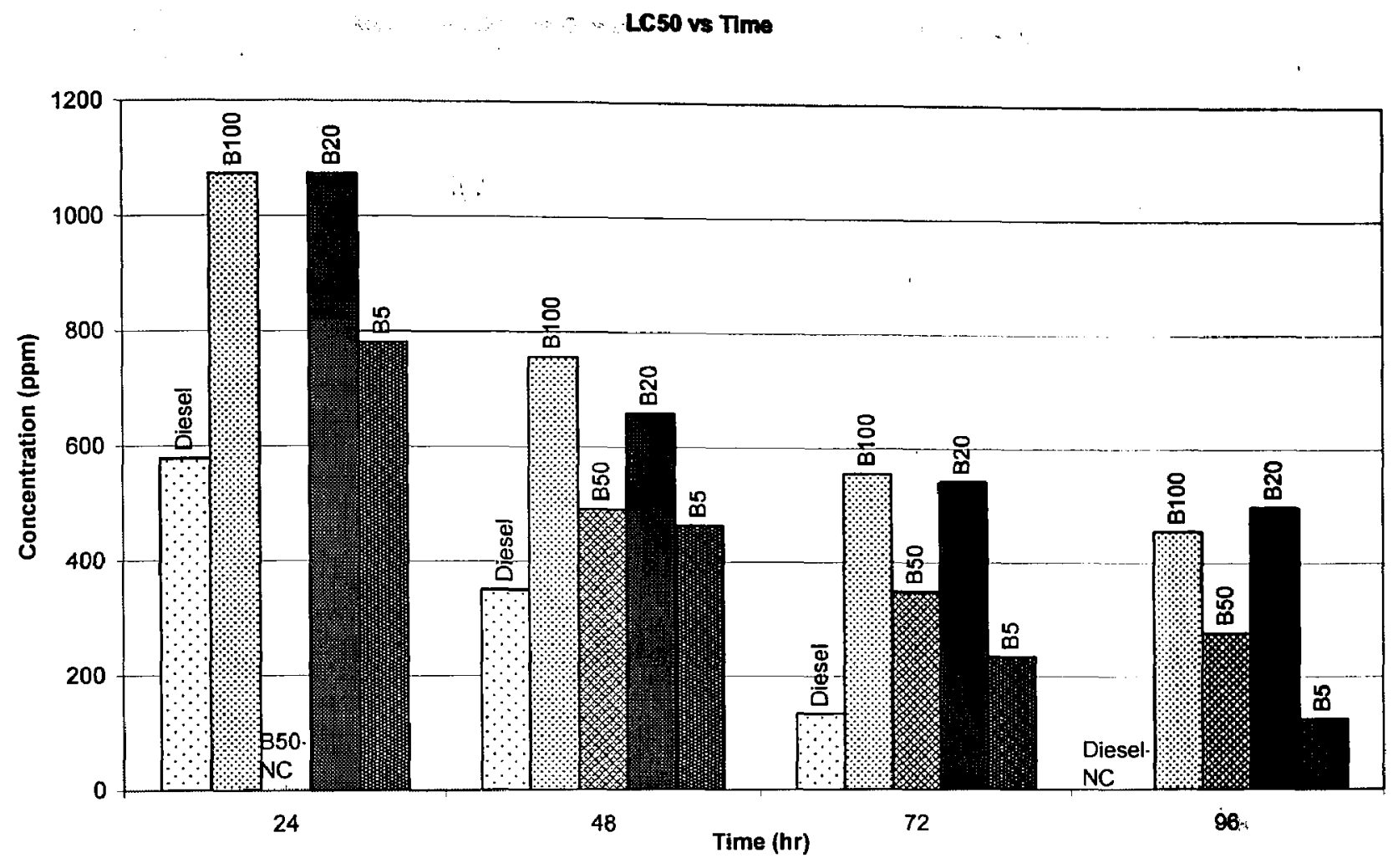

Figure 24: The LC50 values for all fuels used in the acute toxicity tests

\subsection{O. mykiss B20 Comparison}

A comparison of $\mathrm{B} 20$ and $\mathrm{B} 20$ (Topia) was done, O. mykiss treated with $\mathrm{B} 20$ (Topia) were subjected to the same concentrations as fish exposed to B20. There was no significant difference in mortality results among the two trials. Figure 16 shows the average mortality rate of 4 trials over a $24 \mathrm{hr}$ period. For both B20 and B20 (Topia), mortality rate increases as concentration increases; as illustrated in Table 16. 
Table 16: The average mortality rate for B20 (Topia) over $96 \mathrm{hrs}$, using $O$. mykiss

\begin{tabular}{lcc}
\hline $\begin{array}{c}\text { Concentration } \\
\text { (ppm) }\end{array}$ & B20 (\%) & B20 (Topia) (\%) \\
\hline 100 & 7.50 & 5.00 \\
300 & 8.75 & 5.00 \\
600 & 45.00 & 38.75 \\
900 & 76.25 & 57.50 \\
1200 & 86.25 & 82.50 \\
\hline
\end{tabular}

Table 17 shows the overall mortality rate of all concentrations, over the $96 \mathrm{hr}$ period B20 has the higher mortality rate of $44.75 \%$, while B20 (Topia) has a mortality rate of $37.75 \%$, a difference of $7 \%$.

Table 17: The overall mortality rate for $O$. mykiss treated with B20 and B20 (Topia)

\section{FUELS}

B20

B20(Topia)

$44.75 \%$ $37.75 \%$

Figure 25 shows the mortality trends of laboratory blended B20 and commercially blended B20 (B20 (Topia)). 
Mean mortality for O. mykiss treated with B20 and B20 (Topla)

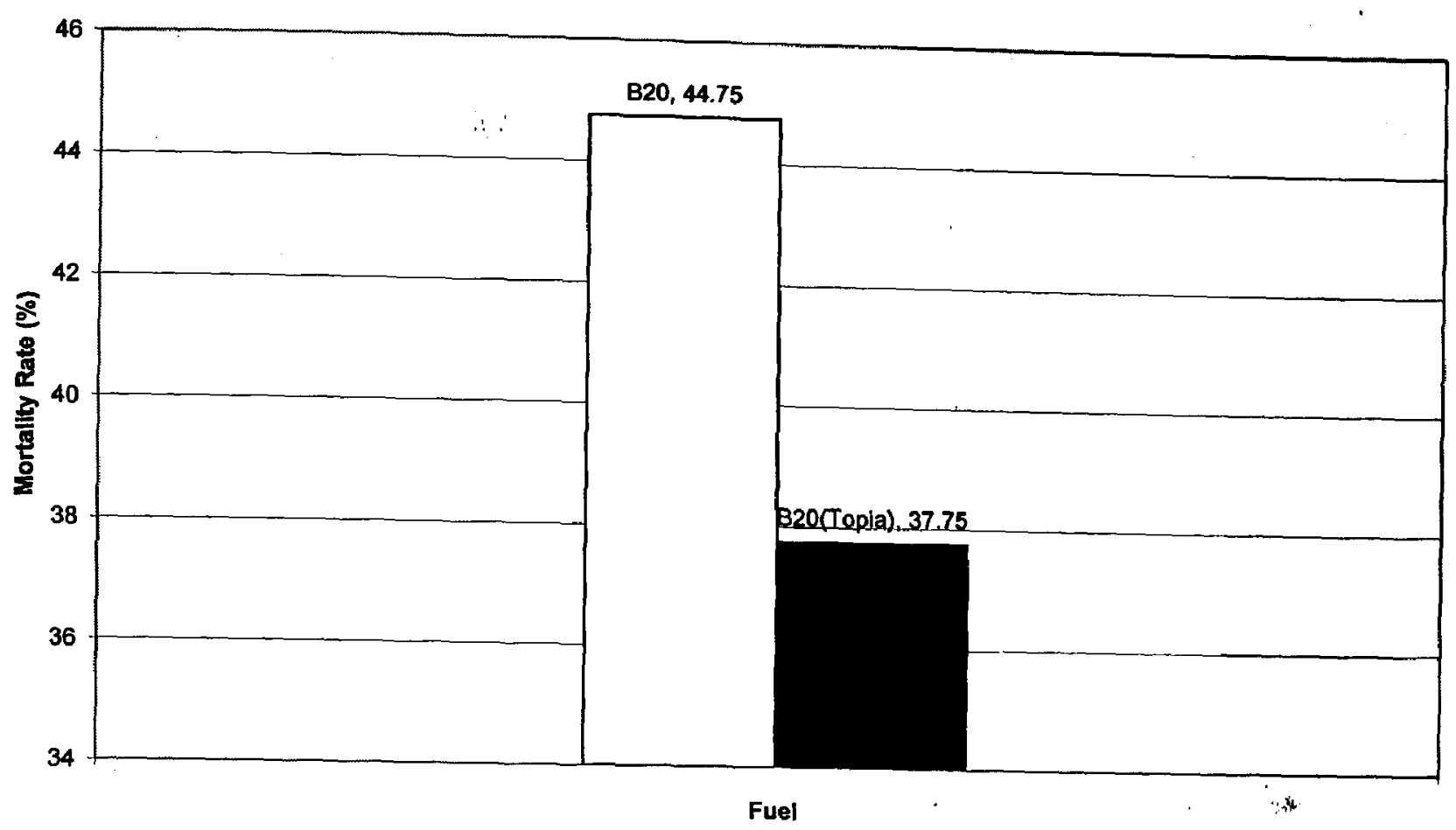

Figure 25: Comparison of mean mortality rate of B20 and B20 (Topia)

\section{Lethal Concentration}

Table 18 shows the LC50 values calculated by the Trimmed Spearman-Karber Method for B20

(Topia). Lower and upper confidence intervals were calculated by the program developed by Hamilton et al (1977).

Table 18: The LC50 values for O. mykiss treated with B20 (Topia)

\begin{tabular}{ccccc}
\hline Time & LC 50 & Lower 95\% & Upper 95\% & \% Trim \\
\hline 24hrs & 1132.91 & 918.15 & 1397.89 & 45 \\
48hrs & 790.87 & 619.02 & 1010.43 & 25 \\
72hrs & 606.21 & 510.08 & 720.46 & 7.5 \\
96hrs & 527.96 & 406.28 & 686.07 & 10 \\
\hline
\end{tabular}


Figure 26 illustrates the LC50 values obtained for B20 (Topia).The LC50 values for B20 (Topia) decreases over time; similar trends were obtained for the B20 blend. The highest LC50 value was obtained after $24 \mathrm{hrs}$, while the lowest LC50 value of $527.96 \mathrm{ppm}$ was obtained for the $96 \mathrm{hr}$ time period.

LC50 values for B20 (Topia)

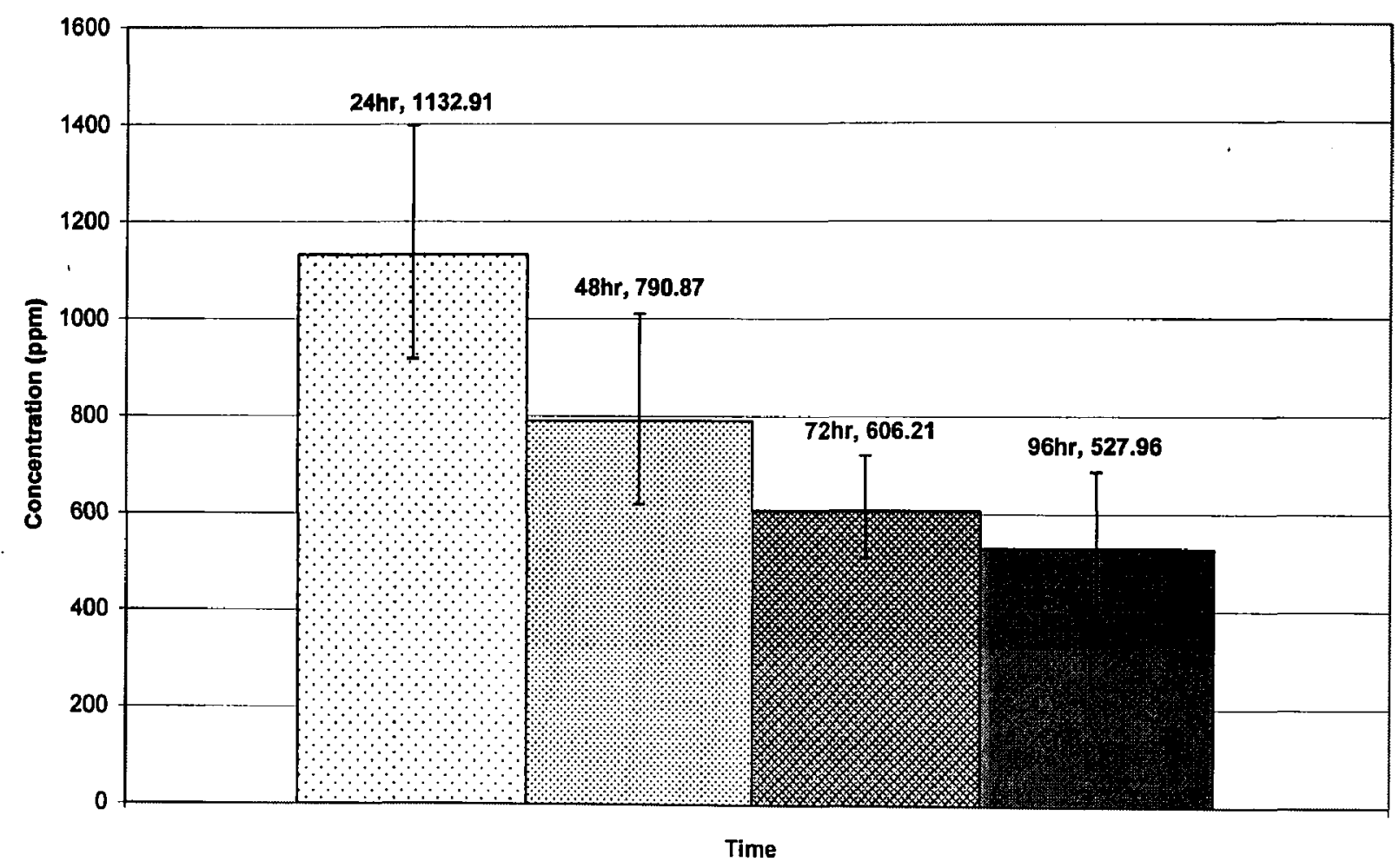

Figure 26: The LC50 values for B20 (Topia)

Figure 27 shows the trend of the mean LC50 values for B20 (Topia) through time. The equation of the line offers an idea of how B20 (Topia) behaves through time. A slope of -1995.95 indicates that the LC50 of diesel decreases every $24 \mathrm{hr}$ at a rate of $199.95 \mathrm{ppm}$. 


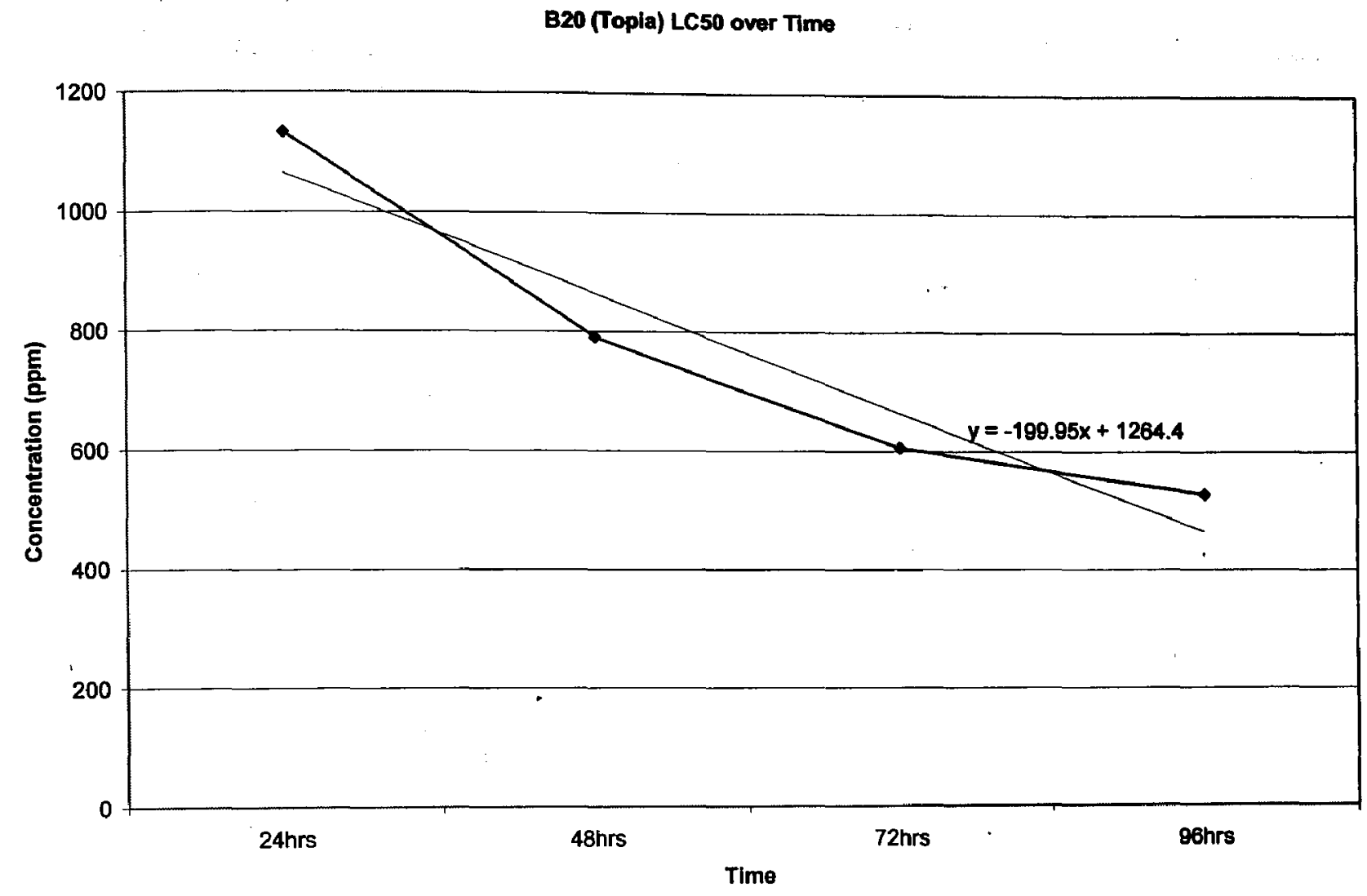

Figure 27: The mean LC50 trend through time for O. mykiss exposed to B20 (Topia)

Figure 28 shows a comparison of B20 and B20 Topia LC50 values. The average LC50 for B20 was $693.05 \pm 131.58 \mathrm{ppm}$, while B20 (Topia) has an average LC50 of $764.49 \pm 134.61 \mathrm{ppm}$. B20 has a slightly lower LC50 than B20 (Topia); a difference of 71.44ppm. 


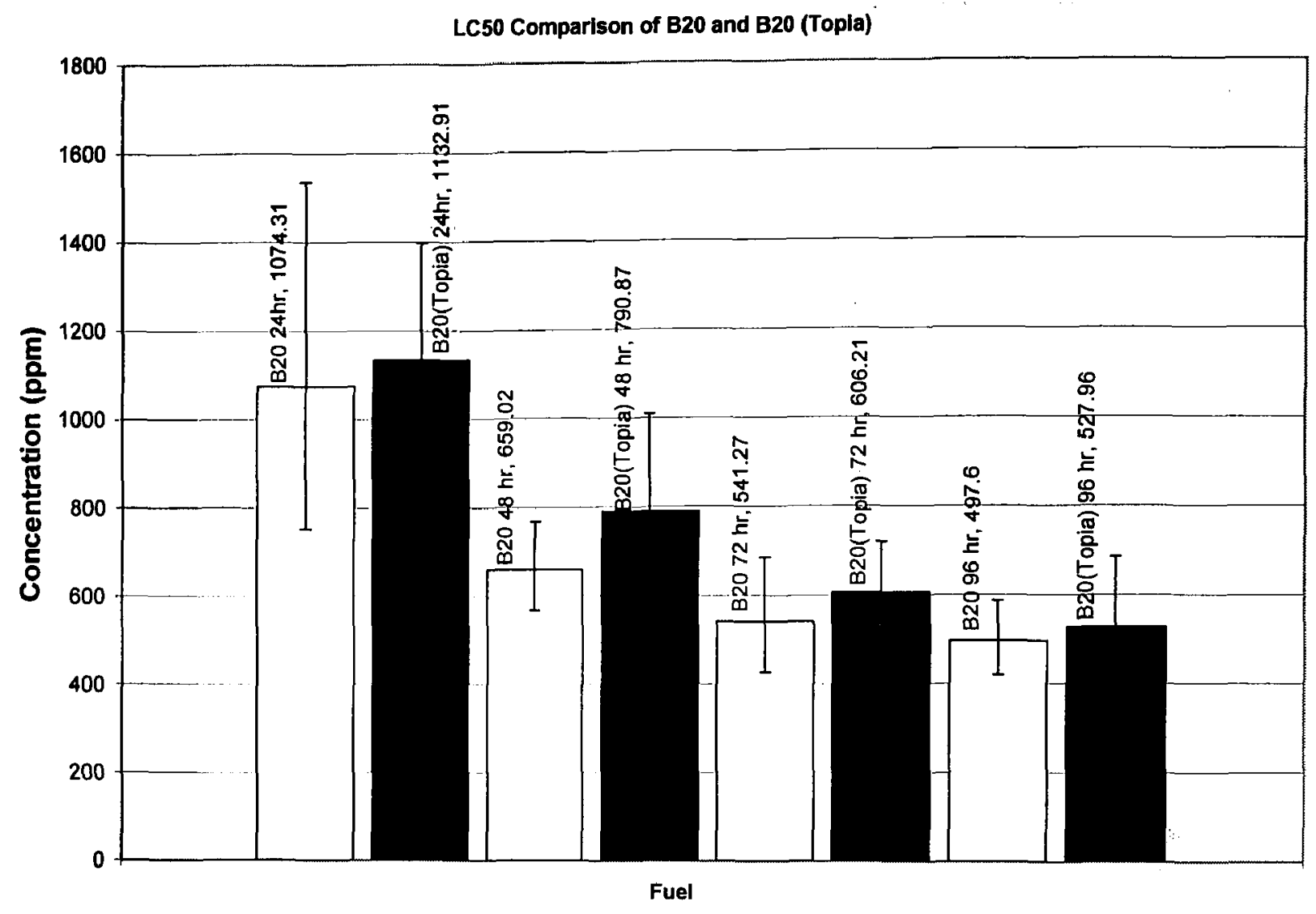

Figure 28: Comparison of the LC50 values of both B20 and B20 (Topia) 


\section{DISCUSSION}

\subsection{Experimental Parameters}

\section{Temperature}

Temperature was a major controlling variable in the experiments conducted; $O$. mykiss (rainbow trout) were very sensitive to both water and environmental temperature changes. The optimal water temperature range was between 8 and $12^{\circ} \mathrm{C}$ and the optimal environmental temperature range was between 8 and $15^{\circ} \mathrm{C}$. Fish exposed to temperatures above or below this range died within a very short time period; as noted in the range-finding results. Like water temperature, environmental temperature was also an important controlling variable; the $O$. mykiss were very sensitive to the ambient environmental temperature; the water and ambient room temperature was maintained at the same temperature to prevent warming up of control and holding water and test chambers to temperatures above $15^{\circ} \mathrm{C}$.

\section{Water}

Besides temperature, another controlling variable was water type, in the control experiments, rainbow trout $(O$. mykiss) were placed in different types of water which included (i) distilled water, (ii) distilled deionised water (DDI) and (iii) tap water; one set of samples was aerated while the other set was not aerated. The tap water was allowed to stand for approximately five days before use in parameter testing. Water samples were aerated for 24 hours before test initiation. The optimal water used for the definitive tests was aerated distilled deionised (DDI) water. 


\section{Bioassay Organisms}

The initial organisms to be studied were Daphnia pulex (D. pulex) and 15-30 day O. mykiss, however, Daphnia pulex was too difficult to culture, catch and use as suitable test organisms because of their small size and it was also difficult to determine mortality with 15-30 day old trout frys; as they were still attached and feeding off their embryonic sacs. Consequently, $D$. magna was used instead of $D$. pulex and 6-week old $O$. mykiss was used instead of trout at a younger life stage.

\subsection{D. magna}

Esters, like methyl and ethyl esters are not soluble in water; these esters formed a sheen or film on the water surface, some D. magna were trapped in this film. Henceforth, D. magna were released below the water surface; significantly less $D$. magna were trapped in the sheen. The sheen was also present in some biodiesel blend trials and similar procedures were used to remediate the problem. The mortality rate was calculated over the $24 \mathrm{hr}$ exposure period; diesel has the highest mortality rate $(78.34 \%)$, while B100 has the lowest mortality rate of $55.98 \%$. Besides diesel, B50, B20 and B5 all contained some amount of diesel fuel in their mixtures prepared. However, of all the prepared mixtures B5 contains the largest amount of diesel (by volume and percent), while B50 has the least amount by volume and percent; $50 \%$ biodiesel and $50 \%$ diesel. The 24hr-LC50 data was calculated using the Trimmed Spearman-Karber Method (Hamilton et al., 1977); diesel has the lowest LC50 of 1.78ppm, while B100 has the highest LC50 value of $4.65 \mathrm{ppm}$. When the $24 \mathrm{hr}-\mathrm{LC} 50$ values were compared, the acute aquatic toxicity of $\mathrm{B} 100$ was 2.6 times less toxic than diesel. 


\subsection{O. mykiss}

For all fuels tested, mortality increases with increasing concentration and increasing time. Diesel has the highest mortality over time among all the five toxins tested. While B100 has the lowest percent mortality over time; in general the more diesel in the toxin, the higher the percent mortality; B5 has a higher percent mortality than either B50 or B20 over time.

LC50 data was calculated using the Trimmed Spearman-Karber Method; there is a general decrease in lethal concentration values for diesel, B100, B50, B20 and B5 over time. For all test substances, the lowest LC50 values were recorded at 96hrs, while the highest LC50 values were recorded at the $24 \mathrm{hr}$ period. The $24 \mathrm{hr}-\mathrm{LC} 50$ value $(578.13 \mathrm{ppm})$ for diesel is the lowest LC50 value among all fuels tested, LC50 values for diesel were calculated for $24 \mathrm{hr}, 48 \mathrm{hr}$ and $72 \mathrm{hr}$, however, no $96 \mathrm{hr}-\mathrm{LC} 50$ was recorded; as more than $50 \%$ of the population were dead even at the lowest concentration. It can be inferred that this non calculable value indicates that diesel is the most toxic of all five toxins. LC50 values for $\mathrm{B} 100$ also decreased with increasing time, from 1073.54ppm to $455.28 \mathrm{ppm}$. LC50 values for B20 also decreased with increasing time; B20 has the highest recorded LC50 value for all test substance (1074.31ppm at $24 \mathrm{hrs})$.

It is also noted that B20 has the highest $96 \mathrm{hr}-\mathrm{LC} 50$ of $497.60 \mathrm{ppm}$, of all of the toxins. Similar trends of decreasing LC50 value with increasing time are observed for B50; however no $24 \mathrm{hr}$ LC50 value was calculated as less than $50 \%$ of the test population showed no signs of lethality at the end of the $24 \mathrm{hr}$ period. There is also a decreasing LC50 trend for B5, the $96 \mathrm{hr}-\mathrm{LC} 50$ value $(129.57 \mathrm{ppm})$ is also the lowest recorded lethal concentration value. $\mathrm{B} 100$ has the highest average

LC50 value $(710.17 \pm 136.38 \mathrm{ppm})$ while diesel has the lowest average LC50 value (354.01士 
$128.36 \mathrm{ppm}$ ); however, overall average LC50 values are not a true indication of toxicity ranking. The $24 \mathrm{hr}$ and $96 \mathrm{hr}-\mathrm{LC} 50$ values for B50 and diesel respectively were not calculable. Since no deaths were greater than $50 \%$ of the population for B50 at the $24 \mathrm{hr}$ time period. All deaths were greater than $50 \%$ of the population for $O$. mykiss treated with diesel after $96 \mathrm{hrs}$. Consequently, a fair comparison could not be made solely on calculated lethal concentration values.

\section{$\underline{5.4 \mathrm{~B} 20 \text { and B20 (Topia) Comparison }}$}

The effects of B20 (Topia) were compared to those of B20; B20 (Topia) was commercially blended, while B20 was blended in the lab and the biodiesel feedstock used was composed of non-edible oils. There was a difference in the mortality rates and calculated LC50 values; B20 has a slightly higher mortality rate than B20 (Topia). B20 has a slightly lower LC50 values for all test periods than B20 (Topia), in comparison B20 is more toxic than B20 (Topia), However, there was not a substantial difference between B20 and B20 (Topia). In addition, difference in values may be a result of the difference in feedstock; the B100 feedstocks may have some influence on the results obtained.

\subsection{Toxicity Ranking}

\subsubsection{Daphnia magna}

Diesel is more toxic than biodiesel and biodiesel blends, neat biodiesel (B100) is less toxic than biodiesel blends of B100 and conventional diesel. A toxicity ranking was done based on the 
mortality rate, the larger the percent mortality the more toxic the fuel. Diesel was the most toxic (78.34\%), followed closely by B5, B50, B20, while B100 was the least toxic (55.98\%).

A toxicity ranking was also done with the lethal concentration (LC50) values recorded, the lower the LC50 value the more toxic the substance. Diesel was the most toxic, followed closely by $\mathrm{B} 5, \mathrm{~B} 50$ and $\mathrm{B} 20$; while $\mathrm{B} 100$ was the least toxic. Diesel is the most toxic at $1.78 \mathrm{ppm}$, while $\mathrm{B} 100$ is the least toxic at $4.65 \mathrm{ppm}$. Biodiesel blends with the larger amounts of diesel, by volume and percent, showed lower LC50 values when compared to those with less diesel blended into the test mixtures. Among the blends, B5 had the lowest calculated LC50 value when compared with $\mathrm{B} 50$ and $\mathrm{B} 20$ respectively. As with the mortality rate, fuels with diesel were more lethal than those with no diesel additive, i.e., neat biodiesel (B100). The LC50 obtained for the $D$. magna static non-renewal tests were very close, the difference for the lowest value obtained (Diesel: $1.78 \mathrm{ppm})$ and the highest value (B100: $4.65 \mathrm{ppm}$ ) was $2.87 \mathrm{ppm}$. The small difference maybe due to the small concentration values tested.

Toxicity ranking based on LC50 also determined diesel is the most toxic, followed closely by $\mathrm{B} 5, \mathrm{~B} 50, \mathrm{~B} 20$ and $\mathrm{B} 100$ (the least toxic). In general, the more diesel in the mixture the more toxic the fuel, however B50 is ranked slightly higher than B20, in terms of toxicity. This difference can be explained by the mortality rate between B50 and B20; for all test concentrations B50 has $10 \pm 3 \%$ more deaths than B20. This difference affects both percent mortality and lethal concentration. Nevertheless, it has been proven that diesel is more toxic than neat biodiesel, as well as biodiesel blends, in terms of mortality rate and lethal concentration that kills $50 \%$ of the population. 


\subsubsection{O. mykiss}

Similar results were obtained for experiments using $O$. mykiss: diesel is more toxic than biodiesel and biodiesel blends. A toxicity ranking was done based on percent mortality; the larger the percent mortality the more toxic the fuel. Diesel $(70.17 \%)$ was the most toxic, followed closely by B5, B50, B20, while B100 (42.50\%) was the least toxic for $O$. mykiss. The more diesel in the fuel mixture the more toxic the fuel; although B50 (51.75\%) ranked slightly higher than B20 (44.75\%). Diesel is more toxic than neat biodiesel or any other biodiesel blend, in terms of percent mortality.

A toxicity ranking was also done with the lethal concentration (LC50) values recorded, the smaller the LC50 value the more toxic the fuel. A high LC50 implies a lower toxicity because more of the chemical is required to result in death. It was difficult to obtain a definite toxicity ranking using LC50 obtained from $O$. mykiss results. For $24 \mathrm{hr}-\mathrm{LC} 50$, diesel was the most toxic; however, no value was obtained for B50 because more than $50 \%$ of the population survived. The $48 \mathrm{hr}-\mathrm{LC} 50$ and $72 \mathrm{hr}-\mathrm{LC} 50$ values produced the same toxicity ranking; Diesel> $\mathrm{B} 5>\mathrm{B} 50>\mathrm{B} 20>\mathrm{B} 100$. B50 appears to be more toxic than $\mathrm{B} 20$, although it contains $30 \%$ less diesel. There is approximately $10 \pm 5 \%$ more deaths of $O$. mykiss treated with B50; particularly at concentrations of 600 and $900 \mathrm{ppm}$. This difference affects the LC50 values and accounts for the higher than expected toxicity ranking. It was difficult to estimate an absolute toxicity ranking based on $96 \mathrm{hr}-\mathrm{LC} 50$ values; the diesel $96 \mathrm{hr}$-LC50 value was not calculable because all the concentrations exhibited more than 50\% mortality; even at the lowest concentration of $100 \mathrm{ppm}$. In addition, B50 had a non-calculable $24 \mathrm{hr}-\mathrm{LC} 50$ value, where less than $50 \%$ of the test population died. Nevertheless, an analysis of $96 \mathrm{hr}-\mathrm{LC} 50$ values was done; diesel is the most 
toxic (based on a non-calculable result), followed by B5, B50, B100 and B20. B20 has a higher ranking (by a difference of $42.32 \mathrm{ppm}$ ) than B100, because slightly more fish treated with $100 \mathrm{ppm}, 600 \mathrm{ppm}$ and $1200 \mathrm{ppm}$ of B100 died when compared to similar B20 concentration trials. However, it was proven that diesel is still more toxic than neat biodiesel or biodiesel blends.

\subsubsection{B20 Toxicity Ranking}

A comparison of D. magna results has determined that B20 (Topia) is less toxic than B20 and B100. According to percent mortality results, B20 (Topia) (54.81\%) is slightly less lethal than $\mathrm{B} 100(55.98 \%)$ as well as B20 (57.78\%). LC50 results has determined than B20 (Topia) has a slightly higher $24 \mathrm{hr}-\mathrm{LC} 50$ value $(6.74 \mathrm{ppm})$ than B100 (4.65ppm) and B20 (4.54ppm). An analysis of $O$. mykiss results has also revealed that B20 (Topia) is less toxic than B20 and B100. According to percent mortality results, B20 (Topia) (37.75\%) is slightly less lethal than B100 $(42.50 \%)$ as well as B20 (44.75\%). B20 (Topia) is slightly less lethal than B100 and B20, based

on LC50 values. These differences can be explained by the number of deaths recorded for each fuel type. These results may also be attributed to different B100 feedstocks; B20 (Topia) was produced from soy and canola oil, while B100 and B20 were produced from waste cooking oils and fats. 


\section{CONCLUSIONS}

Static non-renewal tests were conducted to determine the acute toxicity of biodiesel, biodiesel blends and diesel on freshwater ecosystems; the two main endpoints were mortality rate and lethal concentration which killed $50 \%$ of the test population. The two organisms used were $D$. magna and $O$. mykiss; these organisms were used because of their sensitivity and availability. Neat biodiesel is referred to as B100, while biodiesel blends tested were B50, B20 and B5; these endpoints were compared to results obtained from conventional diesel fuel.

The toxicity tests showed that biodiesel is considerably less toxic than diesel fuel. However, like diesel, biodiesel and biodiesel blends still should be avoided in aquatic environments. Although biodiesel is less toxic than conventional diesel fuel, it can have a serious impact on aquatic organisms in the event of a large spill. Biodiesel and biodiesel blends should be handled like any other fuel to avoid contamination of watersheds. Biodiesel may have a less severe impact on freshwater organisms and the aquatic environment than petroleum diesel; however if accidentally spilled or inadvertently discharged during transportation storage or use, their impact may have similar toxic effects as those of diesel spills.

Based on the results of this study in its entirety, it can be concluded that biodiesel and biodiesel blends produced from non edible oils are less toxic than conventional diesel fuel. Biodiesel maybe a viable and environmentally-friendly alternative to diesel, in terms of acute toxicity levels to freshwater organisms. However, it should be noted that this study is limited in scope; in that the statements concluded are based solely on acute toxicity of diesel, biodiesel and biodiesel blends tested in this study. More specifically, biodiesel and biodiesel blends produced from a 
non-edible oil feedstock. Other aspects of biodiesel toxicity were not addressed by this study. These include acute toxicity of biodiesel and biodiesel blends produced from edible oils, such as soybean and canola oils. With the exception of B20 (Topia), only specific non-edible biodiesel blends were tested; these were limited to B50, B20 and B5 and these blends were only mixed with conventional diesel fuel. This study only examined the effects of biodiesel and biodiesel blends over a short-term period; a study on chronic effects was not performed. Another limitation is concentration, since only a few concentrations were tested. It may be very difficult to predict or compare the extent of biodiesel spills in 'real world' situations, with limited blends and concentrations. In addition, natural processes may influence the extent and nature of any particular biodiesel spill.

Future study should examine acute toxicity of biodiesel produced from edible oils, such as vegetable oils. Long-term effects should also be considered, a comparison of chronic effects of biodiesel and biodiesel blends produced from edible and non-edible oils would also be a worthwhile study to perform.

It is difficult to definitely conclude that all neat biodiesel and all biodiesel blends are less toxic than all the different types of diesel fuel. It is also difficult to compare the results obtained on this study to previous studies, since there is a lack of existing literature pertaining to acute toxicity of biodiesel produced from non-edible oil sources on aquatic organisms.

It is also important to realise that the potential environmental impact of biodiesel spills will depend on other factors, such as (i) the location of the spill, (ii) the volume of the spill (iii) the 
extent of the spill, (iv) chemical components of biodiesel and (v) other prevailing environmental factors. It should also be noted that acute effects may be species-specific, in the bioassay performed, only D. magna and $O$. mykiss was used. Although these two species are significant bio-indicators for acute toxicity of organisms dwelling in the water column, no sediment dwelling organisms were used in the study; these organisms may be affected differently.

There are a number of improvements that could be made to this study in order to obtain greater acceptability of the results. Increasing the number of trials in both bioassays is recommended to improve the statistical validity of the results. Different concentrations could also be tested, as well as different biodiesel blends and chronic exposure may also increase confidence in the results, such as effects on $D$. magna offspring and future generations. Different bioassay organisms can also be used to increase the validity of the results. Acute toxic effects of specific diesel and biodiesel components, as well as by-products of these toxins created by processes such as oxidation or biodegradation would offer valuable information on biodiesel toxicity.

Nevertheless, this study provides a comparison of acute toxicity of neat biodiesel to different biodiesel blends; it also provides a comparison of acute toxicity of biodiesel to diesel. As the interest in biodiesel increases, this study can serve as a baseline for further biodiesel environmental impact studies. 


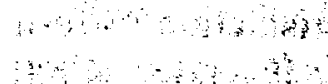

\section{REFERENCES}

Barnwal B.K. and M.P. Sharma. 2005. "Prospects of biodiesel production from vegetable oils in India;" Renewable and Sustainable Energy Reviews 9: 363-378.

Bender M. 1999. "Economic feasibility review for community-scale farmer cooperatives for biodiesel." Bioresource Technology 70: 81-87.

Bhattacharyya S., Klerks P.L., and J.A. Nyman. 2003. "Toxicity to freshwater organisms from oils and oil spill chemical treatments in laboratory microcosms." Environmental Pollution 122: 205-215.

Biswas S., Chaudhari S. K. and S. Mukherji. 2005. "Microbial uptake of diesel oil sorbed on soil and oil spill clean-up sorbents." J. Chem. Technol. Biotechnol. 80:587-593.

Boyd M., Murray-Hill A. and K. Schaddelee. 2004. "Biodiesel in British Columbia Feasibility Study Report". WISE Energy Co-op / Eco-Literacy Canada.

Available from:< http://www.citygreen.ca/news_biodiesel-report.html $>$ [Retrieved: May 2004].

Cripps G. C. and J. Shears. 1997. "The Fate in the Marine Environment of a Minor Diesel Fuel Spill from an Antarctic Research Station". Environmental Monitoring and Assessment 46: 221232.

Dede, E.B. and H.D. Kaglo. 2001. "Aqua-toxicological Effects of Water Soluble Fractions (WSF) Of Diesel Fuel On O. Niloticus Fingerlings.” J. Appl. Sci Environ. Mgt. 5 (1): 93-96.

Dmytryshyn S.L., Dalai A.K., S. T. Chaudhari et al. 2004. "Synthesis and characterization of vegetable oil derived esters: evaluation for their diesel additive properties." Bioresource Technology 92: 55-64.

ENN: Environmental News Network. 2005. "President Signs Energy Bill with Biodiesel Tax Incentive Extension; Numerous Other Pro-Biodiesel Measures Also Included." Available from: $<$ www.ENN.com $>$ [Retrieved August $\left.9^{\text {th }} 2005\right]$.

Enguídanos M., Soria A., Kavalov B. and P. Jensen. May 2002. "Techno-economic analysis of Bio-diesel production in the EU: A short summary for decision-makers." Report EUR 20279EN. European Union: Joint Research Centre, Institute for Prospective Studies. Available from:< http://www.europarl.eu.int/stoa/ta/renewable_energies/biomass/biodiesel(ipts).pdf $>$ [Retrieved on June 2004].

Environment Canada. 2000. Biological Test Method: Reference Method for Determining Acute Lethality of Effluents to Rainbow Trout. Environment Protection Series, Report EPS1/RM13, December 2000. Environment Canada, Conservation and Protection, Ottawa.

EPA. 2002. Fifth Edition. "Methods for Measuring the Acute Toxicity of Effluents and Receiving Waters to Freshwater and Marine Organisms". October 2002. 
Etkin, D.S. 2004. "Twenty-year Trend Analysis of Oil Spills in EPA Jurisdiction." Freshwater Spills Symposium 2004. Available from:< http://www.epa.gov/oilspill/pdfs/etkin_04.pdfs

Gustafson, C. R. "Biodiesel: An Industry Poised for Growth?” 2003. Choices .American Agricultural Economics Association. Third Quarter 2003. Available from:

$<$ http://www.choicesmagazine.org> [Retrieved August 2005].

Holbein B.E., Stephen J. D. and D. B. Layzell. 2005. “Canadian Biodiesel Initiative: Aligning Research Needs and Priorities with the Emerging Industry-Final Report." Available from: $<$ http://www.biocap.ca $>$ [Retrieved August 2005].

Kalam M.A. and H.H. Masjuki. 2002. "Biodiesel from palmoil-an analysis of its properties and potential." Biomass and Bioenergy 23: 471 - 479.

Lee, G., Ellersieck N.R., Mayer F.L., and G. F. Krause. 1995. "Prediction Chronic Lethality of Chemicals to Fishes from Acute Toxicity Test Date: Multi-Probit Analysis." Environmental Toxicology and Chemistry 14 (2):345-349.

Li, J and C. Filteau. 2005. "2005 Oil Spill Analysis Report for Ontario. Department of Civil Engineering. Ryerson University(September, 2005).

Lytle, D. A. and B. L. Peckarsky. 2001. "Spatial and temporal impacts of a diesel fuel spill On stream invertebrates." Freshwater biology 46: 693 -704.

Mohammed, A. 2005. "Toxicity of water-soluble fractions of four fuels for Metamysidopsis insularis, an indigenous tropical mysid species." Environmental Monitoring and Assessment 104: $37-44$.

Mudge. S.M. 1995. "Deleterious Effects from Accidental Spillages of Vegetable Oils." 1995. Spill Science and Technology Bulletin 2 (2/3): 187-191.

Pereira M. G., Mudge S. M. and J. Latchford. 2002. "Consequences of linseed oil spills in salt marsh sediments." Marine Pollution Bulletin 44: 520-533.

Pereira M.G., Mudge, S. M. and J. Latchford. 2003. "Vegetable oil spills on salt marsh sediments; comparison between sunflower and linseed oils." Marine Environmental Research 56: $367-385$.

Prakash . C. B. (Ed). "A Critical Review Of Biodiesel As A Transportation Fuel in Canada." 1998. Environment Canada. Transportation Systems Branch Air Pollution Prevention

Directorate.

Available from: < http://www.ec.gc.ca/transport/publications/biodiesel/biodeisel.pdf $>$ [Retrieved May 2005].

Puppán D. 2002. "Environmental Evaluation of Biofuels". Periodica Polytechnica Ser. Man. Sci. 10 (1): 95-116. 
Radich, A. "Biodiesel Performance, Costs, and Use." Environment Canada. 1990. Biological Test Method: Acute Lethality Test Using Rainbow Trout. Environment Protection Series, $<$ http://www.eia.doe.gov/oiaf/analysispaper/biodiesel/pdf/biodiesel.pdf $>$ [Retrieved July 2005].

Raneses A.R., Glaser L.K., Price J.M. and J.A. Duffield. 1999. "Potential Biodiesel Markets and Their Economic Effects on the Agricultural Sector of the United States." Journal of Industrial Crops and Products 9 ( 2): 151-162.

Rideout, G. (2004). "Biodiesel: the what, how, where, and why, of the Canadian use of this 'new' fuel". Air and Wastewater Management Association-Ottawa Valley Chapter May $26^{\text {th }}$ 2004.

Sagrans M. 1998. "The Regulation of Biodiesel and Biodiesel Feedstocks in Aquatic Environments." Available from: <www.biodiesel.org/resources/reportsdatabase/ reports/mar/19980601_mar-004.pdf $>$ [Retrieved June 2005]

Schumacher, L.G, S.C. Borgelt, and W.G. Hires. 1995. "Fuelling a Diesel Engine with Methylester Soybean Oil". Applied Engineering In Agriculture. 11(1):37-40.

Sheehan, J., V. Camobreco, J. Duffield, J, M. Graboski and H. Shapouri. 1998. "An Overview of Biodiesel and Petroleum Diesel Life Cycles." NREL/SR-580-24089 UC Category 1503. U.S Department of Agriculture and U.S. Department of Energy: National Renewable Energy Laboratory, Golden, CO. Available from: $<$ http://www.nrel.gov/docs/legosti/fy98/24772.pdf $>$ [Retrieved: June 2004].

Tashtoush G.M., Al-Widyan M.I., and M.M. Al Jarrah. 2000. "Experimental study on evaluation and optimization of conversion of waste animal fat into biodiesel." Energy Conversion and Management 45: 2697-2711.

Tyson S. K. 2001. "Biodiesel Handling and Use Guidelines." NREL/TP-580-30004. U.S. Department of Energy National Renewable Energy Laboratory .Golden, Colorado Available from: <www.eere.energy.gov/biomass/pdfs/biodiesel > [Retrieved: June $1^{\text {st }}$ 2004].

Tyson S. K., (Ed) Hamilton, J., J. Jones., J. Stepan. 1998. "Biodiesel Research Progress 19921997." Dyncorp Information \& Engineering Technology." April 1998 · NREL/TP-580-24433. U.S. Department of Energy National Renewable Energy Laboratory .Golden, Colorado Available from: <www.eere.energy.gov/biomass/pdfs/biodiesel> [Retrieved: June $1^{\text {st }} 2004$ ].

United States House of Representatives. 2005. Energy Policy Act. Available from:

$<$ www.house.gov/rules/text_6cr.pdf $>$ [Retrieved on July 2005].

Van Gerpen, J. 2004. "2004 Biodiesel Handling and Use Guidelines”. NREL/SR-510-36240. US Department of Energy Efficiency and Renewable Energy. National Renewable Energy Laboratory Available from: $<$ http://www.nrel.gov/vehiclesandfuels/npbf/feature guidelines.html $>$ [Retrieved February 2005]. 
Zhang X. , Peterson C. L., Reece D., Möller G. and R. Haws. 1995. "Biodegradability of Biodiesel in the Aquatic Environment." Available from:

$<$ http://www.biodiesel.org/resources/reportsdatabase/reports/mar/19950601_mar-009.pdf $>$ [Retrieved October 2004].

Zhang Y., Dub M.A., McLean D.D. and M. Kates. 2003. "Biodiesel production from waste cooking oil: Economic assessment and sensitivity analysis." Bioresource Technology 90: 229240. 


\section{BIBLIOGRAPHY}

Agriculture and Agri-Food Canada. January 2002. "An Economic Analysis of a Major Bio-Fuel Program Undertaken By OECD Countries." Available from: $<$ http://www.agr.gc.ca/spb/raddra/publications/econan/econan_e.php $>$ [Retrieved on July 2005].

Ahouissoussi, N.B.C and M.E. Wetzstein. 1997. "A comparative cost analysis of biodiesel, compressed natural gas, methanol, and diesel for transit bus systems." Resource and Energy Economics 20: 1-15.

Altin, R., Cetinkaya S., and H.S. Yücesu. 2001."The potential of using vegetable oil fuels as fuel for diesel engines." Energy Conversion and Management 42: 529-538.

Anderson, R.L. and P. Shubat. 1984. "Toxicity of Flucytrinate to Gammarus lacstris (Amphipoda), Pteronarcys dorsata (Plecoptera) and Brachycentrus americanus (Trichoptera): Importance of Exposure Duration." Environmental Pollution (Series A) 35: 353-365.

Andréasson M. and G. Dave. 1995. "Toxicity of Bile from Fish exposed to PentachlorophenolSpiked Sediment." Marine Environmental Research 39: 335-339.

Barnwal B.K. and M.P. Sharma. 2005. "Prospects of biodiesel production from vegetable oils in India;" Renewable and Sustainable Energy Reviews 9: 363-378.

Bender M. 1999. "Economic feasibility review for community-scale farmer cooperatives for biodiesel." Bioresource Technology 70: 81- 87.

Beitinger T. L. and D. W. Huey. 1981. "Acute Toxicity of Nitrite to Crayfish Procambar Us Simulans in Varied Environmental Conditions." Environmental Pollution (Series A) 7.6: 305311.

Bernd F. and G. Reinhardt. 1998. "Environmental Impacts of Biodiesel Use" Bioenergy 1998: Expanding Bioenergy Partnerships. Available from:

$<$ http://www.biodiesel.org/resources/reportsdatabase/reports/gen/19981001_gen-110.pdf $>$

[Retrieved: May 2004].

Bhattacharyya S., Klerks P.L., and J.A. Nyman. 2003. "Toxicity to freshwater organisms from oils and oil spill chemical treatments in laboratory microcosms." Environmental Pollution 122: 205-215.

Biswas S., Chaudhari S. K. and S. Mukherji. 2005. "Microbial uptake of diesel oil sorbed on soil and oil spill clean-up sorbents." J Chem. Technol. Biotechnol. 80:587-593.

Borgelt, S.C., Kolb T. S. and L. G. Schumacher. (1994). "Biodiesel: World Status". Proceedings of an Alternative Energy Conference, American Society of Agricultural Engineers Summer Meeting. Kansas City, MO. 
Çağlan A. Benlü K. and G. Köksal. 2005."The Acute Toxicity of Ammonia on Tilapia (Oreochromis niloticus) Larvae and Fingerlings." Turk J Vet Anim Sci 29: 339-344.

Chandler, K., Malcosky N., Kelly K., P. Norton et al. 1996. "Alternative Fuel Transit Bus Evaluation Program Results". International Spring Fuels and Lubricant Meeting. Dearborn, MI. SAE Paper No. 961082. National Transportation Library. Available from: $<$ http://ntl.bts.gov $>$ [Retrieved June 2004].

Chung-Min L., and L. Ming-Chao. 2001. "Acute Toxicity Modeling of Rainbow Trout and Silver Sea Bream Exposed to Waterborne Metals". Environ Toxicol. 16 (4):349-60.

Crane M. and M. C. Newman. 2000 "What Level of Effect Is a No Observed Effect?" Environmental Toxicology and Chemistry 19 (2) 516-519.

Cripps G. C. and J. Shears. 1997. "The Fate in the Marine Environment of a Minor Diesel Fuel Spill from an Antarctic Research Station". Environmental Monitoring and Assessment 46: 221232.

Davis H.K., Moffat C.F. and N.J. Shepherd. 2002."Experimental Tainting of Marine Fish by Three Chemically Dispersed Petroleum Products, with Comparisons to the Braer Oil Spill." Spill Science \& Technology Bulletin, 7 (5-6): 257-278.

Dede, E.B. and H.D. Kaglo. 2001. "Aqua-toxicological Effects of Water Soluble Fractions (WSF) Of Diesel Fuel On O. Niloticus Fingerlings." J. Appl. Sci Environ. Mgt. 5 (1): 93-96.

De Selincourt, K. (1993) “Europe's home grown fuel”. 1995. New Scientist. 140: 22-25.

Dmytryshyn S.L., Dalai A.K., S. T. Chaudhari et al. 2004. "Synthesis and characterization of vegetable oil derived esters: evaluation for their diesel additive properties." Bioresource Technology 92: 55-64.

Enguídanos M., Soria A., Kavalov B. and P. Jensen. May 2002. "Techno-economic analysis of Bio-diesel production in the EU: A short summary for decision-makers." Report EUR 20279 EN. European Union: Joint Research Centre, Institute for Prospective Studies. Available from:< http://www.europarl.eu.int/stoa/ta/renewable_energies/biomass/biodiesel(ipts).pdfs [Retrieved on June 2004].

ENN: Environmental News Network. 2005. "President Signs Energy Bill with Biodiesel Tax Incentive Extension; Numerous Other Pro-Biodiesel Measures Also Included." Available from: $<$ www.ENN.com $>$ [Retrieved August $9^{\text {th }}$ 2005].

Environment Canada. 1990. Biological Test Method: Acute Lethality Test Using Rainbow Trout. Environment Protection Series, Report EPS1/RM9, May 1996 Amendments. Environment Canada, Conservation and Protection, Ottawa. 
Environment Canada. 1990. Biological Test Method: Acute Lethality Test Using Daphnia spp. Environment Protection Series, Report EPS1/RM11, May 1996 Amendments. Environment Canada, Conservation and Protection, Ottawa.

Environment Canada. 1990. Guidance Document on Control of Toxicity Test Precision Using Reference Toxicants. Environment Protection Series, Report EPS1/RM12, August 1990. Environment Canada, Conservation and Protection, Ottawa.

Environment Canada. 2000. Biological Test Method: Reference Method for Determining Acute Lethality of Effluents to Rainbow Trout. Environment Protection Series, Report EPS1/RM13, December 2000. Environment Canada, Conservation and Protection, Ottawa.

Environment Canada. 2000. Biological Test Method: Reference Method for Determining Acute Lethality of Effluents to Daphnia magna. Environment Protection Series, Report EPS1/RM14, December 2000. Environment Canada, Conservation and Protection, Ottawa.

EPA. 2002. "A Comprehensive Analysis of Biodiesel Impacts on Exhaust Emissions - Draft Technical Report". Assessment and Standards Division, Office of Transportation and Air Quality, U.S. Environmental Protection Agency. EPA420-P-02-001 (2002).

Available from: $<$ http://www.epa.gov/otaq/models/analysis/biodsl/p02001.pdf $>$ [Retrieved: May 2004].

EPA. 2002. "Methods for Measuring the Acute Toxicity of Effluents and Receiving Waters to Freshwater and Marine Organisms". Fifth Edition. October 2002.

Etkin, D.S. 2004. "Twenty-year Trend Analysis of Oil Spills in EPA Jurisdiction." Freshwater Spills Symposium 2004. Available from:< http://www.epa.gov/oilspill/pdfs/etkin_04.pdf

Farrell A. P., Gamperl A. K., Hicks J.M.T., H. A. Shiels et al. 1996. "Maximum Cardiac Performance of Rainbow Trout (Oncorhynchus mykiss) At Temperatures Approaching Their Upper Lethal Limit." The Journal of Experimental Biology 199: 663-672.

Feng M., Liu C., Xu J. and Q. Xu. 1998. "Modeling and Biological Implication of Time-DoseMortality Data for the Entomophthoralean Fungus, Zoophthora anhuiensis, on the Green Peach Aphid Myzus persicae" Journal of Invertebrate Pathology 72: 246-251.

Galleger, P. W., Shapouri H., Price J. and G. Schamel. 2003. "Some long-run effects of growing markets and renewable fuel standards on additives markets and the US ethanol industry". Journal of Policy Modelling 25 (617): 585-609.

Gulec I. and D. A. Holdway. 1999. "The Toxicity Of Laboratory Burned Oil To The Amphipod Allorchestes Compressa And The Snail Polinices Conicus." Spill Science \& Technology Bulletin 5 ( 2):135-139.

Haas, M. J. 2005"Improving the economics of biodiesel production through the use of low value lipids as feedstocks: vegetable oil soapstock." Fuel Processing Technology 86: 1087- 1096. 
Hamilton, M.A., Russo R. C. and R.V. Thurston. 1977. "Trimmed Spearman-Karber method for estimating median lethal concentrations in toxicity bioassays." Environ. Sci. Technol. 11:714718.

Hamoutene D., Payne J.F., Rahimtula A. and K. Lee. 2004. "Effect of Water Soluble Fractions of Diesel and an Oil Spill Dispersant (Corexit 9527) on Immune Responses in Mussels." Bull. Environ. Contam. Toxicol. 72:1260-1267.

Holbein B.E., Stephen J. D. and D. B. Layzell. 2005. "Canadian Biodiesel Initiative: Aligning Research Needs and Priorities with the Emerging Industry-Final Report." Available from: $<\underline{\text { http: }: / \text { www.biocap.ca }}>$ [Retrieved August 2005].

Gustafson, C. R. "Biodiesel: An Industry Poised for Growth?" 2003. Choices .American Agricultural Economics Association. Third Quarter 2003. Available from: $<$ http://www.choicesmagazine.org > [Retrieved August 2005].

Kalam M.A. and H.H. Masjuki. 2002. "Biodiesel from palmoil-an analysis of its properties and potential." Biomass and Bioenergy 23: $471-479$.

Keller, A.E., Ruessler D.S., Chafee C.M. 1998. "Testing the toxicity of sediments contaminated with diesel fuel using glochidia and juvenile mussels (Bivalvia, Unionidae)." Aquatic Ecosystem Health and Management. 1(1): 37-47.

Kinast J.A. 2003. "Production of Biodiesel from Multiple Feedstocks and Properties of Biodiesel and Biodiesel/Diesel Blends Final Report: Report 1 in a series of 6." NREL/SR-51031460. National Renewable Energy Laboratory. Golden, Colorado. Available from: $<$ http://www.nrel.gov/docs/fy03osti/31460.pdf [Retrieved February 2005].

Knothe G., Dunn R.O. and M. O. Bagby. "Biodiesel: The Use of Vegetable Oils and Their Derivatives as Alternative Diesel Fuels." Oil Chemical Research. U.S. Department of Agriculture. Peoria, IL. Available from:

$<$ http://journeytoforever.org/biofuel_library/VegetableOilsKnothe.pdf $>$ [Retrieved February 2005].

Koyama J. and A. Kakuno. 2004. "Toxicity of heavy fuel oil, dispersant, and oil-dispersant mixtures to a marine fish, Pagrus major." Fisheries Science 70: 587-594. ticle587594BEES Körbitz W. 1999. "Biodiesel Production in Europe and North America, An Encouraging Prospect." Renewable Energy 16:1078-1083.

Kooijman, S.A.L.M and J.J.M. Bedaux. 1996. "Analysis of Toxicity Test on Daphnia Survival and Reproduction." 1996 Wat. Res. 30 (7): 1711-1723.

Lee, G., Ellersieck N.R., Mayer F.L., and G. F. Krause. 1995. "Prediction Chronic Lethality of Chemicals to Fishes from Acute Toxicity Test Date: Multi-Probit Analysis." Environmental Toxicology and Chemistry 14 (2):345-349. 
Lenwood W. H. Jr., Anderson R. D. and J. V. Kilian. 1997. "Acute And Chronic Toxicity Of Copper To The Estuarine Copepod Eurytemora Affinis: Influence Of Organic Complexation And Speciation." Chemosphere, 35 (7):1567-1597.

Li, J and C. Filteau. 2005. "2005 Oil Spill Analysis Report for Ontario. Department of Civil Engineering. Ryerson University(September, 2005).

Liao, C. M. and M.C. Lin. 2001. "Acute Toxicity Modelling of Rainbow Trout and Silver Sea Bream Exposed to Waterborne Metals." Environmental Toxicology 16 (4): 349-60.

Lytle, D. A. and B. L. Peckarsky. 2001. "Spatial and temporal impacts of a diesel fuel spill On stream invertebrates." Freshwater Biology 46:693-704.

Long S. M., and D. A. Holdway. 2002. "Acute toxicity of crude and dispersed oil to Octopus pallidus hatchlings." Water Research 36: 2769-2776.

Marr J.C.A., Lipton J. and D. Cacela et al. 1999. "Bioavailability and acute toxicity of copper to rainbow trout (Oncorhynchus mykiss) in the presence of organic acids simulating natural dissolved organic carbon." Can. J. Fish. Aquat. Sci. 56: 1471-1483.

Marr J.C.A., Hansen J.A., Meyer J.S. and D. Cacela et al. 1998. "Toxicity of cobalt and copper to rainbow trout: application of a mechanistic model for predicting survival." Aquatic Toxicology 43: $225-238$.

Magaud, H. B. Migeon, P. Morfin, J. Garric and E. Vindimian. 1997. "Modelling Fish Mortality due to urban storm run-off: interaction effects of Hypoxia and un-ionized Ammonia." Wat. Res. 31 (2): 211-218.

McCaya D.F, Rowea J. J., Whittier N., Sankaranarayanan S. and D.S. Etkin. 2004.; "Estimation of potential impacts and natural resource damages of oil." Journal of Hazardous Materials 107:11-25.

McCormick R.L, Graboski M.S., T.L. Alleman, and A.M Herring. 2001. "Impact of Biodiesel Source Material and Chemical Structure on Emissions of Criteria Pollutants from a heavy-duty engine." Environmental Science Technology 35 (9): 1742-1747.

Meyer, J.S. Gulley D.D. and M.S Goodrich et al. 1995. "Modeling Toxicity due to intermittent exposure of rainbow trout and common shiners to monochloramine" Environmental Toxicology 14 (1): $165-175$.

Miller, N.J and S.T Mudge. 1997. "The effect of biodiesel on the rate of removal and weathering characteristic of crude oil within artificial sand columns." Spill Science and Technology Bulletin $4(1): 17-33$. 
Mohammed, A. 2005. "Toxicity of water-soluble fractions of four fuels for Metamysidopsis insularis, an indigenous tropical mysid species." Environmental Monitoring and Assessment 104: $37-44$.

Mudge. S.M. "Deleterious Effects from Accidental Spillages of Vegetable Oils." 1995. Spill Science and Technology Bulletin 2 (2/3): 187-191.

Mudge S. M. and G. Pereira. (1999). "Stimulating the Biodegradation of Crude Oil with Biodiesel Preliminary Results." Spill Science \& Technology Bulletin 5 (5/6): 353- 355.

Mushrush, G.W., Wynne, J.H., Willauer H.D. and C.T. Lloyd et al. 2004. "Recycled Soybean Cooking Oils as Blending Stocks for Diesel fuels." Ind. Eng. Chem.Res. 43 (16): 4944-4946.

Nowierski R. M., Zeng Z., Jaronski S., Delgado F. and W. Swearingen. 1996. “Analysis and Modeling of Time-Dose-Mortality of Melanoplus sanguinipes, Locusta migratoria migratorioides, and Schistocerca gregaria (Orthoptera: Acrididae) from Beauveria, Metarhizium, and Paecilomyces Isolates from Madagascar." Journal Of Invertebrate Pathology 67, no.39: 236-252.

Ohwada K., Nishimura M., Wada M. and H. Nomura et al. 2003. "Study of the effect of watersoluble fractions of heavy-oil on coastal marine organisms using enclosed ecosystems, mesocosms." Marine Pollution Bulletin 47: 78-84.

Omoregie E. "Acute Toxicity of Water Soluble Fractions of Crude Oil to the Nile Tilapia, Oreochromis niloticus (L.). 2002." Bull. Environ. Contam. Toxicol. 68:623-629.

Paixão S. M., Mendonça E., Picado A. and A. M, Anselmo. 1999. "Acute toxicity evaluation of olive oil mill. Wastewaters: a comparative study of three Aquatic organisms." Environmental Toxicology 14 (2): 263-269.

Pereira M. G. and S. M. Mudge. 2004. "Cleaning oiled shores: laboratory experiments testing the potential use of vegetable oil biodiesels." Chemosphere 54: 297-30.

Pereira M. G., Mudge S. M. and J. Latchford. 2002. "Consequences of linseed oil spills in salt marsh sediments." Marine Pollution Bulletin 44: 520-533.

Pereira M.G., Mudge S. M. and J. Latchford. 2003. "Vegetable oil spills on salt marsh sediments; comparison between sunflower and linseed oils." Marine Environmental Research 56: $367-385$.

Pereira M. G., and S. M. Mudge. 2004. "Cleaning oiled shores: laboratory experiments testing the potential use of vegetable oil biodiesels." Chemosphere 54: 297-304.

Pimentel, D., M. Herz, M. Glickstein and M. Zimmerman. 2002. "Renewable Energy: Current and Potential Issues". Bioscience 52 (12): 1111-1121. 
Polat H, Ünlü Erkoc F., Rukiye V. and O. Koçak. 2002. "Investigation of acute toxicity of betacypermethrin on guppies Poecilia reticulate." Chemosphere 49: 39-44.

Prakash . C. B. "A Critical Review Of Biodiesel As A Transportation Fuel in Canada." 1998. Environment Canada. Transportation Systems Branch Air Pollution Prevention Directorate. Available from: < http://www.ec.gc.ca/transport/publications/biodiesel/biodeisel.pdf? [Retrieved May 2005].

Prankl H., M. Wörgetter, and B.L.T Wieselburg. March 2000. "The Introduction of Biodiesel as a Blending Component to Diesel Fuel in Austria Final Report of NTB-net Phase IV" Federal Institute of Agricultural Engineering, Austria. Available from:

$<$ http://www.blt.bmlf.gv.at $>$ [Retrieved: May 2004].

Preisler, H. K. and J. L. Robertson. 1989. "Analysis of time-dose- mortality data." J. Econ. Entomol. 82: 1534-1542.

Puppán D. Environmental Evaluation of Biofuels. 2002. Periodica Polytechnica Ser. Man. Sci. 10 (1): 95-116.

Radich, A. "Biodiesel Performance, Costs, and Use." US Energy Information Administration

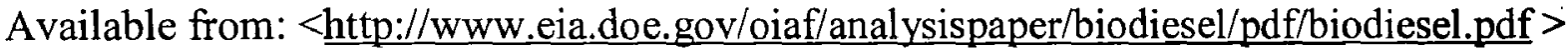
[Retrieved July 2005]

Raneses A.R., Glaser L.K., Price J.M. and J.A. Duffield. 1999. "Potential Biodiesel Markets and Their Economic Effects on the Agricultural Sector of the United States." Journal of Industrial Crops and Products 9 (2): 151-162.

Rhodes J.E., Adams W.J., Biddinger G.R. and K.A. Robillard et al. 1995. "Chronic Toxicity of 14 phthalate esters to Daphnia magna and rainbow trout (Oncorhynchus mykiss)." Environmental Toxicology and Chemistry 14 (11): 1967-1976.

Rideout, G. (2004). "Biodiesel: the what, how, where, and why, of the Canadian use of this 'new' fuel". Air and Wastewater Management Association-Ottawa Valley Chapter May $26^{\text {th }}$ 2004.

Rose, J. 1994. "Biofuel benefits questioned". Environmental Science and Technology 28:63.

Rosen, M.A. (2002). "Case Study on Industrial Ecology". Chapter of Encyclopedia of Life Support Systems, EOLSS Publishers, Oxford, U.K. (in press).

Rukiye V., Ünlü Erkoc F. Polat H., and O Koçak. 2003. "Investigation of acute toxicity of deltamethrin on guppies (Poecilia reticulata)." Ecotoxicology and Environmental Safety 55: 8285. 
Sagrans M., 1998. "The Regulation of Biodiesel and Biodiesel Feedstocks in Aquatic Environments." Available from: <www.biodiesel.org/resources/reportsdatabase/ reports/mar/19980601_mar-004.pdf $>$ [Retrieved June 2005].

Schumacher, L. G., Weber, J. A. and J. G. Krahl. 1995. "An Alternative Fuel for Urban BusesBiodiesel Blends". Proceedings of the Second Biomass Conference of the Americas. Portland, OR.

Schumacher, L G. 1995. "Biodiesel Emissions Data from Series 60 DDC Engines". American Public Transit Association Bus Operations and Technology Conference. Reno, NV.

Schumacher, L. and J. Van Gerpen. 1996. "Research Needs Resulting from Experiences of Fuelling Engines with Biodiesel". Proceedings of the Third Liquid Fuel Conference. Nashville, TN.

Schumacher, L.G, S.C. Borgelt, and W.G. Hires. 1995. "Fuelling a Diesel Engine with Methylester Soybean Oil". Applied Engineering In Agriculture. Vol. 11(1):37-40.

Schumacher, L G., Weber, J. A, and J. G. Krahl, 1995. "Maintenance, Repair, and Engine Exhaust Emissions Associated with Biodiesel Fuelling of Urban Buses". Proceedings of the American Society of Agricultural Engineers Summer Meeting. Chicago, IL. ASAE Paper No. 956736.

Schumacher, L. G., J. A. Weber, and M. D. Russell. 1994. "Fuelling Urban Buses with Soydiesel-Diesel Fuel Blending". Bioenergy '94- Using Biofuels for a Better EnvironmentProceedings of the Sixth National Bioenergy Conference. Reno/Sparks, NV.

Schumacher, L. G., S. Howell. 1994."Lubricating Qualities of Biodiesel and Biodiesel Blends". Bioenergy 1994- Using Biofuels for a Better Environment-Proceedings of the Sixth National Bioenergy Conference. Reno/Sparks, NV.

Schumacher, L. G., S.C. Borgelt, and W.G. Hires. 1993. "Fuelling Diesel Engines with Blends of Methyl Ester Soybean Oil and Diesel Fuel". Proceedings of a Conference on Biodiesel. Sioux Falls, SD.

Schumacher, L.G, S.C. Borgelt, and W.G. Hires. 1995. "Fuelling a Diesel Engine with Methylester Soybean Oil". Applied Engineering In Agriculture. 11(1):37-40.

Schumacher, L. G., Hires, W. G. and S.C. Borgelt. 1992. "Fuelling a Diesel Engine with MethylEster Soybean Oil". Proceedings of an Alternative Energy Conference American Society of Agricultural Engineers Winter Meeting. Nashville, TN.

Schumacher, L.G. and J.V. Gerpen. 2000. "Engine Oil Analysis of Diesel Engines Fuelled with 0, 1, 2, and 100 Percent Biodiesel". Proceedings of the American Society of Agricultural Engineers International Meeting. Milwaukee, WI. ASAE Paper No. 006010. 
Schumacher, L.G. and T. Madzura. 1997. "Lessons Learned While Fuelling With Biodiesel". Proceedings of Commercialization of Biodiesel: Producing a Quality Fuel. Boise, ID.

Sergio, U. 2003." A Comprehensive Energy and Economic Assessment of Biofuels: When 'green' is not enough". Critical Reviews in Plant Sciences. 20 (1): 71-106.

Sheehan, J., V. Camobreco, J. Duffield, J, M. Graboski and H. Shapouri. .1998. "An Overview of Biodiesel and Petroleum Diesel Life Cycles." NREL/SR-580-24089 UC Category 1503. U.S Department of Agriculture and U.S. Department of Energy: National Renewable Energy Laboratory, Golden, CO. Available from: < http://www.nrel.gov/docs/legosti/fy98/24772.pdfs [Retrieved: June 2004].

Smith S. D. A. and R. D. Simpson. 1998. "Recovery of benthic communities at Macquarie Island (sub-Antarctic) following a small oil spill." Marine Biology 131: 567-581.

Srivastava A., and R. Prasad.2000. "Triglycerides-based diesel fuels." Renewable and Sustainable Energy Reviews 4: 111-133.

Stevens D.J, Hogan E., Östman A., Segerborg-Fick A. and M Wörgetter. (November 2001). "Non-technical policy, regulatory, and market influences on the use of liquid biofuel-Final Summary Report". Available from: $<$ www.ieabioenergy.com/library $/ 139$ ieaarweb.pdf $>$ [Retrieved: May 2004].

Sun K., Krause G. F., Mayer Jr. F.L., Ellersieck M.R. and A. P. Basu. 1995."Predicting Chronic Lethality of Chemicals to Fishes from Acute Toxicity Test Data: Theory of Accelerated Life Testing." Environmental Toxicology and Chemistry 14 (10): 1745-1752.

Svecevičius G. 2001."Avoidance Response of Rainbow Trout Oncorhynchus mykiss to Heavy Metal Model Mixtures: A Comparison with Acute Toxicity Tests." Bull. Environ. Contam. Toxicol. 67:680-687.

Tashtoush G.M., Al-Widyan M.I., and M.M. Al Jarrah. 2000. "Experimental study on evaluation and optimization of conversion of waste animal fat into biodiesel." Energy Conversion and Management 45: 2697-2711.

Thomsen L. and J. Eilenberg. 2000. "Time-Concentration Mortality of Pieris brassicae (Lepidoptera: Pieridae) and Agrotis segetum (Lepidoptera: Noctuidae) Larvae from Different Destruxins." Environ. Entomol. 29 (5): 1041-1047.

Tyson S. K. 2001. "Biodiesel Handling and Use Guidelines." NREL/TP-580-30004. U.S. Department of Energy National Renewable Energy Laboratory .Golden, Colorado Available from: <www.eere.energy.gov/biomass/pdfs/biodiesel> [Retrieved: June ${ }^{\text {st }}$ 2004].

Tyson S. K., (Ed) Hamilton, J., J. Jones., J. Stepan. April 1998. "Biodiesel Research Progress 1992-1997." Dyncorp Information \& Engineering Technology." April 1998 - NREL/TP-58024433. U.S. Department of Energy National Renewable Energy Laboratory .Golden, Colorado 
Available from: <www.eere.energy.gov/biomass/pdfs/biodiesel $>$ [Retrieved: June $1^{\text {st }}$ 2004].

USEPA. 2005. Statistical Analysis for Biological Methods. Available from:

$<$ http://www.epa.gov/nerleerd/stat2.htm $>$ [Retrieved on: February 2005].

United States House of Representatives. 2005. Energy Policy Act. Available from:

$<$ www.house.gov/rules/text_6cr.pdf $>$ [Retrieved on July 2005].

Van Dyne, D. L., Weber J.A. and C.H. Braschler. 1996. "Macroeconomic Effects of a community-based biodiesel production system." Bioresource Technology 56: 1-6.

Van Gerpen, J. 2004. "2004 Biodiesel Handling and Use Guidelines.” NREL/SR-510-36240. US Department of Energy Efficiency and Renewable Energy. National Renewable Energy Laboratory Available from:<

http://www.nrel.gov/vehiclesandfuels/npbf/feature_guidelines.html> [Retrieved February 2005].

Waller D. L., Rach J. J., Cope W. G., and L. L. Marking. 1993.“Toxicity of Candidate Molluscicides to Zebra Mussels (Dreissena polymorpha) and Selected Nontarget Organisms." J. Great Lakes Res. 19 (4):695-702

Wörgetter, M and B.L.T Wieselburg. (2000). "Biodiesel and Environment" Liquid BiofuelsTask 27 IEA Energy. Federal Institute of Agricultural Engineering. Prepared for IEA Bioenergy Agreement IEA Bioenergy Task 27, Liquid Biofuels. Available from: $<$ http://www.liquidbiofuels.com/FinalReport2.html\#Tables> [Retrieved: February 2004].

$\mathrm{Xu}, \mathrm{J}$. and M. Feng. 2000. "The Time-Dose-Mortality Modeling and Virulence Indices for Two Entomophthoralean Species, Pandora delphacis and P. neoaphidis, against the Green Peach Aphid, Myzus persicae."Biological Control 17: 29-34.

Yen J., Lin K. H., and Y. Wang. 2002. "Acute Lethal Toxicity of Environmental Pollutants to Aquatic Organisms." Ecotoxicology and Environmental Safety 52: 113-116

Zhang J.F., Wang X.R., H .Y. Guo, et al. 2004. "Effects of water-soluble fractions of diesel oil on the antioxidant defenses of the goldfish, Carassius auratus." Ecotoxicology and Environmental Safety 58: 110-116.

Zhang X., Peterson C. L., Reece D., Möller G. and R. Haws. 1995. "Biodegradability of Biodiesel in the Aquatic Environment." Available from:

$<$ http://www.biodiesel.org/resources/reportsdatabase/reports/mar/19950601 mar-009.pdf $>$ [Retrieved October 2004]

Zhang Y., Dub M.A., McLean D.D. and M. Kates. 2003. "Biodiesel production from waste cooking oil: Economic assessment and sensitivity analysis." Bioresource Technology 90: 229240. 
9. APPENDIX A: Experimental Parameters 


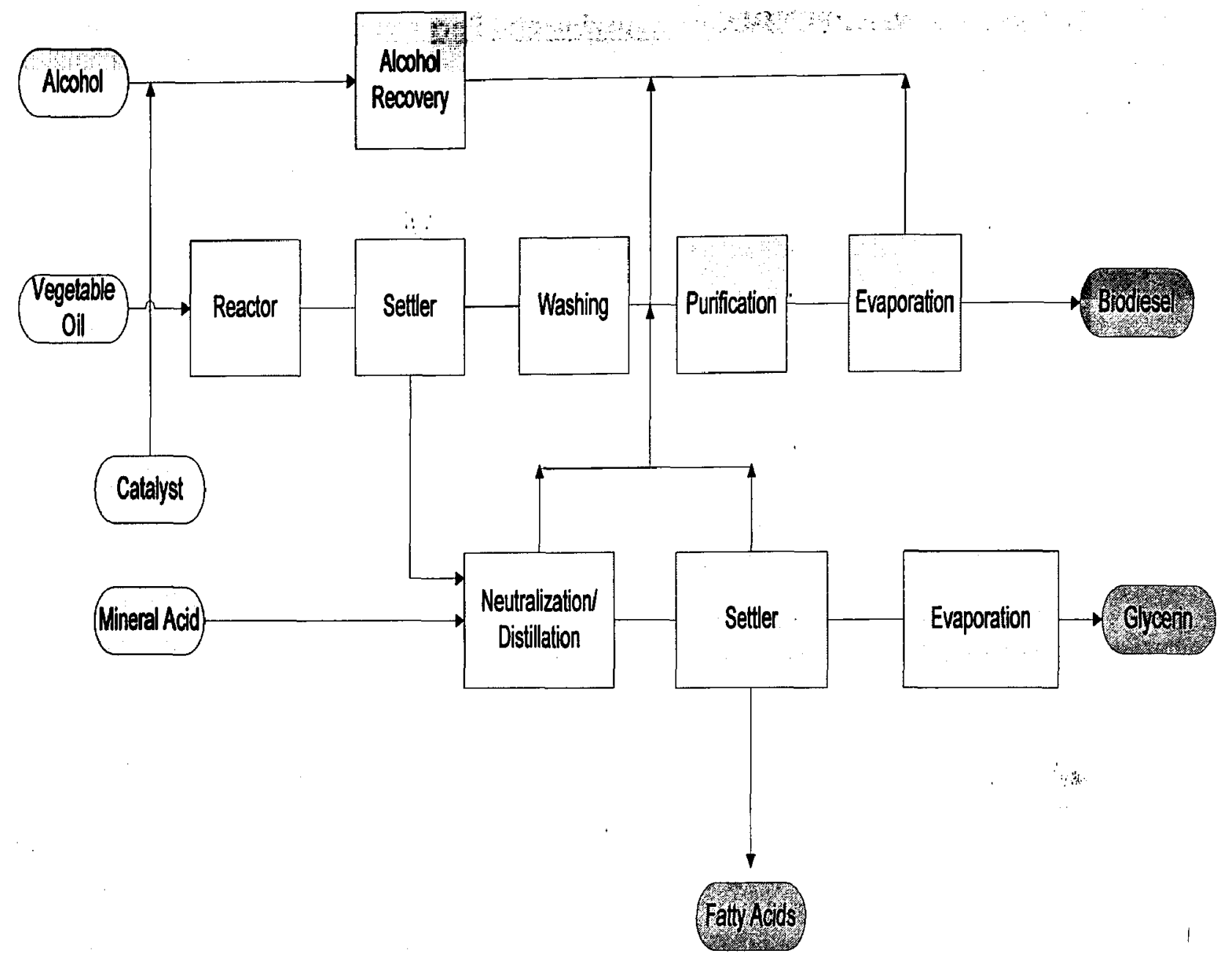

Figure 1: A Simplified Biodiesel Process Technology

Source: Puppán D., 2002. Environmental Evaluation of Biofuels 
TABLE 1

TEST CONDITIONS AND TEST ACCEPTABILITY CRITERIA FOR DAPHNLA

MAGNA ACUTE TOXICITY WITH EFFLUENTS

\begin{tabular}{l|l}
\hline & Static \\
Test type & $48 \mathrm{hr}$ \\
Test duration & $20 \pm 1 \mathrm{C}$ \\
Temperature & Ambient laboratory illumination \\
Light Quality & Ambient laboratory levels \\
Light Intensity & $16 \mathrm{~h} \mathrm{light,} 8 \mathrm{hr}$ darkness \\
Photoperiod & $30 \mathrm{ml}$ \\
Test Chamber Size & $25 \mathrm{ml}$ \\
Test Chamber Volume & Not Required \\
Renewal of Test Solutions & less than $24 \mathrm{hr}$ old \\
Age of Test Organisms & 5 \\
No. of Organisms per Test Chamber & 4 \\
No. of Replicate Chambers per Concentration & 20 \\
No. of organisms per Concentration & Feeding not required \\
Feeding Regime & Cleaning not required \\
Test Chamber Cleaning & None \\
Test Chamber Aeration & DDI water. \\
Dilution Water & 6 and control \\
Test Concentrations & mortality \\
Endpoint & $90 \%$ or greater survival in controls \\
Test Acceptability Criterion &
\end{tabular}


TABLE 2

TEST CONDITIONS AND TEST ACCEPTABILITY CRITERIA FOR RAINBOW TROUT, ONCORHYNCHUS MYKISS ACUTE TOXICITY WITH EFFLUENTS

\begin{tabular}{l|l}
\hline & \\
Test Type & Static \\
Test Duration & $96 \mathrm{hr}$ \\
Temperature & $12 \pm 1 \mathrm{C}$ \\
Light Quality & Ambient laboratory illumination \\
Light Intensity & Ambient laboratory levels \\
Photoperiod & $16 \mathrm{~h}$ light, 8 hr darkness.. \\
Test Chamber Size & $5 \mathrm{~L}$ \\
Test Chamber Volume & $4 \mathrm{~L}$ \\
Renewal of Test Solution & Not Required \\
Age of Test Organisms & $45-60$ days \\
No. of Organisms per Test Chamber & 10 \\
No. of Replicate Chambers per Concentration & 2 \\
No. of Organisms per Concentration & 20 \\
Feeding Regime & Feeding not required \\
Test Chamber Cleaning & Cleaning not required \\
Test Chamber Aeration & None \\
Dilution Water & DDI water \\
Test Concentrations & 5 and control \\
Endpoint & Mortality \\
Test Acceptability Criterion & $90 \%$ or greater survival in controls \\
\hline
\end{tabular}




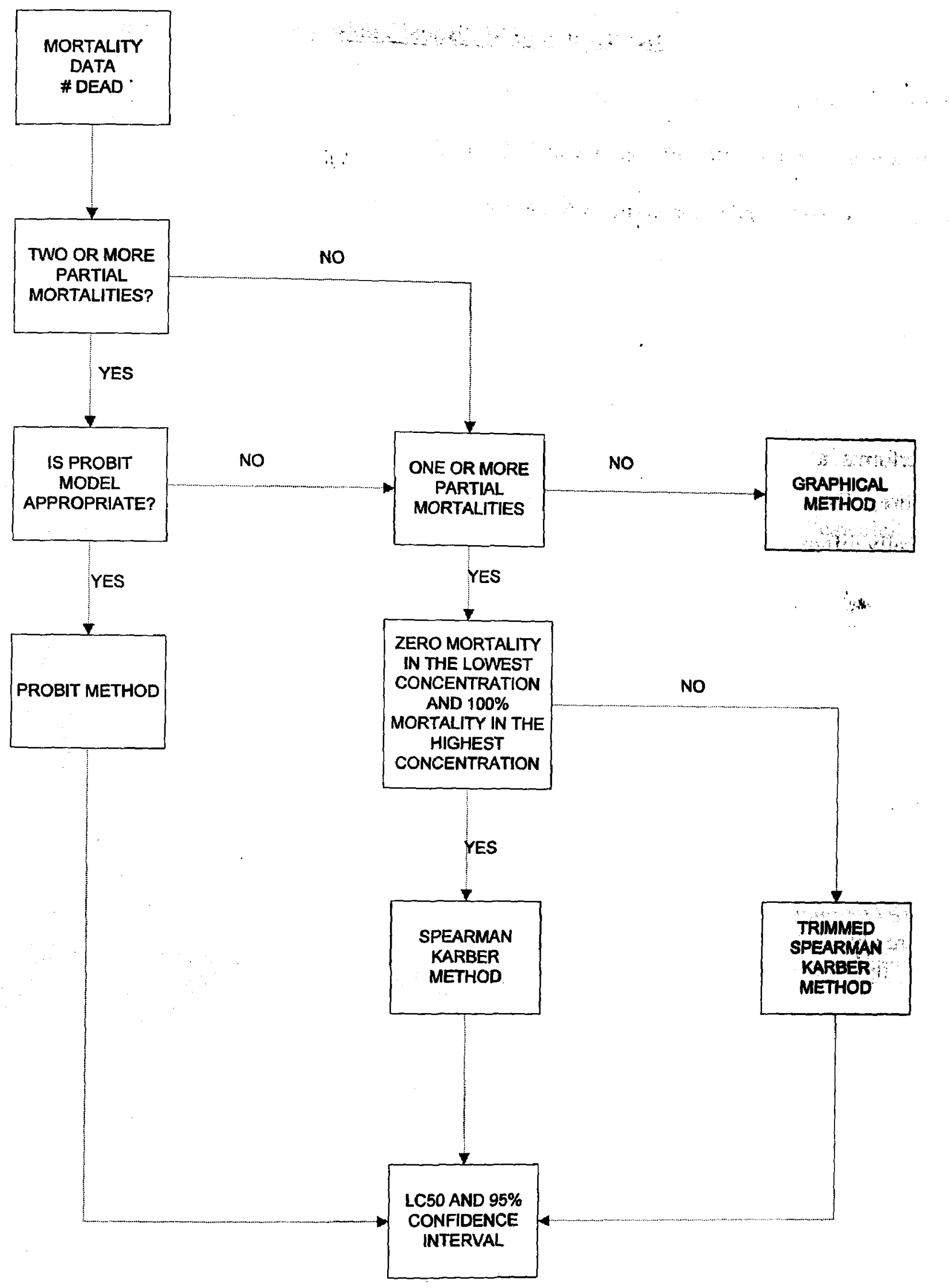

Figure 2: Flowchart for determination of LC50 for multi-toxin concentration acute toxicity tests. 


\section{Description of Statistical Tools}

\section{Dunnett Procedure}

The computer program obtained from the U.S. EPA. The program was designed for the analysis of data from acute and short-term chronic toxicity tests with fish and other aquatic life, performed with effluents, receiving waters and reference toxicants. The software:

A. Performs an analysis of variance (ANOVA), which is used to obtain the error value for Dunnett's Procedure.

B. Performs a multiple comparison of treatment means with the control mean (Dunnett's Procedure). Dunnett's Procedure indicates which toxicant concentration means (if any) are statistically different from the control mean at the $5 \%$ level of significance.

C. Calculates the minimum difference between the control and treatment means that could be detected as statistically significant, and test the validity of the homogeneity of variance assumption using Bartlett's Test.

Source:

EPA. 2002. "Methods for Measuring the Acute Toxicity of Effluents and Receiving Waters to Freshwater and Marine Organisms". Fifth Edition. October 2002.

Software Obtained from

Software obtained from: USEPA. 2005. Statistical Analysis for Biological Methods. Available from: $<$ http://www.epa.gov/nerleerd/stat2.htm $>$ [Accessed on: February, 2005]. 


\section{Trimmed Spearman Karber Method}

The program was designed for the analysis of mortality data from acute and chronic toxicity tests with fish and other aquatic life, performed with effluents, receiving waters, and reference toxicants. Data are input to the screen in an interactive mode. The program performs:

A. Checks the observed response proportions to determine if they are monotonically nondecreasing (i.e., the response proportion for each higher concentration of test substance is greater than or equal to the response at the previous, lower, concentration.

B. Calculates the smoothed response proportions, if necessary.

C. Automatically determines the minimum percent "trim" necessary for calculating the LC/EC50.

D. Calculates the LC/EC50 and confidence limits.

E. Provides output to the screen and printer.

Source:

Hamilton, M.A., Russo, R. C., and R.V. Thurston. 1977. "Trimmed Spearman-Karber Method for Estimating Median Lethal Concentration in Toxicity Bioassays." Environmental Science and Technology (11):714-719; Correction (1978), 12, pp. 417.

Software obtained from: USEPA. 2005. Statistical Analysis for Biological Methods. Available from: $<$ http://www.epa.gov/nerleerd/stat2.htm $>$ [Assessed December 2004]. 


\section{For Example:}

\section{Trimmed Spearman Karber Method}

k The number of concentrations

n(i) The number of individuals exposed at concentration $i, i=1, \ldots, k$

r(i) The number of individuals that responded at concentration $i, i=1, \ldots, k$

$p(i)=r(i) / n(i) \quad$ The proportion of individuals that responded at concentration $i, i=1, \ldots, k$

$x(i) \quad$ Natural log of concentration $i$

m Mean of the log tolerance distribution, i.e.. In of the LC50

Then $m=\sum_{i=1}^{K-1}(p(i)+p(i+1)(x(i)+x(i+1))$

if $p(l)=0.0$ and $p(k)=1.0$.

For example, consider the following test:

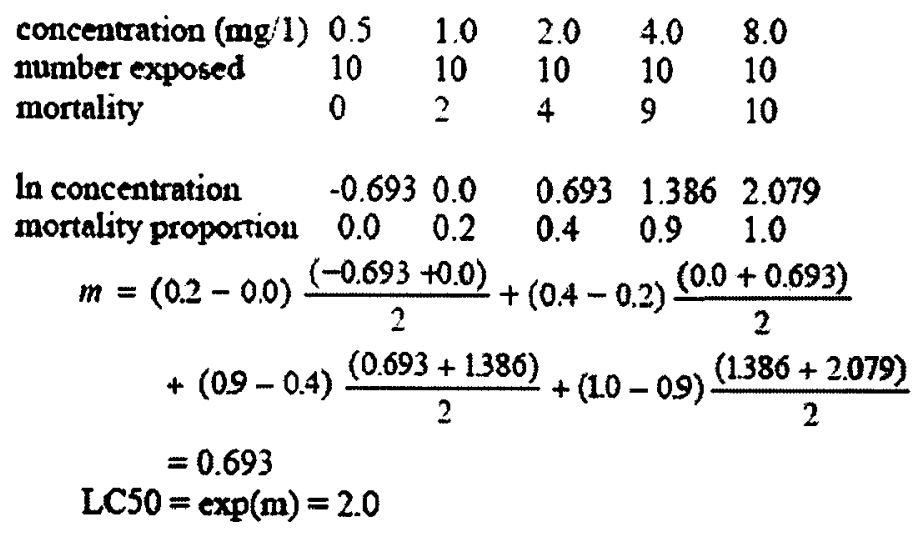




\section{TABLE 3}

\section{Dissolved Oxygen meter readings for different water samples}

\begin{tabular}{||l|c|c|c|c|c||}
\hline Water Type & Trial 1 & Trial 2 & Trial 3 & Trial 4 & Average \\
\hline DDI & $8.76^{*}$ & 8.75 & 8.85 & 8.93 & 8.82 \\
\hline $\begin{array}{l}\text { DDI with } \\
\mathrm{O}_{2}{ }^{* *}\end{array}$ & 9.14 & 9.10 & 8.93 & 9.11 & 9.07 \\
\hline DI & 8.85 & 8.88 & 8.89 & 8.90 & 8.88 \\
\hline DI with $\mathrm{O}_{2}$ & 8.65 & 8.77 & 8.97 & 8.81 & 8.79 \\
\hline Tapwater & 4.29 & 4.57 & 4.75 & 4.97 & \\
\hline $\begin{array}{l}\text { Tapwater } \\
\text { with } \mathrm{O}_{2}\end{array}$ & 8.29 & 8.44 & 8.63 & 8.67 & 4.65 \\
\hline Springwater & 8.72 & 8.58 & 8.46 & 8.76 & 8.63 \\
\hline $\begin{array}{l}\text { Springwater } \\
\text { with } \mathrm{O}_{2}\end{array}$ & 8.87 & 8.88 & 8.90 & 8.85 & 8.88 \\
\hline
\end{tabular}

* Readings in $\mathrm{mg} / \mathrm{L}$

** Aeration with Air Pump

DO Readings performed with DO Thermo Electron Corporation Lab DO Electrode Polargraphic $26.3^{\circ} \mathrm{C}$ at $102.5 \%$ saturation 


\section{REFERENCE TOXICANT}

D. magna

Sodium Chloride $(\mathrm{NaCl})$ used.

TABLE 4

Survival rate after $24 \mathrm{hrs}$

\begin{tabular}{|l|c|c|}
\hline Concentration & Trial 1 & Trial 2 \\
\hline $1.0 \mathrm{mg} / 1$ & 5 & 5 \\
\hline $3.0 \mathrm{mg} / \mathrm{l}$ & 5 & 4 \\
\hline $5.0 \mathrm{mg} / 1$ & 4 & 3 \\
\hline
\end{tabular}

* 5 organisms per test

O.mykiss

Potassium Chloride $(\mathrm{KCl})$ used.

TABLE 5

Survival rate after $24 \mathrm{hrs}$

\begin{tabular}{|l|c|c|}
\hline Concentration & Trial 1 & Trial 2 \\
\hline $3.0 \mathrm{mg} / 1$ & 5 & 5 \\
\hline $5.0 \mathrm{mg} / 1$ & 5 & 5 \\
\hline
\end{tabular}

*5 organisms per test 
10. APPENDIX B: D. Magna Bioassay Data 
TABLE 1

24hr RANGE FINDING TEST FOR DAPHNIA MAGNA

\begin{tabular}{|c|c|c|c|c|c|c|c|c|c|c|c|c|c|c|c|}
\hline \multirow[t]{2}{*}{$\begin{array}{c}\text { Concentration } \\
(\mathrm{ppm})\end{array}$} & \multicolumn{5}{|c|}{$\begin{array}{c}\text { Diesel } \\
\text { (\# Alive) }\end{array}$} & \multicolumn{5}{|c|}{$\begin{array}{c}\text { B100 } \\
\text { (\# Alive) }\end{array}$} & \multicolumn{5}{|c|}{$\begin{array}{c}\text { B20 } \\
\text { (\# Alive) }\end{array}$} \\
\hline & $\begin{array}{c}\text { Trial } \\
1\end{array}$ & $\begin{array}{l}\text { Trial } \\
2\end{array}$ & $\begin{array}{c}\text { Trial } \\
3 \\
\end{array}$ & $\begin{array}{c}\text { Trial } \\
4 \\
\end{array}$ & Ave. & $\begin{array}{c}\text { Trial } \\
1 \\
\end{array}$ & $\begin{array}{l}\text { Trial } \\
2 \\
\end{array}$ & $\begin{array}{c}\text { Trial } \\
3 \\
\end{array}$ & $\begin{array}{c}\text { Trial } \\
4 \\
\end{array}$ & Ave. & $\begin{array}{c}\text { Trial } \\
1\end{array}$ & $\begin{array}{l}\text { Trial } \\
2 \\
\end{array}$ & $\begin{array}{c}\text { Trial } \\
3 \\
\end{array}$ & $\begin{array}{c}\text { Trial } \\
4 \\
\end{array}$ & Ave. \\
\hline Control & 5 & 5 & 5 & 5 & 5 & 5 & 5 & 5 & 5 & 5 & 5 & 5 & 5 & 5 & 5 \\
\hline 35 & 0 & 0 & 0 & 0 & 0 & 3 & 1 & 3 & 2 & 2.25 & 2 & 1 & 3 & 2 & 2 \\
\hline 40 & 0 & 0 & 0 & 0 & 0 & 1 & 1 & 1 & 1 & 1 & 1 & 1 & 1 & 1 & 1 \\
\hline 50 & 0 & 0 & 0 & 0 & 0 & 0 & 0 & 0 & 0 & 0 & 0 & 0 & 0 & 0 & 0 \\
\hline 60 & 0 & 0 & 0 & 0 & 0 & 0 & 0 & 0 & 0 & 0 & 0 & 0 & 0 & 0 & 0 \\
\hline 80 & 0 & 0 & 0 & 0 & 0 & 0 & 0 & 0 & 0 & 0 & 0 & 0 & 0 & 0 & 0 \\
\hline 100 & 0 & 0 & 0 & 0 & 0 & 0 & 0 & 0 & 0 & 0 & 0 & 0 & 0 & 0 & 0 \\
\hline
\end{tabular}

*5 daphnids per trial 


\section{TABLE 2}

DAPHNIA MAGNA PARAMETER DATA

\begin{tabular}{|c|c|c|c|c|}
\hline TRIAL & $\begin{array}{l}\text { TEMPERATURE } \\
\left({ }^{\circ} \mathrm{C}\right)\end{array}$ & $\mathrm{PH}$ & $\begin{array}{l}\text { GENERAL } \\
\text { HARDNESS } \\
(\mathrm{mg} / \mathrm{l})\end{array}$ & REMARKS \\
\hline $\begin{array}{l}\text { Diesel } 1.57 \mathrm{ppm} \\
\mathrm{T} 1(24 \mathrm{hr})\end{array}$ & 20 & 7.81 & 20 & Sheen observed \\
\hline $\begin{array}{l}\text { Diesel } 3.13 \mathrm{ppm} \\
\text { T1 (24hr) }\end{array}$ & 20 & 7.24 & 20 & Sheen observed \\
\hline $\begin{array}{l}\text { Diesel } 6.25 \mathrm{ppm} \\
\mathrm{T} 1 \text { (24hr) }\end{array}$ & 20 & 7.73 & 20 & Sheen observed \\
\hline $\begin{array}{l}\text { Diesel } 12.5 \mathrm{ppm} \\
\mathrm{T} 1(24 \mathrm{hr})\end{array}$ & 20 & 7.53 & 20 & Sheen observed \\
\hline $\begin{array}{l}\text { Diesel } 25 \mathrm{ppm} \\
\mathrm{T} 1(24 \mathrm{hr})\end{array}$ & 20 & 7.33 & 20 & Sheen observed \\
\hline $\begin{array}{l}\text { Diesel } 50 \mathrm{ppm} \\
\mathrm{T} 1(24 \mathrm{hr})\end{array}$ & 20 & 8.01 & 20 & Sheen observed \\
\hline $\begin{array}{l}\text { Diesel } 1.57 \mathrm{ppm} \\
\mathrm{T} 2(24 \mathrm{hr})\end{array}$ & 20 & 7.21 & 20 & Sheen observed \\
\hline $\begin{array}{l}\text { Diesel } 3.13 \mathrm{ppm} \\
\text { T2 (24hr) }\end{array}$ & 20 & 7.66 & 20 & Sheen observed \\
\hline $\begin{array}{l}\text { Diesel } 6.25 \mathrm{ppm} \\
\text { T2 (24hr) }\end{array}$ & 20 & 8.24 & 20 & Sheen observed \\
\hline $\begin{array}{l}\text { Diesel } 12.5 \mathrm{ppm} \\
\text { T2 (24hr) }\end{array}$ & 20 & 8.30 & 20 & Sheen observed \\
\hline $\begin{array}{l}\text { Diesel } 25 \mathrm{ppm} \\
\text { T2 (24hr) }\end{array}$ & 20 & 8.15 & 20 & Sheen observed \\
\hline $\begin{array}{l}\text { Diesel } 50 \mathrm{ppm} \\
\text { T2 }(24 \mathrm{hr})\end{array}$ & 20 & 8.45 & 20 & Sheen observed \\
\hline $\begin{array}{l}\text { Diesel } 1.57 \mathrm{ppm} \\
\text { T3 (24hr) }\end{array}$ & 20 & 7.98 & 20 & Sheen observed \\
\hline $\begin{array}{l}\text { Diesel } 3.13 \mathrm{ppm} \\
\text { T3 (24hr) }\end{array}$ & 20 & 7.55 & 20 & Sheen observed \\
\hline $\begin{array}{l}\text { Diesel } 6.25 \mathrm{ppm} \\
\text { T3 (24hr) }\end{array}$ & 20 & 7.21 & 20 & Sheen observed \\
\hline $\begin{array}{l}\text { Diesel } 12.5 \mathrm{ppm} \\
\text { T3 (24hr) }\end{array}$ & 20 & 8.66 & 20 & Sheen observed \\
\hline $\begin{array}{l}\text { Diesel } 25 \mathrm{ppm} \\
\text { T3 (24hr) }\end{array}$ & 20 & 8.73 & 20 & Sheen observed \\
\hline $\begin{array}{l}\text { Diesel } 50 \mathrm{ppm} \\
\text { T3 (24hr) }\end{array}$ & 20 & 7.44 & 20 & Sheen observed \\
\hline
\end{tabular}




\begin{tabular}{|c|c|c|c|c|}
\hline $\begin{array}{l}\text { Diesel } 1.57 \mathrm{ppm} \\
\text { T4 (0hr) }\end{array}$ & 21 & 7.55 & 20 & Sheen observed \\
\hline $\begin{array}{l}\text { Diesel } 3.13 \mathrm{ppm} \\
\text { T4 (24hr) }\end{array}$ & 21 & 8.61 & 20 & Sheen observed \\
\hline $\begin{array}{l}\text { Diesel } 6.25 \mathrm{ppm} \\
\text { T4 (24hr) }\end{array}$ & 21 & 8.34 & 20 & Sheen observed \\
\hline $\begin{array}{l}\text { Diesel 12.5 ppm } \\
\text { T4 (24hr) }\end{array}$ & 21 & 7.91 & 20 & Sheen observed \\
\hline $\begin{array}{l}\text { Diesel } 25 \mathrm{ppm} \\
\text { T4 (24hr) } \\
\end{array}$ & 21 & 8.22 & 20 & Sheen observed \\
\hline $\begin{array}{l}\text { Diesel } 50 \mathrm{ppm} \\
\mathrm{T} 4(24 \mathrm{hr}) \\
\end{array}$ & 21 & 7.43 & 20 & Sheen observed \\
\hline $\begin{array}{l}\text { AB100 } 1.57 \mathrm{ppm} \\
\mathrm{T} 1(24 \mathrm{hr})\end{array}$ & 20 & 8.64 & 20 & \\
\hline $\begin{array}{l}\text { B100 3.13 ppm } \\
\text { T1 (24hr) }\end{array}$ & 20 & 8.32 & 20 & \\
\hline $\begin{array}{l}\text { B100 6.25 ppm } \\
\text { T1 (24hr) }\end{array}$ & 20 & 7.12 & 20 & \\
\hline $\begin{array}{l}\text { B100 12.5 ppm } \\
\text { T1 (24hr) }\end{array}$ & 20 & 7.23 & 20 & \\
\hline $\begin{array}{l}\text { B100 } 25 \text { ppm T1 } \\
(24 \mathrm{hr})\end{array}$ & 20 & 7.01 & 20 & \\
\hline $\begin{array}{l}\text { B100 50 ppm T1 } \\
(24 \mathrm{hr})\end{array}$ & 21 & 7.44 & 20 & \\
\hline $\begin{array}{l}\text { B100 } 1.57 \mathrm{ppm} \\
\text { T2 (24hr) }\end{array}$ & 20 & 7.21 & 20 & \\
\hline $\begin{array}{l}\text { B100 3.13 ppm } \\
\text { T2 (24hr) }\end{array}$ & 20 & 8.11 & 20 & \\
\hline $\begin{array}{l}\text { B100 6.25 ppm } \\
\text { T2 (24hr) }\end{array}$ & 20 & 7.49 & 20 & \\
\hline $\begin{array}{l}\text { B100 } 12.5 \mathrm{ppm} \\
\text { T2 (24hr) }\end{array}$ & 20 & 7.11 & 20 & \\
\hline $\begin{array}{l}\text { B100 25 ppm T2 } \\
(24 \mathrm{hr})\end{array}$ & 20 & 7.15 & 20 & \\
\hline $\begin{array}{l}\text { B100 50 ppm T2 } \\
(24 \mathrm{hr})\end{array}$ & 21 & 7.32 & 20 & \\
\hline $\begin{array}{l}\text { B100 1.57 ppm } \\
\text { T3 (24hr) }\end{array}$ & 20 & 7.23 & 20 & \\
\hline $\begin{array}{l}\text { B100 3.13 ppm } \\
\text { T3 (24hr) }\end{array}$ & 20 & 7.44 & 20 & \\
\hline $\mathrm{B} 1006.25 \mathrm{ppm}$ & 20 & 8.61 & 20 & \\
\hline
\end{tabular}




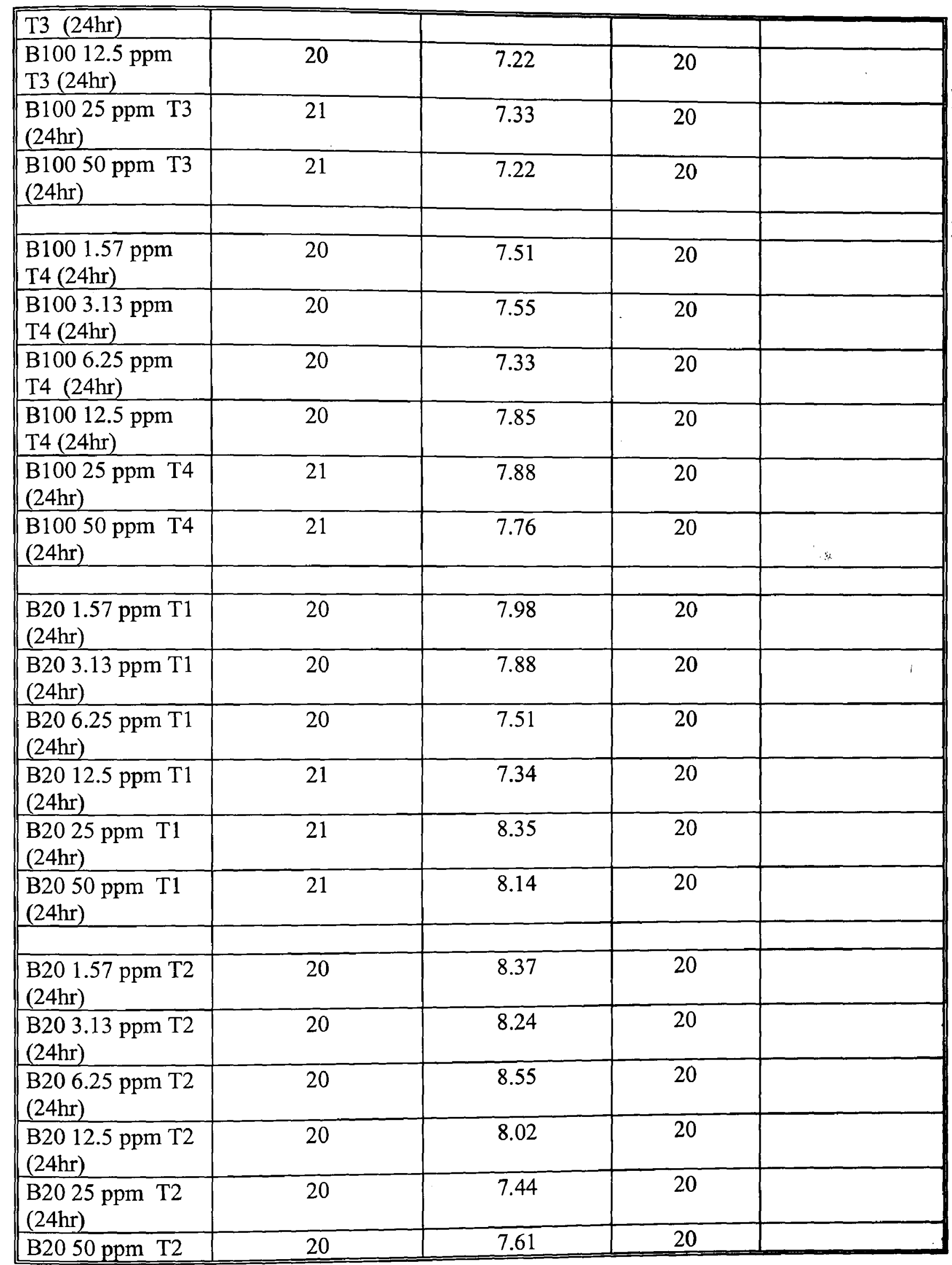




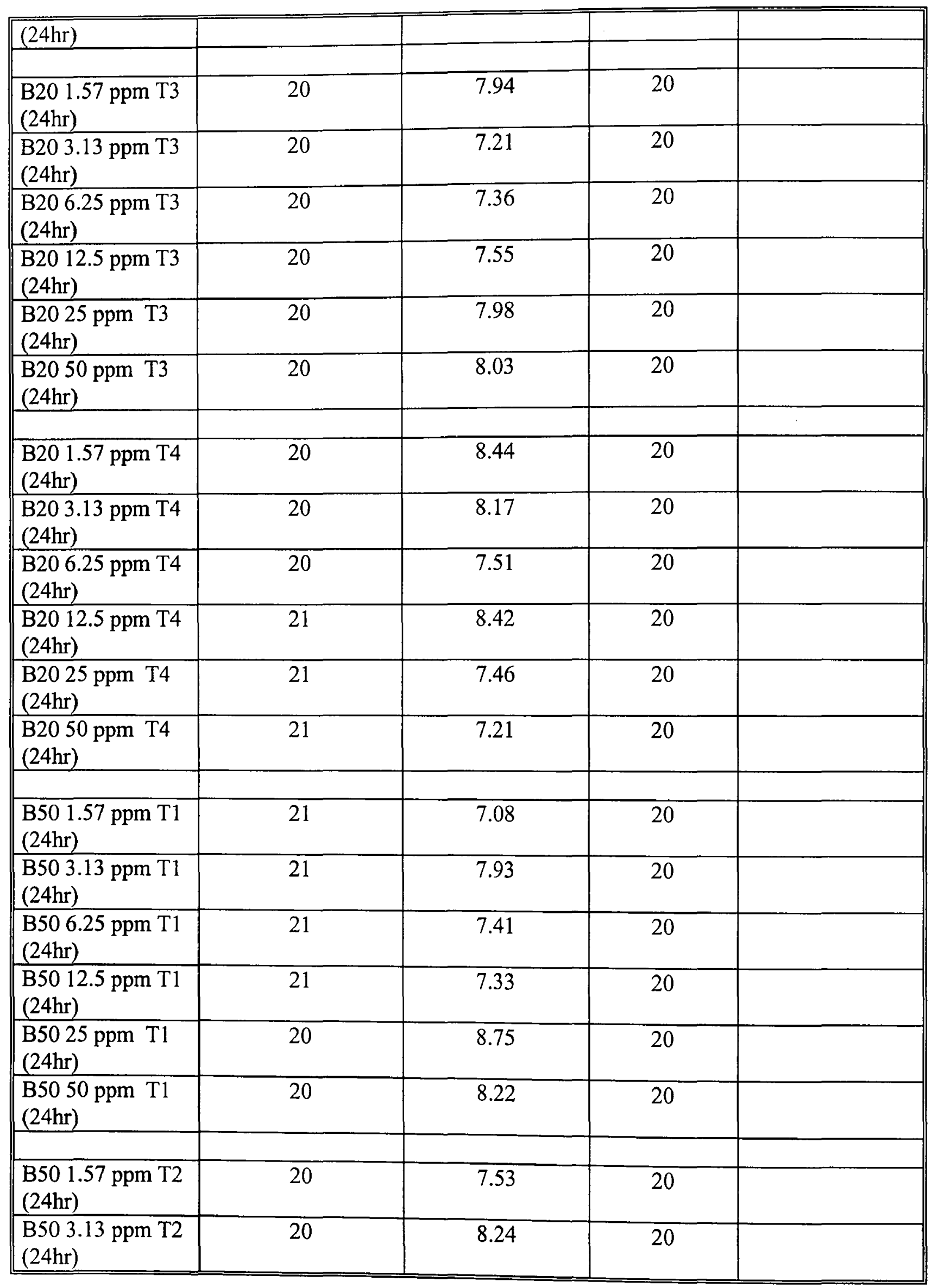




\begin{tabular}{|c|c|c|c|c|}
\hline $\begin{array}{l}\text { B50 6.25 ppm T2 } \\
(24 \mathrm{hr})\end{array}$ & 20 & 8.30 & 20 & \\
\hline $\begin{array}{l}\text { B50 } 12.5 \text { ppm T2 } \\
(24 \mathrm{hr})\end{array}$ & 21 & 8.15 & 20 & \\
\hline $\begin{array}{l}\text { B50 25 ppm T2 } \\
(24 \mathrm{hr})\end{array}$ & 21 & 8.45 & 20 & \\
\hline $\begin{array}{l}\text { B50 50 ppm T2 } \\
(24 \mathrm{hr})\end{array}$ & 20 & 7.18 & 20 & \\
\hline $\begin{array}{l}\text { B50 } 1.57 \mathrm{ppm} \mathrm{T3} \\
(24 \mathrm{hr})\end{array}$ & 20 & 7.44 & 20 & $\begin{array}{c}\text { Slight sheen } \\
\text { observed }\end{array}$ \\
\hline $\begin{array}{l}\text { B50 3.13 ppm T3 } \\
(24 \mathrm{hr})\end{array}$ & 21 & 7.53 & 20 & $\begin{array}{c}\text { Slight sheen } \\
\text { observed }\end{array}$ \\
\hline $\begin{array}{l}\text { B50 } 6.25 \mathrm{ppm} \mathrm{T3} \\
(24 \mathrm{hr})\end{array}$ & 21 & 7.94 & 20 & $\begin{array}{c}\text { Slight sheen } \\
\text { observed }\end{array}$ \\
\hline $\begin{array}{l}\text { B50 } 12.5 \text { ppm T3 } \\
(24 \mathrm{hr})\end{array}$ & 21 & 7.41 & 20 & $\begin{array}{c}\text { Slight sheen } \\
\text { observed }\end{array}$ \\
\hline $\begin{array}{l}\text { B50 25 ppm T3 } \\
(24 \mathrm{hr})\end{array}$ & 20 & 7.68 & 20 & $\begin{array}{c}\text { Slight sheen } \\
\text { observed }\end{array}$ \\
\hline $\begin{array}{l}\text { B50 50 ppm T3 } \\
(24 \mathrm{hr})\end{array}$ & 20 & 7.32 & 20 & $\begin{array}{c}\text { Slight sheen } \\
\text { observed }\end{array}$ \\
\hline $\begin{array}{l}\text { B50 1.57 ppm T4 } \\
(24 \mathrm{hr})\end{array}$ & 20 & 7.42 & 20 & $\begin{array}{c}\text { Slight sheen } \\
\text { observed }\end{array}$ \\
\hline $\begin{array}{l}\text { B50 3.13 ppm T4 } \\
(24 \mathrm{hr})\end{array}$ & 20 & 7.62 & 20 & $\begin{array}{c}\text { Slight sheen } \\
\text { observed }\end{array}$ \\
\hline $\begin{array}{l}\text { B50 6.25 ppm T4 } \\
(24 \mathrm{hr})\end{array}$ & 20 & 7.76 & 20 & $\begin{array}{c}\text { Slight sheen } \\
\text { observed }\end{array}$ \\
\hline $\begin{array}{l}\text { B50 } 12.5 \text { ppm T4 } \\
(24 \mathrm{hr})\end{array}$ & 20 & 7.85 & 20 & $\begin{array}{c}\text { Slight sheen } \\
\text { observed }\end{array}$ \\
\hline $\begin{array}{l}\text { B50 25 ppm T4 } \\
(24 \mathrm{hr})\end{array}$ & 20 & 7.81 & 20 & $\begin{array}{c}\text { Slight sheen } \\
\text { observed }\end{array}$ \\
\hline $\begin{array}{l}\text { B50 50 ppm T4 } \\
(24 \mathrm{hr})\end{array}$ & 20 & 7.36 & 20 & $\begin{array}{c}\text { Slight sheen } \\
\text { observed }\end{array}$ \\
\hline $\begin{array}{l}\text { B5 } 1.57 \mathrm{ppm} \mathrm{T1} \\
\text { (24hr) }\end{array}$ & 20 & 7.58 & 20 & $\begin{array}{c}\text { Slight sheen } \\
\text { observed }\end{array}$ \\
\hline $\begin{array}{l}\text { B5 3.13 ppm T1 } \\
(24 \mathrm{hr})\end{array}$ & 20 & 7.21 & 20 & $\begin{array}{c}\text { Slight sheen } \\
\text { observed }\end{array}$ \\
\hline $\begin{array}{l}\text { B5 } 6.25 \mathrm{ppm} \mathrm{T1} \\
(24 \mathrm{hr})\end{array}$ & 20 & 7.15 & 20 & $\begin{array}{c}\text { Slight sheen } \\
\text { observed }\end{array}$ \\
\hline $\begin{array}{l}\text { B5 } 12.5 \mathrm{ppm} \mathrm{T1} \\
(24 \mathrm{hr})\end{array}$ & 20 & 7.34 & 20 & $\begin{array}{c}\text { Slight sheen } \\
\text { observed }\end{array}$ \\
\hline $\begin{array}{l}\text { B5 25 ppm T1 } \\
(24 \mathrm{hr})\end{array}$ & 20 & 8.98 & 20 & $\begin{array}{c}\text { Slight sheen } \\
\text { observed }\end{array}$ \\
\hline
\end{tabular}




\begin{tabular}{|c|c|c|c|c|}
\hline $\begin{array}{l}\text { B5 } 50 \text { ppm T1 } \\
\text { (24hr) }\end{array}$ & 20 & 8.57 & 20 & $\begin{array}{c}\text { Slight sheen } \\
\text { observed }\end{array}$ \\
\hline $\begin{array}{l}\text { B5 } 1.57 \mathrm{ppm} \mathrm{T2} \\
\text { (24hr) }\end{array}$ & 20 & 8.14 & 20 & $\begin{array}{c}\text { Slight sheen } \\
\text { observed }\end{array}$ \\
\hline $\begin{array}{l}\text { B5 3.13 ppm T2 } \\
(24 \mathrm{hr})\end{array}$ & 20 & 7.55 & 20 & $\begin{array}{c}\text { Slight sheen } \\
\text { observed }\end{array}$ \\
\hline $\begin{array}{l}\text { B5 } 6.25 \mathrm{ppm} \mathrm{T2} \\
(24 \mathrm{hr})\end{array}$ & 20 & 8.25 & 20 & $\begin{array}{c}\text { Slight sheen } \\
\text { observed }\end{array}$ \\
\hline $\begin{array}{l}\text { B5 } 12.5 \mathrm{ppm} \mathrm{T2} \\
(24 \mathrm{hr})\end{array}$ & 20 & 7.41 & 20 & $\begin{array}{c}\text { Slight sheen } \\
\text { observed }\end{array}$ \\
\hline $\begin{array}{l}\text { B5 } 25 \mathrm{ppm} \mathrm{T2} \\
(24 \mathrm{hr})\end{array}$ & 20 & 7.65 & 20 & $\begin{array}{c}\text { Slight sheen } \\
\text { observed }\end{array}$ \\
\hline $\begin{array}{l}\text { B5 } 50 \mathrm{ppm} \mathrm{T2} \\
(24 \mathrm{hr})\end{array}$ & 20 & 7.22 & 20 & $\begin{array}{c}\text { Slight sheen } \\
\text { observed }\end{array}$ \\
\hline $\begin{array}{l}\text { B5 } 1.57 \mathrm{ppm} \mathrm{T3} \\
\text { (24hr) }\end{array}$ & 20 & 7.54 & 20 & $\begin{array}{l}\text { Slight sheen } \\
\text { observed }\end{array}$ \\
\hline $\begin{array}{l}\text { B5 3.13 ppm T3 } \\
\text { (24hr) }\end{array}$ & 20 & 7.21 & 20 & $\begin{array}{c}\text { Slight sheen } \\
\text { observed }\end{array}$ \\
\hline $\begin{array}{l}\text { B5 } 6.25 \mathrm{ppm} \mathrm{T3} \\
\text { (24hr) }\end{array}$ & 20 & 7.11 & 20 & $\begin{array}{c}\text { Slight sheen } \\
\text { observed }\end{array}$ \\
\hline $\begin{array}{l}\text { B5 } 12.5 \mathrm{ppm} \mathrm{T3} \\
\text { (24hr) }\end{array}$ & 20 & 7.87 & 20 & $\begin{array}{c}\text { Slight sheen } \\
\text { observed }\end{array}$ \\
\hline $\begin{array}{l}\text { B5 25 ppm T3 } \\
\text { (24hr) }\end{array}$ & 21 & 7.45 & 20 & $\begin{array}{c}\text { Slight sheen } \\
\text { observed }\end{array}$ \\
\hline $\begin{array}{l}\text { B5 } 50 \mathrm{ppm} \mathrm{T3} \\
\text { (24hr) }\end{array}$ & 21 & 7.85 & 20 & $\begin{array}{c}\text { Slight sheen } \\
\text { observed }\end{array}$ \\
\hline $\begin{array}{l}\text { B5 } 1.57 \mathrm{ppm} \mathrm{T4} \\
(24 \mathrm{hr})\end{array}$ & 20 & 8.44 & 20 & $\begin{array}{l}\text { Slight sheen } \\
\text { observed }\end{array}$ \\
\hline $\begin{array}{l}\text { B5 } 3.13 \mathrm{ppm} \mathrm{T4} \\
\text { (24hr) }\end{array}$ & 20 & 8.75 & 20 & $\begin{array}{c}\text { Slight sheen } \\
\text { observed }\end{array}$ \\
\hline $\begin{array}{l}\text { B5 } 6.25 \mathrm{ppm} \mathrm{T4} \\
(24 \mathrm{hr})\end{array}$ & 20 & 7.30 & 20 & $\begin{array}{c}\text { Slight sheen } \\
\text { observed }\end{array}$ \\
\hline $\begin{array}{l}\text { B5 } 12.5 \text { ppm T4 } \\
\text { (24hr) }\end{array}$ & 21 & 8.38 & 20 & $\begin{array}{c}\text { Slight sheen } \\
\text { observed }\end{array}$ \\
\hline $\begin{array}{l}\text { B5 25 ppm T4 } \\
\text { (24hr) }\end{array}$ & 21 & 7.42 & 20 & $\begin{array}{c}\text { Slight sheen } \\
\text { observed }\end{array}$ \\
\hline $\begin{array}{l}\text { B5 } 50 \mathrm{ppm} \mathrm{T4} \\
(24 \mathrm{hr})\end{array}$ & 21 & 7.15 & 20 & $\begin{array}{c}\text { Slight sheen } \\
\text { observed }\end{array}$ \\
\hline
\end{tabular}


TABLE 3

TOXICITY OF DIESEL ON DAPHNIA MAGNA AT 24HRS (TRIAL 1)

\begin{tabular}{|c|c|c|c|}
\hline $\begin{array}{c}\text { CONCENTRATION } \\
(\text { PPM) }\end{array}$ & NO. SURVIVING & \% ALIVE & \% DEAD \\
\hline Control & 5 & 100 & 0 \\
\hline 1.57 & 2 & 40 & 60 \\
\hline 3.13 & 2 & 40 & 60 \\
\hline 6.25 & 2 & 40 & 60 \\
\hline 12.5 & 0 & 0 & 100 \\
\hline 25 & 1 & 20 & 80 \\
\hline 50 & 2 & 40 & 60 \\
\hline
\end{tabular}

TABLE 4

TOXICITY OF DIESEL ON DAPHNIA MAGNA AT 24HRS (TRIAL 2)

\begin{tabular}{|c|c|c|c|}
\hline $\begin{array}{c}\text { CONCENTRATION } \\
\text { (PPM) }\end{array}$ & NO. SURVIVING & \% ALIVE & \% DEAD \\
\hline Control & 5 & 100 & 0 \\
\hline 1.57 & 1 & 20 & 80 \\
\hline 3.13 & 1 & 20 & 80 \\
\hline 6.25 & 0 & 0 & 100 \\
\hline 12.5 & 1 & 20 & 80 \\
\hline 25 & 1 & 20 & 80 \\
\hline 50 & 0 & 0 & 100 \\
\hline
\end{tabular}

TABLE 5

TOXICITY OF DIESEL ON DAPHNIA MAGNA AT 24HRS (TRIAL 3)

\begin{tabular}{|c|c|c|c|}
\hline \hline $\begin{array}{c}\text { CONCENTRATION } \\
(\mathrm{PPM})\end{array}$ & NO. SURVIVING & \% ALIVE & \% DEAD \\
\hline Control & 5 & 100 & 0 \\
\hline 1.57 & 4 & 80 & 20 \\
\hline 3.13 & 1 & 20 & 80 \\
\hline 6.25 & 0 & 0 & 100 \\
\hline 12.5 & 0 & 0 & 100 \\
\hline 25 & 0 & 0 & 100 \\
\hline 50 & 0 & 0 & 100 \\
\hline
\end{tabular}


TABLE 6

TOXICITY OF DIESEL ON DAPHNIA MAGNA AT 24HRS (TRIAL 4)

\begin{tabular}{|c|c|c|c|}
\hline $\begin{array}{c}\text { CONCENTRATION } \\
\text { (PPM) }\end{array}$ & NO. SURVIVING & \% ALIVE & \% DEAD \\
\hline Control & 5 & 100 & 0 \\
\hline 1.57 & $3 / 3$ & 100 & 0 \\
\hline 3.13 & 1 & 20 & 80 \\
\hline 6.25 & 1 & 20 & 80 \\
\hline 12.5 & 1 & 20 & 80 \\
\hline 25 & 0 & 0 & 100 \\
\hline 50 & 0 & 0 & 100 \\
\hline
\end{tabular}

TABLE 7

TOXICITY OF B100 ON DAPHNIA MAGNA AT 24HRS (TRIAL 1)

\begin{tabular}{|c|c|c|c|}
\hline $\begin{array}{c}\text { CONCENTRATION } \\
(\text { PPM })\end{array}$ & NO. SURVIVING & \% ALIVE & \% DEAD \\
\hline Control & 5 & 100 & 0 \\
\hline 1.57 & 1 & 20 & 80 \\
\hline 3.13 & 2 & 40 & 60 \\
\hline 6.25 & 2 & 40 & 60 \\
\hline 12.5 & 3 & 60 & 40 \\
\hline 25 & 2 & 40 & 60 \\
\hline 50 & 2 & 40 & 60 \\
\hline
\end{tabular}

TABLE 8

TOXICITY OF B100 ON DAPHNIA MAGNA AT 24HRS (TRIAL 2)

\begin{tabular}{|c|c|c|c||}
\hline $\begin{array}{c}\text { CONCENTRATION } \\
\text { (PPM) }\end{array}$ & NO. SURVIVING & \% ALIVE & \% DEAD \\
\hline Control & 5 & 100 & 0 \\
\hline 1.57 & $5 / 6$ & 83.34 & 16.66 \\
\hline 3.13 & 2 & 40 & 60 \\
\hline 6.25 & 2 & 40 & 60 \\
\hline 12.5 & 1 & 20 & 80 \\
\hline 25 & 1 & 20 & 80 \\
\hline 50 & $2 / 6$ & 33.34 & 66.66 \\
\hline
\end{tabular}




\section{TABLE 9}

TOXICITY OF B100 ON DAPHNIA MAGNA AT 24HRS (TRIAL 3)

\begin{tabular}{|c|c|c|c|}
\hline $\begin{array}{c}\text { CONCENTRATION } \\
(\mathrm{PPM})\end{array}$ & NO. SURVIVING & \% ALIVE & \% DEAD \\
\hline Control & 5 & 100 & 0 \\
\hline 1.57 & $9 / 9$ & 100 & 0 \\
\hline 3.13 & 3 & 60 & 40 \\
\hline 6.25 & 3 & 60 & 40 \\
\hline 12.5 & 2 & 40 & 60 \\
\hline 25 & 3 & 60 & 40 \\
\hline 50 & 2 & 40 & 60 \\
\hline
\end{tabular}

TABLE 10

TOXICITY OF B100 ON DAPHNIA MAGNA AT 24HRS (TRIAL 4)

\begin{tabular}{|c|c|c|c|}
\hline $\begin{array}{c}\text { CONCENTRATION } \\
(\text { PPM })\end{array}$ & NO. SURVIVING & \% ALIVE & \% DEAD \\
\hline Control & 5 & 100 & 0 \\
\hline 1.57 & 3 & 60 & 40 \\
\hline 3.13 & 4 & 80 & 20 \\
\hline 6.25 & 2 & 40 & 60 \\
\hline 12.5 & 2 & 40 & 60 \\
\hline 25 & 0 & 0 & 100 \\
\hline 50 & 0 & 0 & 100 \\
\hline
\end{tabular}

TABLE 11

TOXICITY OF B50 ON DAPHNIA MAGNA AT 24HRS (TRIAL 1)

\begin{tabular}{|c|c|c|c|}
\hline $\begin{array}{c}\text { CONCENTRATION } \\
\text { (PPM) }\end{array}$ & NO. SURVIVING & \% ALIVE & \% DEAD \\
\hline Control & 5 & 100 & 0 \\
\hline 1.57 & 3 & 60 & 40 \\
\hline 3.13 & 3 & 60 & 40 \\
\hline 6.25 & 3 & 60 & 40 \\
\hline 12.5 & 1 & 20 & 80 \\
\hline 25 & 1 & 20 & 80 \\
\hline 50 & 1 & 20 & 80 \\
\hline
\end{tabular}


TABLE 12

TOXICITY OF B50 ON DAPHNIA MAGNA AT 24HRS (TRIAL 2)

\begin{tabular}{|c|c|c|c||}
\hline $\begin{array}{c}\text { CONCENTRATION } \\
(\text { PPM })\end{array}$ & NO. SURVIVING & \% ALIVE & \% DEAD \\
\hline Control & 5 & 100 & 0 \\
\hline 1.57 & 3 & 60 & 40 \\
\hline 3.13 & 2 & 40 & 60 \\
\hline 6.25 & 0 & 0 & 100 \\
\hline 12.5 & 1 & 20 & 80 \\
\hline 25 & 1 & 20 & 80 \\
\hline 50 & 1 & 20 & 80 \\
\hline
\end{tabular}

TABLE 13

TOXICITY OF B50 ON DAPHNIA MAGNA AT 24HRS (TRIAL 3)

\begin{tabular}{||c|c|c|c||}
\hline $\begin{array}{c}\text { CONCENTRATION } \\
(\text { PPM })\end{array}$ & NO. SURVIVING & \% ALIVE & \% DEAD \\
\hline Control & 5 & 100 & 0 \\
\hline 1.57 & $1 / 2$ & 50 & 50 \\
\hline 3.13 & 1 & 20 & 80 \\
\hline 6.25 & 0 & 0 & 100 \\
\hline 12.5 & 1 & 20 & 80 \\
\hline 25 & 1 & 20 & 80 \\
\hline 50 & 0 & 0 & 100 \\
\hline
\end{tabular}

TABLE 14

TOXICITY OF B50 ON DAPHNIA MAGNA AT 24HRS (TRIAL 4)

\begin{tabular}{||c|c|c|c||}
\hline $\begin{array}{c}\text { CONCENTRATION } \\
\text { (PPM) }\end{array}$ & NO. SURVIVING & \% ALIVE & \% DEAD \\
\hline Control & 5 & 100 & 0 \\
\hline 1.57 & 3 & 60 & 40 \\
\hline 3.13 & 3 & 60 & 40 \\
\hline 6.25 & 2 & 40 & 60 \\
\hline 12.5 & 1 & 20 & 80 \\
\hline 25 & 1 & 20 & 80 \\
\hline 50 & 1 & 20 & 80 \\
\hline
\end{tabular}




\section{TABLE 15}

\section{TOXICITY OF B20 ON DAPHNIA MAGNA AT 24HRS (TRIAL 1)}

\begin{tabular}{|c|c|c|c|}
\hline $\begin{array}{c}\text { CONCENTRATION } \\
\text { (PPM) }\end{array}$ & NO. SURVIVING & \% ALIVE & \% DEAD \\
\hline Control & 5 & 100 & 0 \\
\hline 1.57 & 3 & 60 & 40 \\
\hline 3.13 & $7 / 9$ & 77.78 & 22.22 \\
\hline 6.25 & 3 & 60 & 40 \\
\hline 12.5 & 3 & 60 & 40 \\
\hline 25 & $2 / 6$ & 33.34 & 66.66 \\
\hline 50 & 1 & 20 & 80 \\
\hline
\end{tabular}

TABLE 16

TOXICITY OF B20 ON DAPHNIA MAGNA AT 24HRS (TRIAL 2)

\begin{tabular}{|c|c|c|c|}
\hline $\begin{array}{c}\text { CONCENTRATION } \\
(\text { PPM })\end{array}$ & NO. SURVIVING & \% ALIVE & \% DEAD \\
\hline Control & 5 & 100 & 0 \\
\hline 1.57 & 3 & 60 & 40 \\
\hline 3.13 & 2 & 40 & 60 \\
\hline 6.25 & 1 & 20 & 80 \\
\hline 12.5 & 1 & 20 & 80 \\
\hline 25 & 2 & 40 & 60 \\
\hline 50 & 2 & 40 & 60 \\
\hline
\end{tabular}

TABLE 17

TOXICITY OF B20 ON DAPHNIA MAGNA AT 24HRS (TRIAL 3)

\begin{tabular}{||c|c|c|c|}
\hline $\begin{array}{c}\text { CONCENTRATION } \\
(\text { PPM })\end{array}$ & NO. SURVIVING & \% ALIVE & \% DEAD \\
\hline Control & 5 & 100 & 0 \\
\hline 1.57 & 2 & 40 & 60 \\
\hline 3.13 & 4 & 80 & 20 \\
\hline 6.25 & 2 & 40 & 60 \\
\hline 12.5 & 1 & 20 & 80 \\
\hline 25 & 1 & 20 & 80 \\
\hline 50 & 1 & 20 & 80 \\
\hline
\end{tabular}


TABLE 18

TOXICITY OF B20 ON DAPHNIA MAGNA AT 24HRS (TRIAL 4)

\begin{tabular}{||c|c|c|c||}
\hline \hline $\begin{array}{c}\text { CONCENTRATION } \\
\text { (PPM) }\end{array}$ & NO. SURVIVING & \% ALIVE & \% DEAD \\
\hline Control & 5 & 100 & 0 \\
\hline 1.57 & 4 & 80 & 20 \\
\hline 3.13 & 2 & 40 & 60 \\
\hline 6.25 & 2 & 40 & 60 \\
\hline 12.5 & 2 & 40 & 60 \\
\hline 25 & 1 & 20 & 80 \\
\hline 50 & $3 / 7$ & 42.29 & 57.71 \\
\hline
\end{tabular}

TABLE 19

TOXICITY OF B5 ON DAPHNIA MAGNA AT 24HRS (TRIAL 1)

\begin{tabular}{||c|c|c|c||}
\hline $\begin{array}{c}\text { CONCENTRATION } \\
(\text { PPM })\end{array}$ & NO. SURVIVING & \% ALIVE & \% DEAD \\
\hline Control & 5 & 100 & 0 \\
\hline 1.57 & 3 & 60 & 40 \\
\hline 3.13 & 2 & 40 & 60 \\
\hline 6.25 & 2 & 40 & 60 \\
\hline 12.5 & 2 & 40 & 60 \\
\hline 25 & 1 & 20 & 80 \\
\hline 50 & 0 & 0 & 100 \\
\hline
\end{tabular}

TABLE 20

\section{TOXICITY OF B5 ON DAPHNIA MAGNA AT 24HRS (TRIAL 2)}

\begin{tabular}{|c|c|c|c|}
\hline $\begin{array}{c}\text { CONCENTRATION } \\
(\mathrm{PPM})\end{array}$ & NO. SURVIVING & \% ALIVE & \% DEAD \\
\hline Control & 5 & 100 & 0 \\
\hline 1.57 & 3 & 60 & 40 \\
\hline 3.13 & 2 & 40 & 60 \\
\hline 6.25 & 1 & 20 & 80 \\
\hline 12.5 & 0 & 0 & 100 \\
\hline 25 & 1 & 20 & 80 \\
\hline 50 & 0 & 0 & 100 \\
\hline
\end{tabular}




\section{TABLE 21}

\section{TOXICITY OF B5 ON DAPHNIA MAGNA AT 24HRS (TRIAL 3)}

\begin{tabular}{|c|c|c|c|}
\hline $\begin{array}{c}\text { CONCENTRATION } \\
\text { (PPM) }\end{array}$ & NO. SURVIVING & \% ALIVE & \% DEAD \\
\hline Control & 5 & 100 & 0 \\
\hline 1.57 & 3 & 60 & 40 \\
\hline 3.13 & 2 & 40 & 60 \\
\hline 6.25 & 0 & 0 & 100 \\
\hline 12.5 & 0 & 0 & 100 \\
\hline 25 & 0 & 0 & 100 \\
\hline 50 & 0 & 0 & 100 \\
\hline
\end{tabular}

TABLE 22

TOXICITY OF B5 ON DAPHNIA MAGNA AT 24HRS (TRIAL 4)

\begin{tabular}{||c|c|c|c|}
\hline $\begin{array}{c}\text { CONCENTRATION } \\
(\text { PPM })\end{array}$ & NO. SURVIVING & \% ALIVE & \% DEAD \\
\hline Control & 5 & 100 & 0 \\
\hline 1.57 & 2 & 40 & 60 \\
\hline 3.13 & 2 & 40 & 60 \\
\hline 6.25 & 1 & 20 & 80 \\
\hline 12.5 & 0 & 0 & 100 \\
\hline 25 & 0 & 0 & 100 \\
\hline 50 & 0 & 0 & 100 \\
\hline
\end{tabular}

TABLE 23

TOXICITY OF B20 (Topia) ON DAPHNIA MAGNA AT 24HRS (TRIAL 1)

\begin{tabular}{|c|c|c|c|}
\hline $\begin{array}{c}\text { CONCENTRATION } \\
\text { (PPM) }\end{array}$ & NO. SURVIVING & $\%$ ALIVE & \% DEAD \\
\hline Control & 5 & 100 & 0 \\
\hline 1.57 & 3 & 60 & 40 \\
\hline 3.13 & $9 / 11$ & 81.82 & 18.18 \\
\hline 6.25 & 4 & 80 & 20 \\
\hline 12.5 & 3 & 60 & 40 \\
\hline 25 & 1 & 20 & 40 \\
\hline 50 & 1 & 20 & 80 \\
\hline
\end{tabular}


TABLE 24

TOXICITY OF B20 (Topia) ON DAPHNIA MAGNA AT 24HRS (TRIAL 2)

\begin{tabular}{|c|c|c|c||}
\hline $\begin{array}{c}\text { CONCENTRATION } \\
\text { (PPM) }\end{array}$ & NO. SURVIVING & \% ALIVE & \% DEAD \\
\hline Control & 5 & 100 & 0 \\
\hline 1.57 & 3 & 60 & 40 \\
\hline 3.13 & 2 & 40 & 60 \\
\hline 6.25 & 1 & 20 & 80 \\
\hline 12.5 & 2 & 40 & 60 \\
\hline 25 & 2 & 40 & 60 \\
\hline 50 & 2 & 40 & 60 \\
\hline
\end{tabular}

TABLE 25

TOXICITY OF B20 (Topia) ON DAPHNIA MAGNA AT 24HRS (TRIAL 3)

\begin{tabular}{||c|c|c|c||}
\hline $\begin{array}{c}\text { CONCENTRATION } \\
\text { (PPM) }\end{array}$ & NO. SURVIVING & \% ALIVE & \% DEAD \\
\hline Control & 5 & 100 & 0 \\
\hline 1.57 & 3 & 60 & 40 \\
\hline 3.13 & 4 & 80 & 20 \\
\hline 6.25 & 2 & 40 & 60 \\
\hline 12.5 & 2 & 40 & 60 \\
\hline 25 & 1 & 20 & 80 \\
\hline 50 & 1 & 20 & 80 \\
\hline
\end{tabular}

TABLE 26

TOXICITY OF B20 (Topia) ON DAPHNIA MAGNA AT 24HRS (TRIAL 4)

\begin{tabular}{|c|c|c|c||}
\hline $\begin{array}{c}\text { CONCENTRATION } \\
\text { (PPM) }\end{array}$ & NO. SURVIVING & \% ALIVE & \% DEAD \\
\hline Control & 5 & 100 & 0 \\
\hline 1.57 & 4 & 80 & 20 \\
\hline 3.13 & 2 & 40 & 60 \\
\hline 6.25 & 2 & 40 & 60 \\
\hline 12.5 & 2 & 40 & 60 \\
\hline 25 & 1 & 20 & 80 \\
\hline 50 & $3 / 7$ & 42.86 & 57.14 \\
\hline
\end{tabular}


TABLE 27

MEAN MORTALITY OF DAPHNIA MAGNA AFFECTED WITH DIESEL

\begin{tabular}{|c|c|c|c|c|c|}
\hline $\begin{array}{c}\text { DIESEL } \\
\text { CONCENTRATION } \\
\text { [PPM] }\end{array}$ & \multicolumn{4}{|c|}{ MORTALITY (\%) IN 4 REPLICATES IN 24HRS } & $\begin{array}{c}\text { MEAN } \\
\text { MORTALITY } \\
\text { (\%) }\end{array}$ \\
\hline & Trial 1 & Trial 2 & Trial 3 & Trial 4 & \\
\hline 1.57 & 60 & 80 & 20 & 0 & 40.00 \\
\hline 3.13 & 60 & 80 & 80 & 80 & 75.00 \\
\hline 6.25 & 60 & 100 & 100 & 80 & 85.00 \\
\hline 12.5 & 100 & 80 & 100 & 80 & 90.00 \\
\hline 25 & 80 & 80 & 100 & 100 & 90.00 \\
\hline 50 & 60 & 100 & 100 & 100 & 90.00 \\
\hline & & & & & \\
\hline
\end{tabular}

TABLE 28

MEAN MORTALITY OF DAPHNIA MAGNA AFFECTED WITH B100

\begin{tabular}{|c|c|c|c|c|c|}
\hline $\begin{array}{c}\text { B100 } \\
\text { CONCENTRATION } \\
\text { [PPM] }\end{array}$ & \multicolumn{4}{|c|}{ MORTALITY (\%) IN 4 REPLICATES IN 24HRS } & $\begin{array}{c}\text { MEAN } \\
\text { MORTALITY } \\
(\%)\end{array}$ \\
\hline & Trial 1 & Trial 2 & Trial 3 & Trial 4 & \\
\hline 1.57 & 80 & 16.66 & 0 & 40 & 34.17 \\
\hline 3.13 & 60 & 60 & 40 & 20 & 45.00 \\
\hline 6.25 & 60 & 60 & 40 & 60 & 55.00 \\
\hline 12.5 & 40 & 80 & 60 & 60 & 60.00 \\
\hline 25 & 60 & 80 & 40 & 100 & 70.00 \\
\hline 50 & 60 & 66.66 & 60 & 100 & 71.67 \\
\hline & & & & & \\
\hline
\end{tabular}


TABLE 29

MEAN MORTALITY OF DAPHNIA MAGNA AFFECTED WITH B50

\begin{tabular}{|c|c|c|c|c|c||}
\hline $\begin{array}{c}\text { B50 } \\
\begin{array}{c}\text { CONCENTRATION } \\
\text { [PPM] }\end{array}\end{array}$ & \multicolumn{4}{|c|}{ MORTALITY (\%) IN 4 REPLICATES IN 24HRS } & $\begin{array}{c}\text { MEAN } \\
\text { MORTALITY } \\
\text { (\%) }\end{array}$ \\
\hline & Trial 1 & Trial 2 & Trial 3 & Trial 4 & \\
\hline 1.57 & 40 & 40 & 50 & 40 & 42.50 \\
\hline 3.13 & 40 & 60 & 80 & 40 & 55.00 \\
\hline 6.25 & 40 & 100 & 100 & 60 & 75.00 \\
\hline 12.5 & 80 & 80 & 80 & 80 & 80.00 \\
\hline 25 & 80 & 80 & 80 & 80 & 80.00 \\
\hline 50 & 80 & 80 & 100 & 80 & 85.00 \\
\hline & & & & & \\
\hline
\end{tabular}

TABLE 30

MEAN MORTALITY OF DAPHNIA MAGNA AFFECTED WITH B20

\begin{tabular}{|c|c|c|c|c|c|}
\hline $\begin{array}{c}\text { B20 } \\
\text { CONCENTRATION } \\
\text { [PPM] }\end{array}$ & \multicolumn{4}{|c|}{ MORTALITY (\%) IN 4 REPLICATES IN 24HRS } & $\begin{array}{c}\text { MEAN } \\
\text { MORTALITY } \\
(\%)\end{array}$ \\
\hline & Trial 1 & Trial 2 & Trial 3 & Trial 4 & \\
\hline 1.57 & 40 & 40 & 60 & 20 & 40 \\
\hline 3.13 & 22.22 & 60 & 20 & 60 & 40.56 \\
\hline 6.25 & 40 & 80 & 60 & 60 & 60 \\
\hline 12.5 & 40 & 80 & 80 & 60 & 65 \\
\hline 25 & 66.66 & 60 & 80 & 80 & 71.67 \\
\hline 50 & 80 & 60 & 80 & 57.71 & 69.43 \\
\hline
\end{tabular}




\section{TABLE 31}

MEAN MORTALITY OF DAPHNIA MAGNA AFFECTED WITH B5

\begin{tabular}{|c|c|c|c|c|c|}
\hline $\begin{array}{c}\text { B5 } \\
\text { CONCENTRATION } \\
\text { PPM] }\end{array}$ & \multicolumn{4}{|c|}{ MORTALITY (\%) IN 4 REPLICATES IN 24HRS } & $\begin{array}{c}\text { MEAN } \\
\text { MORTALITY } \\
(\%)\end{array}$ \\
\hline & Trial 1 & Trial 2 & Trial 3 & Trial 4 & \\
\hline 1.57 & 40 & 40 & 40 & 60 & 45.00 \\
\hline 3.13 & 60 & 60 & 60 & 60 & 60.00 \\
\hline 6.25 & 60 & 80 & 100 & 80 & 80.00 \\
\hline 12.5 & 60 & 100 & 100 & 100 & 90.00 \\
\hline 25 & 80 & 80 & 100 & 100 & 90.00 \\
\hline 50 & 100 & 100 & 100 & 100 & 100.00 \\
\hline & & & & & \\
\hline
\end{tabular}

TABLE 32

MEAN MORTALITY OF DAPHNIA MAGNA AFFECTED WITH B20 (Topia)

\begin{tabular}{|c|c|c|c|c|c|}
\hline $\begin{array}{c}\text { B20 } \\
\begin{array}{c}\text { CONCENTRATION } \\
\text { [PPM] }\end{array}\end{array}$ & \multicolumn{4}{|c|}{ MORTALITY (\%) IN 4 REPLICATES IN 24HRS } & $\begin{array}{c}\text { MEAN } \\
\text { MORTALITY } \\
(\%)\end{array}$ \\
\hline & Trial 1 & Trial 2 & Trial 3 & Trial 4 & \\
\hline 1.57 & 40 & 40 & 40 & 20 & 35 \\
\hline 3.13 & 18.18 & 60 & 20 & 60 & 39.55 \\
\hline 6.25 & 20 & 80 & 60 & 60 & 55 \\
\hline 12.5 & 40 & 60 & 60 & 60 & 55 \\
\hline 25 & 80 & 60 & 80 & 80 & 75 \\
\hline 50 & 80 & 60 & 80 & 57.14 & 69.29 \\
\hline
\end{tabular}


D. magna

DIESEL

Anova: Single

Factor (Diesel)

SUMMARY

\begin{tabular}{lrrrr}
\hline \multicolumn{1}{c}{ Groups } & Count & Sum & Average & Variance \\
\hline Column 1 & 6 & 21 & 3.5 & 0.7 \\
Column 2 & 6 & 26 & 4.333333 & 0.266667 \\
Column 3 & 6 & 25 & 4.166667 & 2.566667 \\
Column 4 & 6 & 22 & 3.666667 & 3.466667 \\
\hline
\end{tabular}

ANOVA

\begin{tabular}{lrrrrrr}
\hline Source of Variation & \multicolumn{1}{c}{$S S$} & \multicolumn{1}{c}{ df } & \multicolumn{1}{c}{ MS } & $F$ & P-value & F crit \\
\hline Between Groups & 2.833333 & 3 & 0.944444 & 0.539683 & 0.660586 & 3.098391 \\
Within Groups & 35 & 20 & 1.75 & & & \\
Total & & & & & & \\
\hline
\end{tabular}

\section{B100}

Anova: Single

Factor (B100)

SUMMARY

\begin{tabular}{rrrrr}
\hline Groups & Count & Sum & Average & Variance \\
\hline Column 1 & 6 & 18 & 3 & 0.4 \\
Column 2 & 6 & 19 & 3.166667 & 1.366667 \\
Column 3 & 6 & 12 & 2 & 1.2 \\
Column 4 & 6 & 19 & 3.166667 & 2.566667 \\
\hline
\end{tabular}

ANOVA

\begin{tabular}{lcrcccc}
\hline \multicolumn{1}{c}{$\begin{array}{c}\text { Source of } \\
\text { Variation }\end{array}$} & \multicolumn{1}{c}{$S S$} & df & MS & $F$ & P-value & F crit \\
\hline Between Groups & 5.666667 & 3 & 1.888889 & 1.365462 & 0.281982 & 3.098391 \\
Within Groups & 27.66667 & 20 & 1.383333 & & & \\
Total & & & & & & \\
\hline
\end{tabular}


B50

Anova: Single Factor (B50)

SUMMARY

\begin{tabular}{lrrrr}
\hline Groups & Count & \multicolumn{1}{c}{ Sum } & Average & Variance \\
\hline Column 1 & 6 & 18 & 3 & 1.2 \\
Column 2 & 6 & 22 & 3.666667 & 1.066667 \\
Column 3 & 6 & 21 & 3.5 & 2.7 \\
Column 4 & 6 & 19 & 3.166667 & 0.966667 \\
\hline
\end{tabular}

ANOVA

\begin{tabular}{lcrcccc}
\hline \multicolumn{1}{c}{$\begin{array}{c}\text { Source of } \\
\text { Variation }\end{array}$} & \multicolumn{1}{c}{ SS } & df & MS & $F$ & P-value & F crit \\
\hline Between Groups & 1.666667 & 3 & 0.555556 & 0.374532 & 0.772292 & 3.098391 \\
Within Groups & 29.66667 & 20 & 1.483333 & & & \\
& & & & & & \\
Total & 31.33333 & 23 & & & & \\
\hline
\end{tabular}

B20

Anova:

Single

Factor

SUMMARY

\begin{tabular}{lrrcc}
\hline \multicolumn{1}{c}{ Groups } & \multicolumn{1}{c}{ Count } & \multicolumn{1}{c}{ Sum } & Average & Variance \\
\hline T1 & 6 & 16 & 2.666666667 & 1.066666667 \\
T2 & 6 & 19 & 3.166666667 & 0.566666667 \\
T3 & 6 & 19 & 3.166666667 & 1.366666667 \\
T4 & 6 & 19 & 3.166666667 & 1.7666666667 \\
\hline
\end{tabular}

\begin{tabular}{lrrrrrr} 
ANOVA & & & & & & \\
\hline $\begin{array}{l}\text { Source of } \\
\text { Variation }\end{array}$ & \multicolumn{1}{c}{ SS } & \multicolumn{1}{c}{ df } & \multicolumn{1}{c}{$M S$} & $F$ & P-value & F crit \\
\hline Between & & & & & & \\
Groups & 1.125 & 3 & 0.375 & 0.314685315 & 0.814567 & 3.098391 \\
Within & & & & & & \\
Groups & 23.83333 & 20 & 1.191666667 & & & \\
Total & 24.95833 & 23 & & & & \\
\hline
\end{tabular}




\section{B5}

Anova: Single Factor

SUMMARY

\begin{tabular}{crrrr}
\hline Groups & \multicolumn{1}{c}{ Count } & \multicolumn{1}{c}{ Sum } & Average & Variance \\
\hline Column 1 & 6 & 20 & 3.333333 & 1.066667 \\
Column 2 & 6 & 23 & 3.833333 & 1.366667 \\
Column 3 & 6 & 25 & 4.166667 & 1.766667 \\
Column 4 & 6 & 25 & 4.166667 & 0.966667 \\
\hline
\end{tabular}

\begin{tabular}{|c|c|c|c|c|c|c|}
\hline \\
\hline $\begin{array}{l}\text { Source of } \\
\text { Variation }\end{array}$ & SS & $d f$ & MS & $F$ & $P$-value & $F$ crit \\
\hline Between Groups & 2.791667 & 3 & 0.930556 & 0.72043 & 0.551483 & 3.098391 \\
\hline Within Groups & 25.83333 & 20 & 1.291667 & & & \\
\hline Total & 28.625 & 23 & & & & \\
\hline
\end{tabular}

B20 (Topia)

Anova: Single

Factor

SUMMARY

\begin{tabular}{|c|c|c|c|c|}
\hline Groups & Count & Sum & Average & Variance \\
\hline T1 & 6 & 15 & 2.5 & 1.5 \\
\hline T2 & 6 & 18 & 3 & 0.4 \\
\hline T3 & 6 & 17 & 2.833333 & 1.366667 \\
\hline T4 & 6 & 18 & 3 & 1.2 \\
\hline
\end{tabular}

\begin{tabular}{lrrrrrr} 
ANOVA \\
\hline Source of Variation & \multicolumn{1}{c}{$S S$} & \multicolumn{1}{c}{ df } & MS & $F$ & P-value & F crit \\
\hline Between Groups & 1 & 3 & 0.333333 & 0.298507 & 0.826048 & 3.098391 \\
Within Groups & 22.33333 & 20 & 1.116667 & & & \\
& & & & & & \\
Total & 23.33333 & 23 & & & & \\
\hline
\end{tabular}


Diesel 24 hrs

\section{Summary Statistics and ANOVA}

Transformation $=\quad$ None

\begin{tabular}{llrlr} 
Conc. (ppm) & $\mathrm{n}$ & Mean & s.d. & cv8 \\
\hline $1=$ control & 4 & 1.0000 & .0000 & .0 \\
$1.57^{*}$ & 4 & .6000 & .3651 & 60.9 \\
$3.13^{*}$ & 4 & .2500 & .1000 & 40.0 \\
$6.25^{*}$ & 4 & .1500 & .1915 & 127.7 \\
$12.5^{*}$ & 4 & .1000 & .1155 & 115.5 \\
$25^{*}$ & 4 & .1000 & .1155 & 115.5 \\
$50^{*}$ & 4 & .1000 & .2000 & 200.0
\end{tabular}

*) the mean for this conc. is significantly less than the control mean at alpha $=0.05$ (1-sided) by Dunnett's test

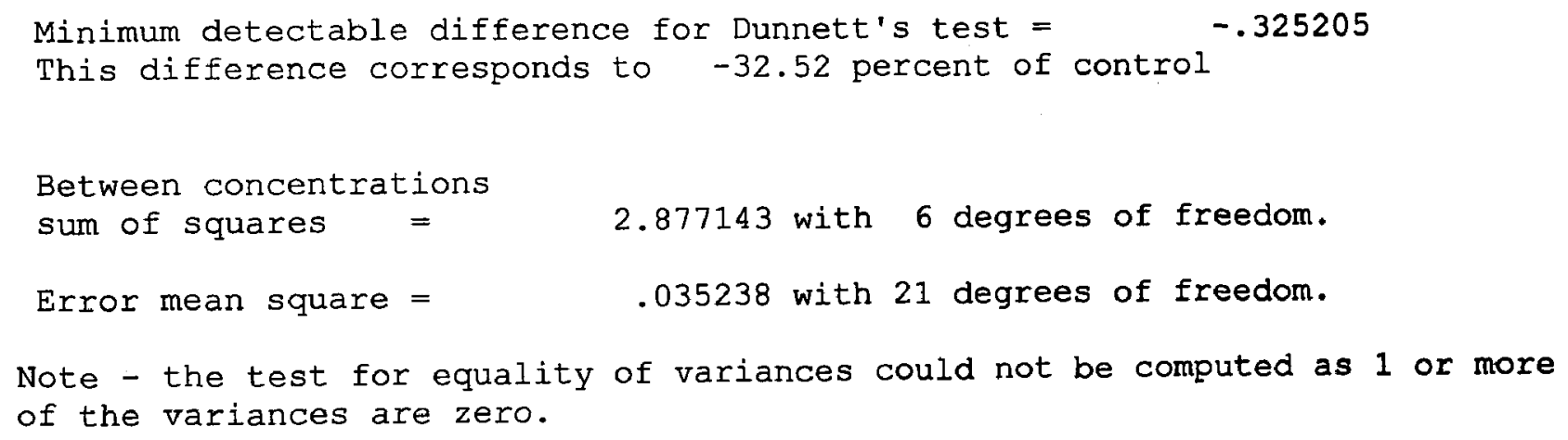


B100 24hrs

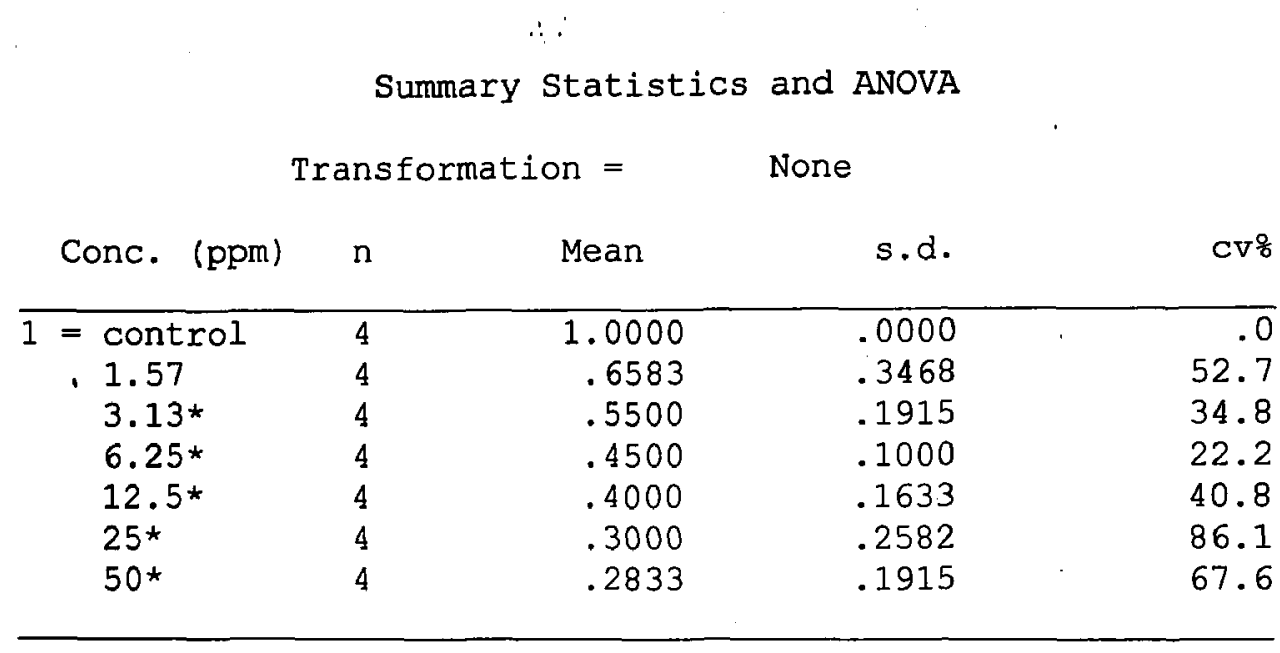

*) the mean for this conc. is significantly less than

the control mean at alpha $=0.05$ (1-sided) by Dunnett's test

Minimum detectable difference for Dunnett's test $=\quad-.356812$

This difference corresponds to -35.68 percent of control

Between concentrations

sum of squares $=1.496587$ with 6 degrees of freedom.

Error mean square $=\quad .042421$ with 21 degrees of freedom.

Note - the test for equality of variances could not be computed as 1 or more of the variances are zero. 
B50 $24 \mathrm{hrs}$

\begin{tabular}{llllr}
\multicolumn{7}{c}{ Sumary Statistics and ANOVA } \\
\multicolumn{7}{c}{ Transformation $=$} & None & \\
Conc. (ppm) & $\mathrm{n}$ & Mean & s.d. & cv8 \\
\hline $1=$ control & 4 & 1.0000 & .0000 & .0 \\
$1.57^{*}$ & 4 & .5750 & .0500 & 42.6 \\
$3.13^{*}$ & 4 & .4500 & .1915 & 120.0 \\
$6.25^{*}$ & 4 & .2500 & .3000 & .0 \\
$12^{*}$ & 4 & .2000 & .0000 & .0 \\
$25^{*}$ & 4 & .2000 & .0000 & 66.7 \\
$50^{*}$ & 4 & .1500 & .1000 &
\end{tabular}

*) the mean for this conc. is significantly less than the control mean at alpha $=0.05$ ( 1 -sided) by Dunnett's test

Minimum detectable difference for Dunnett's test $=$
This difference corresponds to -24.43 percent of control

Between concentrations

sum of squares =

2.232143 with 6 degrees of freedom.

Error mean square $=\quad .019881$ with 21 degrees of freedom.

Note - the test for equality of variances could not be computed as 1 or more of the variances are zero. 
B20 $24 \mathrm{hrs}$

\begin{tabular}{ccccc}
\multicolumn{5}{c}{ Summary Statistics and ANOVA } \\
& \multicolumn{2}{c}{ Transformation $=$} & None & \\
Conc. & $\mathrm{n}$ & Mean & s.d. & cv8 \\
\hline $1=$ control & 4 & 1.0000 & .0000 & .0 \\
$2^{*}$ & 4 & .6000 & .1633 & 27.2 \\
$3^{*}$ & 4 & .6444 & .1859 & 28.9 \\
$4^{*}$ & 4 & .4000 & .1633 & 40.8 \\
$5^{*}$ & 4 & .3500 & .1915 & 54.7 \\
$6^{*}$ & 4 & .2833 & .1000 & 35.3 \\
$7 *$ & 4 & .2417 & .1067 & 44.2 \\
\hline
\end{tabular}

*) the mean for this conc. is significantly less than the control mean at alpha $=0.05$ (1-sided) by Dunnett's test

Minimum detectable difference for Dunnett's test $=\quad-.250158$ This difference corresponds to -25.02 percent of control

Between concentrations

sum of squares $=\quad 1.707963$ with 6 degrees of freedom.

Error mean square $=\quad .020851$ with 21 degrees of freedom.

Note - the test for equality of variances could not be computed as 1 or more of the variances are zero. 
B5 $24 \mathrm{hrs}$

\begin{tabular}{llrrr}
\multicolumn{7}{c}{ Summary Statistics and ANOVA } \\
\multicolumn{7}{c}{ Transformation $=$} & None \\
Conc. (ppm) & $\mathrm{n}$ & Mean & s.d. & cv8 \\
\hline $1=$ control & 4 & 1.0000 & .0000 & .0 \\
$1.57^{*}$ & 4 & .5500 & .1000 & 18.2 \\
$3.13^{*}$ & 4 & .4000 & .0000 & .0 \\
$6.25^{*}$ & 4 & .2000 & .1633 & 81.6 \\
$12.5^{*}$ & 4 & .1000 & .2000 & 200.0 \\
$25^{*}$ & 4 & .1000 & .115 .5 & 115.5 \\
$50^{*}$ & 4 & .0000 & .0000 & .0 \\
\hline
\end{tabular}

*) the mean for this conc. is significantly less than the control mean at alpha $=0.05(1$-sided $)$ by Dunnett's test

Minimum detectable difference for Dunnett's test $=$ $-.196437$ This difference corresponds to -19.64 percent of control
Between concentrations
sum of squares =
2.934286 with 6 degrees of freedom.
Error mean square $=$
.012857 with 21 degrees of freedom.

Note - the test for equality of variances could not be computed as 1 or more of the variances are zero. 
B20 (Topia) $24 \mathrm{hrs}$

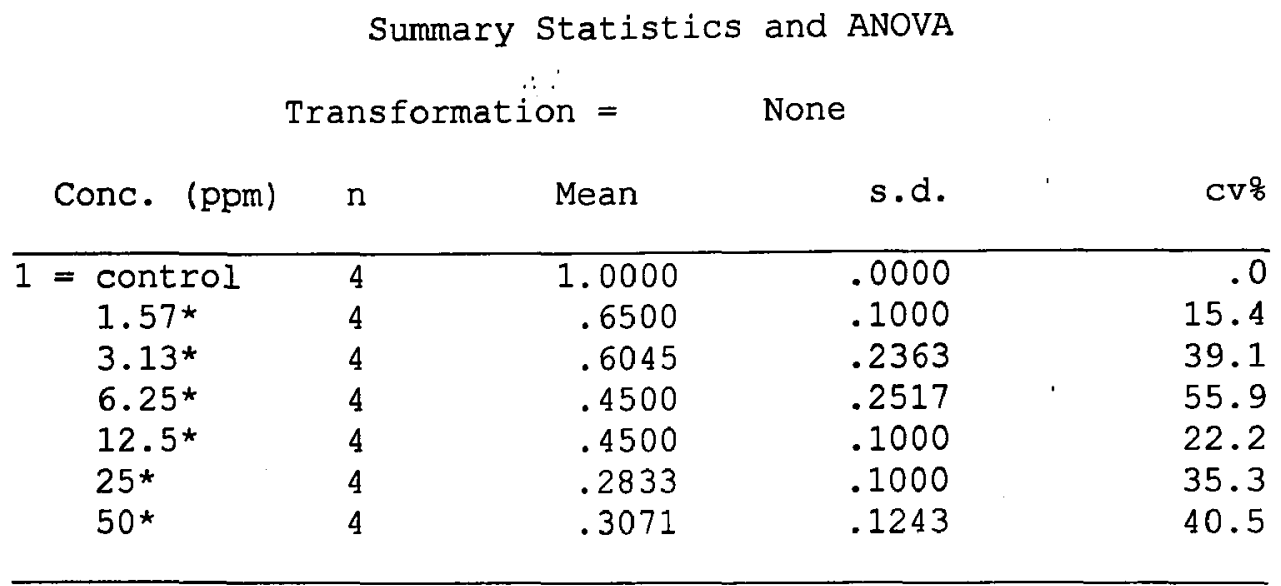

*) the mean for this conc. is significantly less than the control mean at alpha $=0.05$ (1-sided) by Dunnett's test

sum of squares =

1.455966 with 6 degrees of freedom.

Error mean square $=\quad .023517$ with 21 degrees of freedom.

Note - the test for equality of variances could not be computed as 1 or more of the variances are zero. 
TRIMMED SPEARMAN-KARBER METHOD. MONTANA STATE UNIV

FOR REFERENCE, CITE:

HAMILTON, M.A., R.C. RUSSO, AND R.V. THURSTON, 1977.

TRIMMED SPEARMAN-KARBER METHOD FOR ESTIMATING MEDIAN LETHAL CONCENTRATIONS IN TOXICITY BIOASSAYS.

ENVIRON. SCI. TECHNOL. 11(7): 714-719;

CORRECTION 12(4):417 (1978).

DATE: $3-15-2005$

TEST NUMBER: $\mathrm{T} 1+\mathrm{T} 2+\mathrm{T} 3+\mathrm{T} 4$

CHEMICAL: DIESEL

SPECIES: DAPHNIA MAGNA

RAW DATA:

CONCENTRATION(PPM ) $\quad 1.57 \quad 3.13 \quad 6.25 \quad 12.50 \quad 25.00 \quad 50.00$

$\begin{array}{lllllll}\text { NUMBER EXPOSED: } & 18 & 20 & 20 & 20 & 20 & 20\end{array}$

DURATION (HOURS) LC50 LOWER 95\% LIMIT UPPER 95\% LIMIT \%TRIM

24

1.78

1.15

2.76

44.44 
TRIMMED SPEARMAN-KARBER METHOD. MONTANA STATE UNIV

FOR REFERENCE, CITE:

HAMILTON, M.A., R.C. RUSSO, AND R.V. THURSTON, 1977.

TRIMMED SPEARMAN-KARBER METHOD FOR ESTIMATING MEDIAN LETHAL CONCENTRATIONS IN TOXICITY BIOASSAYS.

ENVIRON. SCI. TECHNOL. 11(7): 714-719;

CORRECTION 12(4):417 (1978).

DATE: $3-15-2005$

TEST NUMBER: $\mathrm{T} 1+\mathrm{T} 2+\mathrm{T} 3+\mathrm{T} 4$

CHEMICAL: B100

SPECIES: DAPHNIA MAGNA

RAW DATA:

CONCENTRATION(PPM) $\quad 1.57 \quad 3.13 \quad 6.25 \quad 12.50 \quad 25.00 \quad 50.00$

NUMBER EXPOSED: $\quad \begin{array}{llllll}22 & 20 & 20 & 20 & 20 & 20\end{array}$

DURATION (HOURS) LC50 LOWER 95\% LIMIT UPPER 95\% LIMIT \%TRIM

24

$4.65 \quad 2.22$

9.72

31.82 
TRIMMED SPEARMAN-KARBER METHOD. MONTANA STATE UNIV

FOR REFERENCE, CITE:

HAMILTON, M.A., R.C. RUSSO, AND R.V. THURSTON, 1977.

TRIMMED SPEARMAN-KARBER METHOD FOR ESTIMATING MEDIAN

LETHAL CONCENTRATIONS IN TOXICITY BIOASSAYS.

ENVIRON. SCI. TECHNOL. 11(7): 714-719;

CORRECTION 12(4):417 (1978).

DATE: $3-15-2005$

TEST NUMBER: T1+T2+T3+T4

CHEMICAL: B50

SPECIES: DAPHNIA MAGNA

RAW DATA:

CONCENTRATION (PPM) $\quad 1.57 \quad 3.13 \quad 6.25 \quad 12.50 \quad 25.00 \quad 50.00$

$\begin{array}{lllllll}\text { NUMBER EXPOSED: } & 17 & 20 & 20 & 20 & 20 & 20\end{array}$

DURATION (HOURS) LC50 LOWER 95\% LIMIT UPPER 95\% LIMIT \%TRIM ।

$\begin{array}{lllll}24 & 3.29 & 1.36 & 7.95 & 41.18\end{array}$


TRIMMED SPEARMAN-KARBER METHOD. MONTANA STATE UNIV

FOR REFERENCE, CITE:

HAMILTON, M.A., R.C. RUSSO, AND R.V. THURSTON, 1977.

TRIMMED SPEARMAN-KARBER METHOD FOR ESTIMATING MEDIAN

LETHAL CONCENTRATIONS IN TOXICITY BIOASSAYS.

ENVIRON. SCI. TECHNOL. 11(7): 714-719;

CORRECTION 12(4):417 (1978).

DATE:

CHEMICAL: B20

RAW DATA:

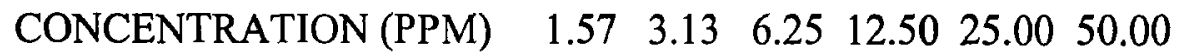

NUMBER EXPOSED: $\quad \begin{array}{llllll}20 & 24 & 20 & 20 & 21 & 21\end{array}$

DURATION (HOURS) LC50 LOWER 95\% LIMIT UPPER 95\% LIMIT \%TRIM

24
TEST NUMBER:

SPECIES: DM
$4.54 \quad 2.55$

8.09

38.64 
TRIMMED SPEARMAN-KARBER METHOD. MONTANA STATE UNIV

FOR REFERENCE, CITE:

HAMILTON, M.A., R.C. RUSSO, AND R.V. THURSTON, 1977.

TRIMMED SPEARMAN-KARBER METHOD FOR ESTIMATING MEDIAN

LETHAL CONCENTRATIONS IN TOXICITY BIOASSAYS.

ENVIRON. SCI. TECHNOL. 11(7): 714-719;

CORRECTION 12(4):417 (1978).

DATE: $3-15-2005$

TEST NUMBER: $\mathrm{T} 1+\mathrm{T} 2+\mathrm{T} 3+\mathrm{T} 4$

CHEMICAL: B5

SPECIES: DAPHNIA MAGNA

RAW DATA:

CONCENTRATION(PPM) $\quad 1.57 \quad 3.13 \quad 6.25 \quad 12.50 \quad 25.00 \quad 50.00$

NUMBER EXPOSED: $\quad \begin{array}{llllll}20 & 20 & 20 & 20 & 20 & 20\end{array}$

DURATION (HOURS ) LC50 LOWER 95\% LIMIT UPPER 95\% LIMIT \% TRIM

24

$1.98 \quad 0.92$

4.23

45.00 
TRIMMED SPEARMAN-KARBER METHOD. MONTANA STATE UNIV

FOR REFERENCE, CITE:

HAMILTON, M.A., R.C. RUSSO, AND R.V. THURSTON, 1977.

TRIMMED SPEARMAN-KARBER METHOD FOR ESTIMATING MEDIAN

LETHAL CONCENTRATIONS IN TOXICITY BIOASSAYS.

ENVIRON. SCI. TECHNOL. 11(7): 714-719;

CORRECTION 12(4):417 (1978).

DATE: $3-15-2005$

TEST NUMBER: $\mathrm{T} 1+\mathrm{T} 2+\mathrm{T} 3+\mathrm{T} 4$

CHEMICAL: B20 (TOPIA)

SPECIES: DAPHNIA MAGNA

RAW DATA:

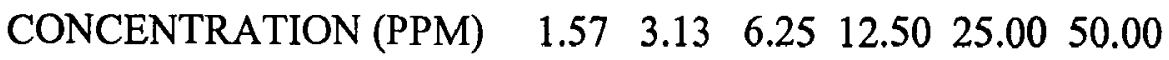

$\begin{array}{lllllll}\text { NUMBER EXPOSED: } & 20 & 26 & 20 & 20 & 20 & 22\end{array}$

DURATION (HOURS) LC50 LOWER 95\% LIMIT UPPER 95\% LIMIT \%TRIM

24

$6.74 \quad 3.25$

13.96

34.78 
11. APPENDIX C: O. mykiss Bioassay Data

$\therefore$

4 


\section{TABLE 1}

TEMPERATURE AFFECT ON O. MYKISS MORTALITY USING CONTROL WATER TRIAL \#1 OF 4 TRIALS

\begin{tabular}{||c|c|c|c|c|c|c||}
\hline \hline Temperature $\left.{ }^{\circ} \mathrm{C}\right)$ & $0 \mathrm{hrs}$ & $6 \mathrm{hrs}$ & $12 \mathrm{hrs}$ & $24 \mathrm{hrs}$ & $48 \mathrm{hrs}$ & $72 \mathrm{hrs}$ \\
\hline 25 & $9^{*}$ & 6 & 3 & 0 & 0 & 0 \\
\hline 22 & 9 & 6 & 4 & 1 & 0 & 0 \\
\hline 18 & 10 & 8 & 5 & 1 & 1 & 0 \\
\hline 15 & 10 & 10 & 10 & 9 & 8 & 8 \\
\hline 12 & 10 & 10 & 10 & 10 & 10 & 10 \\
\hline 8 & 10 & 10 & 10 & 10 & 10 & 10 \\
\hline 4 & 10 & 10 & 10 & 10 & 6 & 5 \\
\hline
\end{tabular}

\section{TABLE 2}

TEMPERATURE AFFECT ON O. MYKISS MORTALITY USING CONTROL WATER TRIAL \#2 OF 4 TRIALS

\begin{tabular}{||c|c|c|c|c|c|c||}
\hline Temperature $\left.{ }^{\circ} \mathrm{C}\right)$ & $0 \mathrm{hrs}$ & $6 \mathrm{hrs}$ & $12 \mathrm{hrs}$ & $24 \mathrm{hrs}$ & $48 \mathrm{hrs}$ & $72 \mathrm{hrs}$ \\
\hline 25 & 10 & 5 & 3 & 1 & 0 & 0 \\
\hline 22 & 10 & 7 & 4 & 3 & 1 & 0 \\
\hline 18 & 10 & 8 & 6 & 4 & 1 & 1 \\
\hline 15 & 10 & 10 & 10 & 9 & 8 & 8 \\
\hline 12 & 10 & 10 & 10 & 10 & 10 & 10 \\
\hline 8 & 10 & 10 & 10 & 10 & 10 & 10 \\
\hline 4 & 10 & 9 & 9 & 7 & 6 & 5 \\
\hline
\end{tabular}




\section{TABLE 3}

TEMPERATURE AFFECT ON O. MYKISS MORTALITY USING CONTROL WATER TRIAL \#3 OF 4 TRIALS

\begin{tabular}{||c|c|c|c|c|c|c|}
\hline Temperature $\left.{ }^{\circ} \mathrm{C}\right)$ & $0 \mathrm{hrs}$ & $6 \mathrm{hrs}$ & $12 \mathrm{hrs}$ & $24 \mathrm{hrs}$ & $48 \mathrm{hrs}$ & $72 \mathrm{hrs}$ \\
\hline 25 & 10 & 6 & 5 & 2 & 0 & 0 \\
\hline 22 & 10 & 7 & 4 & 2 & 1 & 0 \\
\hline 18 & 10 & 7 & 5 & 1 & 1 & 0 \\
\hline 15 & 10 & 10 & 9 & 9 & 9 & 9 \\
\hline 12 & 10 & 10 & 10 & 10 & 10 & 10 \\
\hline 8 & 9 & 9 & 9 & 9 & 9 & 8 \\
\hline 4 & 10 & 10 & 10 & 10 & 6 & 5 \\
\hline
\end{tabular}

TABLE 4

TEMPERATURE AFFECT ON O. MYKISS MORTALITY USING CONTROL WATER TRIAL \#4 OF 4 TRIALS

\begin{tabular}{||c|c|c|c|c|c|c|}
\hline Temperature $\left({ }^{\circ} \mathrm{C}\right)$ & $0 \mathrm{hrs}$ & $6 \mathrm{hrs}$ & $12 \mathrm{hrs}$ & $24 \mathrm{hrs}$ & $48 \mathrm{hrs}$ & $72 \mathrm{hrs}$ \\
\hline 25 & 10 & 7 & 4 & 2 & 0 & 0 \\
\hline 22 & 9 & 5 & 4 & 2 & 0 & 0 \\
\hline 18 & 10 & 8 & 5 & 1 & 1 & 0 \\
\hline 15 & 9 & 9 & 9 & 8 & 8 & 8 \\
\hline 12 & 10 & 10 & 10 & 10 & 10 & 10 \\
\hline 8 & 10 & 10 & 10 & 10 & 10 & 10 \\
\hline 4 & 10 & 10 & 10 & 10 & 6 & 5 \\
\hline
\end{tabular}

*Number of live trout frys 
TABLE 5

RANGE FINDING TEST FOR (4 week old) O. MYKISS

\begin{tabular}{||c|c|c|c|c|c|c|c|c|c||}
\hline $\begin{array}{c}\text { Concentration } \\
(\mathrm{ppm})\end{array}$ & \multicolumn{9}{c|}{ Survival of 2 Trials* after 96hrs } \\
\hline & \multicolumn{3}{|c|}{ Diesel } & \multicolumn{3}{c||}{ B100 } & \multicolumn{3}{c||}{ B20 } \\
\hline & $\begin{array}{c}\text { Trial } \\
1\end{array}$ & $\begin{array}{c}\text { Trial } \\
\end{array}$ & Average & Trial & Trial & Average & Trial & Trial & Average \\
& & 1 & 2 & & 1 & 2 & \\
\hline Control & 7 & 9 & 8 & 9 & 10 & 9.5 & 7 & 7 & 7 \\
\hline 10 & 4 & 3 & 3.5 & 3 & 5 & 4 & 6 & 4 & 5 \\
\hline 50 & 0 & 1 & 0.5 & 1 & 1 & 1 & 0 & 0 & 0 \\
\hline
\end{tabular}

* 10 fish fry per trial

\section{TABLE 6}

RANGE FINDING TEST FOR (6 week old) O. MYKISS

\begin{tabular}{|c|c|c|c|c|c|c|c|c|c|}
\hline \multirow{3}{*}{$\begin{array}{c}\begin{array}{c}\text { Concentration } \\
(\mathrm{ppm})\end{array} \\
\end{array}$} & \multicolumn{9}{|c|}{ Survival of 2 Trials* after $96 \mathrm{hrs}$} \\
\hline & \multicolumn{3}{|c|}{ Diesel } & \multicolumn{3}{|c|}{$\mathrm{B} 100$} & \multicolumn{3}{|c|}{$\bar{B} 20$} \\
\hline & $\begin{array}{c}\text { Trial } \\
1\end{array}$ & $\begin{array}{c}\text { Trial } \\
2\end{array}$ & Average & $\begin{array}{c}\text { Trial } \\
1\end{array}$ & $\begin{array}{c}\text { Trial } \\
2\end{array}$ & Average & $\begin{array}{c}\text { Trial } \\
1\end{array}$ & $\begin{array}{c}\text { Trial } \\
2\end{array}$ & Average \\
\hline Control & 10 & 10 & 10 & 10 & 10 & 10 & 10 & 10 & 10 \\
\hline 2.5 & 10 & 10 & 10 & 10 & 10 & 10 & 10 & 10 & 10 \\
\hline 10 & 10 & 10 & 10 & 10 & 10 & 10 & 10 & 10 & 10 \\
\hline 50 & 10 & 10 & 10 & 10 & 10 & 10 & 10 & 10 & 10 \\
\hline 90 & 10 & 9 & 9.5 & 10 & 10 & 10 & 10 & 10 & 10 \\
\hline 100 & 9 & 8 & 8.5 & 9 & 9 & 9 & 10 & 10 & 10 \\
\hline 1000 & 2 & 1 & 1.5 & 3 & 3 & 3 & 2 & 2 & 2 \\
\hline 2000 & 0 & 0 & 0 & 0 & 0 & 0 & 0 & 0 & 0 \\
\hline
\end{tabular}

* 10 fish fry per trial 
TABLE 7

O. MYKISS PARAMETER DATA

\begin{tabular}{|c|c|c|c|}
\hline TRIAL & $\begin{array}{l}\text { TEMPERATURE } \\
\left({ }^{\circ} \mathrm{C}\right)\end{array}$ & $\mathrm{pH}$ & $\begin{array}{c}\text { GENERAL } \\
\text { HARDNESS } \\
(\mathrm{mg} / \mathrm{l})\end{array}$ \\
\hline $\begin{array}{l}\text { Diesel } 100 \mathrm{ppm} \\
\mathrm{T} 1(0 \mathrm{hr})\end{array}$ & 14 & 8.46 & 40 \\
\hline $\begin{array}{l}\text { Diesel 100 ppm } \\
\mathrm{T} 1 \text { (96hr) }\end{array}$ & 14 & 8.44 & 40 \\
\hline $\begin{array}{l}\text { Diesel } 300 \mathrm{ppm} \\
\mathrm{T} 1 \text { (0hr) }\end{array}$ & 14 & 7.79 & 20 \\
\hline $\begin{array}{l}\text { Diesel } 300 \mathrm{ppm} \\
\text { T1 }(96 \mathrm{hr})\end{array}$ & 14 & 7.95 & 20 \\
\hline $\begin{array}{l}\text { Diesel } 600 \mathrm{ppm} \\
\mathrm{T} 1(0 \mathrm{hr})\end{array}$ & 12 & 8.31 & 20 \\
\hline $\begin{array}{l}\text { Diesel } 600 \mathrm{ppm} \\
\mathrm{T} 1(96 \mathrm{hr})\end{array}$ & 12 & 7.84 & 20 \\
\hline $\begin{array}{l}\text { Diesel } 900 \mathrm{ppm} \\
\mathrm{T} 1 \text { (0hr) }\end{array}$ & 12 & 7.81 & 20 \\
\hline $\begin{array}{l}\text { Diesel } 900 \mathrm{ppm} \\
\mathrm{T} 1(96 \mathrm{hr})\end{array}$ & 12 & 7.94 & 20 \\
\hline $\begin{array}{l}\text { Diesel } 1200 \mathrm{ppm} \\
\mathrm{T} 1 \text { (0hr) }\end{array}$ & 11 & 7.86 & 20 \\
\hline $\begin{array}{l}\text { Diesel } 1200 \mathrm{ppm} \\
\mathrm{T} 1(96 \mathrm{hr})\end{array}$ & 11 & 8.03 & 20 \\
\hline $\begin{array}{l}\text { Diesel } 100 \mathrm{ppm} \\
\text { T2 (0hr) }\end{array}$ & 12 & 8.71 & 20 \\
\hline $\begin{array}{l}\text { Diesel } 100 \mathrm{ppm} \\
\text { T2 }(96 \mathrm{hr})\end{array}$ & 12 & 7.44 & 20 \\
\hline $\begin{array}{l}\text { Diesel } 300 \mathrm{ppm} \\
\mathrm{T} 2(0 \mathrm{hr})\end{array}$ & 12 & 7.72 & 20 \\
\hline $\begin{array}{l}\text { Diesel } 300 \mathrm{ppm} \\
\mathrm{T} 2(96 \mathrm{hr})\end{array}$ & 12 & 7.05 & 20 \\
\hline $\begin{array}{l}\text { Diesel } 600 \mathrm{ppm} \\
\mathrm{T} 2 \text { (0hr) }\end{array}$ & 14 & 8.11 & 20 \\
\hline $\begin{array}{l}\text { Diesel } 600 \mathrm{ppm} \\
\text { T2 (96hr) }\end{array}$ & 14 & 7.64 & 20 \\
\hline $\begin{array}{l}\text { Diesel } 900 \mathrm{ppm} \\
\mathrm{T} 2 \text { (0hr) }\end{array}$ & 14 & 7.39 & 20 \\
\hline $\begin{array}{l}\text { Diesel } 900 \mathrm{ppm} \\
\text { T2 }(96 \mathrm{hr}) \\
\end{array}$ & 14 & 7.44 & 20 \\
\hline Diesel $1200 \mathrm{ppm}$ & 14 & 7.69 & 20 \\
\hline
\end{tabular}




\begin{tabular}{|c|c|c|c|}
\hline $\mathrm{T} 2(0 \mathrm{hr})$ & & & \\
\hline $\begin{array}{l}\text { Diesel } 1200 \mathrm{ppm} \\
\text { T2 (96hr) }\end{array}$ & 14 & 8.13 & 20 \\
\hline $\begin{array}{l}\text { B100 } 100 \text { ppm T1 } \\
(0 \mathrm{hr})\end{array}$ & 14 & 8.27 & 20 \\
\hline $\begin{array}{l}\text { B100 } 100 \text { ppm T1 } \\
\text { (96hr) }\end{array}$ & 14 & 8.39 & 20 \\
\hline $\begin{array}{l}\text { B100 } 300 \mathrm{ppm} \mathrm{T1} \\
(0 \mathrm{hr})\end{array}$ & 14 & 7.55 & 20 \\
\hline $\begin{array}{l}\text { B100 } 300 \mathrm{ppm} \mathrm{T1} \\
(96 \mathrm{hr})\end{array}$ & 14 & 7.81 & 20 \\
\hline $\begin{array}{l}\text { B100 } 600 \mathrm{ppm} \mathrm{T1} \\
\text { (0hr) }\end{array}$ & 11 & 7.64 & 20 \\
\hline $\begin{array}{l}\text { B100 } 600 \mathrm{ppm} \mathrm{T1} \\
(96 \mathrm{hr})\end{array}$ & 11 & 7.40 & 20 \\
\hline $\begin{array}{l}\text { B100 } 900 \mathrm{ppm} \mathrm{T1} \\
(0 \mathrm{hr})\end{array}$ & 11 & 7.08 & 20 \\
\hline $\begin{array}{l}\text { B100 } 900 \mathrm{ppm} \mathrm{T1} \\
(96 \mathrm{hr})\end{array}$ & 14 & 7.19 & 20 \\
\hline $\begin{array}{l}\text { B100 1200 ppm } \\
\text { T1 (Ohr) }\end{array}$ & 14 & 7.25 & 20 \\
\hline $\begin{array}{l}\text { B100 1200 ppm } \\
\text { T1 (96hr) }\end{array}$ & 14 & 7.44 & 20 \\
\hline $\begin{array}{l}\text { B100 } 100 \text { ppm T2 } \\
\text { (Ohr) }\end{array}$ & 14 & 7.46 & 20 \\
\hline $\begin{array}{l}\text { B100 } 100 \mathrm{ppm} \mathrm{T2} \\
(96 \mathrm{hr})\end{array}$ & 12 & 8.45 & 20 \\
\hline $\begin{array}{l}\text { B100 } 300 \text { ppm T2 } \\
\text { (0hr) }\end{array}$ & 12 & 7.31 & 20 \\
\hline $\begin{array}{l}\text { B100 } 300 \text { ppm T2 } \\
(96 \mathrm{hr})\end{array}$ & 12 & 7.07 & 20 \\
\hline $\begin{array}{l}\text { B100 } 600 \text { ppm T2 } \\
\text { (0hr) }\end{array}$ & 11 & 8.21 & 20 \\
\hline $\begin{array}{l}\text { B100 } 600 \mathrm{ppm} \mathrm{T2} \\
(96 \mathrm{hr})\end{array}$ & 11 & 7.94 & 20 \\
\hline $\begin{array}{l}\text { B100 } 900 \text { ppm T2 } \\
\text { (0hr) }\end{array}$ & 12 & 7.61 & 20 \\
\hline $\begin{array}{l}\text { B100 } 900 \text { ppm T2 } \\
(96 \mathrm{hr})\end{array}$ & $\overline{12}$ & 7.54 & 20 \\
\hline $\begin{array}{l}\text { B1001200 ppm } \\
\text { T2 (0hr) }\end{array}$ & 12 & 7.16 & 20 \\
\hline $\begin{array}{l}\text { B100 1200 ppm } \\
\text { T2 }(96 \mathrm{hr})\end{array}$ & 12 & 8.23 & 20 \\
\hline
\end{tabular}




\begin{tabular}{|c|c|c|c|}
\hline $\begin{array}{l}\text { B100 } 1200 \mathrm{ppm} \\
\text { T2 }(96 \mathrm{hr})\end{array}$ & 12 & 8.41 & 20 \\
\hline $\begin{array}{l}\mathrm{B} 50100 \mathrm{ppm} \mathrm{T1} \\
\text { (Ohr) }\end{array}$ & 12 & 8.39 & 20 \\
\hline $\begin{array}{l}\text { B50 } 100 \mathrm{ppm} \mathrm{T1} \\
(96 \mathrm{hr})\end{array}$ & 12 & 6.93 & 40 \\
\hline $\begin{array}{l}\mathrm{B} 50300 \mathrm{ppm} \mathrm{T1} \\
(0 \mathrm{hr})\end{array}$ & 12 & 7.52 & 20 \\
\hline $\begin{array}{l}\text { B50 } 300 \mathrm{ppm} \mathrm{T1} \\
(96 \mathrm{hr})\end{array}$ & 14 & 7.72 & 20 \\
\hline $\begin{array}{l}\text { B50 } 600 \mathrm{ppm} \mathrm{T1} \\
(0 \mathrm{hr})\end{array}$ & 11 & 7.69 & 100 \\
\hline $\begin{array}{l}\text { B50 } 600 \mathrm{ppm} \mathrm{T1} \\
(96 \mathrm{hr})\end{array}$ & 11 & 7.29 & 100 \\
\hline $\begin{array}{l}\text { B50 } 900 \mathrm{ppm} \mathrm{T1} \\
(0 \mathrm{hr})\end{array}$ & 14 & 7.71 & 100 \\
\hline $\begin{array}{l}\text { B50 } 900 \mathrm{ppm} \mathrm{T1} \\
(96 \mathrm{hr})\end{array}$ & 14 & 7.52 & 100 \\
\hline $\begin{array}{l}\text { B50 } 1200 \mathrm{ppm} \mathrm{T1} \\
\text { (0hr) }\end{array}$ & 12 & 7.14 & $\overline{20}$ \\
\hline $\begin{array}{l}\text { B50 } 1200 \mathrm{ppm} \mathrm{T1} \\
(96 \mathrm{hr})\end{array}$ & 12 & 6.93 & 20 \\
\hline $\begin{array}{l}\text { B50 100 ppm T2 } \\
\text { (0hr) }\end{array}$ & 12 & 7.78 & 100 \\
\hline $\begin{array}{l}\text { B50 } 100 \mathrm{ppm} \mathrm{T2} \\
\text { (96hr) }\end{array}$ & 12 & 7.31 & 100 \\
\hline $\begin{array}{l}\text { B50 } 300 \mathrm{ppm} \mathrm{T2} \\
\text { (0hr) }\end{array}$ & 12 & 7.80 & 20 \\
\hline $\begin{array}{l}\text { B50 } 300 \text { ppm T2 } \\
(96 \mathrm{hr})\end{array}$ & 12 & 7.65 & 20 \\
\hline $\begin{array}{l}\text { B50 } 600 \mathrm{ppm} \mathrm{T2} \\
(0 \mathrm{hr})\end{array}$ & 14 & 7.42 & 100 \\
\hline $\begin{array}{l}\text { B50 600 ppm T2 } \\
(96 \mathrm{hr})\end{array}$ & 14 & 7.37 & 100 \\
\hline $\begin{array}{l}\text { B50 } 900 \mathrm{ppm} \mathrm{T2} \\
\text { (0hr) }\end{array}$ & 14 & 7.63 & 20 \\
\hline $\begin{array}{l}\text { B50 900 ppm T2 } \\
(96 \mathrm{hr})\end{array}$ & 14 & 7.40 & 20 \\
\hline $\begin{array}{l}\mathrm{B} 501200 \mathrm{ppm} \mathrm{T} 2 \\
\text { (0hr) }\end{array}$ & 12 & 7.98 & 40 \\
\hline $\begin{array}{l}\text { B50 1200 ppm T2 } \\
(96 \mathrm{hr})\end{array}$ & 12 & 8.31 & 40 \\
\hline
\end{tabular}




\begin{tabular}{|c|c|c|c|}
\hline $\begin{array}{l}\text { B20 } 100 \mathrm{ppm} \mathrm{T1} \\
\text { (Ohr) }\end{array}$ & 12 & 7.41 & 20 \\
\hline $\begin{array}{l}\text { B20 } 100 \mathrm{ppm} \mathrm{T1} \\
(96 \mathrm{hr})\end{array}$ & 12 & 8.46 & 20 \\
\hline $\begin{array}{l}\mathrm{B} 20300 \mathrm{ppm} \mathrm{T1} \\
(\mathrm{Ohr})\end{array}$ & 12 & 8.24 & 20 \\
\hline $\begin{array}{l}\text { B20 } 300 \mathrm{ppm} \mathrm{T1} \\
(96 \mathrm{hr})\end{array}$ & 12 & 7.40 & 20 \\
\hline $\begin{array}{l}\mathrm{B} 20600 \mathrm{ppm} \mathrm{T1} \\
(\mathrm{Ohr})\end{array}$ & 12 & 8.26 & 20 \\
\hline $\begin{array}{l}\text { B20 } 600 \mathrm{ppm} \mathrm{T1} \\
(96 \mathrm{hr})\end{array}$ & 12 & 8.15 & 20 \\
\hline $\begin{array}{l}\mathrm{B} 20900 \mathrm{ppm} \mathrm{T1} \\
(\mathrm{Ohr})\end{array}$ & 12 & 7.96 & 20 \\
\hline $\begin{array}{l}\text { B20 } 900 \mathrm{ppm} \mathrm{T1} \\
(96 \mathrm{hr})\end{array}$ & 12 & 8.03 & 20 \\
\hline $\begin{array}{l}\mathrm{B} 201200 \mathrm{ppm} \mathrm{T1} \\
(\mathrm{Ohr})\end{array}$ & 12 & 8.21 & 20 \\
\hline $\begin{array}{l}\text { B20 1200 ppm T1 } \\
(96 \mathrm{hr})\end{array}$ & 12 & 7.48 & 20 \\
\hline $\begin{array}{l}\mathrm{B} 20100 \mathrm{ppm} \mathrm{T2} \\
(\mathrm{Ohr})\end{array}$ & 14 & 7.21 & 20 \\
\hline $\begin{array}{l}\text { B20 } 100 \mathrm{ppm} \mathrm{T2} \\
(96 \mathrm{hr})\end{array}$ & 14 & 7.54 & 20 \\
\hline $\begin{array}{l}\text { B20 } 300 \mathrm{ppm} \mathrm{T2} \\
(\mathrm{Ohr})\end{array}$ & 14 & 7.97 & 20 \\
\hline $\begin{array}{l}\text { B20 300 ppm T2 } \\
(96 \mathrm{hr})\end{array}$ & 14 & 7.64 & 20 \\
\hline $\begin{array}{l}\text { B20 } 600 \mathrm{ppm} \mathrm{T2} \\
(0 \mathrm{hr})\end{array}$ & 11 & 7.35 & 20 \\
\hline $\begin{array}{l}\text { B20 } 600 \mathrm{ppm} \mathrm{T2} \\
(96 \mathrm{hr})\end{array}$ & 11 & 7.31 & 20 \\
\hline $\begin{array}{l}\text { B20 } 900 \mathrm{ppm} \mathrm{T2} \\
(0 \mathrm{hr})\end{array}$ & 12 & 7.89 & 20 \\
\hline $\begin{array}{l}\text { B20 } 900 \text { ppm T2 } \\
\text { (96hr) }\end{array}$ & 12 & 8.02 & 20 \\
\hline $\begin{array}{l}\text { B20 } 1200 \mathrm{ppm} \mathrm{T2} \\
(\mathrm{Ohr})\end{array}$ & 12 & 8.35 & 20 \\
\hline $\begin{array}{l}\text { B5 } 100 \mathrm{ppm} \mathrm{T1} \\
\text { (Ohr) }\end{array}$ & 12 & 8.39 & 20 \\
\hline $\begin{array}{l}\text { B5 } 100 \mathrm{ppm} \mathrm{T1} \\
(96 \mathrm{hr})\end{array}$ & 12 & 7.40 & 20 \\
\hline B5 $300 \mathrm{ppm} \mathrm{T1}$ & 12 & 8.49 & 20 \\
\hline
\end{tabular}




\begin{tabular}{|c|c|c|c|}
\hline$(0 \mathrm{hr})$ & & & \\
\hline $\begin{array}{l}\text { B5 } 300 \mathrm{ppm} \mathrm{T1} \\
\text { (96hr) }\end{array}$ & 12 & 8.76 & 20 \\
\hline $\begin{array}{l}\text { B5 } 600 \mathrm{ppm} \mathrm{T1} \\
(0 \mathrm{hr})\end{array}$ & 12 & 8.52 & 20 \\
\hline $\begin{array}{l}\text { B5 } 600 \mathrm{ppm} \mathrm{T1} \\
(96 \mathrm{hr})\end{array}$ & 12 & 7.74 & 40 \\
\hline $\begin{array}{l}\text { B5 } 900 \mathrm{ppm} \mathrm{T1} \\
\text { (0hr) }\end{array}$ & 12 & 8.35 & 20 \\
\hline $\begin{array}{l}\text { B5 } 900 \mathrm{ppm} \mathrm{T1} \\
(96 \mathrm{hr})\end{array}$ & 14 & 7.81 & 20 \\
\hline $\begin{array}{l}\text { B5 } 1200 \mathrm{ppm} \mathrm{T1} \\
\text { (0hr) }\end{array}$ & 14 & 7.68 & 20 \\
\hline $\begin{array}{l}\text { B5 } 1200 \text { ppm T1 } \\
\text { (96hr) }\end{array}$ & 14 & 7.73 & 20 \\
\hline $\begin{array}{l}\text { B5 } 100 \mathrm{ppm} \mathrm{T2} \\
\text { (0hr) }\end{array}$ & 14 & 8.51 & 40 \\
\hline $\begin{array}{l}\text { B5 } 100 \text { ppm T2 } \\
\text { (96hr) }\end{array}$ & 14 & 8.49 & 40 \\
\hline $\begin{array}{l}\text { B5 } 300 \mathrm{ppm} \mathrm{T2} \\
\text { (0hr) }\end{array}$ & 14 & 8.76 & 20 \\
\hline $\begin{array}{l}\text { B5 } 300 \mathrm{ppm} \mathrm{T2} \\
\text { (96hr) }\end{array}$ & 14 & 8.41 & 20 \\
\hline $\begin{array}{l}\text { B5 } 600 \mathrm{ppm} \mathrm{T2} \\
\text { (0hr) }\end{array}$ & 14 & 7.49 & 20 \\
\hline $\begin{array}{l}\text { B5 } 600 \mathrm{ppm} \mathrm{T2} \\
(96 \mathrm{hr})\end{array}$ & 14 & 6.97 & 20 \\
\hline $\begin{array}{l}\text { B5 } 900 \mathrm{ppm} \mathrm{T2} \\
\text { (Ohr) }\end{array}$ & 11 & 5.13 & 20 \\
\hline $\begin{array}{l}\text { B5 } 900 \text { ppm T2 } \\
\text { (96hr) }\end{array}$ & 12 & 6.62 & 20 \\
\hline $\begin{array}{l}\text { B5 } 1200 \mathrm{ppm} \mathrm{T2} \\
\text { (0hr) }\end{array}$ & 12 & 6.39 & 20 \\
\hline $\begin{array}{l}\text { B5 } 1200 \mathrm{ppm} \mathrm{T2} \\
(96 \mathrm{hr})\end{array}$ & 12 & 7.41 & 20 \\
\hline & & & \\
\hline
\end{tabular}




\section{TABLE 8}

TOXICITY OF DIESEL ON O. MYKISS AT 24HRS (TRIAL 1)

\begin{tabular}{|c|c|c|c||}
\hline $\begin{array}{c}\text { CONCENTRATION } \\
\text { (PPM) }\end{array}$ & NO. SURVIVING & \% ALIVE & \% DEAD \\
\hline Control & 10 & 10 & 0 \\
\hline 100 & 7 & 70 & 30 \\
\hline 300 & 8 & 80 & 20 \\
\hline 600 & 7 & 70 & 30 \\
\hline 900 & 1 & 10 & 90 \\
\hline 1200 & 1 & 10 & 90 \\
\hline $100(\mathrm{ii})$ & 10 & 100 & 0 \\
\hline
\end{tabular}

TABLE 9

TOXICITY OF DIESEL ON O. MYKISS AT 48HRS (TRIAL 1)

\begin{tabular}{||c|c|c|c||}
\hline $\begin{array}{c}\text { CONCENTRATION } \\
\text { (PPM) }\end{array}$ & NO. SURVIVING & \% ALIVE & $\%$ DEAD \\
\hline Control & 10 & 10 & 0 \\
\hline 100 & 5 & 50 & 50 \\
\hline 300 & 6 & 60 & 40 \\
\hline 600 & 5 & 50 & 50 \\
\hline 900 & 1 & 10 & 90 \\
\hline 1200 & 0 & 0 & 100 \\
\hline $100(\mathrm{ii})$ & 9 & 90 & 10 \\
\hline
\end{tabular}

TABLE 10

TOXICITY OF DIESEL ON O. MYKISS AT 72HRS (TRIAL 1)

\begin{tabular}{|c|c|c|c||}
\hline $\begin{array}{c}\text { CONCENTRATION } \\
\text { (PPM) }\end{array}$ & NO. SURVIVING & \% ALIVE & \% DEAD \\
\hline Control & 10 & 10 & 0 \\
\hline 100 & 5 & 50 & 50 \\
\hline 300 & 2 & 20 & 80 \\
\hline 600 & 3 & 30 & 70 \\
\hline 900 & 0 & 0 & 100 \\
\hline 1200 & 0 & 0 & 100 \\
\hline 100 (ii) & 8 & 80 & 20 \\
\hline
\end{tabular}




\section{TABLE 11}

\section{TOXICITY OF DIESEL ON O. MYKISS AT 96HRS (TRIAL 1)}

\begin{tabular}{|c|c|c|c|}
\hline $\begin{array}{c}\text { CONCENTRATION } \\
(\text { PPM })\end{array}$ & NO. SURVIVING & \% ALIVE & \% DEAD \\
\hline Control & 10 & 10 & 0 \\
\hline 100 & 2 & 20 & 80 \\
\hline 300 & 2 & 20 & 80 \\
\hline 600 & 3 & 30 & 70 \\
\hline 900 & 0 & 0 & 100 \\
\hline 1200 & 0 & 0 & 100 \\
\hline $100(\mathrm{ii})$ & 8 & 80 & 20 \\
\hline
\end{tabular}

TABLE 12

TOXICITY OF DIESEL ON O. MYKISS AT 24HRS (TRIAL 2)

\begin{tabular}{|c|c|c|c|}
\hline $\begin{array}{c}\text { CONCENTRATION } \\
\text { (PPM) }\end{array}$ & NO. SURVIVING & \% ALIVE & \% DEAD \\
\hline Control & 10 & 10 & 0 \\
\hline 100 & 8 & 80 & 20 \\
\hline 300 & 7 & 70 & 30 \\
\hline 600 & 7 & 70 & 30 \\
\hline 900 & 1 & 10 & 90 \\
\hline 1200 & 1 & 10 & 90 \\
\hline $600(\mathrm{ii})$ & 7 & 70 & 30 \\
\hline
\end{tabular}

TABLE 13

TOXICITY OF DIESEL ON O. MYKISS AT 48HRS (TRIAL 2)

\begin{tabular}{|c|c|c|c|}
\hline $\begin{array}{c}\text { CONCENTRATION } \\
\text { (PPM) }\end{array}$ & NO. SURVIVING & $\%$ ALIVE & $\%$ DEAD \\
\hline Control & 10 & 10 & 0 \\
\hline 100 & 6 & 60 & 40 \\
\hline 300 & 5 & 50 & 50 \\
\hline 600 & 4 & 40 & 60 \\
\hline 900 & 1 & 10 & 90 \\
\hline 1200 & 0 & 0 & 100 \\
\hline $600(\mathrm{ii})$ & 4 & 40 & 60 \\
\hline
\end{tabular}




\section{TABLE 14}

TOXICITY OF DIESEL ON O. MYKISS AT 72HRS (TRIAL 2)

\begin{tabular}{||c|c|c|c||}
\hline $\begin{array}{c}\text { CONCENTRATION } \\
\text { (PPM) }\end{array}$ & NO. SURVIVING & \% ALIVE & \% DEAD \\
\hline Control & 10 & 10 & 0 \\
\hline 100 & 5 & 50 & 50 \\
\hline 300 & 0 & 0 & 100 \\
\hline 600 & 3 & 30 & 70 \\
\hline 900 & 0 & 0 & 100 \\
\hline 1200 & 0 & 0 & 100 \\
\hline 600 (ii) & 3 & 30 & 70 \\
\hline
\end{tabular}

TABLE 15

TOXICITY OF DIESEL ON O. MYKISS AT 96HRS (TRIAL 2)

\begin{tabular}{|c|c|c|c||}
\hline \hline $\begin{array}{c}\text { CONCENTRATION } \\
\text { (PPM) }\end{array}$ & NO. SURVIVING & \% ALIVE & \% DEAD \\
\hline Control & 10 & 10 & 0 \\
\hline 100 & 1 & 10 & 90 \\
\hline 300 & 0 & 0 & 100 \\
\hline 600 & 3 & 30 & 70 \\
\hline 900 & 0 & 0 & 100 \\
\hline 1200 & 0 & 0 & 100 \\
\hline $600(\mathrm{ii})$ & 2 & 20 & 80 \\
\hline
\end{tabular}

TABLE 16

TOXICITY OF B100 ON O. MYKISS AT 24HRS (TRIAL 1)

\begin{tabular}{||c|c|c|c||}
\hline $\begin{array}{l}\text { CONCENTRATION } \\
\text { (PPM) }\end{array}$ & NO. SURVIVING & \% ALIVE & \% DEAD \\
\hline Control & 10 & 10 & 0 \\
\hline 100 & 9 & 90 & 10 \\
\hline 300 & 10 & 100 & 0 \\
\hline 600 & 7 & 70 & 30 \\
\hline 900 & 9 & 90 & 10 \\
\hline 1200 & 3 & 30 & 70 \\
\hline $600(\mathrm{ii})$ & 10 & 100 & 0 \\
\hline
\end{tabular}


TABLE 17

\section{TOXICITY OF B100 ON O. MYKISS AT 48HRS (TRIAL 1)}

\begin{tabular}{||c|c|c|c|}
\hline $\begin{array}{c}\text { CONCENTRATION } \\
\text { (PPM) }\end{array}$ & NO. SURVIVING & \% ALIVE & \% DEAD \\
\hline Control & 10 & 10 & 0 \\
\hline 100 & 9 & 90 & 10 \\
\hline 300 & 10 & 100 & 0 \\
\hline 600 & 3 & 30 & 70 \\
\hline 900 & 9 & 90 & 10 \\
\hline 1200 & 1 & 10 & 90 \\
\hline 600 (ii) & 8 & 80 & 20 \\
\hline
\end{tabular}

TABLE 18

TOXICITY OF B100 ON O. MYKISS AT 72HRS (TRIAL 1)

\begin{tabular}{|c|c|c|c|}
\hline $\begin{array}{c}\text { CONCENTRATION } \\
(\mathrm{PPM})\end{array}$ & NO. SURVIVING & $\%$ ALIVE & \% DEAD \\
\hline Control & 10 & 10 & 0 \\
\hline 100 & 9 & 90 & 10 \\
\hline 300 & 10 & 100 & 0 \\
\hline 600 & 1 & 10 & 90 \\
\hline 900 & 4 & 40 & 60 \\
\hline 1200 & 1 & 10 & 90 \\
\hline $600(\mathrm{ii})$ & 8 & 80 & 20 \\
\hline
\end{tabular}

\section{TABLE 19}

TOXICITY OFB100 ON O. MYKISS AT 96HRS (TRIAL 1)

\begin{tabular}{|c|c|c|c|}
\hline $\begin{array}{c}\text { CONCENTRATION } \\
\text { (PPM) }\end{array}$ & NO. SURVIVING & $\%$ ALIVE & $\%$ DEAD \\
\hline Control & 10 & 10 & 0 \\
\hline 100 & 9 & 90 & 10 \\
\hline 300 & 10 & 100 & 0 \\
\hline 600 & 1 & 10 & 90 \\
\hline 900 & 2 & 20 & 80 \\
\hline 1200 & 0 & 0 & 100 \\
\hline $600(\mathrm{ii})$ & 5 & 50 & 50 \\
\hline
\end{tabular}


TABLE 20

TOXICITY OF B100 ON O. MYKISS AT 24HRS (TRIAL 2)

\begin{tabular}{||c|c|c|c||}
\hline $\begin{array}{c}\text { CONCENTRATION } \\
\text { (PPM) }\end{array}$ & NO. SURVIVING & \% ALIVE & \% DEAD \\
\hline Control & 10 & 10 & 0 \\
\hline 100 & 7 & 70 & 30 \\
\hline 300 & 10 & 100 & 0 \\
\hline 600 & 7 & 70 & 30 \\
\hline 900 & 9 & 90 & 10 \\
\hline 1200 & 3 & 30 & 70 \\
\hline 900 (ii) & 7 & 70 & 30 \\
\hline
\end{tabular}

TABLE 21

TOXICITY OF B100 ON O. MYKISS AT 48HRS (TRIAL 2)

\begin{tabular}{||c|c|c|c||}
\hline $\begin{array}{c}\text { CONCENTRATION } \\
\text { (PPM) }\end{array}$ & NO. SURVIVING & \% ALIVE & \% DEAD \\
\hline Control & 10 & 10 & 0 \\
\hline 100 & 7 & 70 & 30 \\
\hline 300 & 10 & 100 & 0 \\
\hline 600 & 3 & 30 & 70 \\
\hline 900 & 9 & 90 & 10 \\
\hline 1200 & 1 & 10 & 90 \\
\hline $900(\mathrm{ii})$ & 5 & 50 & 50 \\
\hline
\end{tabular}

TABLE 22

TOXICITY OF B100 ON O. MYKISS AT 72HRS (TRIAL 2)

\begin{tabular}{||c|c|c|c||}
\hline $\begin{array}{c}\text { CONCENTRATION } \\
\text { (PPM) }\end{array}$ & NO. SURVIVING & \% ALIVE & \% DEAD \\
\hline Control & 10 & 10 & 0 \\
\hline 100 & 5 & 50 & 50 \\
\hline 300 & 10 & 100 & 0 \\
\hline 600 & 1 & 10 & 90 \\
\hline 900 & 4 & 40 & 60 \\
\hline 1200 & 1 & 10 & 90 \\
\hline 900 (ii) & 4 & 40 & 60 \\
\hline
\end{tabular}


TABLE 23

TOXICITY OF B100 ON O. MYKISS AT 96HRS (TRIAL 2)

\begin{tabular}{|c|c|c|c|}
\hline $\begin{array}{c}\text { CONCENTRATION } \\
(\text { PPM })\end{array}$ & NO. SURVIVING & $\%$ ALIVE & $\%$ DEAD \\
\hline Control & 10 & 10 & 0 \\
\hline 100 & 5 & 50 & 50 \\
\hline 300 & 10 & 100 & 0 \\
\hline 600 & 1 & 10 & 90 \\
\hline 900 & 1 & 10 & 90 \\
\hline 1200 & 0 & 0 & 100 \\
\hline 900 (ii) & 2 & 20 & 80 \\
\hline
\end{tabular}

TABLE 24

TOXICITY OF B50 ON O. MYKISS AT 24HRS (TRIAL 1)

\begin{tabular}{||c|c|c|c|}
\hline $\begin{array}{c}\text { CONCENTRATION } \\
\text { (PPM) }\end{array}$ & NO. SURVIVING & \% ALIVE & \% DEAD \\
\hline Control & 10 & 10 & 0 \\
\hline 100 & 10 & 100 & 0 \\
\hline 300 & 10 & 100 & 0 \\
\hline 600 & 6 & 60 & 40 \\
\hline 900 & 3 & 30 & 70 \\
\hline 1200 & 10 & 100 & 0 \\
\hline
\end{tabular}

TABLE 25

TOXICITY OF B50 ON O. MYKISS AT 48HRS (TRIAL 1)

\begin{tabular}{|c|c|c|c|}
\hline $\begin{array}{c}\text { CONCENTRATION } \\
(\text { PPM })\end{array}$ & NO. SURVIVING & $\%$ ALIVE & \% DEAD \\
\hline Control & 10 & 10 & 0 \\
\hline 100 & 10 & 100 & 0 \\
\hline 300 & 6 & 60 & 40 \\
\hline 600 & 3 & 30 & 70 \\
\hline 900 & 3 & 30 & 70 \\
\hline 1200 & 1 & 10 & 90 \\
\hline
\end{tabular}


TABLE 26

TOXICITY OF B50 ON O. MYKISS AT 72HRS (TRIAL 1)

\begin{tabular}{||c|c|c|c|}
\hline $\begin{array}{c}\text { CONCENTRATION } \\
\text { (PPM) }\end{array}$ & NO. SURVIVING & \% ALIVE & \% DEAD \\
\hline Control & 10 & 10 & 0 \\
\hline 100 & 9 & 90 & 10 \\
\hline 300 & 6 & 60 & 40 \\
\hline 600 & 0 & 0 & 100 \\
\hline 900 & 0 & 0 & 100 \\
\hline 1200 & 0 & 0 & 100 \\
\hline
\end{tabular}

TABLE 27

TOXICITY OF B50 ON O. MYKISS AT 96HRS (TRIAL 1)

\begin{tabular}{||c|c|c|c|}
\hline $\begin{array}{c}\text { CONCENTRATION } \\
\text { (PPM) }\end{array}$ & NO. SURVIVING & \% ALIVE & $\%$ DEAD \\
\hline Control & 10 & 10 & 0 \\
\hline 100 & 9 & 90 & 10 \\
\hline 300 & 3 & 30 & 70 \\
\hline 600 & 0 & 0 & 100 \\
\hline 900 & 0 & 0 & 100 \\
\hline 1200 & 0 & 0 & 100 \\
\hline
\end{tabular}

TABLE 28

TOXICITY OF B50 ON O. MYKISS AT 24HRS (TRIAL 2)

\begin{tabular}{||c|c|c|c||}
\hline \hline $\begin{array}{c}\text { CONCENTRATION } \\
\text { (PPM) }\end{array}$ & NO. SURVIVING & \% ALIVE & \% DEAD \\
\hline Control & 10 & 10 & 0 \\
\hline 100 & 10 & 100 & 0 \\
\hline 300 & 10 & 100 & 0 \\
\hline 600 & 6 & 60 & 40 \\
\hline 900 & 3 & 30 & 70 \\
\hline 1200 & 10 & 100 & 0 \\
\hline
\end{tabular}


TABLE 29

TOXICITY OF B50 ON O. MYKISS AT 48HRS (TRIAL 2)

\begin{tabular}{||c|c|c|c|}
\hline \hline $\begin{array}{c}\text { CONCENTRATION } \\
\text { (PPM) }\end{array}$ & NO. SURVIVING & \% ALIVE & \% DEAD \\
\hline Control & 10 & 10 & 0 \\
\hline 100 & 10 & 100 & 0 \\
\hline 300 & 10 & 100 & 0 \\
\hline 600 & 3 & 30 & 70 \\
\hline 900 & 3 & 30 & 70 \\
\hline 1200 & 1 & 10 & 90 \\
\hline
\end{tabular}

TABLE 30

TOXICITY OF B50 ON O. MYKISS AT 72HRS (TRIAL 2)

\begin{tabular}{|c|c|c|c|}
\hline $\begin{array}{c}\text { CONCENTRATION } \\
(\text { PPM })\end{array}$ & NO. SURVIVING & $\%$ ALIVE & $\%$ DEAD \\
\hline Control & 10 & 10 & 0 \\
\hline 100 & 9 & 90 & 10 \\
\hline 300 & 8 & 80 & 20 \\
\hline 600 & 3 & 30 & 70 \\
\hline 900 & 0 & 0 & 100 \\
\hline 1200 & 1 & 10 & 90 \\
\hline
\end{tabular}

TABLE 31

TOXICITY OF B50 ON O. MYKISS AT 96HRS (TRIAL 2)

\begin{tabular}{|c|c|c|c|}
\hline $\begin{array}{c}\text { CONCENTRATION } \\
\text { (PPM) }\end{array}$ & NO. SURVIVING & $\%$ ALIVE & $\%$ DEAD \\
\hline Control & 10 & 10 & 0 \\
\hline 100 & 9 & 90 & 10 \\
\hline 300 & 8 & 80 & 20 \\
\hline 600 & 0 & 0 & 100 \\
\hline 900 & 0 & 0 & 100 \\
\hline 1200 & 0 & 0 & 100 \\
\hline
\end{tabular}


TABLE 32

TOXICITY OF B20 ON O. MYKISS AT 24HRS (TRIAL 1)

\begin{tabular}{|c|c|c|c||}
\hline $\begin{array}{c}\text { CONCENTRATION } \\
\text { (PPM) }\end{array}$ & NO. SURVIVING & \% ALIVE & $\%$ DEAD \\
\hline Control & 10 & 10 & 0 \\
\hline 100 & 10 & 100 & 0 \\
\hline 300 & 10 & 100 & 0 \\
\hline 600 & 7 & 70 & 30 \\
\hline 900 & 6 & 60 & 40 \\
\hline 1200 & 5 & 50 & 50 \\
\hline $600(\mathrm{ii})$ & 6 & 60 & 40 \\
\hline
\end{tabular}

TABLE 33

TOXICITY OF B20 ON O. MYKISS AT 48HRS (TRIAL 1)

\begin{tabular}{||c|c|c|c||}
\hline $\begin{array}{c}\text { CONCENTRATION } \\
\text { (PPM) }\end{array}$ & NO. SURVIVING & $\%$ ALIVE & $\%$ DEAD \\
\hline Control & 10 & 10 & 0 \\
\hline 100 & 10 & 100 & 0 \\
\hline 300 & 9 & 90 & 10 \\
\hline 600 & 7 & 70 & 30 \\
\hline 900 & 3 & 30 & 70 \\
\hline 1200 & 1 & 10 & 90 \\
\hline $600(\mathrm{ii})$ & 3 & 30 & 70 \\
\hline
\end{tabular}

TABLE 34

TOXICITY OF B20 ON O. MYKISS AT 72HRS (TRIAL 1)

\begin{tabular}{|c|c|c|c|}
\hline $\begin{array}{c}\text { CONCENTRATION } \\
\text { (PPM) }\end{array}$ & NO. SURVIVING & \% ALIVE & \% DEAD \\
\hline Control & 10 & 100 & 0 \\
\hline 100 & 10 & 100 & 0 \\
\hline 300 & 7 & 70 & 30 \\
\hline 600 & 5 & 0 & 50 \\
\hline 900 & 0 & 0 & 100 \\
\hline 1200 & 3 & 30 & 100 \\
\hline $600(\mathrm{ii})$ & 7 & 70 & 30 \\
\hline
\end{tabular}


TABLE 35

TOXICITY OF B20 ON O. MYKISS AT 96HRS (TRIAL 1)

\begin{tabular}{||c|c|c|c|}
\hline $\begin{array}{c}\text { CONCENTRATION } \\
(\text { PPM })\end{array}$ & NO. SURVIVING & \% ALIVE & \% DEAD \\
\hline Control & 10 & 10 & $\mathbf{0}$ \\
\hline 100 & 10 & 100 & 0 \\
\hline 300 & 7 & 70 & 30 \\
\hline 600 & 5 & 50 & 50 \\
\hline 900 & 0 & 0 & 100 \\
\hline 1200 & 0 & 0 & 100 \\
\hline $600(\mathrm{ii})$ & 2 & 20 & 80 \\
\hline
\end{tabular}

TABLE 36

TOXICITY OF B20 ON O. MYKISS AT 24HRS (TRIAL 2)

\begin{tabular}{||c|c|c|c|}
\hline $\begin{array}{c}\text { CONCENTRATION } \\
\text { (PPM) }\end{array}$ & NO. SURVIVING & $\%$ ALIVE & $\%$ DEAD \\
\hline Control & 10 & 10 & 0 \\
\hline 100 & 10 & 100 & 0 \\
\hline 300 & 10 & 100 & 0 \\
\hline 600 & 7 & 70 & 30 \\
\hline 900 & 7 & 70 & 30 \\
\hline 1200 & 4 & 40 & 60 \\
\hline
\end{tabular}

TABLE 37

TOXICITY OF B20 ON O. MYKISS AT 48HRS (TRIAL 2)

\begin{tabular}{|c|c|c|c|}
\hline $\begin{array}{c}\text { CONCENTRATION } \\
\text { (PPM) }\end{array}$ & NO. SURVIVING & \% ALIVE & \% DEAD \\
\hline Control & 10 & 10 & 0 \\
\hline 100 & 10 & 100 & 0 \\
\hline 300 & 10 & 100 & 0 \\
\hline 600 & 7 & 70 & 30 \\
\hline 900 & 3 & 30 & 30 \\
\hline 1200 & 1 & 10 & 90 \\
\hline
\end{tabular}


TABLE 38

TOXICITY OF B20 ON O. MYKISS AT 72HRS (TRIAL 2)

\begin{tabular}{|c|c|c|c|}
\hline $\begin{array}{c}\text { CONCENTRATION } \\
\text { (PPM) }\end{array}$ & NO. SURVIVING & \% ALIVE & \% DEAD \\
\hline Control & 10 & 10 & 0 \\
\hline 100 & 8 & 80 & 20 \\
\hline 300 & 10 & 100 & 0 \\
\hline 600 & 5 & 50 & 50 \\
\hline 900 & 0 & 0 & 100 \\
\hline 1200 & 0 & 0 & 100 \\
\hline
\end{tabular}

TABLE 39

TOXICITY OF B20 ON O. MYKISS AT 96HRS (TRIAL 2)

\begin{tabular}{|c|c|c|c|}
\hline $\begin{array}{c}\text { CONCENTRATION } \\
\text { (PPM) }\end{array}$ & NO. SURVIVING & \% ALIVE & \% DEAD \\
\hline Control & 10 & 10 & 0 \\
\hline 100 & 6 & 60 & 40 \\
\hline 300 & 10 & 100 & 0 \\
\hline 600 & 5 & 50 & 50 \\
\hline 900 & 0 & 0 & 100 \\
\hline 1200 & 0 & 0 & 100 \\
\hline
\end{tabular}

TABLE 40

TOXICITY OF B5 ON O. MYKISS AT 24HRS (TRIAL 1)

\begin{tabular}{||c|c|c|c||}
\hline $\begin{array}{c}\text { CONCENTRATION } \\
(\mathrm{PPM})\end{array}$ & NO. SURVIVING & \% ALIVE & \% DEAD \\
\hline Control & 10 & 10 & 0 \\
\hline 100 & 10 & 100 & 0 \\
\hline 300 & 9 & 90 & 10 \\
\hline 600 & 10 & 100 & 0 \\
\hline 900 & 2 & 20 & 80 \\
\hline 1200 & 1 & 10 & 90 \\
\hline
\end{tabular}


TABLE 41

TOXICITY OF B5 ON O. MYKISS AT 48HRS (TRIAL 1)

\begin{tabular}{||c|c|c|c|}
\hline \hline $\begin{array}{c}\text { CONCENTRATION } \\
\text { (PPM) }\end{array}$ & NO. SURVIVING & \% ALIVE & \% DEAD \\
\hline Control & 10 & 10 & 0 \\
\hline 100 & 9 & 90 & 10 \\
\hline 300 & 7 & 70 & 30 \\
\hline 600 & 5 & 50 & 50 \\
\hline 900 & 2 & 20 & 80 \\
\hline 1200 & 0 & 0 & 100 \\
\hline
\end{tabular}

TABLE 42

TOXICITY OF B5 ON O. MYKISS AT 72HRS (TRIAL 1)

\begin{tabular}{||c|c|c|c|}
\hline $\begin{array}{c}\text { CONCENTRATION } \\
\text { (PPM) }\end{array}$ & NO. SURVIVING & \% ALIVE & $\%$ DEAD \\
\hline Control & 10 & 10 & 0 \\
\hline 100 & 9 & 90 & 10 \\
\hline 300 & 2 & 20 & 80 \\
\hline 600 & 2 & 20 & 80 \\
\hline 900 & 0 & 0 & 100 \\
\hline 1200 & 0 & 0 & 100 \\
\hline
\end{tabular}

TABLE 43

TOXICITY OF B5 ON O. MYKISS AT 96HRS (TRIAL 1)

\begin{tabular}{||c|c|c|c|}
\hline $\begin{array}{c}\text { CONCENTRATION } \\
(\mathrm{PPM})\end{array}$ & NO. SURVIVING & $\%$ ALIVE & $\%$ DEAD \\
\hline Control & 10 & 10 & 0 \\
\hline 100 & 9 & 90 & 10 \\
\hline 300 & 2 & 20 & 80 \\
\hline 600 & 2 & 20 & 80 \\
\hline 900 & 0 & 0 & 100 \\
\hline 1200 & 0 & 0 & 100 \\
\hline
\end{tabular}


TABLE 44

TOXICITY OF B5 ON O. MYKISS AT 24HRS (TRIAL 2)

\begin{tabular}{|c|c|c|c|}
\hline $\begin{array}{c}\text { CONCENTRATION } \\
\text { (PPM) }\end{array}$ & NO. SURVIVING & \% ALIVE & \% DEAD \\
\hline Control & 10 & 10 & 0 \\
\hline 100 & 10 & 100 & 0 \\
\hline 300 & 10 & 100 & 0 \\
\hline 600 & 10 & 100 & 0 \\
\hline 900 & 2 & 20 & 80 \\
\hline 1200 & 1 & 10 & 90 \\
\hline
\end{tabular}

TABLE 45

TOXICITY OF B5 ON O. MYKISS AT 48HRS (TRIAL 2)

\begin{tabular}{||c|c|c|c||}
\hline $\begin{array}{c}\text { CONCENTRATION } \\
(\text { PPM })\end{array}$ & NO. SURVIVING & \% ALIVE & $\%$ DEAD \\
\hline Control & 10 & 10 & 0 \\
\hline 100 & 9 & 90 & 10 \\
\hline 300 & 7 & 70 & 30 \\
\hline 600 & 5 & 50 & 50 \\
\hline 900 & 2 & 20 & 80 \\
\hline 1200 & 1 & 10 & 90 \\
\hline
\end{tabular}

TABLE 46

TOXICITY OF B5 ON O. MYKISS AT 72HRS (TRIAL 2)

\begin{tabular}{||c|c|c|c||}
\hline \hline $\begin{array}{c}\text { CONCENTRATION } \\
(\mathrm{PPM})\end{array}$ & NO. SURVIVING & \% ALIVE & \% DEAD \\
\hline Control & 10 & 10 & 0 \\
\hline 100 & 9 & 90 & 10 \\
\hline 300 & 2 & 20 & 80 \\
\hline 600 & 5 & 50 & 50 \\
\hline 900 & 0 & 0 & 100 \\
\hline 1200 & 1 & 10 & 90 \\
\hline
\end{tabular}


TABLE 47

TOXICITY OF B5 ON O. MYKISS AT 96HRS (TRIAL 2)

\begin{tabular}{|c|c|c|c|}
\hline $\begin{array}{c}\text { CONCENTRATION } \\
(\mathrm{PPM})\end{array}$ & NO. SURVIVING & \% ALIVE & \% DEAD \\
\hline Control & 10 & 10 & 0 \\
\hline 100 & 3 & 30 & 70 \\
\hline 300 & 0 & 0 & 100 \\
\hline 600 & 0 & 0 & 100 \\
\hline 900 & 0 & 0 & 100 \\
\hline 1200 & 1 & 10 & 90 \\
\hline
\end{tabular}

TABLE 48

TOXICITY OF B20 (Topia) ON O. MYKISS AT 24HRS (TRIAL 1)

\begin{tabular}{|c|c|c|c|}
\hline $\begin{array}{c}\text { CONCENTRATION } \\
\text { (PPM) }\end{array}$ & NO. SURVIVING & $\%$ ALIVE & \% DEAD \\
\hline Control & 10 & 10 & 0 \\
\hline 100 & 10 & 100 & 0 \\
\hline 300 & 10 & 100 & 0 \\
\hline 600 & 9 & 90 & 10 \\
\hline 900 & 8 & 80 & 20 \\
\hline 1200 & 5 & 50 & 50 \\
\hline
\end{tabular}

TABLE 49

TOXICITY OF B20 (Topia) ON O. MYKISS AT 48HRS (TRIAL 1)

\begin{tabular}{|c|c|c|c|}
\hline $\begin{array}{c}\text { CONCENTRATION } \\
(\mathrm{PPM})\end{array}$ & NO. SURVIVING & $\%$ ALIVE & \% DEAD \\
\hline Control & 10 & 10 & 0 \\
\hline 100 & 10 & 100 & 0 \\
\hline 300 & 10 & 100 & 0 \\
\hline 600 & 7 & 70 & 30 \\
\hline 900 & 5 & 50 & 50 \\
\hline 1200 & 3 & 30 & 70 \\
\hline
\end{tabular}




\section{TABLE 50}

\section{TOXICITY OF B20 (Topia) ON O. MYKISS AT 72HRS (TRIAL 1)}

\begin{tabular}{||c|c|c|c||}
\hline $\begin{array}{c}\text { CONCENTRATION } \\
\text { (PPM) }\end{array}$ & NO. SURVIVING & \% ALIVE & \% DEAD \\
\hline Control & 10 & 100 & 0 \\
\hline 100 & 10 & 100 & 0 \\
\hline 300 & 9 & 90 & 10 \\
\hline 600 & 5 & 50 & 50 \\
\hline 900 & 3 & 30 & 70 \\
\hline 1200 & 0 & 0 & 100 \\
\hline
\end{tabular}

TABLE 51

TOXICITY OF B20 (Topia) ON O. MYKISS AT 96HRS (TRIAL 1)

\begin{tabular}{||c|c|c|c||}
\hline $\begin{array}{c}\text { CONCENTRATION } \\
\text { (PPM) }\end{array}$ & NO. SURVIVING & \% ALIVE & \% DEAD \\
\hline Control & 10 & 10 & 0 \\
\hline 100 & 10 & 100 & 0 \\
\hline 300 & 7 & 70 & 30 \\
\hline 600 & 5 & 50 & 50 \\
\hline 900 & 3 & 30 & 70 \\
\hline 1200 & 0 & 0 & 100 \\
\hline
\end{tabular}

TABLE 52

TOXICITY OF B20 (Topia) ON O. MYKISS AT 24HRS (TRIAL 2)

\begin{tabular}{|c|c|c|c|}
\hline $\begin{array}{c}\text { CONCENTRATION } \\
\text { (PPM) }\end{array}$ & NO. SURVIVING & \% ALIVE & \% DEAD \\
\hline Control & 10 & 10 & 0 \\
\hline 100 & 10 & 100 & 0 \\
\hline 300 & 10 & 100 & 0 \\
\hline 600 & 90 & 90 & 90 \\
\hline 900 & 60 & 60 & 40 \\
\hline 1200 & 40 & 40 & 60 \\
\hline
\end{tabular}


TABLE 53

TOXICITY OF B20 (Topia) ON O. MYKISS AT 48HRS (TRIAL 2)

\begin{tabular}{|c|c|c|c|}
\hline $\begin{array}{c}\text { CONCENTRATION } \\
(\mathrm{PPM})\end{array}$ & NO. SURVIVING & \% ALIVE & \% DEAD \\
\hline Control & 10 & 10 & 0 \\
\hline 100 & 10 & 100 & 0 \\
\hline 300 & 10 & 100 & 0 \\
\hline 600 & 5 & 50 & 50 \\
\hline 900 & 5 & 50 & 50 \\
\hline 1200 & 2 & 20 & 80 \\
\hline
\end{tabular}

TABLE 54

TOXICITY OF B20 (Topia) ON O. MYKISS AT 72HRS (TRIAL 2)

\begin{tabular}{|c|c|c|c|}
\hline \hline $\begin{array}{c}\text { CONCENTRATION } \\
\text { (PPM) }\end{array}$ & NO. SURVIVING & \% ALIVE & $\%$ DEAD \\
\hline Control & 10 & 10 & 0 \\
\hline 100 & 8 & 80 & 20 \\
\hline 300 & 10 & 100 & 0 \\
\hline 600 & 5 & 50 & 50 \\
\hline 900 & 3 & 30 & 30 \\
\hline 1200 & 0 & 0 & 100 \\
\hline
\end{tabular}

TABLE 55

TOXICITY OF B20 (Topia) ON O. MYKISS AT 96HRS (TRIAL 2)

\begin{tabular}{|c|c|c|c|}
\hline $\begin{array}{c}\text { CONCENTRATION } \\
(\mathrm{PPM})\end{array}$ & NO. SURVIVING & $\%$ ALIVE & $\%$ DEAD \\
\hline Control & 10 & 10 & 0 \\
\hline 100 & 8 & 80 & 20 \\
\hline 300 & 10 & 100 & 0 \\
\hline 600 & 4 & 40 & 60 \\
\hline 900 & 1 & 10 & 90 \\
\hline 1200 & 0 & 0 & 100 \\
\hline
\end{tabular}


TABLE 56

MEAN MORTALITY OF O. MYKISS AFFECTED WITH DIESEL

\begin{tabular}{c|ccccc}
\hline $\begin{array}{c}\text { Diesel } \\
\begin{array}{c}\text { Concentration } \\
\text { [ppm] }\end{array}\end{array}$ & \multicolumn{3}{|c}{ Mean Mortality (\%) in 2 Replicates } & $\begin{array}{c}\text { Mean } \\
\text { Mortality } \\
\text { (\%) over } \\
\mathbf{9 6 h r s}\end{array}$ \\
\hline & $24 \mathrm{hr}$ & $48 \mathrm{hr}$ & $72 \mathrm{hr}$ & $96 \mathrm{hr}$ & \\
100 & 16.66 & 33.33 & 40.00 & 63.33 & 38.33 \\
300 & 25.00 & 45.00 & 90.00 & 90.00 & 62.50 \\
600 & 30.00 & 56.66 & 70.00 & 73.33 & 57.50 \\
900 & 90.00 & 90.00 & 100.00 & 100.00 & 95.00 \\
1200 & 90.00 & 100.00 & 100.00 & 100.00 & 97.50 \\
$\begin{array}{c}\text { Average } \\
\text { Mortality for } \\
\text { each 24hr } \\
\text { period }\end{array}$ & 50.33 & 64.50 & 80 & 85.33 & \\
\hline
\end{tabular}

TABLE 57

MEAN MORTALITY OF O. MYKISS AFFECTED WITH B100

\begin{tabular}{|c|c|c|c|c|c|}
\hline $\begin{array}{c}B 100 \\
\text { Concentration } \\
{[p p m]} \\
\end{array}$ & \multicolumn{4}{|c|}{ Mean Mortality(\%) in 2 Replicates } & $\begin{array}{c}\text { Mean } \\
\text { Mortality } \\
(\%)\end{array}$ \\
\hline 100 & $\begin{array}{c}24 \mathrm{hr} \\
20.00\end{array}$ & $\begin{array}{c}48 \mathrm{hr} \\
20.00\end{array}$ & $\begin{array}{c}72 \mathrm{hr} \\
3000\end{array}$ & $96 \mathrm{hr}$ & 2500 \\
\hline 300 & 0.00 & 0.00 & 0.00 & 0.00 & $\begin{array}{c}25.00 \\
0.00\end{array}$ \\
\hline 600 & 20.00 & 53.33 & 66.66 & 76.66 & 54.16 \\
\hline 900 & 16.66 & 23.33 & 60.00 & 83.33 & 45.83 \\
\hline 1200 & 70.00 & 90.00 & 90.00 & 100.00 & 87.50 \\
\hline $\begin{array}{l}\text { Average } \\
\text { Mortality for } \\
\text { each } 24 \mathrm{hr} \\
\text { period }\end{array}$ & 25.33 & 37.33 & 49.33 & 57.98 & \\
\hline
\end{tabular}


TABLE 58

MEAN MORTALITY OF O. MYKISS AFFECTED WITH B50

\begin{tabular}{|c|c|c|c|c|c|}
\hline $\begin{array}{c}B 50 \\
\text { Concentration } \\
{[p p m]} \\
\end{array}$ & \multicolumn{4}{|c|}{ Mean Mortality(\%) in 2 Replicates } & $\begin{array}{c}\text { Mean } \\
\text { Mortality } \\
(\%) \\
\end{array}$ \\
\hline & $24 \mathrm{hr}$ & $48 \mathrm{hr}$ & $72 \mathrm{hr}$ & $96 \mathrm{hr}$ & \\
\hline 100 & 0.00 & 0.00 & 10.00 & 10.00 & 5.00 \\
\hline 300 & 0.00 & 20.00 & 30.00 & 45.00 & 23.75 \\
\hline 600 & 40.00 & 70.00 & 85.00 & 100.00 & 73.75 \\
\hline 900 & 70.00 & 70.00 & 100.00 & 100.00 & 85.00 \\
\hline 1200 & 0.00 & 90.00 & 95.00 & 100.00 & 71.25 \\
\hline Average & 22 & 50 & 64 & 71 & \\
\hline $\begin{array}{l}\text { Mortality for } \\
\text { each } 24 \mathrm{hr} \\
\text { period }\end{array}$ & & & & & \\
\hline
\end{tabular}

TABLE 59

MEAN MORTALITY OF O. MYKISS AFFECTED WITH B20

\begin{tabular}{|c|c|c|c|c|c|}
\hline $\begin{array}{c}B 20 \\
\text { Concentration } \\
{[\mathrm{ppm}]} \\
\end{array}$ & \multicolumn{4}{|c|}{ Mean Mortality (\%) in 2 Replicates } & \multirow{2}{*}{$\begin{array}{c}\text { Mean } \\
\text { Mortality } \\
(\%) \\
\end{array}$} \\
\hline & $24 \mathrm{hr}$ & $48 \mathrm{hr}$ & $72 \mathrm{hr}$ & $96 \mathrm{hr}$ & \\
\hline 100 & 0.00 & 0.00 & 10.00 & 20.00 & 7.50 \\
\hline 300 & 0.00 & 5.00 & 15.00 & 15.00 & 8.75 \\
\hline 600 & 33.33 & 43.33 & 43.33 & 60.00 & 45.00 \\
\hline 900 & 35.00 & 70.00 & 100.00 & 100.00 & 76.25 \\
\hline 1200 & 55.00 & 90.00 & 100.00 & 100.00 & 86.25 \\
\hline Average & 24.67 & 41.67 & 53.67 & 59 & \\
\hline $\begin{array}{l}\text { Mortality for } \\
\text { each } 24 \mathrm{hr} \\
\text { period }\end{array}$ & & & & & \\
\hline
\end{tabular}


TABLE 60

MEAN MORTALITY OF O. MYKISS AFFECTED WITH B5

\begin{tabular}{|c|c|c|c|c|c|}
\hline \multirow{2}{*}{$\begin{array}{c}B 5 \\
\text { Concentration } \\
{[p p m]}\end{array}$} & \multicolumn{4}{|c|}{ Mean Mortality in 2 Replicates } & \multirow{2}{*}{$\begin{array}{c}\text { Mean } \\
\text { Mortality } \\
(\%) \\
\end{array}$} \\
\hline & $24 \mathrm{hr}$ & $48 \mathrm{hr}$ & $72 \mathrm{hr}$ & $96 \mathrm{hr}$ & \\
\hline 100 & 0.00 & 10.00 & 10.00 & 40.00 & 15.00 \\
\hline 300 & 5.00 & 30.00 & 80.00 & 90.00 & 51.25 \\
\hline 600 & 0.00 & 50.00 & 65.00 & 90.00 & 51.25 \\
\hline 900 & 80.00 & 80.00 & 100.00 & 100.00 & 90.00 \\
\hline 1200 & 90.00 & 95.00 & 95.00 & 95.00 & 93.75 \\
\hline Average & 35 & 53 & 70 & 83 & \\
\hline $\begin{array}{l}\text { Mortality for } \\
\text { each } 24 \mathrm{hr} \\
\text { period }\end{array}$ & & & & & \\
\hline
\end{tabular}

TABLE 61

MEAN MORTALITY OF O. MYKISS AFFECTED WITH B20 (Topia)

\begin{tabular}{|c|c|c|c|c|c|}
\hline \multirow{2}{*}{$\begin{array}{c}\text { B20 } \\
\text { Concentration } \\
{[p p m]} \\
\end{array}$} & \multicolumn{4}{|c|}{ Mean Mortality (\%) in 2 Replicates } & \multirow{2}{*}{$\begin{array}{c}\text { Mean } \\
\text { Mortality } \\
(\%) \\
\end{array}$} \\
\hline & $24 \mathrm{hr}$ & $48 \mathrm{hr}$ & $72 \mathrm{hr}$ & $96 \mathrm{hr}$ & \\
\hline 100 & 0 & 0 & 10 & 10 & 5.00 \\
\hline 300 & 0 & 0 & 5 & 15 & 5.00 \\
\hline 600 & 10 & 40 & 50 & 55 & 38.75 \\
\hline 900 & 30 & 50 & 70 & 80 & 57.5 \\
\hline 1200 & 55 & 75 & 100 & 100 & 82.5 \\
\hline Average & 19 & 33 & 47 & 52 & \\
\hline $\begin{array}{l}\text { Mortality for } \\
\text { each } 24 \mathrm{hr} \\
\text { period }\end{array}$ & & & & & \\
\hline
\end{tabular}




\section{O. mykiss}

\section{DIESEL}

Anova: Single Factor

SUMMARY

\begin{tabular}{lcccc}
\hline Groups & Count & Sum & Average & Variance \\
\hline Diesel 24hrs T1 & 6 & 26 & 4.333333 & 14.26667 \\
Diesel 24hrs T2 & 6 & 29 & 4.833333 & 10.56667 \\
\hline
\end{tabular}

ANOVA

\begin{tabular}{lcccccc}
\hline Source of Variation & $S S$ & $d f$ & $M S$ & $F$ & $P$-value & F crit \\
\hline Between Groups & 0.75 & 1 & 0.75 & 0.060403 & 0.810831 & 4.964603 \\
Within Groups & 124.1667 & 10 & 12.41667 & & & $\cdot$ \\
Total & 124.9167 & 11 & & & & \\
\hline
\end{tabular}

Anova: Single Factor

SUMMARY

\begin{tabular}{lcccc}
\hline Groups & Count & Sum & Average & Variance \\
\hline Diesel 48hrs T1 & 6 & 34 & 5.666667 & 11.06667 \\
Diesel 48hrs T2 & 6 & 40 & 6.666667 & 5.466667 \\
\hline
\end{tabular}

\begin{tabular}{|c|c|c|c|c|c|c|}
\hline Source of Variation & SS & $d f$ & $M S$ & $F$ & P-value & $F$ crit \\
\hline Between Groups & 3 & 1 & 3 & 0.362903 & 0.56031 & 4.964603 \\
\hline Within Groups & 82.66667 & 10 & 8.266667 & & & \\
\hline Total & 85.66667 & 11 & & & & \\
\hline
\end{tabular}

Anova: Single Factor

SUMMARY

Groups

Diesel 72hrs T1

Diesel 72hrs T2

$\begin{array}{cccc}\text { Count } & \text { Sum } & \text { Average } & \text { Variance } \\ 6 & 42 & 7 & 9.6 \\ 6 & 49 & 8.166667 & 4.566667\end{array}$

\section{ANOVA}

Source of Variation

Between Groups

$\begin{array}{cccccc}\text { SS } & d f & M S & F & P \text {-value } & F \text { crit } \\ 4.083333 & 1 & 4.083333 & 0.576471 & 0.46522 & 4.964603 \\ 70.83333 & 10 & 7.083333 & & & \end{array}$

Total

$74.91667 \quad 11$ 
Anova: Single Factor

SUMMARY

\begin{tabular}{ccccc}
\hline Groups & Count & Sum & Average & Variance \\
\hline Diesel 96hrs T1 & 6 & 45 & 7.5 & 8.7 \\
Diesel 96hrs T2 & 6 & 54 & 9 & 1.6 \\
\hline
\end{tabular}

ANOVA

\begin{tabular}{lcccccc}
\hline \multicolumn{1}{c}{ Source of Variation } & $S S$ & $d f$ & $M S$ & $F$ & $P$-value & $F$ crit \\
\hline Between Groups & 6.75 & 1 & 6.75 & 1.31068 & 0.278933 & 4.964603 \\
Within Groups & 51.5 & 10 & 5.15 & & & \\
& & & & & & \\
Total & 58.25 & 11 & & & & \\
\hline
\end{tabular}

B100

Anova: Single Factor

SUMMARY

\begin{tabular}{rcccc}
\hline Groups & Count & Sum & Average & Variance \\
\hline B100 24hrs T1 & 6 & 12 & 2 & 7.2 \\
B100 24hrs T2 & 6 & 12 & 2 & 7.2 \\
\hline
\end{tabular}

\begin{tabular}{|c|c|c|c|c|c|c|}
\hline Source of Variation & SS & $d f$ & $M S$ & $F$ & P-value & $F_{\text {crit }}$ \\
\hline Between Groups & 0 & 1 & 0 & 0 & 1 & 4.964603 \\
\hline Within Groups & 72 & 10 & 7.2 & & & \\
\hline Total & 72 & 11 & & & & \\
\hline
\end{tabular}

Anova: Single Factor

SUMMARY

\begin{tabular}{rcccc}
\hline Groups & Count & Sum & Average & Variance \\
\hline B100 48hrs T1 & 6 & 20 & 3.333333 & 13.86667 \\
B100 48hrs T2 & 6 & 25 & 4.166667 & 12.16667 \\
\hline
\end{tabular}

\begin{tabular}{|c|c|c|c|c|c|c|}
\hline Source of Variation & SS & $d f$ & $M S$ & $F$ & $P$-value & $F$ crit \\
\hline Between Groups & 2.083333 & 1 & 2.083333 & 0.160051 & 0.697522 & 4.964603 \\
\hline Within Groups & 130.1667 & 10 & 13.01667 & & & \\
\hline Total & 132.25 & 11 & & & & \\
\hline
\end{tabular}


Anova: Single Factor

SUMMARY

\begin{tabular}{rcccc}
\hline Groups & Count & Sum & Average & Variance \\
\hline B100 72hrs T1 & 6 & 27 & 4.5 & 16.3 \\
B100 72hrs T2 & 6 & 35 & 5.833333 & 10.96667 \\
\hline
\end{tabular}

ANOVA

\begin{tabular}{lcccccc}
\hline \multicolumn{1}{c}{ Source of Variation } & $S S$ & $d f$ & $M S$ & $F$ & $P$-value & F crit \\
\hline Between Groups & 5.333333 & 1 & 5.333333 & 0.391198 & 0.545679 & 4.964603 \\
Within Groups & 136.3333 & 10 & 13.63333 & & & \\
& & & & & & \\
Total & 141.6667 & 11 & & & & \\
\hline
\end{tabular}

Anova: Single Factor

SUMMARY

\begin{tabular}{rcccc}
\hline Groups & Count & Sum & Average & Variance \\
\hline B100 96hrs T1 & 6 & 33 & 5.5 & 17.9 \\
B100 96hrs T2 & 6 & 41 & 6.833333 & 14.16667 \\
\hline
\end{tabular}

ANOVA

\begin{tabular}{lcccccc}
\hline \multicolumn{1}{c}{ Source of Variation } & $S S$ & $d f$ & $M S$ & $F$ & P-value & F crit \\
\hline Between Groups & 5.333333 & 1 & 5.333333 & 0.33264 & 0.57686 & 4.964603 \\
Within Groups & 160.3333 & 10 & 16.03333 & & & \\
& & & & & & \\
Total & 165.6667 & 11 & & & & \\
\hline
\end{tabular}

B50

Anova: Single Factor

SUMMARY

\begin{tabular}{lcccc}
\hline \multicolumn{1}{c}{ Groups } & Count & Sum & Average & Variance \\
\hline B50 24hrs T1 & 5 & 11 & 2.2 & 10.2 \\
B50 24hrs T2 & 5 & 11 & 2.2 & 10.2 \\
\hline
\end{tabular}

\begin{tabular}{lccccc} 
ANOVA & \multicolumn{6}{c}{ MS } & $F$ & F crit \\
\hline \multicolumn{1}{c}{ Source of Variation } & SS & df & MS & \\
\hline Between Groups & $-1.4 \mathrm{E}-14$ & 1 & $-1.4 \mathrm{E}-14$ & $-1.4 \mathrm{E}-15$ & 5.317655 \\
Within Groups & 81.6 & 8 & 10.2 & & \\
& & & & & \\
Total & 81.6 & 9 & & & \\
\hline
\end{tabular}


Anova: Single

Factor

SUMMARY

\begin{tabular}{rcccc}
\hline Groups & Count & Sum & Average & Variance \\
\hline B50 48hrs T1 & 5 & 27 & 5.4 & 12.3 \\
B50 48hrs T2 & 5 & 23 & 4.6 & 18.3 \\
\hline
\end{tabular}

\begin{tabular}{|c|c|c|c|c|c|c|}
\hline Source of Variation & SS & $d f$ & MS & $F$ & P-value & $F_{\text {crit }}$ \\
\hline Between Groups & 1.6 & 1 & 1.6 & 0.104575 & 0.754698 & 5.317655 \\
\hline Within Groups & 122.4 & 8 & 15.3 & & & \\
\hline Total & 124 & 9 & & & & \\
\hline
\end{tabular}

Anova: Single

Factor

SUMMARY

\begin{tabular}{rcccc}
\hline Groups & Count & Sum & Average & Variance \\
\hline B50 72hrs T1 & 5 & 35 & 7 & 18 \\
B50 72hrs T2 & 5 & 29 & 5.8 & 16.7 \\
\hline
\end{tabular}

\begin{tabular}{lcccccc} 
ANOVA & \multicolumn{7}{c}{ MS } & F & P-value & F crit \\
\hline Source of Variation & $S S$ & $d f$ & $M S$ & 1 & & \\
\hline Between Groups & 3.6 & 1 & 3.6 & 0.207493 & 0.660849 & 5.317655 \\
Within Groups & 138.8 & 8 & 17.35 & & & \\
Total & 142.4 & 9 & & & & \\
\hline
\end{tabular}

Anova: Single

Factor

SUMMARY

\begin{tabular}{rcccc}
\hline Groups & Count & Sum & Average & Variance \\
\hline B50 96hrs T1 & 5 & 38 & 7.6 & 15.3 \\
B50 96hrs T2 & 5 & 33 & 6.6 & 21.8 \\
\hline
\end{tabular}

\begin{tabular}{lcccccc} 
ANOVA & \multicolumn{7}{c}{ Source of Variation } & $S S$ & $d f$ & $M S$ & $F$ & $P$-value & F crit \\
\hline Between Groups & 2.5 & 1 & 2.5 & 0.134771 & 0.723057 & 5.317655 \\
Within Groups & 148.4 & 8 & 18.55 & & & \\
& & & & & & \\
Total & 150.9 & 9 & & & & \\
\hline
\end{tabular}


B20

Anova: Single Factor

SUMMARY

\begin{tabular}{rcccc}
\hline Groups & Count & Sum & Average & Variance \\
\hline B20 24hrs T1 & 6 & 16 & 2.666667 & 4.666667 \\
B20 24hrs T2 & 5 & 12 & 2.4 & 6.3 \\
\hline
\end{tabular}

\begin{tabular}{lcccccc} 
ANOVA & \multicolumn{7}{c}{ S } \\
\hline \multicolumn{1}{c}{ Source of Variation } & $S S$ & $d f$ & $M S$ & $F$ & $P$-value & F crit \\
\hline Between Groups & 0.193939 & 1 & 0.193939 & 0.035964 & 0.853798 & 5.117355 \\
Within Groups & 48.53333 & 9 & 5.392593 & & & \\
& & & & & & \\
Total & 48.72727 & 10 & & & & \\
\hline
\end{tabular}

Anova: Single Factor

SUMMARY

\begin{tabular}{rcccc}
\hline Groups & Count & Sum & Average & Variance \\
\hline B20 48hrs T1 & 6 & 27 & 4.5 & 13.5 \\
B20 48hrs T2 & 5 & 19 & 3.8 & 16.7 \\
\hline
\end{tabular}

\begin{tabular}{lcccccc} 
ANOVA & \multicolumn{8}{c}{ Source of Variation } & SS & $d f$ & MS & F & P-value & F crit \\
\hline Between Groups & 1.336364 & 1 & 1.336364 & 0.089555 & 0.771539 & 5.117355 \\
Within Groups & 134.3 & 9 & 14.92222 & & & \\
Total & 135.6364 & 10 & & & & \\
\hline
\end{tabular}

Anova: Single Factor

SUMMARY

\begin{tabular}{rcccc}
\hline Groups & Count & Sum & Average & Variance \\
\hline B20 72hrs T1 & 6 & 31 & 5.166667 & 16.56667 \\
B20 72hrs T2 & 5 & 27 & 5.4 & 20.8 \\
\hline
\end{tabular}

\begin{tabular}{|c|c|c|c|c|c|c|}
\hline Source of Variation & SS & $d f$ & $M S$ & $F$ & P-value & F crit \\
\hline Between Groups & 0.148485 & 1 & 0.148485 & 0.008049 & 0.930479 & 5.117355 \\
\hline Within Groups & 166.0333 & 9 & 18.44815 & & & \\
\hline Total & 166.1818 & 10 & & & & \\
\hline
\end{tabular}


Anova: Single Factor

SUMMARY

\begin{tabular}{rcccc}
\hline Groups & Count & Sum & Average & Variance \\
\hline B20 96hrs T1 & 6 & 36 & 6 & 16.4 \\
B20 96hrs T2 & 5 & 29 & 5.8 & 18.2 \\
\hline
\end{tabular}

ANOVA

\begin{tabular}{lcccccc}
\hline \multicolumn{1}{c}{ Source of Variation } & $S S$ & $d f$ & $M S$ & $F$ & $P$-value & F crit \\
\hline Between Groups & 0.109091 & 1 & 0.109091 & 0.006342 & 0.938266 & 5.117355 \\
Within Groups & 154.8 & 9 & 17.2 & & & \\
& & & & & & \\
Total & 154.9091 & 10 & & & & \\
\hline
\end{tabular}

B5

Anova: Single Factor

SUMMARY

\begin{tabular}{lcccc}
\hline \multicolumn{1}{c}{ Groups } & Count & Sum & Average & Variance \\
\hline B5 24hrs T1 & 5 & 18 & 3.6 & 20.3 \\
B5 24hrs T2 & 5 & 17 & 3.4 & 21.8 \\
\hline
\end{tabular}

ANOVA

\begin{tabular}{lcccccc}
\hline \multicolumn{1}{c}{ Source of Variation } & $S S$ & $d f$ & $M S$ & $F$ & $P$-value & $F$ crit \\
\hline Between Groups & 0.1 & 1 & 0.1 & 0.004751 & 0.946741 & 5.317655 \\
Within Groups & 168.4 & 8 & 21.05 & & & \\
Total & 168.5 & 9 & & & & \\
\hline
\end{tabular}

Anova: Single Factor

SUMMARY

\begin{tabular}{lrrrr}
\hline Groups & Count & \multicolumn{1}{c}{ Sum } & Average & Variance \\
\hline B5 48hrs T1 & 5 & 27 & 5.4 & 13.3 \\
B5 48hrs T2 & 5 & 26 & 5.2 & 11.2 \\
\hline
\end{tabular}

\begin{tabular}{|c|c|c|c|c|c|c|}
\hline Source of Variation & SS & $d f$ & MS & $F$ & $P$-value & $F$ crit \\
\hline Between Groups & 0.1 & 1 & 0.1 & 0.008163 & 0.93023 & 5.317655 \\
\hline Within Groups & 98 & 8 & 12.25 & & & \\
\hline Total & 98.1 & 9 & & & & \\
\hline
\end{tabular}


Anova: Single Factor

SUMMARY

\begin{tabular}{rcccc}
\hline Groups & Count & Sum & Average & Variance \\
\hline B5 72hrs T1 & 5 & 37 & 7.4 & 13.8 \\
B5 72hrs T2 & 5 & 33 & 6.6 & 13.3 \\
\hline
\end{tabular}

\begin{tabular}{lcccccc} 
ANOVA & \multicolumn{1}{c}{ MS } & $F$ & P-value & F crit \\
\hline Source of Variation & $S S$ & $d f$ & MS & \\
\hline Between Groups & 1.6 & 1 & 1.6 & 0.118081 & 0.739982 & 5.317655 \\
Within Groups & 108.4 & 8 & 13.55 & & & \\
Total & 110 & 9 & & & & \\
\hline
\end{tabular}

Anova: Single Factor

SUMMARY

\begin{tabular}{lcccc}
\hline \multicolumn{1}{c}{ Groups } & Count & Sum & Average & Variance \\
\hline B5 96hrs T1 & 5 & 37 & 7.4 & 13.8 \\
B5 96hrs T2 & 5 & 46 & 9.2 & 1.7 \\
\hline
\end{tabular}

\begin{tabular}{lcccccc} 
ANOVA & \multicolumn{1}{c}{ MS } & $F$ & P-value & F crit \\
\hline Source of Variation & $S S$ & $d f$ & MS & \\
\hline Between Groups & 8.1 & 1 & 8.1 & 1.045161 & 0.336541 & 5.317655 \\
Within Groups & 62 & 8 & 7.75 & & & \\
& & & & & & \\
Total & 70.1 & 9 & & & & \\
\hline
\end{tabular}




\section{B20 (Topia)}

Anova: Single Factor

SUMMARY

\begin{tabular}{crrrr}
\hline Groups & Count & \multicolumn{1}{c}{ Sum } & Average & Variance \\
\hline B20(Topia)T1 24hrs & 5 & 8 & 1.6 & 4.3 \\
B20(Topia)T2 24hrs & 5 & 11 & 2.2 & 7.2 \\
\hline
\end{tabular}

\begin{tabular}{|c|c|c|c|c|c|c|}
\hline Source of Variation & SS & $d f$ & $M S$ & $F$ & P-value & F crit \\
\hline Between Groups & 0.9 & 1 & 0.9 & 0.156522 & 0.70272 & 5.317655 \\
\hline Within Groups & 46 & 8 & 5.75 & & & \\
\hline Total & 46.9 & 9 & & & & \\
\hline
\end{tabular}

Anova: Single Factor

SUMMARY

\begin{tabular}{crrrr}
\hline Groups & Count & \multicolumn{1}{c}{ Sum } & Average & Variance \\
\hline B20(Topia)T1 48hrs & 5 & 15 & 3 & 9.5 \\
B20(Topia)T2 48hrs & 5 & 18 & 3.6 & 12.3 \\
\hline
\end{tabular}

ANOVA

\begin{tabular}{|c|c|c|c|c|c|c|}
\hline Source of Variation & SS & $d f$ & $M S$ & $F$ & P-value & $F$ crit \\
\hline Between Groups & 0.9 & 1 & 0.9 & 0.082569 & 0.781149 & 5.317655 \\
\hline Within Groups & 87.2 & 8 & 10.9 & & & \\
\hline Total & 88.1 & 9 & & & & \\
\hline
\end{tabular}

Anova: Single Factor

SUMMARY

\begin{tabular}{crrrr}
\hline Groups & Count & \multicolumn{1}{c}{ Sum } & Average & Variance \\
\hline B20(Topia)T1 72hrs & 5 & 23 & 4.6 & 17.3 \\
B20(Topia)T2 72hrs & 5 & 24 & 4.8 & 15.7 \\
\hline
\end{tabular}

\begin{tabular}{|c|c|c|c|c|c|c|}
\hline Source of Variation & SS & $d f$ & $M S$ & $F$ & $P$-value & $F$ crit \\
\hline Between Groups & 0.1 & 1 & 0.1 & 0.006061 & 0.939859 & 5.317655 \\
\hline Within Groups & 132 & 8 & 16.5 & & & \\
\hline Total & 132.1 & 9 & & & & \\
\hline
\end{tabular}


Anova: Single Factor

SUMMARY

\begin{tabular}{crrrr}
\hline Groups & Count & \multicolumn{1}{c}{ Sum } & Average & Variance \\
\hline B20(Topia)T1 96hrs & 5 & 25 & 5 & 14.5 \\
B20(Topia)T2 96hrs & 5 & 27 & 5.4 & 18.8 \\
\hline
\end{tabular}

ANOVA

\begin{tabular}{lrrrrrr}
\hline Source of Variation & \multicolumn{1}{c}{ SS } & \multicolumn{1}{c}{ df } & \multicolumn{1}{c}{ MS } & \multicolumn{1}{c}{$F$} & $P$-value & F crit \\
\hline Between Groups & 0.4 & 1 & 0.4 & 0.024024 & 0.880663 & 5.317655 \\
Within Groups & 133.2 & 8 & 16.65 & & & \\
& & & & & & \\
Total & 133.6 & 9 & & & & \\
\hline
\end{tabular}


Diesel $24 \mathrm{hrs}$

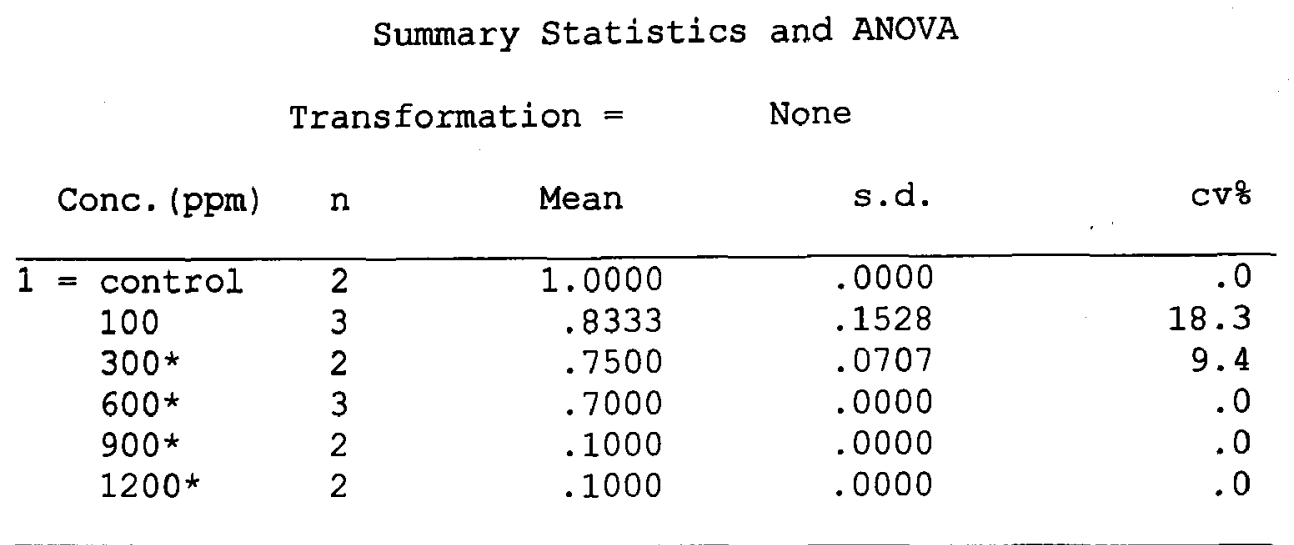

*) the mean for this conc. is significantly less than the control mean at alpha $=0.05$ (1-sided) by a $t$ - test with Bonferroni adjustment of alpha level

Minimum detectable difference for t-tests with Bonferroni adjustment $=$ $-.232823$

This difference corresponds to -23.28 percent of control

Note - the above value for the minimum detectable difference is approximate as the sample sizes are not the same for all of the concentrations.

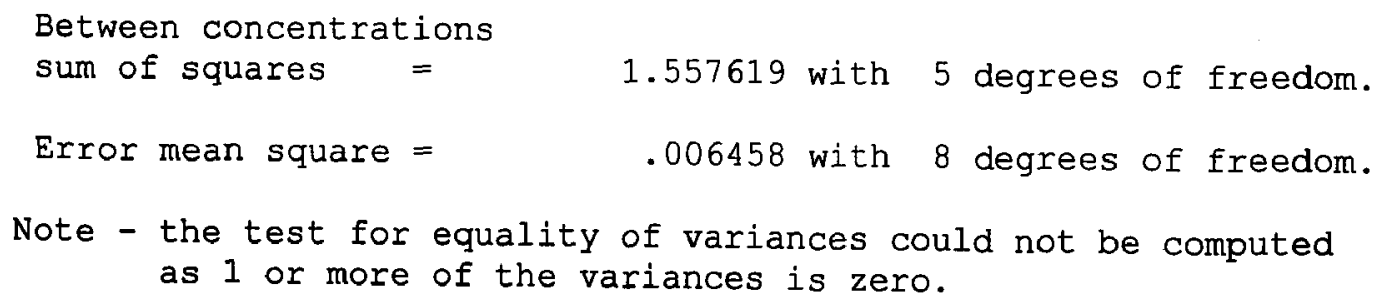




\begin{tabular}{llrrr}
\multicolumn{5}{c}{ Summary Statistics and ANOVA } \\
Transformation $=$ & None & \\
Conc. (ppm) & $\mathrm{n}$ & Mean & s.d. & cv8 \\
\hline $1=$ control & 2 & 1.0000 & .0000 & .0 \\
$100^{*}$ & 3 & .6667 & .2082 & 31.2 \\
$300^{*}$ & 2 & .5500 & .0707 & 12.9 \\
$600^{*}$ & 3 & .4333 & .0577 & 13.3 \\
$900^{*}$ & 2 & .1000 & .0000 & .0 \\
$1200^{*}$ & 2 & .0000 & .0000 & .0 \\
\end{tabular}

*) the mean for this conc. is significantly less than the control mean at alpha $=0.05(1-$ sided) by a $t$ - test with Bonferroni adjustment of alpha level

Minimum detectable difference for t-tests with Bonferroni adjustment $=$ $-.321196$

This difference corresponds to -32.12 percent of control

Note - the above value for the minimum detectable difference is approximate as the sample sizes are not the same for all of the concentrations.

Between concentrations sum of squares $=$

Error mean square $=$
1.410238 with 5 degrees of freedom.

.012292 with 8 degrees of freedom.

Note - the test for equality of variances could not be computed as 1 or more of the variances is zero. 
Diesel $72 \mathrm{hrs}$

\begin{tabular}{llccr}
\multicolumn{5}{c}{ Summary Statistics and ANOVA } \\
Transformation $=$ & None \\
Conc. (ppm) & $\mathrm{n}$ & Mean & s.d. & CV 8 \\
\hline $1=$ control & 2 & 1.0000 & .0000 & .0 \\
$100^{\star}$ & 3 & .6000 & .1732 & 28.9 \\
$300^{\star}$ & 2 & .1000 & .1414 & 141.4 \\
$600^{*}$ & 3 & .3000 & .0000 & .0 \\
$900^{*}$ & 2 & .0000 & .0000 & .0 \\
$1200^{*}$ & 2 & .0000 & .0000 & .0 \\
\hline
\end{tabular}

*) the mean for this conc. is significantly less than the control mean at alpha $=0.05$ (1-sided) by a $t$ - test with Bonferroni adjustment of alpha level

Minimum detectable difference for t-tests with Bonferroni adjustment $=$ $-.289711$

This difference corresponds to -28.97 percent of control

Note - the above value for the minimum detectable difference is approximate as the sample sizes are not the same for all of the concentrations.

Between concentrations

sum of squares=

1.655000 with 5 degrees of freedom.

Error mean square $=$ .010000 with 8 degrees of freedom.

Note - the test for equality of variances could not be computed as 1 or more of the variances is zero. 
Diesel 96hrs

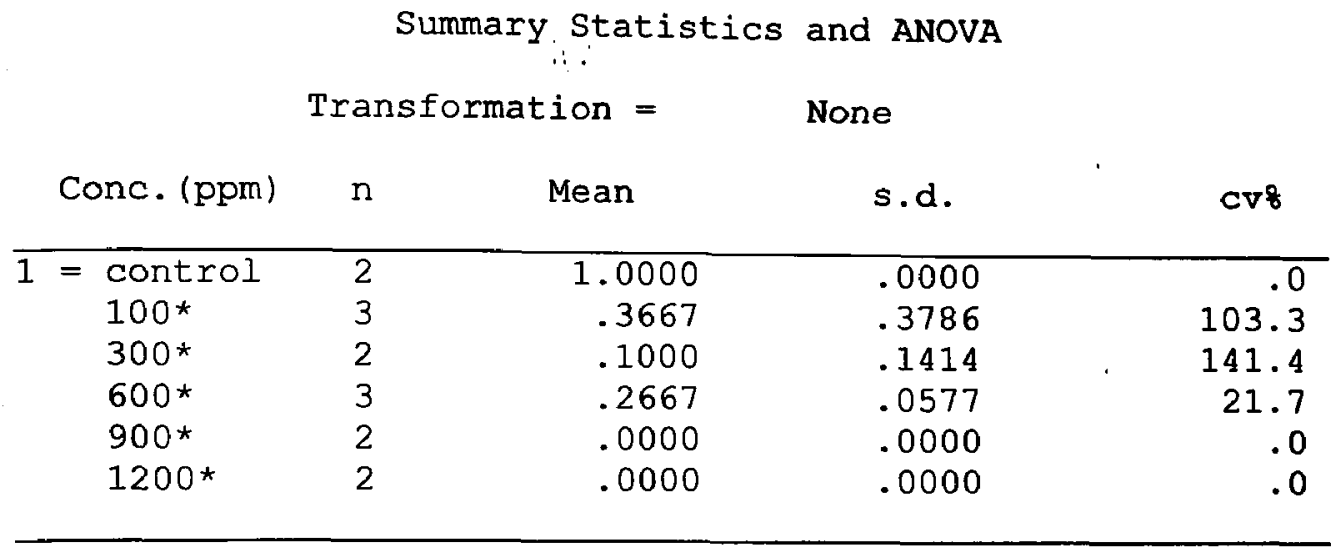

*) the mean for this conc. is significantly less than the control mean at alpha $=0.05$ (1-sided) by a $t$ - test with Bonferroni adjustment of alpha level

Minimum detectable difference for t-tests with Bonferroni adjustment $=$ $-.573354$

This difference corresponds to -57.34 percent of control

Note - the above value for the minimum detectable difference is approximate as the sample sizes are not the same for all of the concentrations.

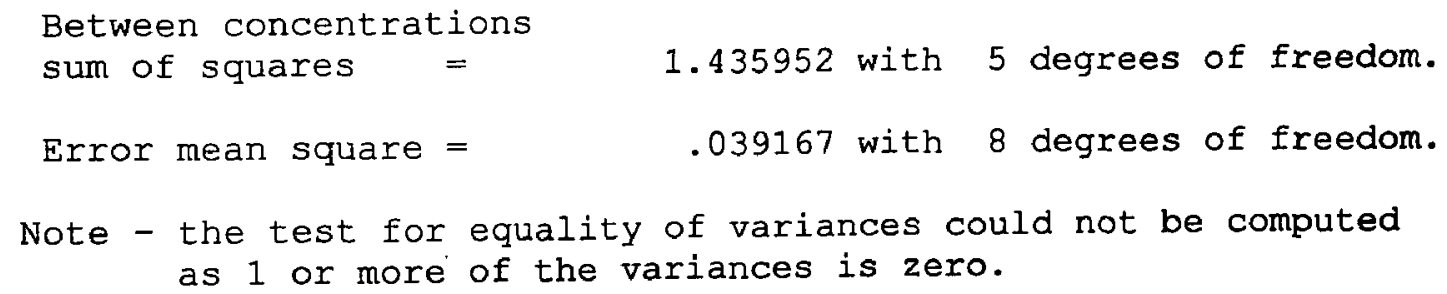


B100 24hrs

\begin{tabular}{|c|c|c|c|c|c|}
\hline \multirow{2}{*}{\multicolumn{2}{|c|}{ Conc. (ppm) }} & \multicolumn{2}{|c|}{ Transformation $=$} & $\begin{array}{l}\text { and ANOVA } \\
\text { None }\end{array}$ & \multirow[b]{2}{*}{$c v^{\circ}$} \\
\hline & & $\mathrm{n}$ & Mean & $s . d$. & \\
\hline \multirow[t]{6}{*}{$\overline{1}$} & $=$ control & 2 & 1.0000 & .0000 & .0 \\
\hline & 100 & 2 & .8000 & .1414 & 17.7 \\
\hline & 300 & 2 & 1.0000 & .0000 & .0 \\
\hline & 600 & 3 & .8000 & .1732 & 21.7 \\
\hline & 900 & 3 & .8333 & .1155 & 13.9 \\
\hline & $1200 *$ & 2 & .3000 & .0000 & .0 \\
\hline
\end{tabular}

*) the mean for this conc. is significantly less than the control mean at alpha $=0.05$ (1-sided) by a $t$ - test with Bonferroni adjustment of alpha level

Minimum detectable difference for t-tests with Bonferroni adjustment $=$ $-.334529$

This difference corresponds to -33.45 percent of control

Note - the above value for the minimum detectable difference is approximate as the sample sizes are not the same for all of the concentrations.

Between concentrations sum of squares = .662619 with 5 degrees of freedom.

Error mean square $=$ .013333 with 8 degrees of freedom.

Note - the test for equality of variances could not be computed as 1 or more of the variances is zero. 
B100 $48 \mathrm{hrs}$

\begin{tabular}{llrrr}
\multicolumn{7}{c}{ Summary Statistics and ANOVA } \\
\multicolumn{1}{c}{ Transformation $=$} & None & \\
Conc. (ppm) & $\mathrm{n}$ & Mean & s.d. & cv8 \\
\hline $1=$ control & 2 & 1.0000 & .0000 & .0 \\
100 & 2 & .8000 & .1414 & 17.7 \\
300 & 2 & 1.0000 & .0000 & .0 \\
$600^{*}$ & 3 & .4667 & .2887 & 61.9 \\
900 & 3 & .7667 & .2309 & 30.1 \\
$1200^{*}$ & 2 & .1000 & .0000 & .0 \\
\hline
\end{tabular}

*) the mean for this conc. is significantly less than the control mean at alpha $=0.05$ (1-sided) by a $t$ - test with Bonferroni adjustment of alpha level

Minimum detectable difference for t-tests with Bonferroni adjustment $=$ $-.554754$

This difference corresponds to -55.48 percent of control

Note - the above value for the minimum detectable difference is approximate as the sample sizes are not the same for all of the concentrations.

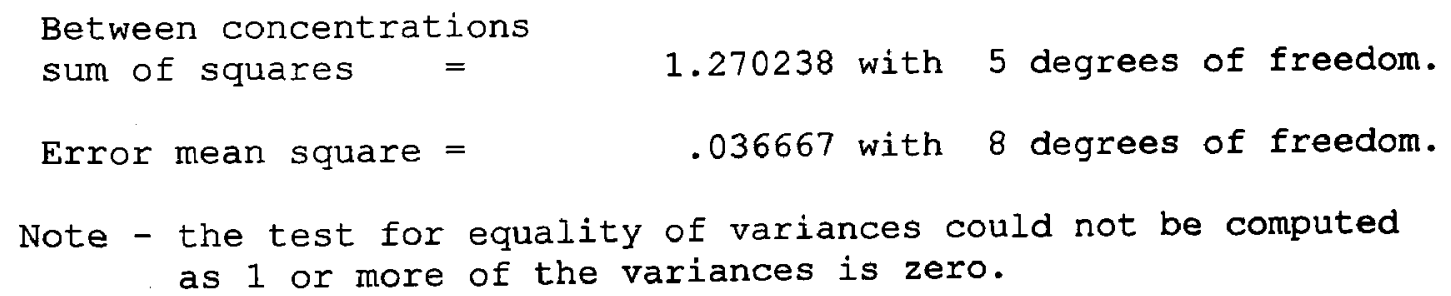


B100 $72 \mathrm{hrs}$

\begin{tabular}{llllr}
\multicolumn{5}{c}{ Summary Statistics and ANOVA } \\
Transformation $=$ & None \\
Conc. (ppm) & $\mathrm{n}$ & Mean & s.d. & cvo \\
\hline $1=$ control & 2 & 1.0000 & .0000 & .0 \\
100 & 2 & .7000 & .2828 & .0 \\
300 & 2 & 1.0000 & .0000 & 121.2 \\
$600^{*}$ & 3 & .3333 & .4041 & .0 \\
$900^{*}$ & 3 & .4000 & .0000 & .0 \\
$1200^{*}$ & 2 & .1000 & .0000 & \\
\hline
\end{tabular}

*) the mean for this conc. is significantly less than the control mean at alpha $=0.05$ (1-sided) by a $t$ - test with Bonferroni adjustment of alpha level

Minimum detectable difference for t-tests with Bonferroni adjustment $=$ $-.653189$

This difference corresponds to -65.32 percent of control

Note - the above value for the minimum detectable difference is approximate as the sample sizes are not the same for all of the concentrations.

Between concentrations

sum of squares $=1.467619$ with 5 degrees of freedom.

Error mean square $=\quad .050833$ with 8 degrees of freedom.

Note - the test for equality of variances could not be computed as 1 or more of the variances is zero. 
B100 96hrs

\begin{tabular}{|c|c|c|c|c|c|}
\hline \multirow{2}{*}{\multicolumn{2}{|c|}{ Conc. (ppm) }} & \multicolumn{2}{|c|}{ Transformation $=$} & \multirow{2}{*}{$\begin{array}{l}\text { and ANOVA } \\
\text { None } \\
\text { s.d. }\end{array}$} & \multirow[b]{2}{*}{ CVZ } \\
\hline & & $\mathrm{n}$ & Mean & & \\
\hline \multirow[t]{6}{*}{$\overline{1}=$} & $=$ control & 2 & 1.0000 & .0000 & .0 \\
\hline & 100 & 2 & .7000 & .2828 & 40.4 \\
\hline & 300 & 2 & 1.0000 & .0000 & .0 \\
\hline & $600 *$ & 3 & .2333 & .2309 & 99.0 \\
\hline & $900 *$ & 3 & .1667 & .0577 & 34.6 \\
\hline & $1200^{*}$ & 2 & .0000 & .0000 & .0 \\
\hline
\end{tabular}

*) the mean for this conc. is significantly less than the control mean at alpha $=0.05$ (1-sided) by a $t$ - test with Bonferroni adjustment of alpha level

Minimum detectable difference for t-tests with Bonferroni adjustment $=$ $-.450374$

This difference corresponds to -45.04 percent of control

Note - the above value for the minimum detectable difference is approximate as the sample sizes are not the same for all of the concentrations.

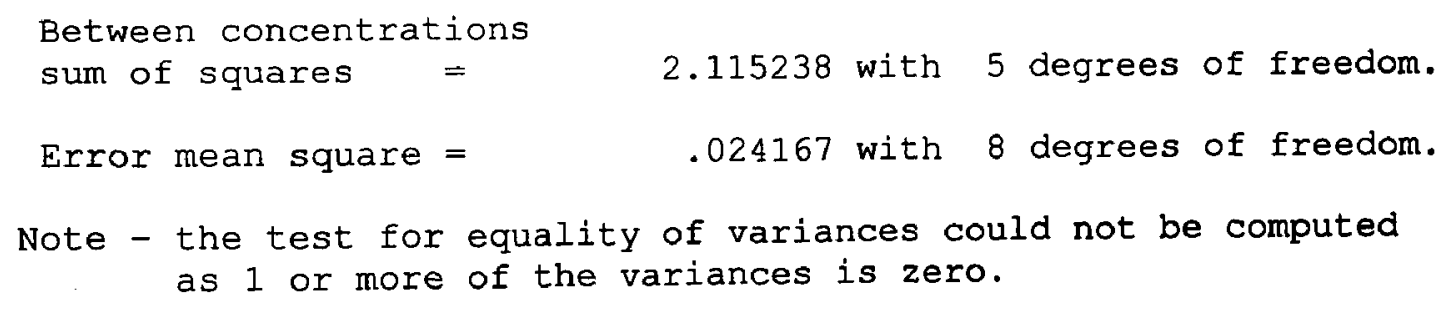




\section{B50 24hrs}

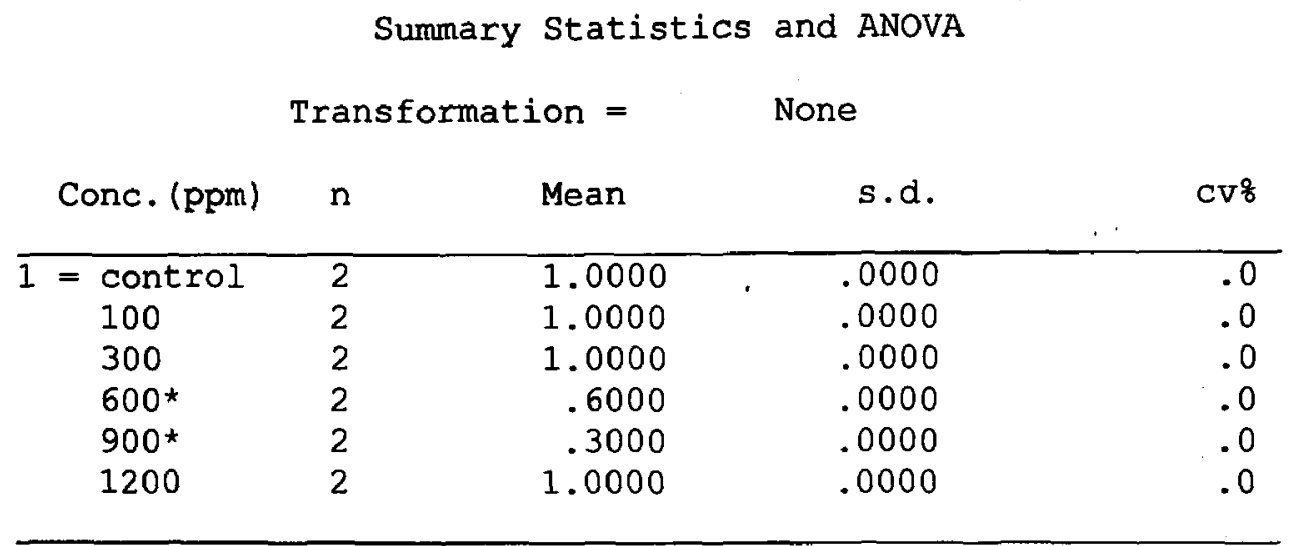

*) the mean for this conc. is significantly less than the control mean at alpha $=0.05(1-$ sided) by Dunnett's test

Minimum detectable difference for Dunnett's test = This difference corresponds to .00 percent of control

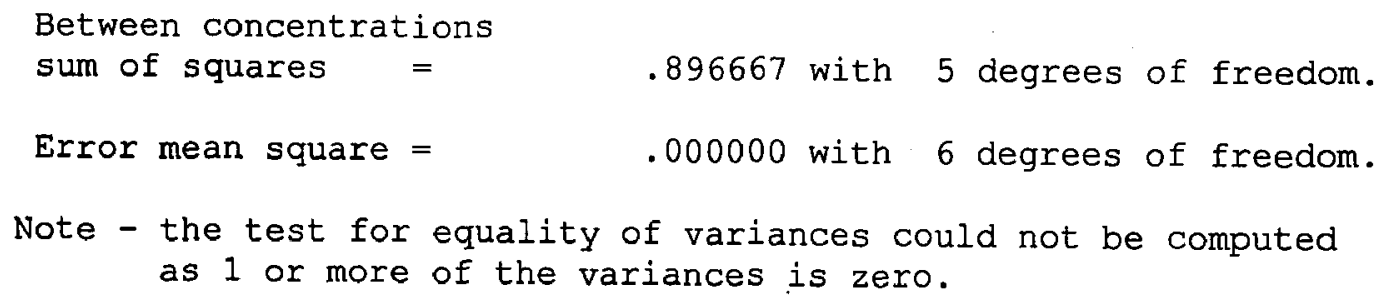


B50 48 hrs

\begin{tabular}{|c|c|c|c|c|c|}
\hline \multirow{2}{*}{\multicolumn{2}{|c|}{ Conc. (ppm) }} & \multicolumn{2}{|c|}{ Transformation = } & \multirow{2}{*}{$\begin{array}{l}\text { and ANOVA } \\
\text { None } \\
\text { s.d. }\end{array}$} & \multirow[b]{2}{*}{$\mathrm{Cr}$} \\
\hline & & $\mathrm{n}$ & Mean & & \\
\hline \multirow[t]{6}{*}{$\overline{1}$} & $=$ control & 2 & 1.0000 & .0000 & .0 \\
\hline & 100 & 2 & 1.0000 & .0000 & .0 \\
\hline & 300 & 2 & .8000 & .2828 & 35.4 \\
\hline & $600 *$ & 2 & .3000 & .0000 & .0 \\
\hline & $900 *$ & 2 & .3000 & .0000 & .0 \\
\hline & $1200^{*}$ & 2 & .1000 & .0000 & .0 \\
\hline
\end{tabular}

*) the mean for this conc. is significantly less than the control mean at alpha $=0.05(1$-sided) by Dunnett's test

Minimum detectable difference for Dunnett's test $=\quad-\mathbf{- 3 2 6 7 8 0}$ This difference corresponds to -32.68 percent of control

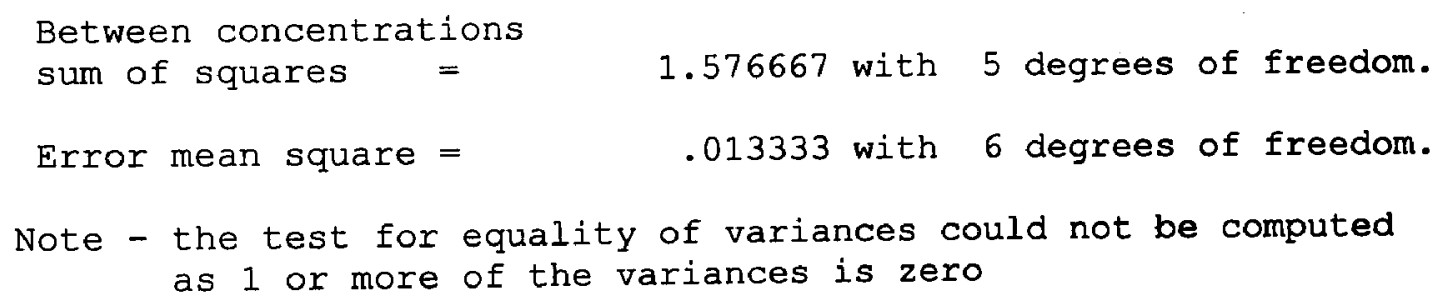


B50 $72 \mathrm{hrs}$

\begin{tabular}{|c|c|c|c|c|c|}
\hline \multirow{2}{*}{\multicolumn{2}{|c|}{ Conc. (ppm) }} & \multicolumn{2}{|c|}{ Transformation $=$} & $\begin{array}{l}\text { and ANOVA } \\
\text { None }\end{array}$ & \multirow[b]{2}{*}{$\mathrm{CV} \%$} \\
\hline & & $\mathbf{n}$ & Mean & s.d. & \\
\hline \multirow[t]{6}{*}{$1=$} & $=$ control & 2 & 1.0000 & .0000 & .0 \\
\hline & 100 & 2 & .9000 & .0000 & .0 \\
\hline & 300 & 2 & .7000 & .1414 & 20.2 \\
\hline & $600^{*}$ & 2 & .1500 & .2121 & 141.4 \\
\hline & $900 *$ & 2 & .0000 & .0000 & .0 \\
\hline & $1200 *$ & 2 & .0500 & .0707 & 141.4 \\
\hline
\end{tabular}

*) the mean for this conc. is significantly less than

the control mean at alpha $=0.05$ (1-sided) by Dunnett's test

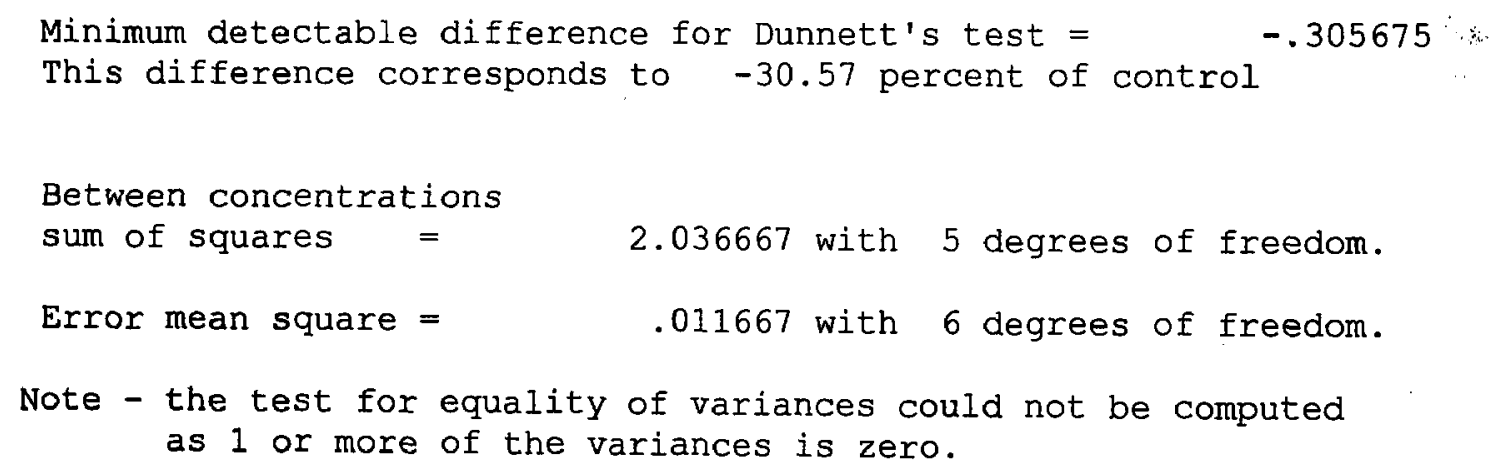




\begin{tabular}{|c|c|c|c|c|c|}
\hline \multirow{2}{*}{\multicolumn{2}{|c|}{ Conc. (ppm) }} & \multicolumn{2}{|c|}{ Transformation $=$} & \multirow{2}{*}{$\begin{array}{l}\text { None } \\
\qquad s . d .\end{array}$} & \multirow[b]{2}{*}{ cri } \\
\hline & & $\mathrm{n}$ & Mean & & \\
\hline \multirow[t]{6}{*}{$1=$} & $=$ control & 2 & 1.0000 & .0000 & .0 \\
\hline & 100 & 2 & .9000 & .0000 & .0 \\
\hline & $300 \star$ & 2 & .5500 & .3536 & 64.3 \\
\hline & $600 *$ & 2 & .0000 & .0000 & .0 \\
\hline & $900 *$ & 2 & .0000 & .0000 & .0 \\
\hline & $1200^{\star}$ & 2 & .0000 & .0000 & .0 \\
\hline
\end{tabular}

*) the mean for this conc. is significantly less than the control mean at alpha $=0.05$ (1-sided) by Dunnett's test

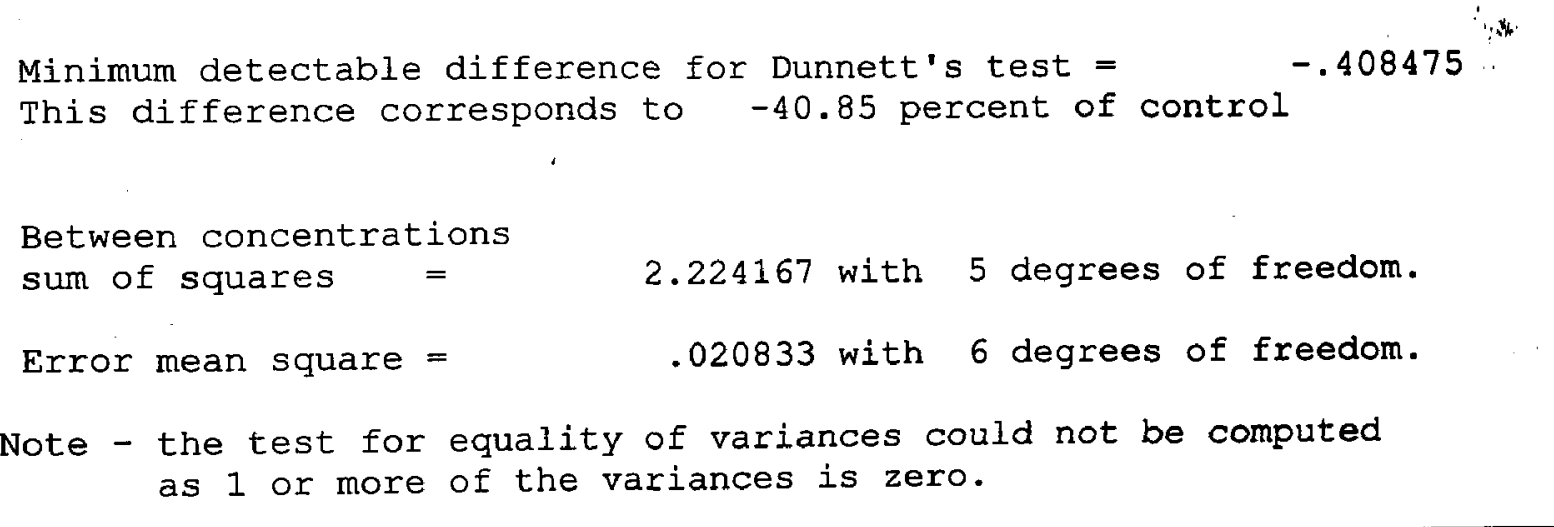




\section{B5 $24 \mathrm{hrs}$}

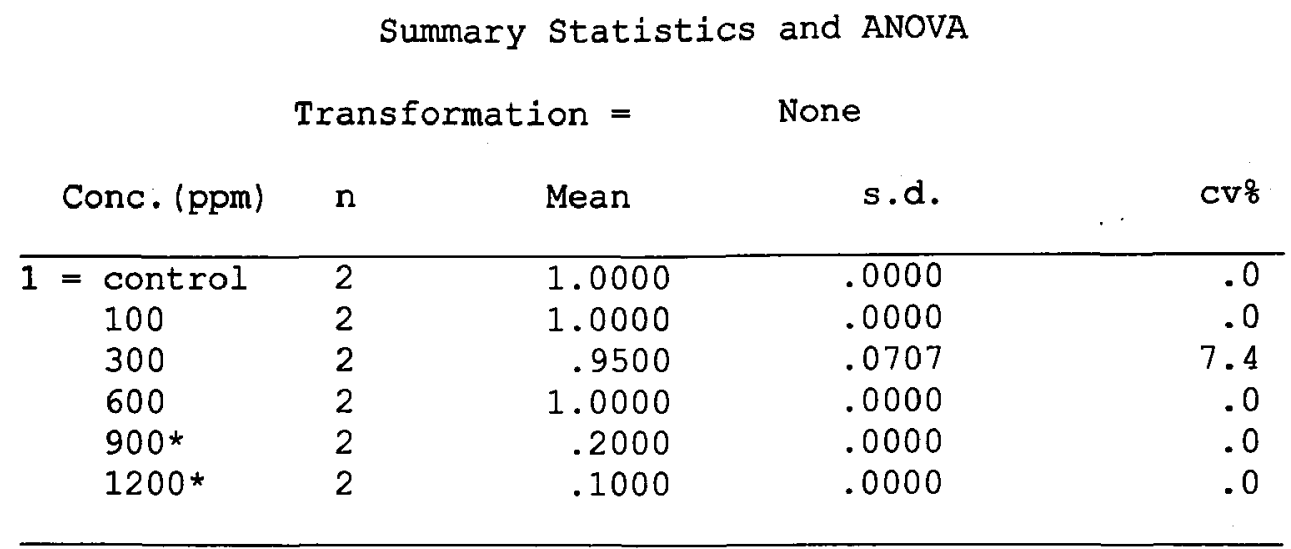

*) the mean for this conc. is significantly less than the control mean at alpha $=0.05$ (1-sided) by Dunnett's test

Minimum detectable difference for Dunnett's test $=$ This difference corresponds to -8.17 percent of control

Between concentrations sum of squares = 1.884167 with 5 degrees of freedom.

Error mean square $=$ .000833 with 6 degrees of freedom.

Note - the test for equality of variances could not be computed as 1 or more of the variances is zero. 


\begin{tabular}{llrrr}
\multicolumn{5}{c}{ Summary Statistics and ANOVA } \\
Transformation $=$ & None \\
Conc. (ppm) & $\mathrm{n}$ & Mean & s.d. & cv8 \\
\hline $1=$ control & 2 & 1.0000 & .0000 & .0 \\
100 & 2 & .4500 & .6364 & 141.4 \\
300 & 2 & .7000 & .0000 & .0 \\
600 & 2 & .5000 & .0000 & .0 \\
$900^{*}$ & 2 & .2000 & .0000 & .0 \\
$1200^{*}$ & 2 & .0500 & .0707 & 141.4 \\
\end{tabular}

*) the mean for this conc. is significantly less than the control mean at alpha $=0.05$ (1-sided) by Dunnett's test

Minimum detectable difference for Dunnett's test $=\quad-.739780$ This difference corresponds to -73.98 percent of control

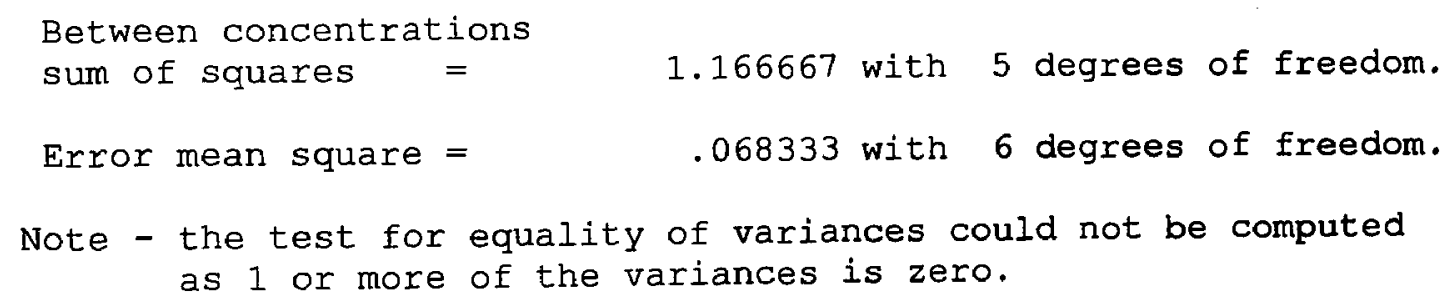


B5 $72 \mathrm{hrs}$

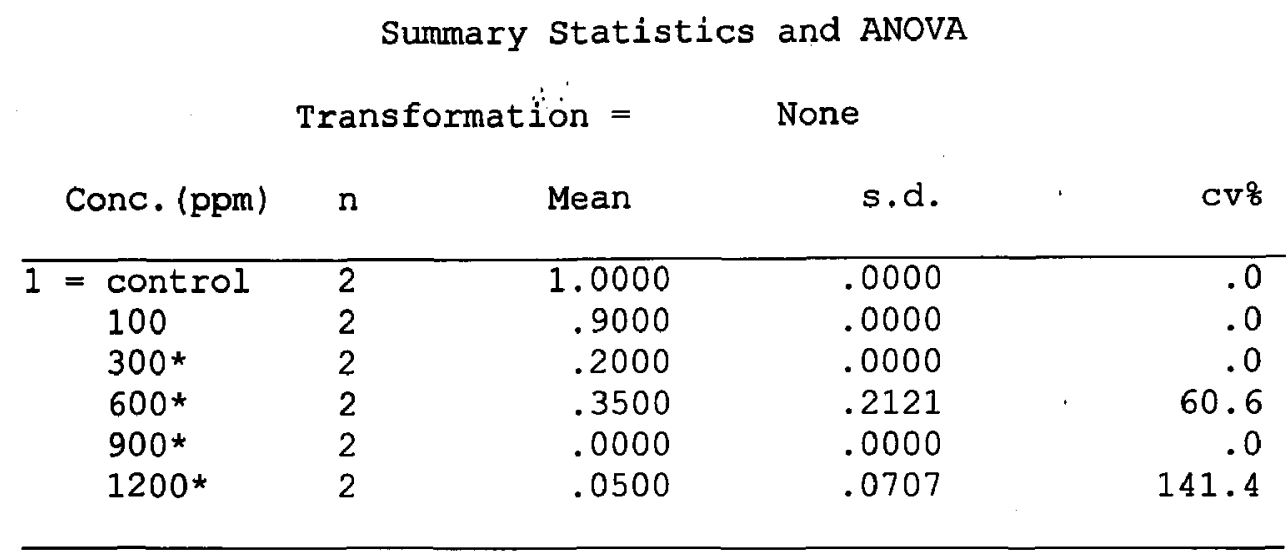

*) the mean for this conc. is significantly less than the control mean at alpha $=0.05$ (1-sided) by Dunnett's test

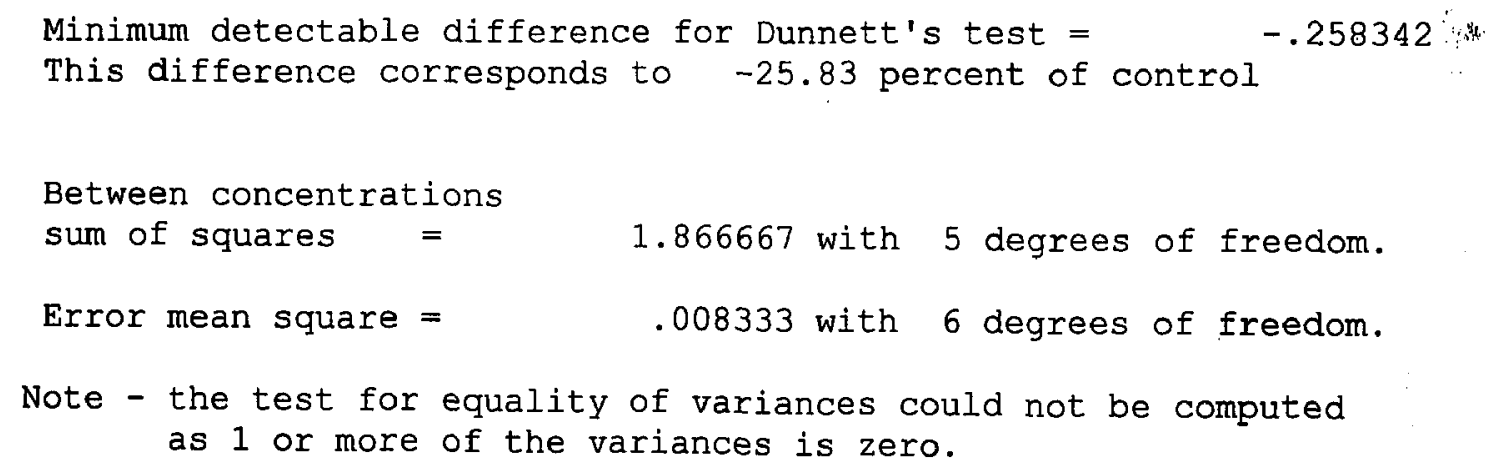


B5 96hrs

\begin{tabular}{llllr}
\multicolumn{7}{c}{ Summary Statistics and ANOVA } \\
\multicolumn{7}{c}{ Transformation $=$} & None & \\
Conc. (ppm) & $\mathrm{n}$ & Mean & s.d. & cv8 \\
\hline $1=$ control & 2 & 1.0000 & .0000 & .0 \\
100 & 2 & .6000 & .4243 & 70.7 \\
$300^{*}$ & 2 & .1000 & .1414 & 141.4 \\
$600^{*}$ & 2 & .1000 & .1414 & 141.4 \\
$900^{*}$ & 2 & .0000 & .0000 & .0 \\
$1200^{*}$ & 2 & .0500 & .0707 & 141.4 \\
\hline
\end{tabular}

*) the mean for this conc. is significantly less than the control mean at alpha $=0.05(1$-sided $)$ by Dunnett's test

Minimum detectable difference for Dunnett's test = This difference corresponds to -54.80 percent of control

$-.548027$

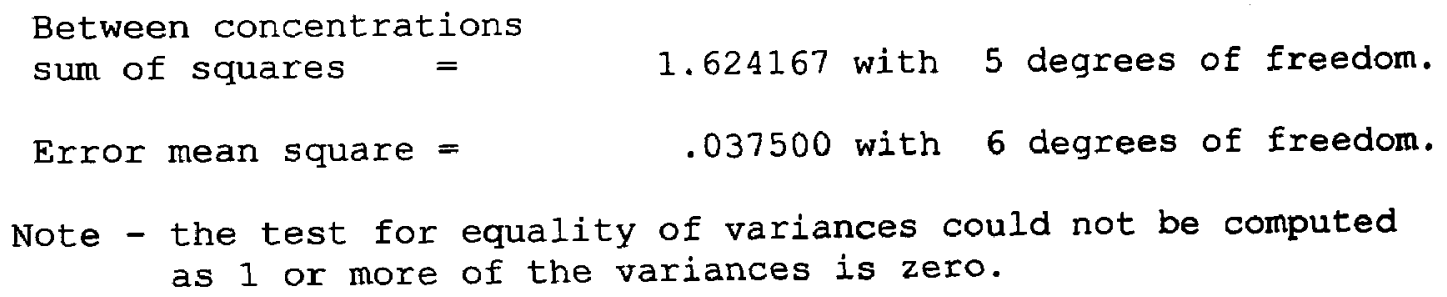


B20 (Topia) $24 \mathrm{hrs}$

\begin{tabular}{|c|c|c|c|c|}
\hline \multirow[b]{2}{*}{ Conc. } & \multicolumn{2}{|c|}{ Transformation = } & \multirow{2}{*}{$\begin{array}{l}\text { None } \\
\text { s.d. }\end{array}$} & \multirow[b]{2}{*}{$\mathrm{CV} \%$} \\
\hline & $\mathrm{n}$ & Mean & & \\
\hline $1=$ control & 2 & 1.0000 & .0000 & .0 \\
\hline 2 & 2 & 1.0000 & .0000 & .0 \\
\hline 3 & 2 & 1.0000 & .0000 & .0 \\
\hline 4 & 2 & .9000 & .0000 & .0 \\
\hline $5 *$ & 2 & .7000 & .1414 & 20.2 \\
\hline $6 *$ & 2 & .4500 & .0707 & 15.7 \\
\hline
\end{tabular}

*) the mean for this conc. is significantly less than

the control mean at alpha $=0.05$ (1-sided) by Dunnett's test

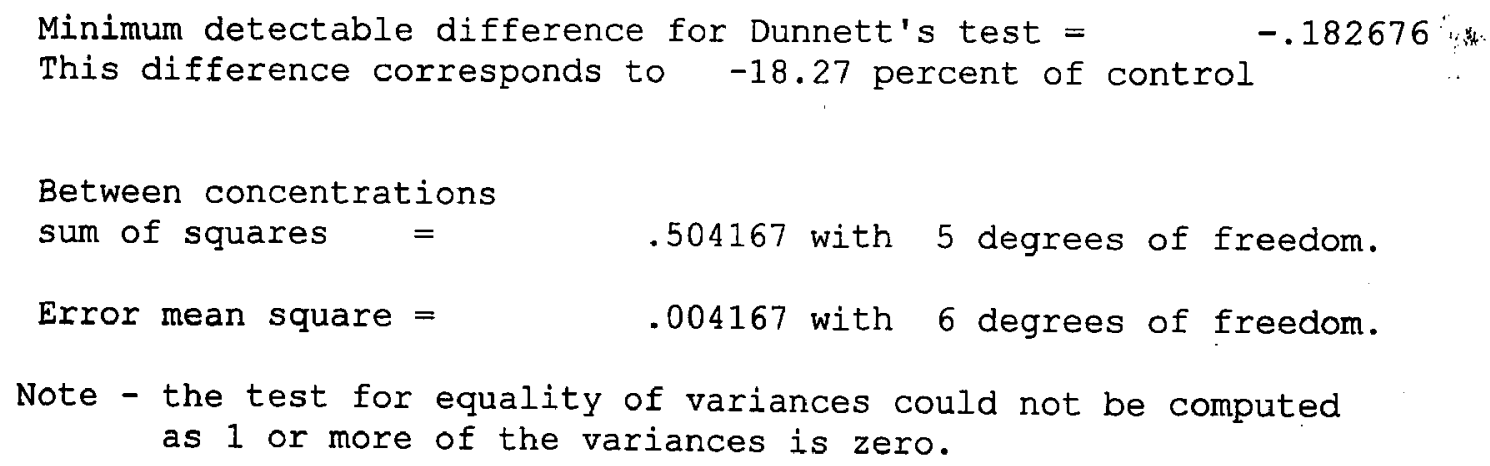


B20 (Topia) $48 \mathrm{hrs}$

\begin{tabular}{ccccc}
\multicolumn{5}{c}{ Summary Statistics and ANOVA } \\
\multicolumn{7}{c}{ Transformation $=$} & None & \\
Conc. & $\mathrm{n}$ & Mean & s.d. & cv8 \\
\hline $1=$ control & 2 & 1.0000 & .0000 & .0 \\
2 & 2 & 1.0000 & .0000 & .0 \\
3 & 2 & 1.0000 & .0000 & .0 \\
$4^{*}$ & 2 & .6000 & .1414 & 23.6 \\
$5^{\star}$ & 2 & .5000 & .0000 & .0 \\
$6^{*}$ & 2 & .2500 & .0707 & 28.3 \\
\hline
\end{tabular}

*) the mean for this conc. is significantly less than the control mean at alpha $=0.05$ (1-sided) by Dunnett's test

Minimum detectable difference for Dunnett's test $=$
This difference corresponds to $\quad-18.27$ percent of control

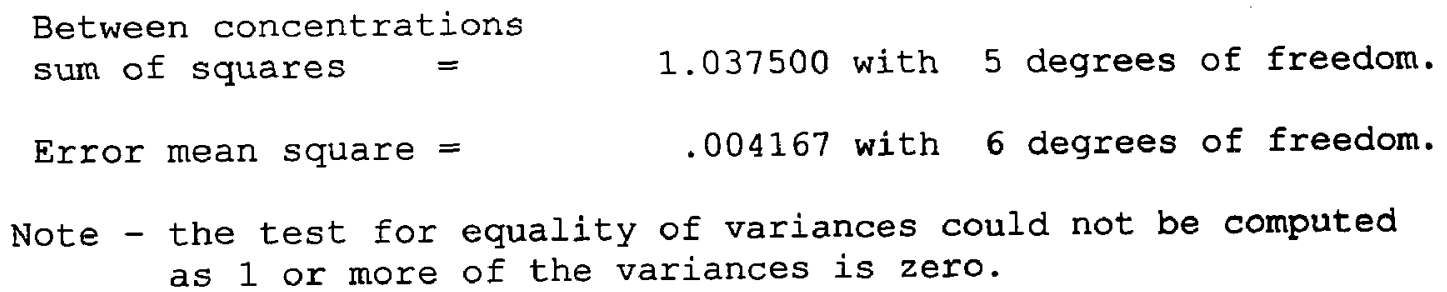


B20 (Topia) $72 \mathrm{hrs}$

\begin{tabular}{|c|c|c|c|c|c|}
\hline \multirow{2}{*}{\multicolumn{2}{|c|}{ Conc. }} & \multicolumn{2}{|c|}{ Transformation $=$} & \multirow{2}{*}{$\begin{array}{l}\text { None } \\
\text { s.d. }\end{array}$} & \multirow[b]{2}{*}{$\mathrm{CV}^{\circ}$} \\
\hline & & $\mathrm{n}$ & Mean & & \\
\hline \multirow[t]{6}{*}{1} & $=$ control & 2 & 1.0000 & .0000 & .0 \\
\hline & 2 & 2 & .9000 & .1414 & 15.7 \\
\hline & 3 & 2 & .9500 & .0707 & 7.4 \\
\hline & 4 * & 2 & .5000 & .0000 & .0 \\
\hline & $5 *$ & 2 & .3000 & .0000 & .0 \\
\hline & $6 *$ & 2 & .0000 & .0000 & .0 \\
\hline
\end{tabular}

*) the mean for this conc. is significantly less than the control mean at alpha $=0.05$ (1-sided) by Dunnett's test

Minimum detectable difference for Dunnett's test $=\quad-\mathbf{1 8 2 6 7 6}$ This difference corresponds to -18.27 percent of control

Between concentrations

sum of squares $\approx \quad=\quad 1.664167$ with 5 degrees of freedom.

Error mean square $=\quad .004167$ with 6 degrees of freedom.

Note - the test for equality of variances could not be computed as 1 or more of the variances is zero. 


\begin{tabular}{clrrr}
\multicolumn{5}{c}{ Summary Statistics and ANOVA } \\
Conc. & Transformation $=$ & None & \\
\hline $1=$ control & 2 & Mean & s.d. & cv8 \\
\hline 2 & 2 & 1.0000 & .0000 & .0 \\
3 & 2 & .9000 & .1414 & 15.7 \\
$4^{*}$ & 2 & .8500 & .2121 & 25.0 \\
$5^{*}$ & 2 & .4500 & .0707 & 15.7 \\
$6^{*}$ & 2 & .2000 & .1414 & 70.7 \\
\hline
\end{tabular}

*) the mean for this conc. is significantly less than

the control mean at alpha $=0.05(1-$ sided $)$ by Dunnett's test

Minimum detectable difference for Dunnett's test $=$ This difference corresponds to -34.66 percent of control

Between concentrations

sum of squares=

Error mean square $=$

Note - the test for equality of variances could not be computed as 1 or more of the variances is zero. 
TRIMMED SPEARMAN-KARBER METHOD. MONTANA STATE UNIV

FOR REFERENCE, CITE:

HAMILTON, M.A., R.C. RUSSO, AND R.V. THURSTON, 1977.

TRIMMED SPEARMAN-KARBER METHOD FOR ESTIMATING MEDIAN LETHAL CONCENTRATIONS IN TOXICITY BIOASSAYS.

ENVIRON. SCI. TECHNOL. 11(7): 714-719;

CORRECTION 12(4):417 (1978).

DATE: $6-12-2004$

TEST NUMBER: T1 \& T2

CHEMICAL: DIESEL

SPECIES: O.MYKISS

RAW DATA:

CONCENTRATION (PPM) 100.00300 .00600 .00900 .001200 .00

$\begin{array}{llllll}\text { NUMBER EXPOSED: } & 30 & 20 & 30 & 20 & 20\end{array}$

DURATION (HOURS) LC50 LOWER 95\% LIMIT UPPER 95\% LIMIT \% TRIM

$\begin{array}{ccrcc}24 & 578.13 & 421.28 & 793.37 & 16.67 \\ 48 & 350.38 & 173.04 & 709.47 & 33.33 \\ 72 & 133.52 & 88.94 & 200.45 & 40.00 \\ 96 & \text { NC } & \text { NC } & \text { NC } & \text { NC }\end{array}$


TRIMMED SPEARMAN-KARBER METHOD. MONTANA STATE UNIV

FOR REFERENCE, CITE:

HAMILTON, M.A., R.C. RUSSO, AND R.V. THURSTON, 1977.

TRIMMED SPEARMAN-KARBER METHOD FOR ESTIMATING MEDIAN

LETHAL CONCENTRATIONS IN TOXICITY BIOASSAYS.

ENVIRON. SCI. TECHNOL. 11(7): 714-719;

CORRECTION 12(4):417 (1978).

DATE: 6-12-2004

TEST NUMBER: (T1 \& T2)

CHEMICAL: B100

SPECIES: O.MYKISS

RAW DATA:

CONCENTRATION(PPM) $\quad 100.00300 .00600 .00900 .001200 .00$

$\begin{array}{llllll}\text { NUMBER EXPOSED: } & 20 & 20 & 30 & 30 & 20\end{array}$

DURATION (HOURS) LC50 LOWER 95\% LIMIT UPPER 95\% LIMIT \% TRIM

$\begin{array}{rrrrr}24 & 1073.54 & 994.69 & 1158.63 & 30.00 \\ 48 & 756.68 & 646.56 & 885.56 & 10.00 \\ 72 & 555.19 & 462.94 & 665.82 & 15.00 \\ 96 & 455.28 & 391.30 & 529.73 & 15.00\end{array}$


TRIMMED SPEARMAN-KARBER METHOD. MONTANA STATE UNIV

FOR REFERENCE, CITE:

HAMILTON, M.A., R.C. RUSSO, AND R.V. THURSTON, 1977.

TRIMMED SPEARMAN-KARBER METHOD FOR ESTIMATING MEDIAN

LETHAL CONCENTRATIONS IN TOXICITY BIOASSAYS.

ENVIRON. SCI. TECHNOL. 11(7): 714-719;

CORRECTION 12(4):417 (1978).

DATE: $6-12-2004$

TEST NUMBER: (T1 \& T2)

CHEMICAL: B50

SPECIES: O.MYKISS

RAW DATA:

CONCENTRATION (PPM) 100.00300 .00600 .00900 .001200 .00

NUMBER EXPOSED: $\quad \begin{array}{lllll}20 & 20 & 20 & 20 & 20\end{array}$

DURATION (HOURS) LC50 LOWER 95\% LIMIT UPPER 95\% LIMIT \% TRIM

$\begin{array}{ccccc}24 & \text { NC } & \text { NC } & \text { NC } & \text { NC } \\ 48 & 491.11 & 386.78 & 623.59 & 10.00 \\ 72 & 348.32 & 267.24 & 453.99 & 10.00 \\ 96 & 276.71 & 212.79 & 359.82 & 10.00\end{array}$


TRIMMED SPEARMAN-KARBER METHOD. MONTANA STATE UNIV

FOR REFERENCE, CITE:

HAMILTON, M.A., R.C. RUSSO, AND R.V. THURSTON, 1977.

TRIMMED SPEARMAN-KARBER METHOD FOR ESTIMATING MEDIAN

LETHAL CONCENTRATIONS IN TOXICITY BIOASSAYS.

ENVIRON. SCI. TECHNOL. 11(7): 714-719;

CORRECTION 12(4):417 (1978).

DATE: 6-12-2004

TEST NUMBER: (T1 \& T2)

CHEMICAL: B20

SPECIES: O.MYKISS

RAW DATA:

CONCENTRATION (PPM) 100.00300 .00600 .00900 .001200 .00

NUMBER EXPOSED: $\quad \begin{array}{lllll}20 & 20 & 30 & 20 & 20\end{array}$

DURATION (HOURS) LC50 LOWER 95\% LIMIT UPPER 95\% LIMIT \% TRIM

$\begin{array}{rrrrr}24 & 1074.31 & 752.15 & 1534.46 & 45.00 \\ 48 & 659.02 & 566.51 & 766.64 & 10.00 \\ 72 & 541.27 & 427.62 & 685.13 & 10.00 \\ 96 & 497.60 & 421.00 & 588.15 & 17.50\end{array}$


TRIMMED SPEARMAN-KARBER METHOD. MONTANA STATE UNIV

FOR REFERENCE, CITE:

HAMILTON, M.A., R.C. RUSSO, AND R.V. THURSTON, 1977.

TRIMMED SPEARMAN-KARBER METHOD FOR ESTIMATING MEDIAN

LETHAL CONCENTRATIONS IN TOXICITY BIOASSAYS.

ENVIRON. SCI. TECHNOL. 11(7): 714-719;

CORRECTION 12(4):417 (1978).

DATE: $6-12-2004$

TEST NUMBER: (T1 \& T2)

CHEMICAL: B5

SPECIES: O.MYKISS

RAW DATA:

CONCENTRATION (PPM) 100.00300 .00600 .00900 .001200 .00

$\begin{array}{llllll}\text { NUMBER EXPOSED: } & 20 & 20 & 20 & 20 & 20\end{array}$

DURATION (HOURS) LC50 LOWER 95\% LIMIT UPPER 95\% LIMIT \% TRIM

$\begin{array}{lrrrr}24 & 780.67 & 718.61 & 848.09 & 10.00 \\ 48 & 463.30 & 343.07 & 625.65 & 10.00 \\ 72 & 234.47 & 177.93 & 308.97 & 10.00 \\ 96 & 124.57 & 84.38 & 183.92 & 40.00\end{array}$


TRIMMED SPEARMAN-KARBER METHOD. MONTANA STATE UNIV

FOR REFERENCE, CITE:

HAMILTON, M.A., R.C. RUSSO, AND R.V. THURSTON, 1977.

TRIMMED SPEARMAN-KARBER METHOD FOR ESTIMATING MEDIAN

LETHAL CONCENTRATIONS IN TOXICITY BIOASSAYS.

ENVIRON. SCI. TECHNOL. 11(7): 714-719;

CORRECTION 12(4):417 (1978).

DATE: 2-10-2005

TEST NUMBER: T1+T2

CHEMICAL: B20 TOPIA

SPECIES: O.MYKISS

RAW DATA:

CONCENTRATION (PPM) 100.00300 .00600 .00900 .001200 .00

$\begin{array}{llllll}\text { NUMBER EXPOSED: } & 20 & 20 & 20 & 20 & 20\end{array}$

DURATION (HOURS) $\quad$ LC50 LOWER 95\% LIMIT UPPER 95\% LIMIT $\quad$ \%TRIM

$\begin{array}{rlllr}24 & 1132.91 & 918.15 & 1397.89 & 45.00 \\ 48 & 790.87 & 619.02 & 1010.43 & 25.00 \\ 72 & 606.21 & 510.08 & 720.46 & 7.50 \\ 96 & 527.96 & 406.28 & 686.07 & 10.00\end{array}$


$\therefore$

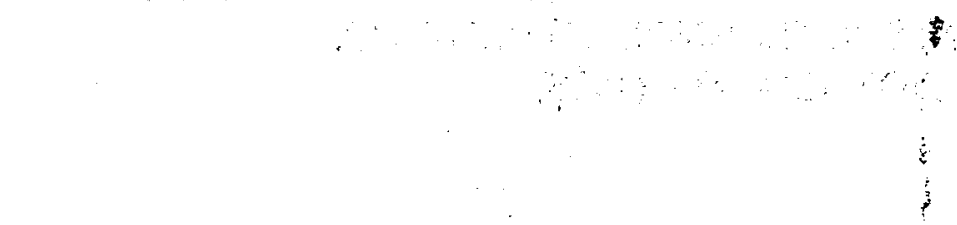

$+2$

क

an

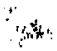

1

d) B $(.74-136$ 